\title{
AN EXPERIMENTAL STUDY ON STRAP TENSION-ONLY BRACE
}

\author{
A thesis submitted to \\ the Faculty of Graduate Studies and Research \\ in partial fulfillment of the requirements for the degree of \\ Masters of Applied Science \\ by
}

Mani Razavi Aghdam
Department of Civil and Environmental Engineering
Carleton University

Ottawa-Carleton Institute of Civil and Environmental Engineering

September, 2009 


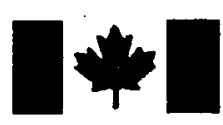

\author{
Library and Archives \\ Canada \\ Published Heritage \\ Branch \\ 395 Wellington Street \\ Ottawa ON K1A 0N4 \\ Canada
}

Bibliothèque et

Archives Canada

Direction du

Patrimoine de l'édition

395 , rue Wellington

Ottawa ON K1A ON4

Canada
Your file Votre référence
ISBN: $978-0-494-60231-7$
Our file Notre référence
ISBN: $978-0-494-60231-7$
NOTICE:

The author has granted a nonexclusive license allowing Library and Archives Canada to reproduce, publish, archive, preserve, conserve, communicate to the public by telecommunication or on the Internet, loan, distribute and sell theses worldwide, for commercial or noncommercial purposes, in microform, paper, electronic and/or any other formats.

The author retains copyright ownership and moral rights in this thesis. Neither the thesis nor substantial extracts from it may be printed or otherwise reproduced without the author's permission.
AVIS:

L'auteur a accordé une licence non exclusive permettant à la Bibliothèque et Archives Canada de reproduire, publier, archiver, sauvegarder, conserver, transmettre au public par télécommunication ou par l'Internet, prêter, distribuer et vendre des thèses partout dans le monde, à des fins commerciales ou autres, sur support microforme, papier, électronique et/ou autres formats.

L'auteur conserve la propriété du droit d'auteur et des droits moraux qui protège cette thèse. $\mathrm{Ni}$ la thèse ni des extraits substantiels de celle-ci ne doivent être imprimés ou autrement reproduits sans son autorisation.
In compliance with the Canadian Privacy Act some supporting forms may have been removed from this thesis.

While these forms may be included in the document page count, their removal does not represent any loss of content from the thesis.
Conformément à la loi canadienne sur la protection de la vie privée, quelques formulaires secondaires ont été enlevés de cette thèse.

Bien que ces formulaires aient inclus dans la pagination, il n'y aura aucun contenu manquant. 


\begin{abstract}
An Experimental study has been carried out to evaluate the feasibility of using flat bars in a tension-only bracing system for seismic design. Flexible steel straps (flat bars) with the slenderness ratio between 200 and 800 were tested under cyclic loading. Various slenderness ratios and connection details were investigated. Three bolted connection details were considered in the study: no reinforcement, clamped with an extra plate and welded with an extra plate.

In National Building Code of Canada 2005, a normal building is permitted to deflect up to $2.5 \%$ in storey drift due to seismic load. Ideally, a brace in a Seismic Force Resisting System should be able to sustain this deformation under cyclic condition without any significant loss of strength. None of the specimens tested experienced any loss of strength with the increasing cyclic deformation until fracture occurred. Based on the maximum extension observed in the tests, a flat bar brace with the welded plate reinforcement can achieve the ductility required for $2.5 \%$ storey drift at a slenderness ratio as low as 200 . On the other hand the ductility of the flat bar brace with either of the other two connection details was found to be greatly dependent on its slenderness ratio, length and net section fracture to gross section yielding strength ratio. Specimens with the net section fracture to gross section yielding strength ratio at around 1.20 were able to meet the ductility requirement.
\end{abstract}




\section{ACKNOWLEDGMENTS}

The author whishes to thank Dr. Heng Aik Khoo, supervisor of this thesis for his guidance, advice and support through out project.

I also would like to thank those people who helped me perform the tests, Zhiqi Wen, Jianwei Chen and Civil and Environmental Engineering laboratory technicians at Carleton University.

This research project is funded by Steel Structures Education Foundation and the Natural Sciences and Engineering Research Council of Canada (NSERC).

Last but not the least, I would like to thank my parents, in-law family, my wife (Shirin) and new born daughter (Sarina) for their understanding and encouragement during the period of this research. 


\section{TABLE OF CONTENTS}

Chapter

Page

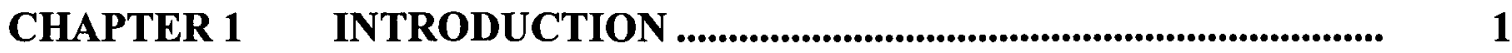

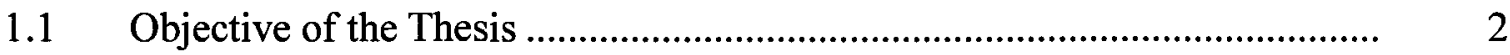

1.2 Methodology Used in the Research ........................................................ 2

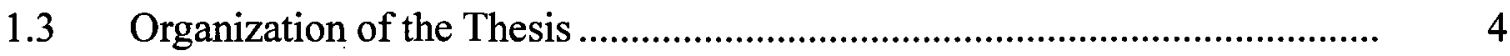

CHAPTER $2 \quad$ LITERUTURE REVIEW ................................................. 6

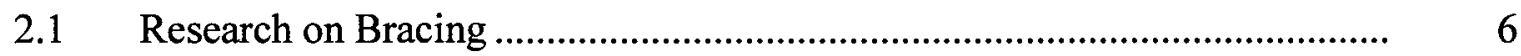

2.1.1 General Behaviour of Bracing................................................. 7

2.1.2 Experimental Studies.......................................................... 8

2.1.3 Analytical and Numerical Studies ......................................... 11

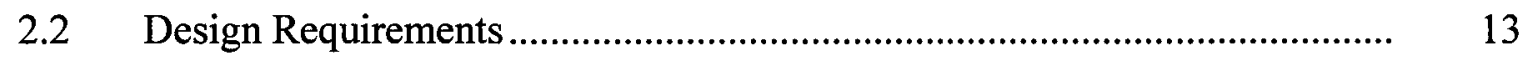

CHAPTER $3 \quad$ TESTING PROGRAM.................................................. 17

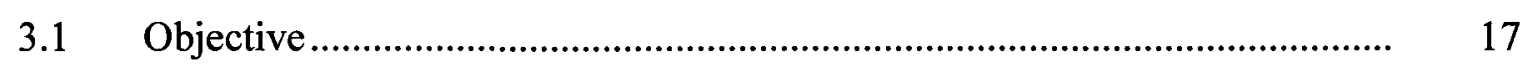

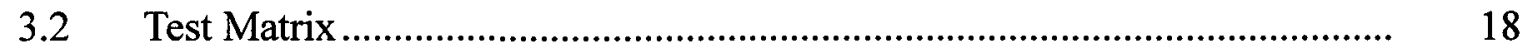

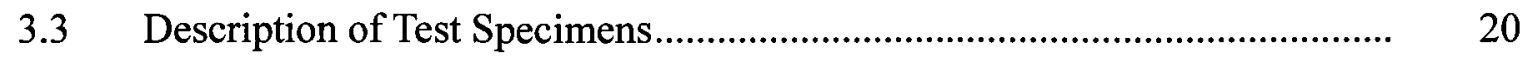

3.4 Specimen Preparation and Measurement............................................ 22

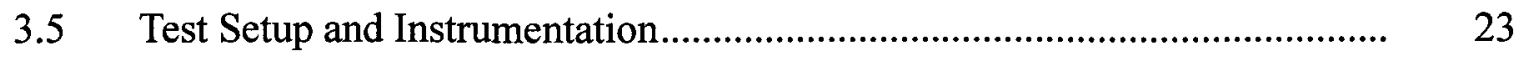

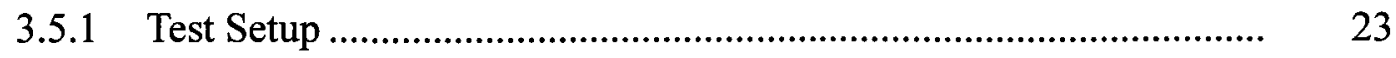

3.5.2 Instrumentation................................................................. 23

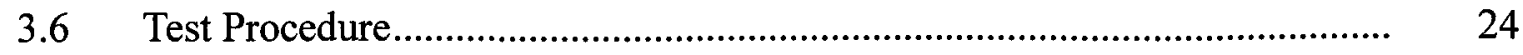


$3.7 \quad$ Material Properties.............................................................................. 27

CHAPTER $4 \quad$ TEST RESULTS ...................................................................... 48

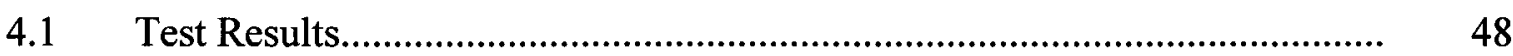

4.1.1 Direction of Buckling and Fracture Location..................................... 50

4.1.2 Out-of-plane Deformation of a Buckled Strap................................... 52

4.1.3 Comparison of Monotonic and Cyclic Tests ...................................... 54

4.1.4 Effects of $\mathrm{A}_{\mathrm{n}} / \mathrm{A}_{\mathrm{g}}$ and $\mathrm{A}_{\mathrm{n}} \mathrm{F}_{\mathrm{u}} / \mathrm{A}_{\mathrm{g}} \mathrm{F}_{\mathrm{y}}$ Ratios....................................... 56

4.1.5 Influence of Connection Details.................................................... 57

4.1.6 Effects of Slenderness Ratio ........................................................... 58

4.2 Guidelines and Recommendations on Using Strap Tension-only Brace in

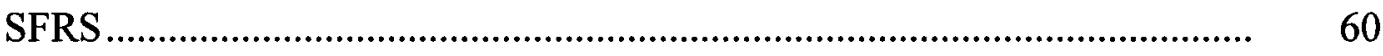

\section{CHAPTER 5 SUMMARY, CONCLUSIONS, AND}

RECOMMENDATIONS........................................................ 82

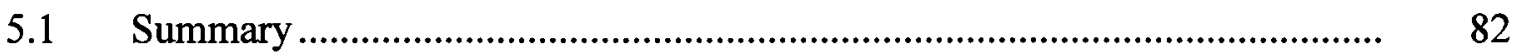

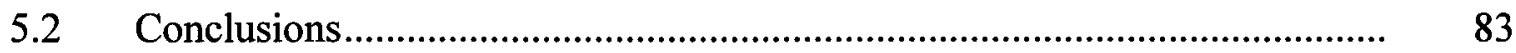

$5.3 \quad$ Recommendations...............................................................................

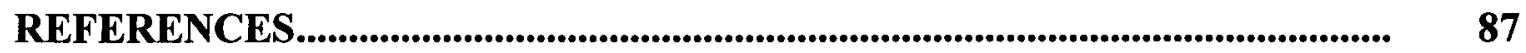

APPENDIX A: $\quad$ MATERIAL PROPERTIES ........................................................ 91

APPENDIX B: LOAD VERSUS DEFORMATION CURVES .......................... 96

APPENDIX C: PICTURES OF SPECIMEN FRACTURE AND

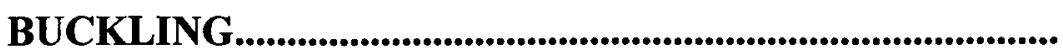




\section{LIST OF TABLES}

Table

Page

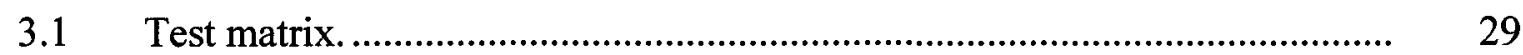

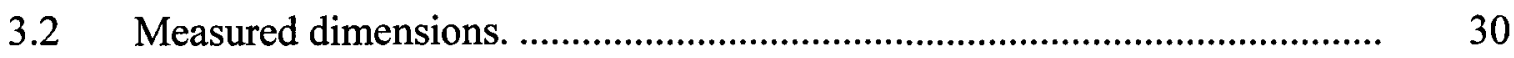

3.3 Nominal and expected net section to gross section yielding strength ratio for Type A and B specimens.

3.4 Loading rate for different specimen length.......................................... 33

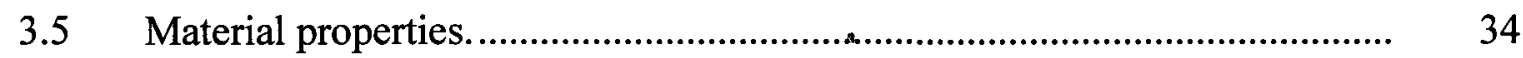

3.6 Material dynamic to static yield and ultimate strength ratios..................... 36

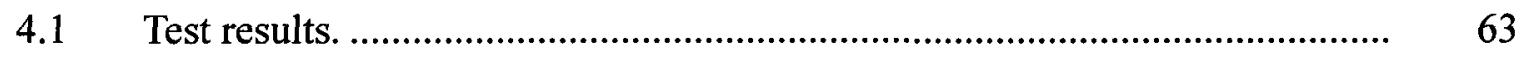

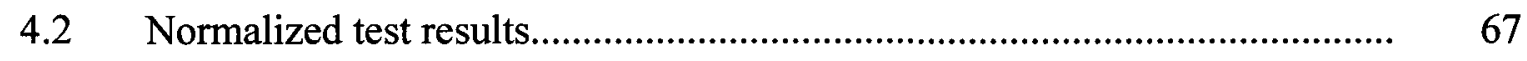

4.3 Ratios of average cross-section area and tension capacity for Type A and B

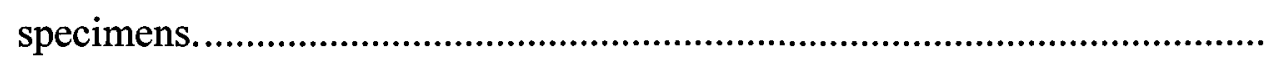

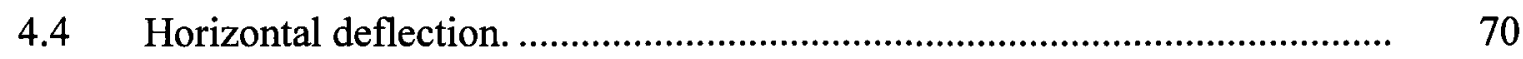

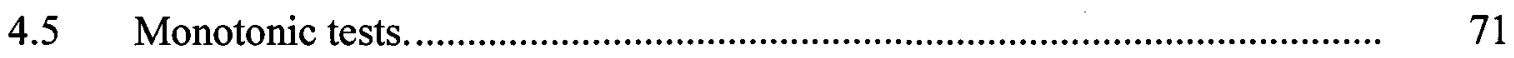

C.6 Comparison of monotonic and cyclic tests......................................... 72

4.7 Average normalized maximum extension and hysteretic energy for Type A specimens.

4.8 Comparison of average normalized maximum extension for various connection details.

4.9 Comparison of average normalized hysteretic energy for various vii 
connection details.

A.1 Material ductility and elastic modulus....................................................... 91

A.2 Material yield and ultimate strengths at various loading rates....................... 93

A.3 Average specimen strength for various loading rates..................................... 95 


\section{LIST OF FIGURES}

Figure

Page

1.1 Steel strap specimen with various connection details................................ 5

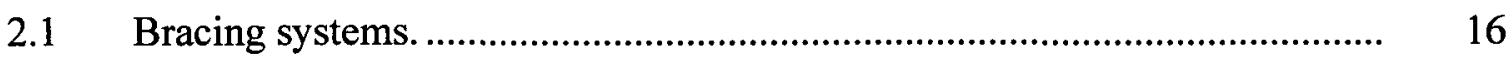

3.1 Strap with no reinforcement, Type A............................................... 37

Strap clamped with reinforcement plate, Type B.................................. 38

3.3 Strap welded with reinforcement plate, Type C..................................... 39

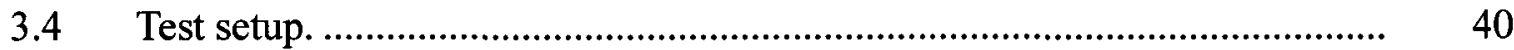

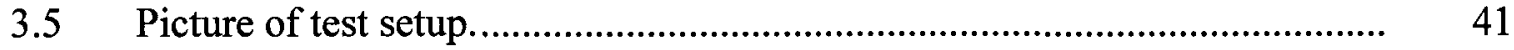

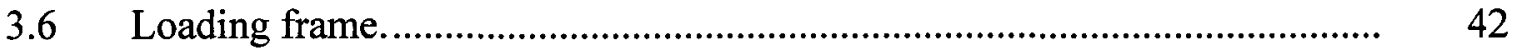

3.7 Bottom connection..................................................................... 43

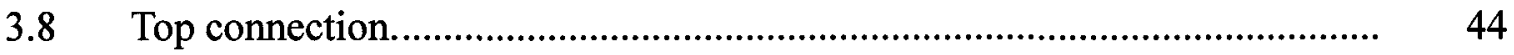

Positions of cable transducer ................................................................

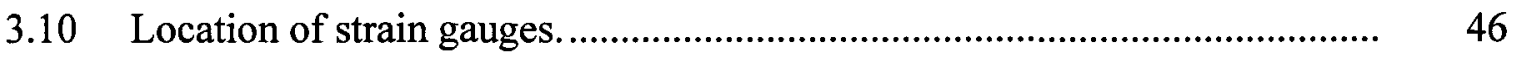

3.11 Example of a Type C specimen with strain gauges. ................................ 47

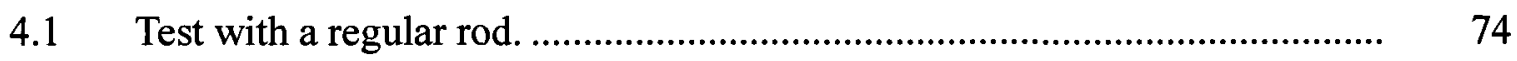

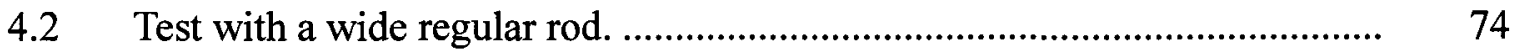

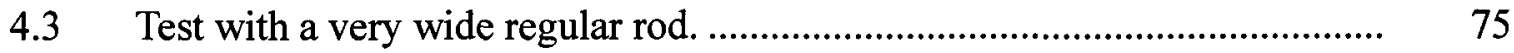

4.4 Fracture for Type A specimens. ....................................................... 76

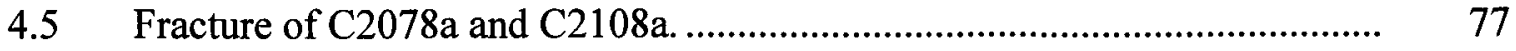

4.6 Out-of-plane deformation for fixed end elastic buckling. ....................... 78 
4.7 Out-of-plane deformation for pinned end elastic buckling............................ $\quad 78$

4.8 Comparison of A2078c (cyclic) and A2078e (monotonic)............................ 79

4.9 Comparison of A2128b (cyclic) and A2128e (monotonic)......................... 79

4.10 Normalized maximum tension versus slenderness ratio for Type A

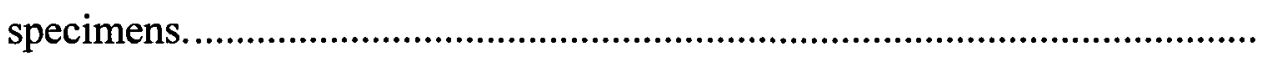

4.11 Normalized maximum extension load versus slenderness ratio for Type A specimens

4.12 Normalized maximum tension versus slenderness ratio for Type C specimens

4.13 Normalized maximum extension load versus slenderness ratio for Type $C$ specimens

B.1 Axial load versus axial deformation for A8075a specimen.

B.2 Axial load versus axial deformation for A8075b specimen.

B.3 Axial load versus axial deformation for A6075a specimen.

B.4 Axial load versus axial deformation for $\mathrm{A} 6075 \mathrm{~b}$ specimen.

B.5 Axial load versus axial deformation for A4075a specimen.

B.6 Axial load versus axial deformation for A $4075 \mathrm{~b}$ specimen.

B.7 Axial load versus axial deformation for A4075c specimen.

B.8 Axial load versus axial deformation for A4078a specimen.

B.9 Axial load versus axial deformation for A4078b specimen. 100

B.10 Axial load versus axial deformation for A2078a specimen. 100 
B.11 Axial load versus axial deformation for A2078b specimen. ........................ 101

B.12 Axial load versus axial deformation for A2078c specimen........................... 101

B.13 Axial load versus axial deformation for A2078d specimen.......................... 102

B.14 Axial load versus axial deformation for A2078e specimen. ......................... 102

B.15 Axial load versus axial deformation for A4108a specimen.......................... 103

B.16 Axial load versus axial deformation for A4108b specimen........................... 103

B.17 Axial load versus axial deformation for A2108a specimen. ......................... 104

B.18 Axial load versus axial deformation for A2108b specimen........................... 104

B.19 Axial load versus axial deformation for A4128a specimen. ........................... 105

B.20 Axial load versus axial deformation for A4128b specimen........................... 105

B.21 Axial load versus axial deformation for A2128a specimen........................... 106

B.22 Axial load versus axial deformation for A2128b specimen......................... 106

B.23 Axial load versus axial deformation for A2128c specimen.......................... 107

B.24 Axial load versus axial deformation for A2128d specimen.......................... 107

B.25 Axial load versus axial deformation for A2128e specimen.......................... 108

B.26 Axial load versus axial deformation for A2128f specimen........................... 108

B.27 Axial load versus axial deformation for B8075a specimen. ........................... 109

B.28 Axial load versus axial deformation for B8075b specimen........................... 109

B.29 Axial load versus axial deformation for B2078a specimen.......................... 110

B.30 Axial load versus axial deformation for B2078b specimen........................... 110

B.31 Axial load versus axial deformation for B2128a specimen.......................... 111 
B.32 Axial load versus axial deformation for B2128b specimen.......................... 111

B.33 Axial load versus axial deformation for B2128c specimen.......................... 112

B.34 Axial load versus axial deformation for B2128d specimen......................... 112

B.35 Axial load versus axial deformation for C8075a specimen............................ 113

B.36 Axial load versus axial deformation for C8075b specimen........................... 113

B.37 Axial load versus axial deformation for C6075a specimen. ......................... 114

B.38 Axial load versus axial deformation for C6075b specimen........................... 114

B.39 Axial load versus axial deformation for C4075a specimen........................... 115

B.40 Axial load versus axial deformation for $\mathrm{C} 4075 \mathrm{~b}$ specimen. .......................... 115

B.41 Axial load versus axial deformation for C4078a specimen. ......................... 116

B.42 Axial load versus axial deformation for $\mathrm{C} 4078 \mathrm{~b}$ specimen........................... 116

B.43 Axial load versus axial deformation for C4108a specimen........................... 117

B.44 Axial load versus axial deformation for C4108b specimen........................... 117

B.45 Axial load versus axial deformation for C2078a specimen. ........................ 118

B.46 Axial load versus axial deformation for $\mathrm{C} 2078 \mathrm{~b}$ specimen............................ 118

B.47 Axial load versus axial deformation for C2108a specimen. ......................... 119

B.48 Axial load versus axial deformation for C2108b specimen........................... 119

B.49 Axial load versus axial deformation for $\mathrm{C} 2108 \mathrm{c}$ specimen. .......................... 120

C.1 Failure of A8075a and A8075b............................................................... 121

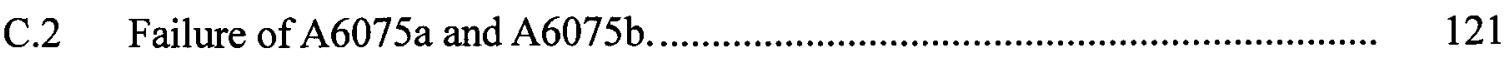

C.3 Failure of A4075a and A4075b............................................................ 122

xii 
C.4 Failure of A4075c and A4078a.

C.5 Failure of A4078b and A2078a.

C.6 Failure of A2078b and A2078d.

C.7 Failure of A2078e and A4108a.

C.8 Failure of A4108b and A2108a.

C.9 Failure of A2108b and A4128a.

C.10 Failure of A4128b and A2128a.

C.11 Failure of A2128b and A2128c.

C.12 Failure of A42128e and A2128f

126

C.13 Failure of B8075a and B8075b.

127

C.14 Failure of B2078a and B2078b.

127

C.15 Failure of B2128a and B2128b.

128

C.16 Failure of B2128c and B2128d.

128

C.17 Buckling of C8075a and C8075b.

C.18 Buckling of C6075a and C6075b.

C.19 Buckling of C4075a and C4075b.

C.20 Buckling of C4078a and C4078b

C.21 Failure of C2078a and C2078b.

C.22 Buckling of C4108a and C4108b.

C.23 Failure of C2108a and C2108b

132

C.24 Failure of $\mathrm{C} 2108 \mathrm{c}$. 


\section{LIST OF SYMBOLES}

a

A

$\mathrm{A}_{\mathbf{f}}$

$\mathrm{Ag}$

$A_{n}$

$\mathrm{A}_{0}$

b

$b_{0}$

$\mathrm{E}$

$\mathrm{E}_{\mathrm{h}}$

$\mathrm{E}_{\mathrm{n}}$

F

FB

$\mathrm{F}_{\mathrm{m}}$

$\mathrm{F}_{\mathbf{u}}$

$\mathrm{F}_{\mathrm{y}}$

$F_{y s}$

h

$\mathbf{h}_{\mathrm{s}}$
- maximum out-of-plane deformation

- cross-section area

- average cross-section area at fracture

- measured gross cross-section area

- $\quad$ measured net cross-section area

- undeformed cross-section area

- deformed length

- relaxed length at zero load

- measured elastic modulus

- $\quad$ average hysteretic energy

- $\quad$ average normalized energy

- measured force in the member

- flat bar

- maximum tension force up to the time of consideration

- nominal ultimate strength

- nominal yield strength

- measured static yield strength

- vertical distance between horizontal cable transducers

- interstorey height 
- moment of inertia

K

- effective length factor

$\mathrm{KL} / \mathrm{r} \quad$ - effective or nominal slenderness ratio

L

- nominal length of specimen measured between the middle bolt holes

$\mathrm{L}_{\mathrm{d}}$

- undeformed centre-to-centre distance of the innermost bolt holes

LD

- limited-ductility frame

$\mathrm{L}_{\mathrm{o}}$

- $\quad$ specimen overall length

$\mathrm{L}_{\mathbf{r}}$

- reinforcement plate length

MD

- moderately ductile frame

NBCC

- National Building Code of Canada

OCBF

- Ordinary Concentrically Braced Frame

r

- radius of gyration

$\mathrm{R}$

- force modification factor

$\mathrm{R}_{\mathbf{d}}$

- ductility-related force modification factor

$\mathrm{R}_{0}$

- over strength-related force modification factor

$\mathrm{R}_{\mathrm{y}}$

- ratio of the expected yield stress to the specified minimum yield stress

SFRS

t

- $\quad$ specimen thickness

$t_{r}$

- $\quad$ reinforcement plate thickness

$T_{\max }$

- maximum tension force

$\mathrm{T}_{\text {nmax }}$

- maximum normalized tension force 
W

$\mathbf{W}_{\mathrm{r}}$

$\mathbf{X}$

y

Z

$\delta$

$\delta_{\mathrm{y}}$

$\Delta$

$\Delta_{\max }$

$\Delta_{\mathrm{m}}$

$\Delta_{\mathrm{nmax}}$

$\lambda$

$\mu_{\mathrm{f}}$

$\Phi$
- specimen width

- reinforcement plate width

- horizontal deflection variable

- vertical deflection variable

- plastic section modulus

- half of the applied deformation range

- yield deformation

- axial deformation from the original undeformed position

- maximum extension

- maximum extension up to the time of consideration

- maximum normalized extension

- non-dimensional slenderness ratio

- maximum normalized deformation range

- resistance factor 


\section{CHAPTER 1 INTRODUCTION}

Bracing is commonly used in buildings to provide lateral support. During an earthquake, a brace can help dissipating energy through inelastic deformation. When cycling through tension and compression, plastic hinges can form in the brace and at the connection. The formation of these hinges lead to strain localization that accelerates the failure of the bracing system. Instead of using stocky braces, very flexible braces that buckle elastically can be used to delay the formation of plastic hinge and improve the ductility of the bracing system. At a moderate compression deformation, a flexible brace with a high slenderness ratio will be able to accommodate the compressive deformation by buckling elastically, while a stockier brace may have to accommodate the deformation through the rotation at plastic hinges.

With a very flexible brace, the end of brace and the gusset plate at the connection can be easily designed to be stiffer than the brace member to ensure that plastic hinge and fracture do not occur at the gusset plate and the connection. Thus by avoiding and delaying the formation of the plastic hinge, fracture of the brace and connection may be prevented, and only the brace may have to be replaced after a severe earthquake as a result of inelastic extension.

A very flexible brace can be constructed with a steel strap. Unlike cables and round rods, there is no special detailing required for connecting a steel strap. A number of 
studies have been carried out on very flexible light gage steel straps in cold-formed structures under cyclic loading. Results from these studies showed that very flexible braces can be used satisfactory in low-rise steel frame buildings. The slenderness ratio of the braces investigated in these studies were generally larger than 800 , while in the other studies, the focus was mainly on braces of other structural shapes with the slenderness ratio less than 200 . Thus, it is useful to have more information on the performance of braces with slenderness ratio from 200 to 800 .

\subsection{Objective of the Thesis}

The primary objective of this research project is to investigate the performance of flexible steel straps with the slenderness ratio between 200 and 800 under cyclic loading. Various slenderness ratios and connection details will be investigated. The feasibility of using various steel strap configurations will be investigated experimentally. These tests will also provide the data for the validation of finite element model to be developed for the parametric finite element study on the strap tension-only bracing system that is to be carried out in a separate study.

\subsection{Methodology Used in the Research}

The total of nineteen combinations of brace and connection detail with at least two specimens for each combination were tested. Flat bars were used as the bracing 
member. The braces are considered to be fixed supported at both ends. The general configuration of the experiment along with the three different bolted connection details investigated are shown in Fig. 1.1.

These details consist of the connection with no reinforcement, and with reinforcement of either clamping or welding an additional plate. The test specimens have been designed to investigate effects of slenderness ratio and connection detail. The slenderness ratio investigated varies from 200 to 800 by changing the specimen length and thickness. Various net to gross cross-section area ratios at the connection were tested by using straps of different width.

A thick gusset plate was used to connect the brace in order to prevent any plastic hinge from forming in the gusset plate. The loading sequence of the test was conducted according to Guidelines for Cyclic Seismic Testing of Components of Steel Structures ATC-24 (ATC 1992) for single specimen testing program, but with some modifications for the later stages of the loading cycle. A small number of monotonic tests were also carried out to compare the response between monotonic and cyclic loading sequences.

All the tests were conducted under deformation control. Mechanical properties from tension coupon tests were used in analyzing the data in the test program. The hysteretic energy, maximum load and deformation, were determined for the tests. These values were normalized with respect to the yield load and yield deformation to allow for a better comparison between specimens of different lengths and material properties. Equations to predict the out-of-plane deflection of a buckled strap were developed and 
verified. Based on the test data, effects of slenderness ratio and connection detail were assessed and recommendations provided on using strap tension-only bracing in a Seismic Force Resisting System.

\subsection{Organization of the Thesis}

Chapter 2 presents a brief literature review of previous studies on structural bracing systems. Provisions in design standards for the tension-only bracing system are presented.

In Chapter 3, the experimental program is presented. This chapter describes the test setup, testing procedure, test matrix and specimen geometry. A brief description of the tension coupon tests is provided.

Test results are presented in Chapter 4. Effects of slenderness ratio and connection detail on the ductility and the energy dissipation capability of the specimen are discussed. Discussions of the test results with respect to the design provisions for the tension-only bracing systems are presented, together with the recommendations.

Chapter 5 consists of the summary of the thesis, and as well as the conclusions and recommendations.

Additional test data are presented in appendices. 


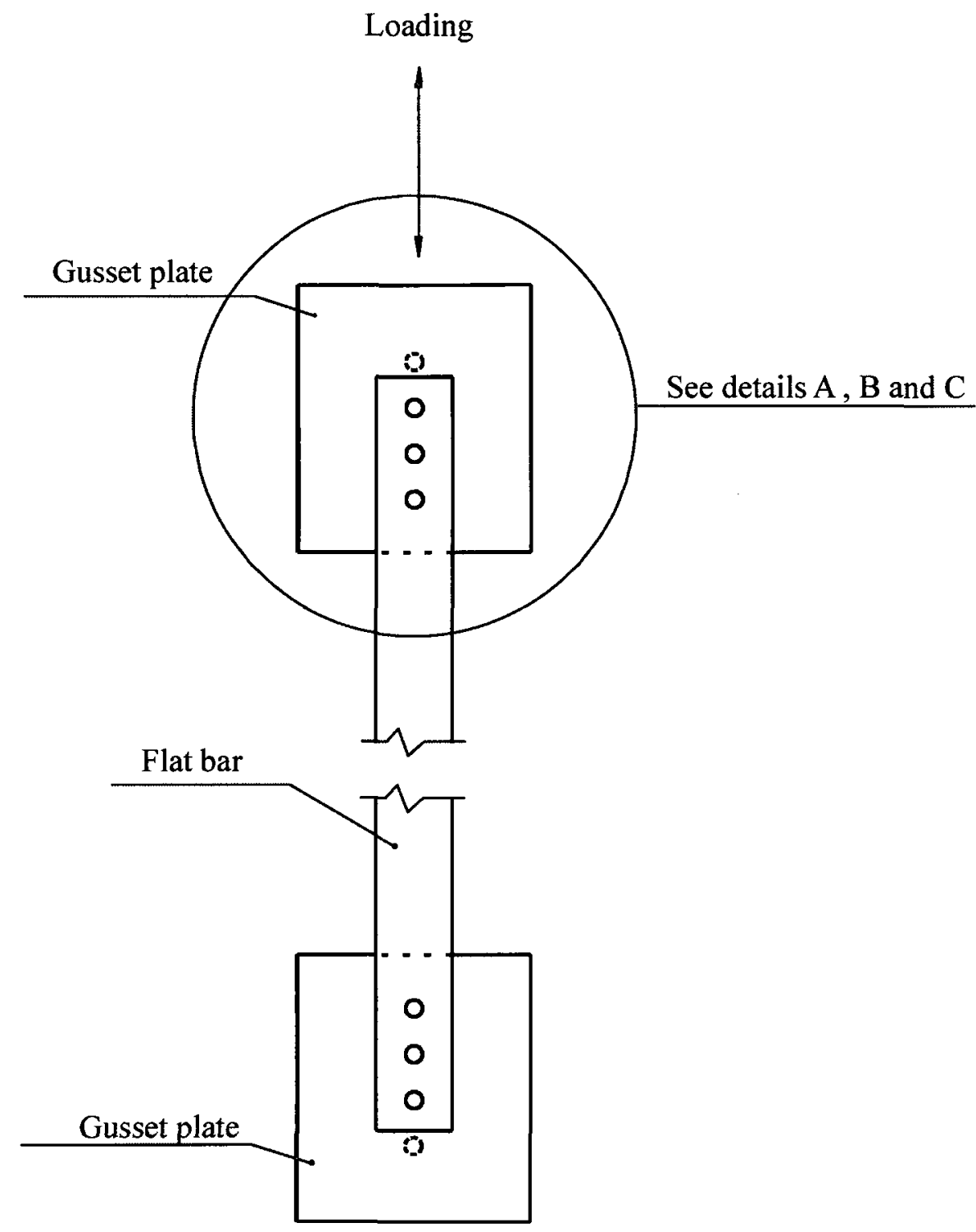

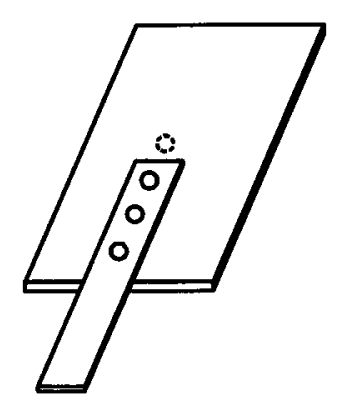

Detail A

No reinforcement
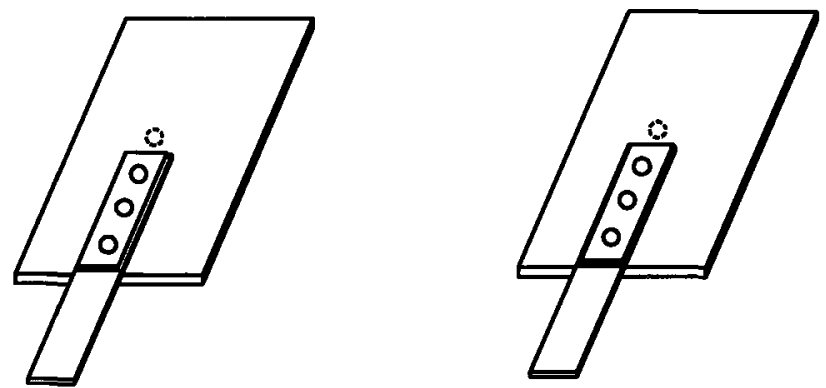

Detail B

Detail C $\overline{\text { Clamped down with extra plate }} \quad \overline{\text { Welded with extra plate }}$

Figure 1.1 Steel strap specimen with various connection details. 


\section{CHAPTER 2 LITERATURE REVIEW}

Vertical bracing is commonly used in non-moment-resisting steel frames to provide lateral support. When designed as members of a Seismic Force Resisting System (SFRS), the bracing member helps dissipate energy through plastic deformation during an earthquake. A compact bracing member can resist both compression and tension loads, while a very slender bracing member is only effective in providing resistance in tension. Figure 2.1 shows various bracing configurations that can be used in a structure. Among these, only $\mathrm{X}$ and diagonal bracing configurations are permissible when using a slender tension-only bracing member in a concentrically braced frame.

Many studies have been carried out to investigate the performance of bracing in an earthquake. Most of these studies focused on hollow structural sections, angles and sheet-metal strips. A brief review of bracing design and research is provided. Only some of the studies are discussed.

\subsection{Research on Bracing}

A number of tests have been carried out on the bracing member either individually, in a frame or in a building. Some of these tests were carried out by Astaneh-Asl et al. (1985) on angles, Kahn and Hanson (1976) on flat bars, Popov and Black (1981) on various structural sections, Tremblay et al. (2003) on rectangular HSS, Shaback and 
Brown (2003) on square HSS, Al-Kharat and Rogers (2007) on cold-formed steel straps, and Filiatrault and Tremblay (1998) on tie-rods. Various numerical studies on seismic response of concentric braced frames have been carried out by Tremblay et al. (1997), and Tremblay $(2000,2001)$. Analytical studies of the bracing response have also been conducted by Tremblay (2002), El-Tayem and Geol (1986), Higginbotham and Hanson (1976), and Dewolf and Pelliccione (1979). Slenderness ratio, width to thickness ratio, ultimate to yield strength ratio, and deformation rate are some of the factors that have been found to affect the performance of the brace.

\subsubsection{General Behaviour of Bracing}

Generally, a bracing member will buckle under severe compressive deformation. For the configuration with a diagonal or a cross bracing without the mid-length attached, the initial buckled shape of the brace is between half and full sine curve depending on the end constraint. The deformed shape normally generates the largest curvature at the ends and the mid-span of the brace. Inelastic buckling eventually develops with the increase in the cyclic deformation.

Tests on various structural shapes by Kahn and Hanson (1976), Popov and Black (1981), Astaneh-Asl et al. (1985), Shaback and Brown (2003) and Tremblay et al. (2003) have shown that all specimens formed plastic hinges at these three locations. The formation of plastic hinges accelerates the strength degradation and fracture of the 
member under cyclic loading since almost all the cyclic deformation is accommodated through the strain reversal at the plastic hinge. This eventually leads to fracture of the member at one of these locations.

\subsubsection{Experimental Studies}

There have been many tests on bracing under cyclic loading. Kahn and Hanson (1976) tested steel bars with slenderness ratios ranging from 85 to 210 and two loading rates. The fast rate was approximately 100 times faster than the slow rate. As anticipated, shorter specimens were found to have dissipated greater energy than larger specimens under the same relative deflection cycle. The maximum compressive buckling load was also found to decrease with increasing number of cycle, with a greater decrease after the first cycle than subsequent cycles. The hysteresis response was nearly identified under the two loading rates, with the response slightly stiffer in the tension region at the faster loading rate.

Popov and Black (1981) also tested different structural shapes with slenderness ratios from 40 to 120 . The slenderness ratio was found to be the single most important parameter in determining the hysteretic behavior. Members with the lower slenderness ratio generate fuller loop than those with a higher ratio. The hysteretic performance of a member was also found to be influenced by the structural shape with respect to its susceptibility to local buckling. Local buckling occurred in the regions of plastic hinges 
in advanced stages of cyclic load application. Normalized values of the load and displacement were used in order to make the comparison between members with different material properties. The normalized force and displacement are the corresponding measured force and displacement divided by the yield force and yield displacement respectively.

An experimental study was carried out by Astaneh-Asl et al. (1985) on double-angle bracing in a hinged frame. The overall ductility and cyclic behavior of out-of-plane buckling double-angle members are greatly affected by the stitches and end gusset plates. It was recommended that stitches stronger than nominal stitches should be provided. A minimum free length equal to twice the thickness of the gusset plate beyond the angles is necessary to allow the free formation of plastic hinges and to improve the ductility.

Jain et al. (1978), Shaback and Brown (2003), and Tremblay et al. (2003) tested tubular members under cyclic loading. While Jain et al. (1978) only tested for two cycles, Shaback and Brown (2003) and Tremblay et al. (2003) tested the specimens until fracture. Similar to other studies, slenderness ratio has been found to be the single most important parameter influencing hysteric behavior of the specimen. Shaback and Brown (2003) found that the width to thickness ratio of the cross-section has a great influence on the brace fracture life, but has minimal effect on the hysteretic behavior. Both Tremblay (2002) from examining results from tubular members including tests by others, and Goggings et al. (2005) from tests on cold-formed tubes, concluded that the ductility of the 
brace is strongly dependent on the slenderness ratio, and to a lesser extent, the width-to-thickness ratio of the cross-section. Equations in terms of slenderness ratio and width-to-thickness ratio were proposed to predict the fracture life of the brace by Shaback and Brown (2003) and Tremblay et al. (2003). Tremblay et al. (2003) proposed a simple fracture life equation defined for the maximum normalized deformation range.

$$
\begin{aligned}
& \mu_{\mathrm{f}}=8.3 \lambda+2.4 \text { with } \\
& \lambda=\frac{\mathrm{KL}}{\mathrm{r}} \sqrt{\frac{F_{\mathrm{y}}}{\pi^{2} \mathrm{E}}}
\end{aligned}
$$

where $\mathrm{KL}$ is the effective length, $\mathrm{r}$ is the radius of gyration, $\mathrm{F}_{\mathrm{y}}$ is the yield strength and $\mathrm{E}$ is the elastic modulus. Shaback and Brown (2003) also proposed two equations to predict the out-of-plane deflection of the brace. A number of lateral brace deflection equations have also been proposed by Tremblay (2002) from initial buckling to the formation of plastic hinges.

Most cyclic tests on the structural sections have been limited to specimens with the slenderness ratio less than 200 . Some tests have been carried out on specimens with the slenderness ratio greater than 200 using round steel bars and thin straps as tension-only bracing. Filiatrault and Tremblay $(1996,1998)$ tested a frame braced with tie-rods under various seismic ground excitations. It was found that the frame response exhibited severe pinching in the hysteretic loop. The maximum force in the bracing was equivalent to approximately 1.14 times that at yielding for the rod. This was attributed to the increase in the yield strength of the rod as the deformation rate increases. 
Kim et al. (2006) carried out shake table tests on cold-formed steel shear panel. The shear panel braced with the thin steel straps performed satisfactory for the ground motion considered in the test. Al-Kharat and Rogers $(2007,2008)$ also tested cold-formed steel strap braced walls. The force demand due to brace yielding was found to be higher than anticipated partly due to the strain rate effect increase in the yield strength. As the strain rate increases, the ultimate to yield strength ratio of the material decreases. This has been noted to affect the capacity design requirement of the connection for the test specimen to ensure gross section yielding of the brace before net section fracture occurs. All cold-formed steel strap braced walls by Kim et al. (2006), and Al-Kharat and Rogers $(2007,2008)$ exhibited severe pinching in the hysteretic loop. There were also significant slack in the braces at the end of the tests.

\subsubsection{Analytical and Numerical Studies}

Besides experimental studies, analytical studies have been conducted to study the effective length factor of bracing systems and to model their axial hysteretic behaviour. Numerical studies have also been conducted on seismic response of concentrically braced steel frames.

In the analytical and experimental studies of X-bracing system of single angle, ElTayem and Goel (1986) recommended that an effective length of 0.85 times the half diagonal length can be considered for X-bracing systems made from single equal-leg 
angles. An analytical study by Picard and Beaulieu (1987) showed that the effective length of the diagonal brace in a X-bracing system can be taken as 0.5 times the diagonal length when the diagonals are continuous and attached at the intersection point without including the rotation constraint provided by the complementary member and gusset plate considered by El-Tayem and Geol (1986). The results were further extended by Sabelli and Hohbach (1999) for other additional end restraints. Upper bound and lower bound in-plane and out-of-plane effective length factors were established by Sabelli and Hohbach (1999).

Davaran (2001) carried out an analytical study to investigate the effect of having a discontinuous brace in X-bracing systems. Various details were suggested to improve the rotational stiffness of center connection to increase the load carrying capacity of X-bracing systems with discontinuous brace. Jain et al. (1978) also provided a procedure to calculate the effective length factor for a single diagonal tubular member slotted into the gusset plate. In a X-bracing system, the peak compression force and tension force do not occur at the same time. Dewolf and Pelliccione (1979) in the analytical and experimental studies of the X-bracing frame found that when the compression force was at its maximum, the capacity of the frame was only between $40 \%$ to $70 \%$ of the test failure load. Both Tremblay (2002) and Shaback and Brown (2003) proposed equations to calculate the post-buckling strength of the compression brace so that the bracing capacity can be accounted for at the instance of the tension brace yielding. Performing the numerical analysis to investigate the seismic response of the braced frame requires the 
knowledge of the axial hysteretic behaviour of the brace. This behaviour is normally represented by mathematical models to be incorporated into the numerical analysis. Some of these models have been proposed by Higginbotham and Hanson (1976) and Prathuangsit et al. (1978). Using a mathematical hysteretic model, Tremblay et al. (1997) and Tremblay (2000) studied the influence of brace slenderness on the seismic response of concentrically braced frames including tension-only braced frame. Tremblay et al. (1997) suggested that the tension-only braced frame should be limited to 4 storeys even if it is designed with a force modification factor $\mathrm{R}$ of 2 . Tremblay (2000) also recommended that tension-only braced frame should be permitted up to four storeys, but with some limitations on the maximum slenderness ratio.

\subsection{Design Requirements}

Both Canadian and American design standards, Limit States Design of Steel Structures CSA-S16-01 (CSA 2005) and Seismic Provisions for Structural Steel Buildings ANSI/AISC 341-05 (AISC 2005) permit the use of tension-only brace in the Seismic Force Resisting Systems (SFRS). Since the complete design requirements are extensive, only a brief summary of bracing system design requirements are discussed.

In CSA-S16-01 (CSA 2005), tension-only bracing systems can be used in both moderately ductile (MD) and limited-ductility (LD) concentrically braced frames as well as in conventional construction. A height limit of $20 \mathrm{~m}$ for MD frame and $40 \mathrm{~m}$ for $\mathrm{LD}$ 
frame are prescribed when tension-only bracing systems are used. However, there is a difference in the slenderness ratio $(\mathrm{KL} / \mathrm{r})$ limit for each type of these frames, where $\mathrm{K}$ is the effective length factor, $\mathrm{L}$ is the brace length and $\mathrm{r}$ is the radius of gyration. Due to the higher expected capability to dissipate energy through inelastic behavior, the slenderness ratio of the brace in MD Type braced frames has an upper limit 200. This is followed by LD Type braced frames with a higher upper limit of 300 , and conventional construction where the limit can be waived if other means are provided to control the brace flexibility, sag, vibration, and slack in a member that is in line with the service conditions of the structure or if it can be shown that such factors are not detrimental to the performance of the structure.

For MD and LD Type braced frames, the brace connections shall be designed to resist at least both $\mathrm{A}_{\mathrm{g}} \mathrm{R}_{\mathrm{y}} \mathrm{F}_{\mathrm{y}}$ in tension and 1.2 times the probable compressive resistance of the bracing members, where $A_{g}$ is the gross area and $R_{y}$ is the ratio of the expected yield stress to the specified minimum yield stress, $F_{y}$. The net section factored resistance of an unreinforced brace may be increased by a factor $R_{y} / \Phi$ with $R_{y}$ not greater than 1.1 and $\Phi$ is the resistance factor. However for conventional construction, the braced connections are required only to be proportioned so that the expected failure mode is ductile. Nevertheless in all cases, the maximum design tensile force need not exceed the combined effect of gravity load and effects of seismic loads corresponding to $R_{d} R_{0}=1.3$, where $R_{d}$ is ductility-related force modification factor and $R_{0}$ is the over-strength related force modification factor. The brace members or connections must also have ductile 
rotational behavior in MD and LD Type braced frames. When rotation is expected in the bracing member, the connections shall have a factored flexural resistance of at least $1.1 \mathrm{ZR}_{\mathrm{y}} \mathrm{F}_{\mathrm{y}}$ of the bracing member where $\mathrm{Z}$ is the plastic section modulus. Besides the strength requirements in CSA-S16-01, the largest calculated interstorey drift due to the seismic load is also limited to $0.01 \mathrm{~h}_{\mathrm{s}}$ for post-disaster buildings, $0.02 \mathrm{~h}_{\mathrm{s}}$ for schools, and $0.025 \mathrm{~h}_{s}$ for all other buildings by the National Building Code of Canada 2005 (NRCC 2005), where $h_{s}$ is the interstorey height.

ANSI/AISC 341-05 (AISC 2005) also has connection design requirements for Ordinary Concentrically Braced Frames (OCBF) that are similar to MD and LD Type braced frames in CSA-S16-01 (CSA 2005). While CSA-S16-01 (CSA 2005) places some limits on the $\mathrm{KL} / \mathrm{r}$ ratio of tension-only brace, no $\mathrm{KL} / \mathrm{r}$ ratio limit has been specified for tension-only brace in ANSI/AISC 341-05 (AISC 2005) for OCBF. 


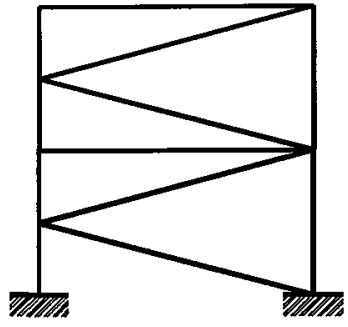

K bracing

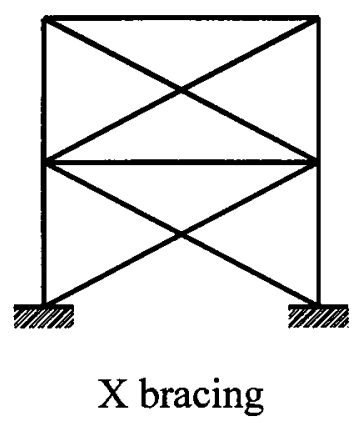

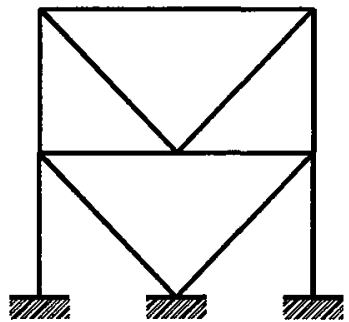

V bracing

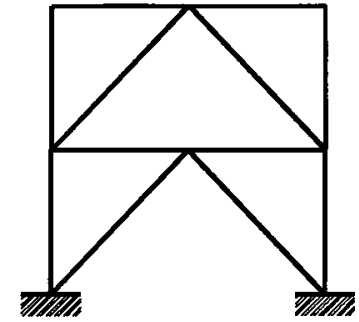

Inverted-V bracing

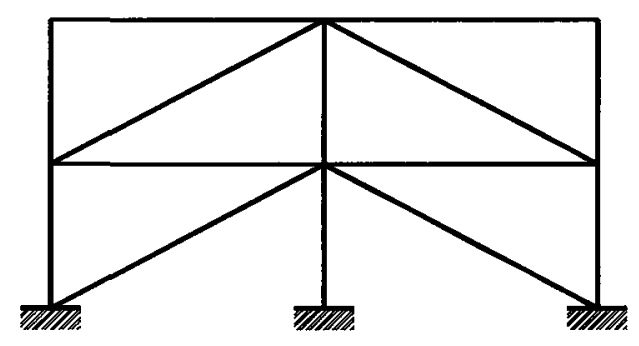

Diagonal bracing

Figure. 2.1 Bracing systems. 


\section{CHAPTER 3 TESTING PROGRAM}

Although many experimental studies have been carried out on bracing systems, there have been only a few studies conducted on braces with the slenderness ratio between 200 and 800 under cyclic loadings. Tests on specimens with the slenderness ratio greater than 200 have mainly been limited to tie-rods and thin cold-formed steel straps.

This experimental study focused on steel straps with the slenderness ratio between 200 and 800 using hot-rolled flat bars. Tests were conducted in the Civil and Environmental Engineering Laboratory at Carleton University under displacement control. Strain gauges were instrumented to measure the strain distribution and cable transducers employed to record the transverse and axial deformations. A series of cyclic loading tests were carried out on flat bars with various slenderness ratios and three connection details in order to gain a better understanding of the ductility and performance of tension-only steel straps at this range of slenderness ratios, and eventually developing the corresponding design recommendations and guidelines for steel straps.

\subsection{Objective}

The objective of the testing program is to investigate the feasibility of using high slenderness ratio flat bar braces in steel structures for seismic design requirements. Effects of slenderness ratio and connection detail on the ductility and performance of the 
braces will be studied experimentally. In addition, data obtained from this experimental study will be used in the validation of the finite element models developed for the parametric finite element analysis to be carried out that is outside the scope of this thesis.

\subsection{Test Matrix}

A total of 49 hot-rolled flat bar specimens were tested. Four cross-section sizes of flat bar specimens were used. They were FB 76x4.8 (3"x3/16"), FB 76x7.9 (3"x5/16"), FB $102 \times 7.9\left(4^{\prime \prime} \times 5 / 16^{\prime \prime}\right)$, and FB $127 \times 7.9\left(5^{\prime \prime} \times 5 / 16^{\prime \prime}\right)$. In addition, FB $64 \times 4.8$ $\left(2-1 / 2 " x 3 / 16^{\prime \prime}\right)$ and FB $64 \times 7.9\left(2-1 / 2^{\prime \prime} \times 5 / 16^{\prime \prime}\right)$ were also used as the reinforcement plate. All flat bars were CAN/CSA G40.20/21 (CSA 2004) 300W (44W) steel, except for FB $76 \times 7.9$ and FB $127 \times 7.9$, which met the specifications for both $300 \mathrm{~W}(44 \mathrm{~W})$ and $345 \mathrm{~W}$ (50W) grades. Welding was carried out using E49XX electrodes. Effects of slenderness ratio, connection detail and ultimate to yield load ratio were investigated. Even though not ideal, the different ultimate to yield load ratio was obtained indirectly by using the flat bar of various width to achieve the different net to gross section area ratio. The parameters considered are described below.

1) Slenderness ratio

For a bracing member, one of the most important parameters is the slenderness ratio. With a flat bar brace, the bending strain due to buckling at the same axial deformation decreases with a higher slenderness ratio. In the test program, 
nominal slenderness ratios of $200,400,600$, and 800 were considered. These ratios were achieved changing the specimen length and thickness. The calculation of the nominal slenderness ratio adopted will be described later.

\section{2) Connections}

The energy dissipating capability of a SFRS requires the proper design of the connections to control the location of the plastic deformation. Figures 3.1 to 3.3 show the three connection types investigated. Type A connection in Fig. 3.1 has no reinforcement where the plastic deformation localization due to axial extension and buckling occurs at the section across the bolt hole. In Type B, the connection is stiffened by clamping an additional plate so that the plastic deformation due to buckling occurs away from the bolt hole in order to improve the ductility of the brace. Type $\mathrm{C}$ connection is welded with an additional plate to further improve the ductility of the brace by ensuring the connection is stronger than the rest of the brace in bending and tension.

3) Net to gross section area ratio

Three net to gross section area ratios were considered in order to investigate the effect of the ultimate to yield capacity ratio. Having the same material properties, the ductility of the flat bar brace is expected to improve with a higher net to gross section ratio at the connection. Three net to gross section area ratios of $0.71,0.78$, and 0.83 were considered. Even though the holes were punched, the net area is calculated by removing only $22 \mathrm{~mm}$ width. 


\subsection{Description of Test Specimens}

The following notation was adopted to identify the test specimen:

$\alpha \beta \chi \chi \eta \tau$

a) $\alpha$

The first letter $\alpha$ denotes the type of connection used for the specimen.

$\mathrm{A}=$ Type $\mathrm{A}$ connection with no reinforcement plate.

$\mathrm{B}=$ Type $\mathrm{B}$ connection clamped with a reinforcement plate.

$\mathrm{C}=$ Type $\mathrm{C}$ connection with a welded reinforcement plate.

b) $\quad \beta$

The second digit represents the nominal slenderness ratio from 200 to 800 with 2 , $4,6,8$ representing $200,400,600$, and 800 respectively.

c) $\quad \chi \chi$

The third and forth digits identify the specimen width with 07 for 76,10 for 102 , and 12 for $127 \mathrm{~mm}$.

d) $\quad \eta$

The fifth digit indicates the thickness of the specimen. It is either 5 for $4.8 \mathrm{~mm}$ or 8 for $7.9 \mathrm{~mm}$.

e) $\tau$

Finally the last letter, which is a, b, c, and so on, represents duplicate specimens. 
The nominal and measured dimensions of the specimen are presented in Tables 3.1 and 3.2 respectively. Table 3.3 shows the nominal and expected net section fracture to gross section yielding strength ratio for Grade $300 \mathrm{~W}$ Type A and $\mathrm{B}$ straps, where $\mathrm{R}_{\mathrm{y}} \mathrm{F}_{\mathrm{y}}$ is taken as $385 \mathrm{MPa}$ and the expected $\mathrm{F}_{\mathrm{u}}$ is taken as 1.1 times the nominal as according to CSA-S16-01 (CSA 2005). The following symbols are adopted to represent dimensions of the specimen according to Figs. 3.1 to 3.3 .

1) Specimen overall length $\left(L_{o}\right)$.

Five different lengths between 1120 and $2510 \mathrm{~mm}$ were used in the test to achieve the nominal slenderness ratio between 200 and 800 .

2) Specimen thickness ( $t$ ).

Flat bar thicknesses of 4.8 and $7.9 \mathrm{~mm}$ were used.

3) Specimen width (w).

The specimens have three widths of 76,102 , and $127 \mathrm{~mm}$.

4) Nominal slenderness ratio $(\mathrm{KL} / \mathrm{r})$.

Four nominal slenderness ratios of $200,400,600$, and 800 were tested. To simplify the discussion, the nominal slenderness ratio of the specimen is henceforth referred to as the slenderness ratio. The slenderness ratio of the specimen is calculated as

$$
\frac{\mathrm{KL}}{\mathrm{r}}=\frac{\mathrm{KL}}{\sqrt{\frac{\mathrm{I}}{\mathrm{A}}}}=\frac{\mathrm{KL}}{\sqrt{\frac{\left(\frac{\mathrm{wt}^{3}}{12}\right)}{\mathrm{wt}}}}=3.46 \frac{\mathrm{KL}}{\mathrm{t}},
$$


where $\mathrm{K}$ is the effective length factor is taken as 0.5 for both ends fixed condition, $\mathrm{L}$ is the distance between the middle bolt holes (second bolt hole), $\mathrm{r}$ is the radius of gyration, $\mathrm{I}$ is the moment of inertia, and $\mathrm{A}$ is the cross-section area.

5) Reinforcement plate length $\mathrm{x}$ width $\mathrm{x}$ thickness $\left(\mathrm{L}_{\mathrm{r}} \mathrm{X} \mathrm{w}_{\mathrm{r}} \mathrm{x} \mathrm{t}_{\mathrm{r}}\right)$.

Specimens with Type B and C connection details have reinforcement plates either clamped or welded to the ends. All reinforcement plates were $200 \mathrm{~mm}$ long. For Type B specimens, the reinforcement plates were of the same width and thickness as the main specimen. In Type $\mathrm{C}$ specimens, $64 \mathrm{~mm}$ wide reinforcement plates were used with $76 \mathrm{~mm}$ wide straps and $76 \mathrm{~mm}$ wide plates with $102 \mathrm{~mm}$ wide straps, but the same thickness was maintained for the main specimen and reinforcement plate.

\subsection{Specimen Preparation and Measurement}

The contact surface of the specimen at the connection was cleaned to Class A, clean mill scale surface in accordance to SSPC (2004) Solvent Cleaning, Hand Tool Cleaning, and Power Tool Cleaning Specifications. The specimen width and thickness, and its reinforcement plate length, width and thickness were measured with a digital caliper. A digital micrometer was also used in measuring the thickness of the specimen. A measuring tape was used in measuring the length of the specimen. Average measured dimensions of each specimen and its corresponding reinforcement plate are shown in 
Table 3.2 .

\subsection{Test Setup and Instrumentation}

Tests were carried out using a $1000 \mathrm{kN}$ hydraulic jack with a $450 \mathrm{~mm}$ stroke limit. The machine stroke, cable transducer, load cell, and strain gauge readings were recorded continuously through the data acquisition system during the test.

\subsubsection{Test Setup}

Figures 3.4 to 3.8 show details of the fixtures for attaching the specimen and the general test setup. The end fixtures were reinforced and rigidly connected to the base plate and the head of the loading jack to prevent the ends from rotating about horizontal axis. Even though each end of the specimens was connected with only three M20 ASTM A490M bolts, four bolt holes were provided on the gusset plate to minimize the frequency of lifting of the loading cross beam needed to accommodate the different specimen length. All bolts were pre-tensioned using the turn-of-nut method. Figure 3.8 shows the loading frame used in the test.

\subsubsection{Instrumentation}

Strain gauges and cable transducers were used in the tests to measure the 
deformation of the specimen. Figure 3.9 shows locations of the cable transducers. The horizontal cable transducers were always positioned on the side away from the gusset plate such that the specimen was always between the gusset plate and horizontal cable transducer. All cable transducers have a $500 \mathrm{~mm}$ extension range. Two cable transducers measured the vertical deformation, and the other two measured the horizontal deflection at the mid-length. The actuator stroke was used in the deformation control. It is expected that the actuator stroke and axial deflection measured by the cable transducer to be close. In some tests, the horizontal cable transducers may have to be removed in the middle of the test because either the deflection has exceeded the range of the cable transducer or the attachment for the cable connection was interfering with the vertical cable transducer.

Depending on the connection type, two or three strain gauges were instrumented on the specimen. Locations of the strain gauges are shown in Fig. 3.10. These strain gauges are numbered G1 to G3 as shown in the Figure. Figure 3.11 illustrates the layout of strain gauges on Type $\mathrm{C}$ specimens. In the test, the primary data collected were the axial deformation and load. For this reason, mainly one specimen in each configuration has been instrumented with strain gauges.

\subsection{Test Procedure}

All specimens were tested under cyclic deformation except specimens A2078e, A2078d, A2128f, and A2128e, which were tested under monotonic tension at a 
displacement control loading rate of $5 \mathrm{~mm} / \mathrm{min}$. In the monotonic test, static readings were taken after the loading crosshead was paused for 30 seconds at a displacement interval of about $2 \mathrm{~mm}$.

For the cyclic tests, the loading sequence was conducted according to ATC-24 Guidelines for Cyclic Seismic Testing of Components of Steel Structures (ATC 1992) for single specimen testing program with some modifications for the later stages of the loading cycle. The following loading pattern was used in the test:

1) Three cycles at $\delta=0.25 \delta_{\mathrm{y}}$

2) Three cycles at $\delta=0.5 \delta_{\mathrm{y}}$

3) Three cycles at $\delta=0.6 \delta_{y}$

4) Three cycles at $\delta=0.8 \delta_{\mathrm{y}}$

5) Three cycles at $\delta=\delta_{\mathrm{y}}$

6) Three cycles at $\delta=2 \delta_{\mathrm{y}}$

7) Three cycles at $\delta=3 \delta_{\mathrm{y}}$

8) Two cycles at $\delta=4 \delta_{y}$

After $\delta=4 \delta_{y}$ the applied deformation increased by $\delta_{y}$ for every two cycles. $\delta$ is half of the applied deformation range and $\delta_{\mathrm{y}}$ is the yield deformation taken as

$$
\delta_{y}=\frac{F_{y} L}{E}
$$

where $F_{y}$ is the nominal yield strength taken as $300 \mathrm{MPa}, \mathrm{E}$ is the elastic modulus taken as $200000 \mathrm{MPa}$ and $\mathrm{L}$ is the nominal length of the specimen measured between the 
middle bolt holes. ATC-24 specifies at least six cycles should be at $\delta<\delta_{\mathrm{y}}$. In the tests, twelve cycles and four loading ranges at $\delta<\delta_{\mathrm{y}}$ were specified with the loading range $\delta$ at the bounds suggested in Appendix S 1997 Seismic Provisions for Structural Steel Buildings (AISC 1997). All specimens were tested under displacement control. Since the specimen has a high slenderness ratio, the buckling load of the specimen is very small. For this reason, load control was not used in the elastic cycle even though that has been suggested by ATC-24 (ATC 1992). A number of static readings were also taken during the cyclic test of at least one specimen for each test configuration after pausing the loading crosshead for 30 seconds.

Further modifications were made to the testing protocol suggested by ATC- 24 (ATC 1992) due to constraints in the loading control and testing time. In the beginning of the test, the loading range is small. Thus, a low loading rate was used in order to better control the applied displacement. However, maintaining the same low loading rate throughout the test will make the test prohibitory long. Thus, a variable loading rate was adopted for the test. Table 3.4 shows the loading (strain) rates applied at different stages of the test for various specimen lengths. For a small number of tests where a large number of applied cycles were required, the increment step for the loading displacement range was increased to $5 \delta_{\mathrm{y}}$ after the half loading displacement range $\delta=50 \delta_{\mathrm{y}}$. However, the number of loading cycle per displacement range remained at two cycles. Due to the high slenderness ratio of some of the specimens, the specimens may not fail before the actuator stroke limit has been exceeded. For these specimens, the loading were carried 
out for 30 cycles at the maximum stroke before the test was terminated even if fracture has not occurred.

NBCC 2005 (NRCC 2005) limits the storey drift due to seismic load to $2.5 \%$ at near collapse state for ordinary buildings. A $2.5 \%$ storey drift with the brace at $45^{\circ}$ is equal to $1.25 \%$ strain in the brace, which is at $\delta=8.3 \delta_{y}$ for $F_{y}=300 \mathrm{MPa}$. The ductility demand is the greatest when the brace is at $45^{\circ}$. Thus changing the deformation increment from $\delta_{\mathrm{y}}$ as specified in ATC-24 loading protocol to $5 \delta_{\mathrm{y}}$ after $\delta=50 \delta_{\mathrm{y}}$ does not affect validity of using the test data to assess the specimen suitability to be used in a seismic design since the deformation at $\delta=50 \delta_{\mathrm{y}}$ has far exceeded the ductility requirement for $2.5 \%$ strorey drift.

\subsection{Material Properties}

Actual material properties of the flat bars are required to evaluate the test results.

The tension coupon tests were conducted by another student as part of a separate study in strain rate dependent material properties. Thus, only a brief description of the coupon test is provided here. Coupons were cut and machined according to ASTM-E8-04 (ASTM 2004). For every flat bar size, two coupons were tested in tension at the strain rate of $0.0001,0.01$, and $0.5 \mathrm{~s}^{-1}$ for a total of six coupons. In addition, static readings were also taken during the $0.0001 \mathrm{~s}^{-1}$ strain rate test after pausing machine crosshead for around 90 seconds during the test at $0.0001 \mathrm{~s}^{-1}$ strain rate, at which point the cross-section 
dimensions were also measured manually with a caliper and a micrometer.

Results of the coupon tests are listed in Appendix A with the summarized averages in Table 3.5. The elastic modulus $E$, yield strength $F_{y}$, ultimate strength $F_{u}$, elongation of $50 \mathrm{~mm}$ gauge length and ratio of undeformed over average cross-section area at fracture $\left(\mathrm{A}_{0} / \mathrm{A}_{\mathrm{f}}\right)$ are listed in the Table 3.5. The average cross-section area at fracture is the product of the average of the maximum and minimum width and thickness at the location of fracture. The ultimate to yield strength $\left(\mathrm{F}_{\mathrm{u}} / \mathrm{F}_{\mathrm{y}}\right)$ ratio varies with the material and decreases with a higher loading rate. Among the flat bars, the static $F_{u} / F_{y}$ ratio varies from a low of 1.43 for $\mathrm{FB} 76 \times 4.8$ to 1.74 for $\mathrm{FB} 76 \times 7.9$, while the ratio ranges from 1.26 to 1.57 at the $0.5 \mathrm{~s}^{-1}$ strain rate. The $\mathrm{F}_{\mathrm{u}} / \mathrm{F}_{\mathrm{y}}$ ratio affects the design that requires gross section yielding before net section fractures. At the strain rate of $0.5 \mathrm{~s}^{-1}$, the yield strength of all six flat bars also exceeds the expected yield strength of $385 \mathrm{MPa}$ in CSA S16-01 for Grade 300W and 350W steels. Unlike the $F_{u} / F_{y}$ ratio, the yield and ultimate strength increase with the strain rate. Material dynamic to static yield and ultimate strength ratios for the flat bar specimens are shown in Table 3.6. The rate of increase for yield strength is faster than the ultimate strength, which corresponds to the reduction in the $\mathrm{F}_{\mathrm{u}} / \mathrm{F}_{\mathrm{y}}$ ratio with a higher strain rate. 
Table 3.1 Test matrix.

\begin{tabular}{|c|c|c|c|c|c|}
\hline $\begin{array}{c}\text { Specimen } \\
\text { no. }\end{array}$ & $\begin{array}{c}\text { Length } \times \text { width } \times \text { thickness } \\
\mathrm{L}_{0} \times \mathrm{w} \times \mathrm{t}(\mathrm{mm})\end{array}$ & $\begin{array}{c}\text { Reinforcement } \\
\mathrm{L}_{\mathrm{r}} \times \mathrm{w}_{\mathrm{r}} \times \mathrm{t}_{\mathrm{r}}(\mathrm{mm})\end{array}$ & $\frac{\mathrm{KL}}{\mathrm{r}}$ & $\frac{\mathrm{A}_{\mathrm{n}}}{\mathrm{A}_{\mathrm{g}}}$ & $\begin{array}{c}\text { Connection } \\
\text { type }\end{array}$ \\
\hline A8075a-b & $2510 \times 76 \times 4.8$ & - & 800 & 0.71 & $\mathrm{~A}$ \\
\hline A6075a-b & $1930 \times 76 \times 4.8$ & - & 600 & 0.71 & $\mathrm{~A}$ \\
\hline A4075a-c & $1360 \times 76 \times 4.8$ & - & 400 & 0.71 & $\mathrm{~A}$ \\
\hline A4078a-b & $2050 \times 76 \times 7.9$ & - & 400 & 0.71 & $\mathrm{~A}$ \\
\hline A2078a-e & $1120 \times 76 \times 7.9$ & - & 200 & 0.71 & $\mathrm{~A}$ \\
\hline A4108a-b & $2050 \times 102 \times 7.9$ & - & 400 & 0.78 & $\mathrm{~A}$ \\
\hline A2108a-b & $1120 \times 102 \times 7.9$ & - & 200 & 0.78 & $\mathrm{~A}$ \\
\hline A4128a-b & $2050 \times 127 \times 7.9$ & - & 400 & 0.83 & $\mathrm{~A}$ \\
\hline A2128a-f & $1120 \times 127 \times 7.9$ & - & 200 & 0.83 & $\mathrm{~A}$ \\
\hline B8075a-b & $2510 \times 76 \times 4.8$ & $200 \times 76 \times 4.8$ & 800 & 0.71 & $\mathrm{~B}$ \\
\hline B2078a-b & $1120 \times 76 \times 7.9$ & $200 \times 76 \times 7.9$ & 200 & 0.71 & $\mathrm{~B}$ \\
\hline B2128a-d & $1120 \times 127 \times 7.9$ & $200 \times 127 \times 7.9$ & 200 & 0.83 & $\mathrm{~B}$ \\
\hline C8075a-b & $2510 \times 76 \times 4.8$ & $200 \times 64 \times 4.8$ & 800 & - & $\mathrm{C}$ \\
\hline C6075a-b & $1930 \times 76 \times 4.8$ & $200 \times 64 \times 4.8$ & 600 & - & $\mathrm{C}$ \\
\hline C4075a-b & $1360 \times 76 \times 4.8$ & $200 \times 64 \times 4.8$ & 400 & - & $\mathrm{C}$ \\
\hline C4078a-b & $2050 \times 76 \times 7.9$ & $200 \times 64 \times 7.9$ & 400 & - & $\mathrm{C}$ \\
\hline C4108a-b & $2050 \times 102 \times 7.9$ & $200 \times 76 \times 7.9$ & 400 & - & $\mathrm{C}$ \\
\hline C2078a-b & $1120 \times 76 \times 7.9$ & $200 \times 64 \times 7.9$ & 200 & - & $\mathrm{C}$ \\
\hline C2108a-c & $1120 \times 102 \times 7.9$ & $200 \times 76 \times 7.9$ & 200 & - & C \\
\hline
\end{tabular}


Table 3.2 Measured dimensions.

\begin{tabular}{|c|c|c|c|c|c|}
\hline $\begin{array}{c}\text { Specimen } \\
\text { no. }\end{array}$ & $\begin{array}{c}\text { Length, } \\
\mathrm{L}_{\mathbf{o}} \\
(\mathrm{mm})\end{array}$ & $\begin{array}{c}\text { Width, } \\
\mathbf{w} \\
(\mathrm{mm})\end{array}$ & $\begin{array}{c}\text { Thickness, } \\
\mathbf{t} \\
(\mathrm{mm})\end{array}$ & $\begin{array}{c}\text { Top } \\
\text { reinforcement } \\
\text { plate, } \\
\mathrm{L}_{\mathrm{r}} \times \mathrm{w}_{\mathrm{r}} \times \mathrm{t}_{\mathrm{r}}(\mathrm{mm})\end{array}$ & $\begin{array}{c}\text { Bottom } \\
\text { reinforcement } \\
\text { plate, } \\
\mathrm{L}_{\mathrm{r}} \times \mathrm{w}_{\mathrm{r}} \times \mathrm{t}_{\mathrm{r}}(\mathrm{mm})\end{array}$ \\
\hline A8075a & 2510 & 75.9 & 4.67 & - & - \\
\hline A8075b & 2509 & 76.0 & 4.64 & - & - \\
\hline A6075a & 1931 & 76.1 & 4.66 & - & - \\
\hline A6075b & 1930 & 76.0 & 4.65 & - & - \\
\hline A4075a & 1358 & 76.1 & 4.68 & - & - \\
\hline A4075b & 1359 & 76.1 & 4.68 & - & - \\
\hline A4075c & 1360 & 76.2 & 4.65 & - & - \\
\hline A4078a & 2050 & 76.4 & 7.89 & - & - \\
\hline A4078b & 2049 & 76.3 & 7.87 & - & - \\
\hline A2078a & 1120 & 76.3 & 7.86 & - & - \\
\hline A2078b & 1119 & 76.4 & 7.87 & - & - \\
\hline A2078c & 1120 & 76.2 & 7.87 & - & - \\
\hline A2078d & 1121 & 76.2 & 7.91 & - & - \\
\hline A2078e & 1120 & 76.3 & 7.87 & - & - \\
\hline A4108a & 2050 & 101.9 & 7.88 & - & - \\
\hline A4108b & 2050 & 101.9 & 7.89 & - & - \\
\hline A2108a & 1120 & 101.9 & 7.87 & - & - \\
\hline A2108b & 1120 & 102.0 & 7.90 & - & - \\
\hline A4128a & 2049 & 127.5 & 7.76 & - & - \\
\hline A4128b & 2049 & 127.5 & 7.78 & - & - \\
\hline A2128a & 1118 & 127.2 & 7.72 & - & - \\
\hline A2128b & 1119 & 127.0 & 7.68 & - & - \\
\hline A2128c & 1118 & 126.9 & 7.74 & - & - \\
\hline A2128d & 1119 & 126.9 & 7.70 & - & - \\
\hline A2128e & 1118 & 127.4 & 7.80 & - & - \\
\hline A2128f & 1120 & 126.9 & 7.69 & - & - \\
\hline & & & & & - \\
\hline
\end{tabular}


Table 3.2 Continue.

\begin{tabular}{|c|c|c|c|c|c|}
\hline $\begin{array}{c}\text { Specimen } \\
\text { no. }\end{array}$ & $\begin{array}{c}\text { Length } \\
\mathrm{L}_{\mathrm{o}} \\
(\mathrm{mm})\end{array}$ & $\begin{array}{c}\text { Width, } \\
\mathrm{w} \\
(\mathrm{mm})\end{array}$ & $\begin{array}{c}\text { Thickness, } \\
\mathrm{t} \\
(\mathrm{mm})\end{array}$ & $\begin{array}{c}\text { Top } \\
\text { reinforcement } \\
\text { plate, } \\
\mathrm{L}_{\mathrm{r}} \times \mathrm{w}_{\mathrm{r}} \times \mathrm{t}_{\mathrm{r}}(\mathrm{mm})\end{array}$ & $\begin{array}{c}\text { Bottom } \\
\text { reinforcement } \\
\text { plate, } \\
\mathrm{L}_{\mathrm{r}} \times \mathrm{w}_{\mathrm{r}} \times \mathrm{r}_{\mathrm{r}}(\mathrm{mm})\end{array}$ \\
\hline B8075a & 2510 & 75.9 & 4.64 & $199 \times 76.1 \times 4.72$ & $199 \times 76.1 \times 4.73$ \\
\hline B8075b & 2510 & 76.0 & 4.65 & $198 \times 76.0 \times 4.72$ & $198 \times 76.0 \times 4.70$ \\
\hline B2078a & 1120 & 76.4 & 7.88 & $198 \times 76.3 \times 7.95$ & $199 \times 76.3 \times 7.95$ \\
\hline B2078b & 1119 & 76.3 & 7.85 & $200 \times 76.2 \times 7.95$ & $199 \times 76.3 \times 7.96$ \\
\hline B2128a & 1119 & 127.1 & 7.76 & $204 \times 126.9 \times 7.70$ & $204 \times 127.1 \times 7.70$ \\
\hline B2128b & 1117 & 127.8 & 7.72 & $203 \times 126.9 \times 7.96$ & $204 \times 126.9 \times 7.78$ \\
\hline B2128c & 1120 & 126.8 & 7.70 & $203 \times 127.1 \times 7.73$ & $203 \times 126.8 \times 7.80$ \\
\hline B2128d & 1120 & 126.8 & 7.77 & $200 \times 127.7 \times 7.80$ & $199 \times 127.3 \times 7.81$ \\
\hline C8075a & 2509 & 76.0 & 4.65 & $198 \times 62.5 \times 4.84$ & $198 \times 62.7 \times 4.86$ \\
\hline C8075b & 2509 & 76.1 & 4.62 & $198 \times 62.8 \times 4.91$ & $198 \times 62.7 \times 4.89$ \\
\hline C6075a & 1928 & 75.9 & 4.73 & $198 \times 62.1 \times 4.76$ & $198 \times 62.3 \times 4.83$ \\
\hline C6075b & 1928 & 76.0 & 4.68 & $198 \times 62.0 \times 4.81$ & $198 \times 62.2 \times 4.64$ \\
\hline C4075a & 1358 & 76.0 & 4.67 & $198 \times 62.6 \times 4.82$ & $198 \times 62.6 \times 4.77$ \\
\hline C4075b & 1358 & 76.2 & 4.67 & $198 \times 62.6 \times 4.79$ & $198 \times 62.0 \times 4.73$ \\
\hline C4078a & 2049 & 76.2 & 7.89 & $198 \times 63.4 \times 8.01$ & $198 \times 63.3 \times 7.96$ \\
\hline C4078b & 2048 & 76.3 & 7.89 & $199 \times 63.3 \times 7.96$ & $196 \times 63.3 \times 7.95$ \\
\hline C4108a & 2049 & 101.9 & 7.87 & $199 \times 76.3 \times 7.93$ & $199 \times 76.3 \times 8.00$ \\
\hline C4108b & 2050 & 101.9 & 7.86 & $199 \times 76.3 \times 7.93$ & $199 \times 76.5 \times 8.00$ \\
\hline C2078a & 1116 & 76.4 & 7.95 & $198 \times 63.7 \times 7.96$ & $198 \times 63.7 \times 7.96$ \\
\hline C2078b & 1118 & 76.5 & 7.92 & $198 \times 63.4 \times 7.90$ & $198 \times 63.6 \times 7.88$ \\
\hline C2108a & 1119 & 101.9 & 7.87 & $198 \times 76.4 \times 7.98$ & $199 \times 76.6 \times 7.98$ \\
\hline C2108b & 1120 & 101.9 & 7.86 & $199 \times 76.5 \times 7.95$ & $199 \times 76.6 \times 7.95$ \\
\hline C2108c & 1119 & 101.8 & 7.86 & $199 \times 76.9 \times 7.97$ & $199 \times 76.5 \times 7.99$ \\
\hline
\end{tabular}


Table 3.3 Nominal and expected net section fracture to gross section yielding strength ratio for Type $A$ and $B$ specimens.

\begin{tabular}{|c|c|c|c|}
\hline \multirow{2}{*}{ Strap } & & Nominal & Expected \\
& $\frac{\mathrm{A}_{\mathrm{n}}}{\mathrm{A}_{\mathrm{g}}}$ & $\frac{\mathrm{A}_{\mathrm{n}} \mathrm{F}_{\mathrm{u}}}{\mathrm{A}_{\mathrm{g}} \mathrm{F}_{\mathrm{y}}}$ & $\frac{1.1 \mathrm{~A}_{\mathrm{n}} \mathrm{F}_{\mathrm{u}}}{\mathrm{R}_{\mathrm{y}} \mathrm{A}_{\mathrm{g}} \mathrm{F}_{\mathrm{y}}}$ \\
\hline $76 \mathrm{~mm} \times 4.8 \mathrm{~mm}$ & 0.71 & 1.07 & 0.91 \\
\hline $76 \mathrm{~mm} \times 7.9 \mathrm{~mm}$ & 0.71 & 1.07 & 0.91 \\
\hline $102 \mathrm{~mm} \times 7.9 \mathrm{~mm}$ & 0.78 & 1.18 & 1.01 \\
\hline $127 \mathrm{~mm} \times 7.9 \mathrm{~mm}$ & 0.83 & 1.24 & 1.06 \\
\hline
\end{tabular}


Table 3.4 Loading rate for different specimen length.

\begin{tabular}{|c|c|c|c|c|}
\hline Target displacement & $\begin{array}{c}\text { Displacement } \\
\text { rate, }(\mathrm{mm} / \mathrm{min})\end{array}$ & $\begin{array}{c}\text { Strain } \\
\text { rate, }\left(\mathrm{s}^{-1}\right)\end{array}$ & $\begin{array}{c}\text { Gusset plate } \\
\text { bolt hole }\end{array}$ & $\begin{array}{c}30 \\
\text { cycles at }\end{array}$ \\
\hline \multicolumn{5}{|c|}{ Specimen length, $\mathrm{L}_{0}=1120 \mathrm{~mm}(\mathrm{KL} / \mathrm{r}=200)$} \\
\hline$|\delta| \leq 10 \delta_{\mathrm{y}}$ & 15 & 0.00027 & \multirow{4}{*}{ Closest } & \multirow{4}{*}{ - } \\
\hline $10 \delta_{\mathrm{y}}<|\delta| \leq 21 \delta_{\mathrm{y}}$ & 30 & 0.00054 & & \\
\hline $21 \delta_{\mathrm{y}}<|\delta| \leq 40 \delta_{\mathrm{y}}$ & 60 & 0.00109 & & \\
\hline $40 \delta_{\mathrm{y}}<|\delta|$ & 120 & 0.00218 & & \\
\hline \multicolumn{5}{|c|}{ Specimen length, $\mathrm{L}_{\mathrm{o}}=1360 \mathrm{~mm}(\mathrm{KL} / \mathrm{r}=400)$} \\
\hline$|\delta| \leq 8 \delta_{\mathrm{y}}$ & 15 & 0.00022 & \multirow{4}{*}{ Farthest } & \multirow{4}{*}{ - } \\
\hline $8 \delta_{\mathrm{y}}<|\delta| \leq 17 \delta_{\mathrm{y}}$ & 30 & 0.00044 & & \\
\hline $17 \delta_{\mathrm{y}}<|\delta| \leq 34 \delta_{\mathrm{y}}$ & 60 & 0.00088 & & \\
\hline $34 \delta_{\mathrm{y}}<|\delta|$ & 120 & 0.00176 & & \\
\hline \multicolumn{5}{|c|}{ Specimen length, $\mathrm{L}_{0}=1930 \mathrm{~mm}(\mathrm{KL} / \mathrm{r}=600)$} \\
\hline$|\delta| \leq 11 \delta_{\mathrm{y}}$ & 30 & 0.00029 & \multirow{4}{*}{ Closest } & \multirow{4}{*}{$90 \delta_{\mathrm{y}}{ }^{1}$} \\
\hline $11 \delta_{\mathrm{y}}<|\delta| \leq 23 \delta_{\mathrm{y}}$ & 60 & 0.00058 & & \\
\hline $23 \delta_{\mathrm{y}}<|\delta| \leq 40 \delta_{\mathrm{y}}$ & 120 & 0.00116 & & \\
\hline $40 \delta_{\mathrm{y}}<|\delta|$ & 240 & 0.00232 & & \\
\hline \multicolumn{5}{|c|}{ Specimen length, $\mathrm{L}_{\mathrm{o}}=2050 \mathrm{~mm}(\mathrm{KL} / \mathrm{r}=400)$} \\
\hline$|\delta| \leq 10 \delta_{\mathrm{y}}$ & 30 & 0.00027 & \multirow{4}{*}{ Farthest } & \multirow{4}{*}{$75 \delta_{\mathrm{y}}$} \\
\hline $10 \delta_{\mathrm{y}}<|\delta| \leq 21 \delta_{\mathrm{y}}$ & 60 & 0.00054 & & \\
\hline $21 \delta_{\mathrm{y}}<|\delta| \leq 40 \delta_{\mathrm{y}}$ & 120 & 0.00108 & & \\
\hline $40 \delta_{\mathrm{y}}<|\delta|$ & 240 & 0.00216 & & \\
\hline \multicolumn{5}{|c|}{ Specimen length, $\mathrm{L}_{\mathrm{o}}=2510 \mathrm{~mm}(\mathrm{KL} / \mathrm{r}=800)$} \\
\hline$|\delta| \leq 17 \delta_{\mathrm{y}}$ & 60 & 0.00043 & \multirow{3}{*}{ Farthest } & \multirow{3}{*}{$65 \delta_{\mathrm{y}}$} \\
\hline $17 \delta_{\mathrm{y}}<|\delta| \leq 34 \delta_{\mathrm{y}}$ & 120 & 0.00086 & & \\
\hline $34 \delta_{y}<|\delta|$ & 240 & 0.00172 & & \\
\hline
\end{tabular}

Notes:

${ }^{1}$ Only for specimen C6075b. 
Table 3.5 Material properties.

\begin{tabular}{|c|c|c|c|c|c|c|c|}
\hline Strap & $\begin{array}{c}\text { Strain } \\
\operatorname{rate}\left(\mathrm{s}^{-1}\right)\end{array}$ & $\begin{array}{c}\text { Yield } \\
\text { strength, } \\
\mathrm{F}_{\mathrm{y}}(\mathrm{MPa})\end{array}$ & $\begin{array}{l}\text { Ultimate } \\
\text { strength, } \\
\mathrm{F}_{\mathrm{u}}(\mathrm{MPa})\end{array}$ & $\frac{F_{u}}{F_{y}}$ & $\frac{A_{o}}{A_{f}}$ & $\begin{array}{c}\text { Elongation } \\
(\%)\end{array}$ & $\begin{array}{c}\text { Elastic } \\
\text { modulus, } \\
\mathrm{E}(\mathrm{MPa})\end{array}$ \\
\hline \multirow{4}{*}{ 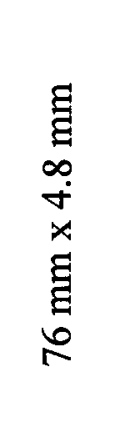 } & $\begin{array}{c}\text { Static } \\
(0.0001) \\
\end{array}$ & 308.0 & 440.9 & 1.43 & - & - & \multirow{4}{*}{210700} \\
\hline & 0.0001 & 326.1 & 466.6 & 1.43 & 2.71 & 34.7 & \\
\hline & 0.01 & 356.8 & 472.3 & 1.32 & 2.52 & 31.9 & \\
\hline & 0.5 & 387.2 & 489.1 & 1.26 & 2.55 & 38.1 & \\
\hline \multirow{4}{*}{ 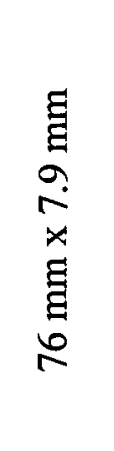 } & $\begin{array}{c}\text { Static } \\
(0.0001)\end{array}$ & 318.2 & 553.8 & 1.74 & - & - & \multirow{4}{*}{205100} \\
\hline & 0.0001 & 342.6 & 577.6 & 1.69 & 2.33 & 28.5 & \\
\hline & 0.01 & 369.3 & 589.7 & 1.60 & 2.46 & 29.2 & \\
\hline & 0.5 & 394.3 & 619.7 & 1.57 & 2.41 & 28.1 & \\
\hline \multirow{4}{*}{ 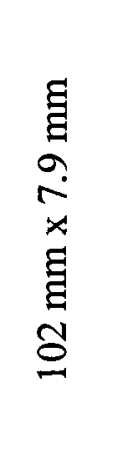 } & $\begin{array}{c}\text { Static } \\
(0.0001)\end{array}$ & 348.1 & 562.1 & 1.61 & - & - & \multirow{4}{*}{204200} \\
\hline & 0.0001 & 375.1 & 586.3 & 1.56 & 2.44 & 31.9 & \\
\hline & 0.01 & 394.8 & 596.9 & 1.51 & 2.54 & 30.7 & \\
\hline & 0.5 & 422.6 & 628.0 & 1.49 & 2.44 & 30.7 & \\
\hline \multirow{4}{*}{ 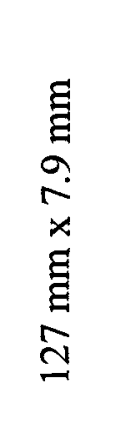 } & $\begin{array}{c}\text { Static } \\
(0.0001)\end{array}$ & 328.5 & 494.2 & 1.50 & - & - & \multirow{4}{*}{208300} \\
\hline & 0.0001 & 345.9 & 518.4 & 1.50 & 2.59 & 33.5 & \\
\hline & 0.01 & 361.7 & 524.2 & 1.45 & 2.50 & 31.2 & \\
\hline & 0.5 & 408.7 & 552.8 & 1.35 & 2.54 & 34.1 & \\
\hline
\end{tabular}


Table 3.5 Continue.

\begin{tabular}{|c|c|c|c|c|c|c|c|}
\hline Strap & $\begin{array}{c}\text { Strain } \\
\text { rate }\left(\mathrm{s}^{-1}\right)\end{array}$ & $\begin{array}{c}\text { Yield } \\
\text { strength, } \\
\mathrm{F}_{\mathrm{y}}(\mathrm{MPa})\end{array}$ & $\begin{array}{l}\text { Ultimate } \\
\text { strength, } \\
\mathrm{F}_{\mathrm{u}}(\mathrm{MPa})\end{array}$ & $\frac{F_{u}}{F_{y}}$ & $\frac{A_{o}}{A_{f}}$ & $\begin{array}{c}\text { Elongation } \\
(\%)\end{array}$ & $\begin{array}{c}\text { Elastic } \\
\text { modulus, } \\
\text { E (MPa) }\end{array}$ \\
\hline \multirow{4}{*}{ 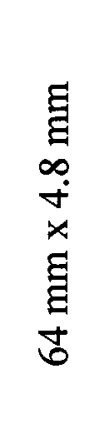 } & $\begin{array}{c}\text { Static } \\
(0.0001)\end{array}$ & 337.6 & 490.7 & 1.45 & - & - & \multirow{4}{*}{212700} \\
\hline & 0.0001 & 351.5 & 515.8 & 1.47 & 2.23 & 28.6 & \\
\hline & 0.01 & 373.5 & 521.6 & 1.40 & 2.43 & 30.9 & \\
\hline & 0.5 & 418.2 & 547.9 & 1.31 & 2.41 & 32.3 & \\
\hline \multirow{4}{*}{ 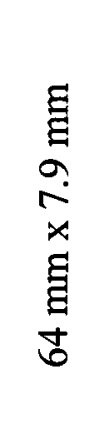 } & $\begin{array}{c}\text { Static } \\
(0.0001)\end{array}$ & 325.2 & 497.4 & 1.53 & - & - & \multirow{4}{*}{213400} \\
\hline & 0.0001 & 339.9 & 518.6 & 1.53 & 2.36 & 33.5 & \\
\hline & 0.01 & 363.2 & 527.8 & 1.45 & 2.38 & 33.0 & \\
\hline & 0.5 & 407.3 & 555.3 & 1.36 & 2.35 & 34.5 & \\
\hline
\end{tabular}


Table 3.6 Material dynamic to static yield and ultimate strength ratios.

\begin{tabular}{|c|c|c|c|c|c|c|c|c|}
\hline \multirow{4}{*}{ Strap } & \multicolumn{4}{|c|}{$\frac{F_{y}}{F_{y}(\text { static })}$} & \multicolumn{4}{|c|}{$\frac{F_{u}}{F_{u}(\text { static })}$} \\
\hline & \multicolumn{4}{|c|}{ Strain rate $\left(\mathrm{s}^{-1}\right)$} & \multicolumn{4}{|c|}{ Strain rate $\left(\mathrm{s}^{-1}\right)$} \\
\hline & \multirow{2}{*}{$\begin{array}{l}\text { Static } \\
0.0001\end{array}$} & \multicolumn{3}{|c|}{ Dynamic } & Static & \multicolumn{3}{|c|}{ Dynamic } \\
\hline & & 0.0001 & 0.01 & 0.5 & 0.0001 & 0.0001 & 0.01 & 0.5 \\
\hline $76 \mathrm{~mm} \times 4.8 \mathrm{~mm}$ & 1 & 1.06 & 1.16 & 1.26 & 1 & 1.06 & 1.07 & 1.11 \\
\hline $76 \mathrm{~mm} \times 7.9 \mathrm{~mm}$ & 1 & 1.08 & 1.16 & 1.24 & 1 & 1.04 & 1.06 & 1.12 \\
\hline $102 \mathrm{~mm} \times 7.9 \mathrm{~mm}$ & 1 & 1.08 & 1.13 & 1.21 & 1 & 1.04 & 1.06 & 1.12 \\
\hline $127 \mathrm{~mm} \times 7.9 \mathrm{~mm}$ & 1 & 1.05 & 1.10 & 1.24 & 1 & 1.05 & 1.06 & 1.12 \\
\hline
\end{tabular}




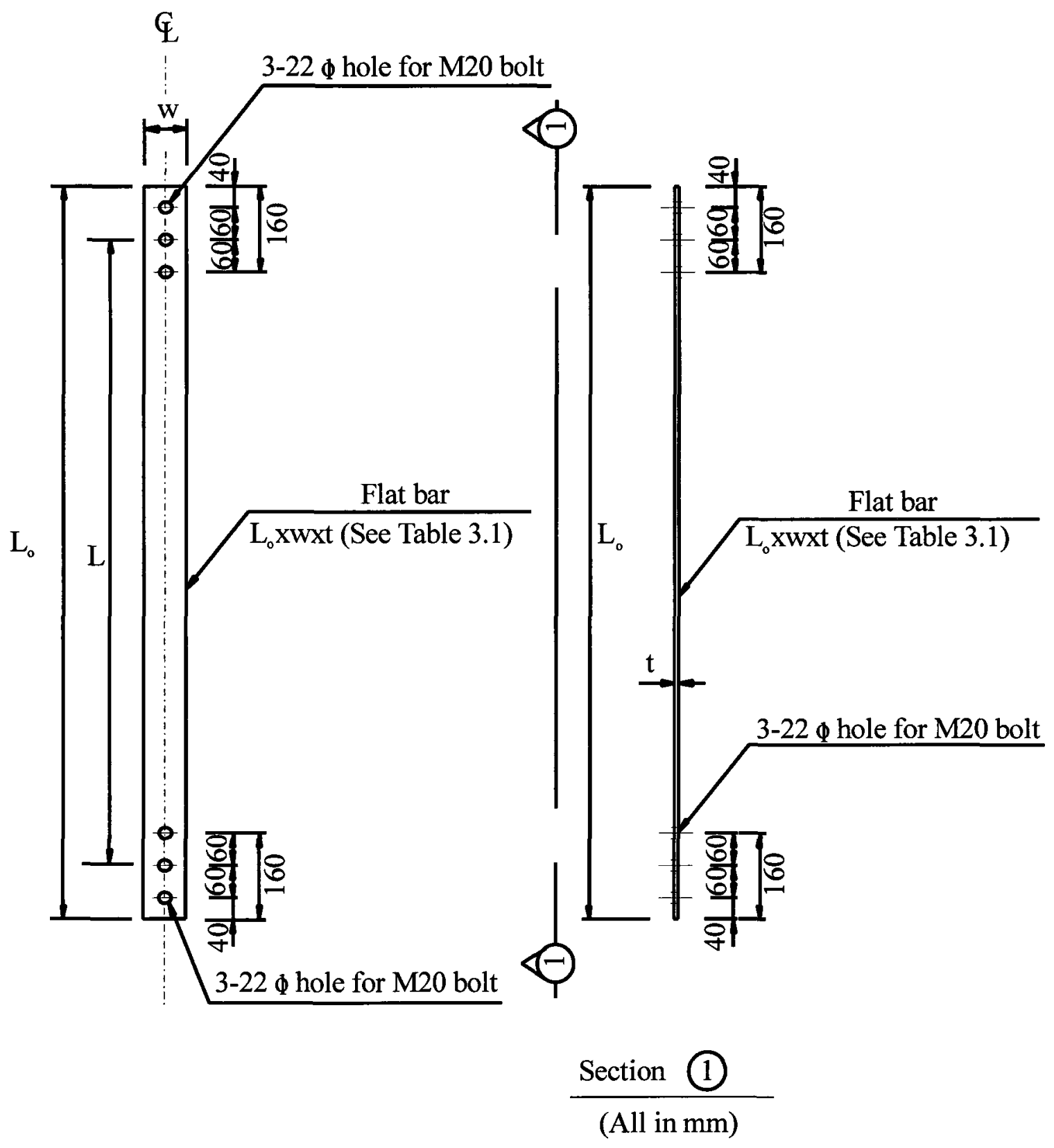

Figure 3.1 Strap with no reinforcement, Type A. 


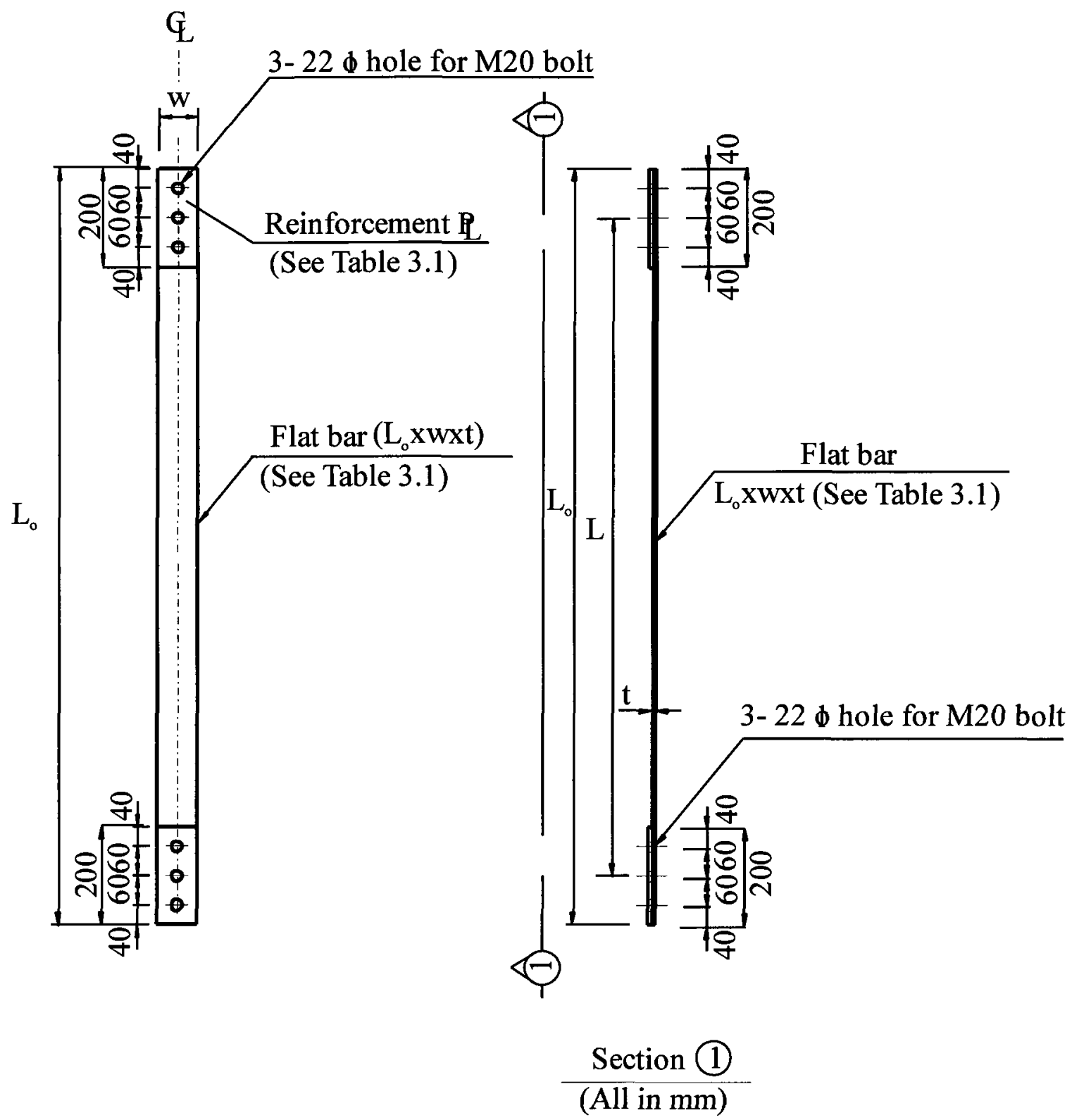

Figure 3.2 Strap clamped with reinforcement plate, Type B. 


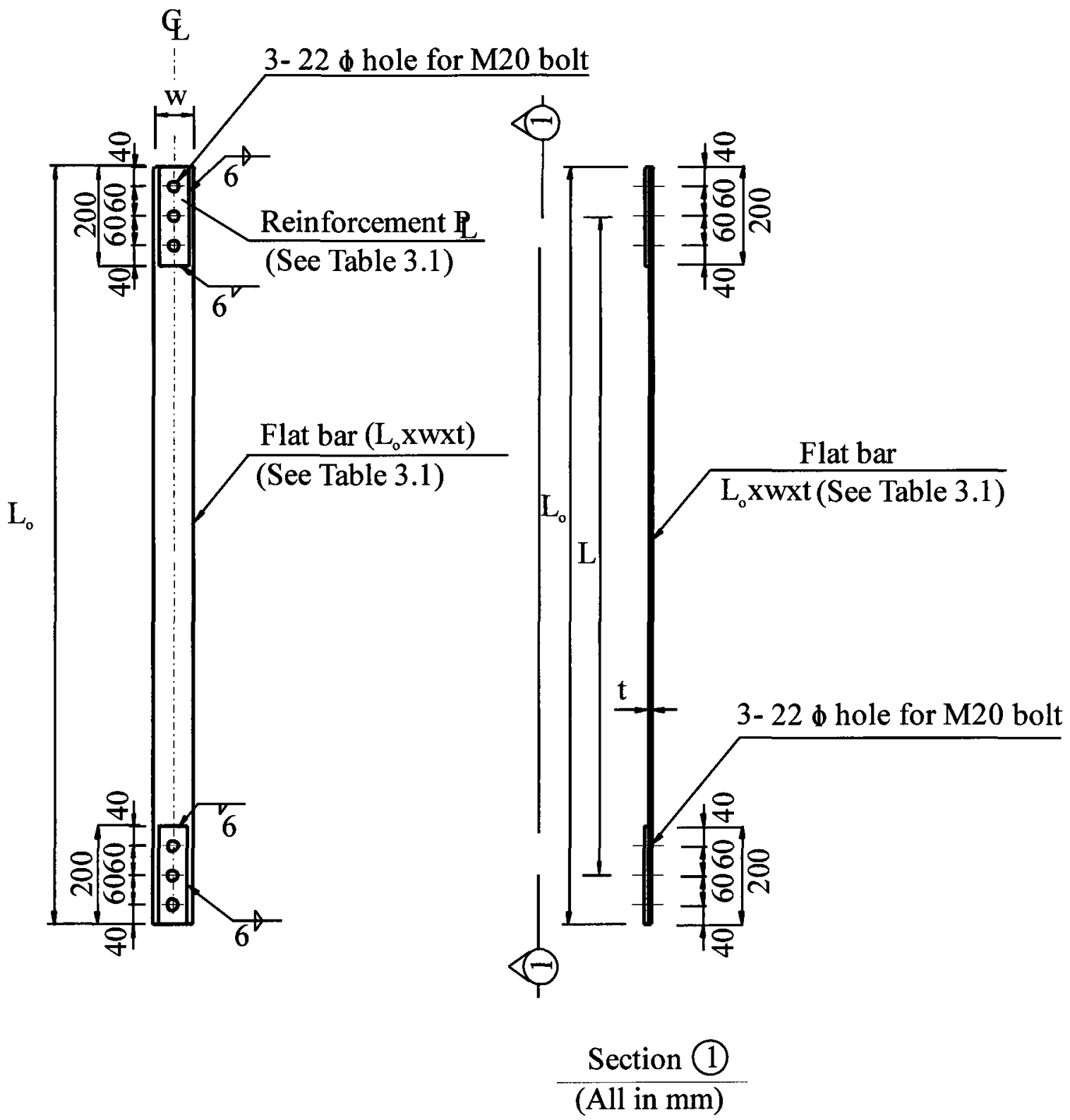

Figure 3.3 Strap welded with reinforcement plate, Type C. 


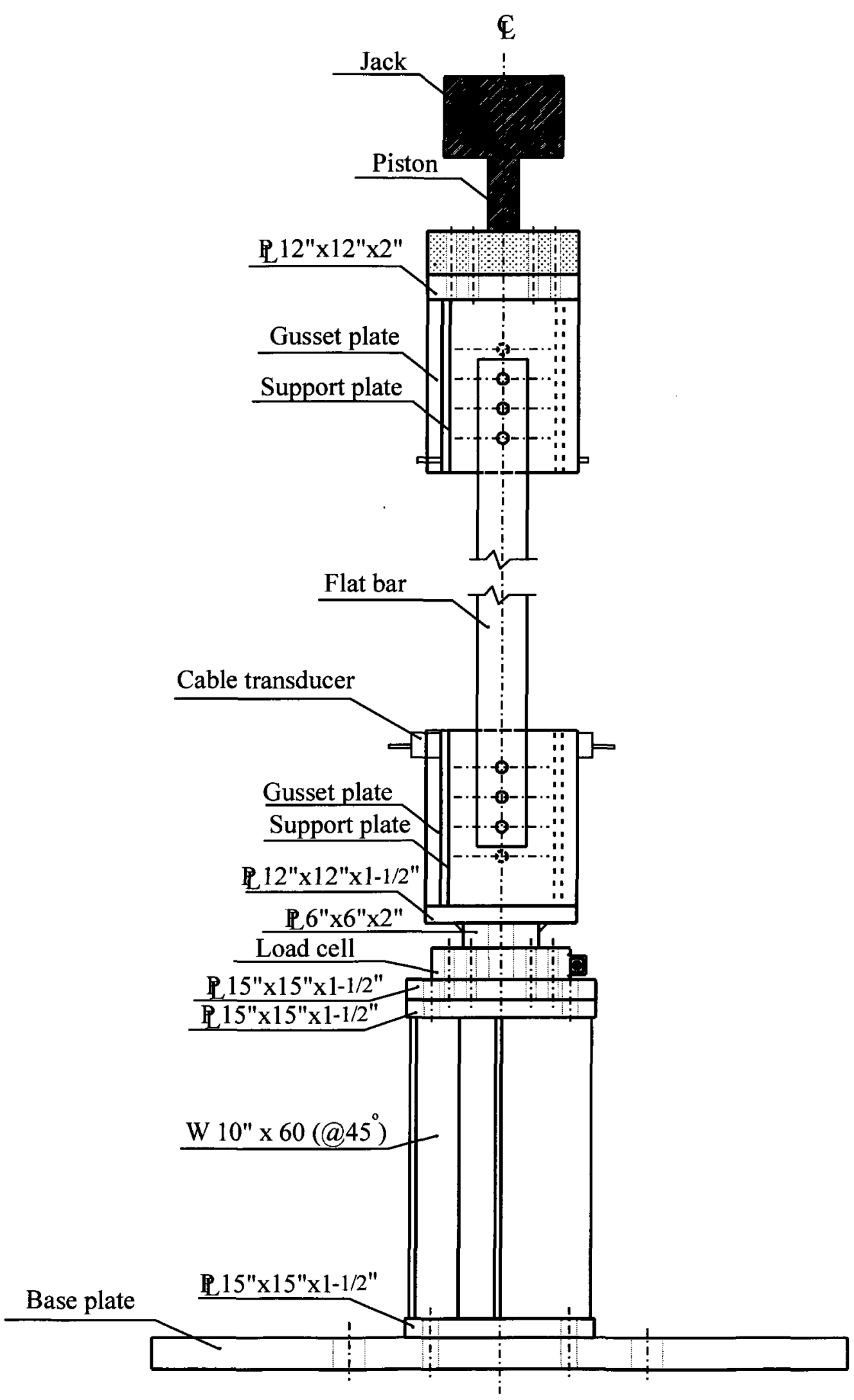

Figure. 3.4 Test setup. 


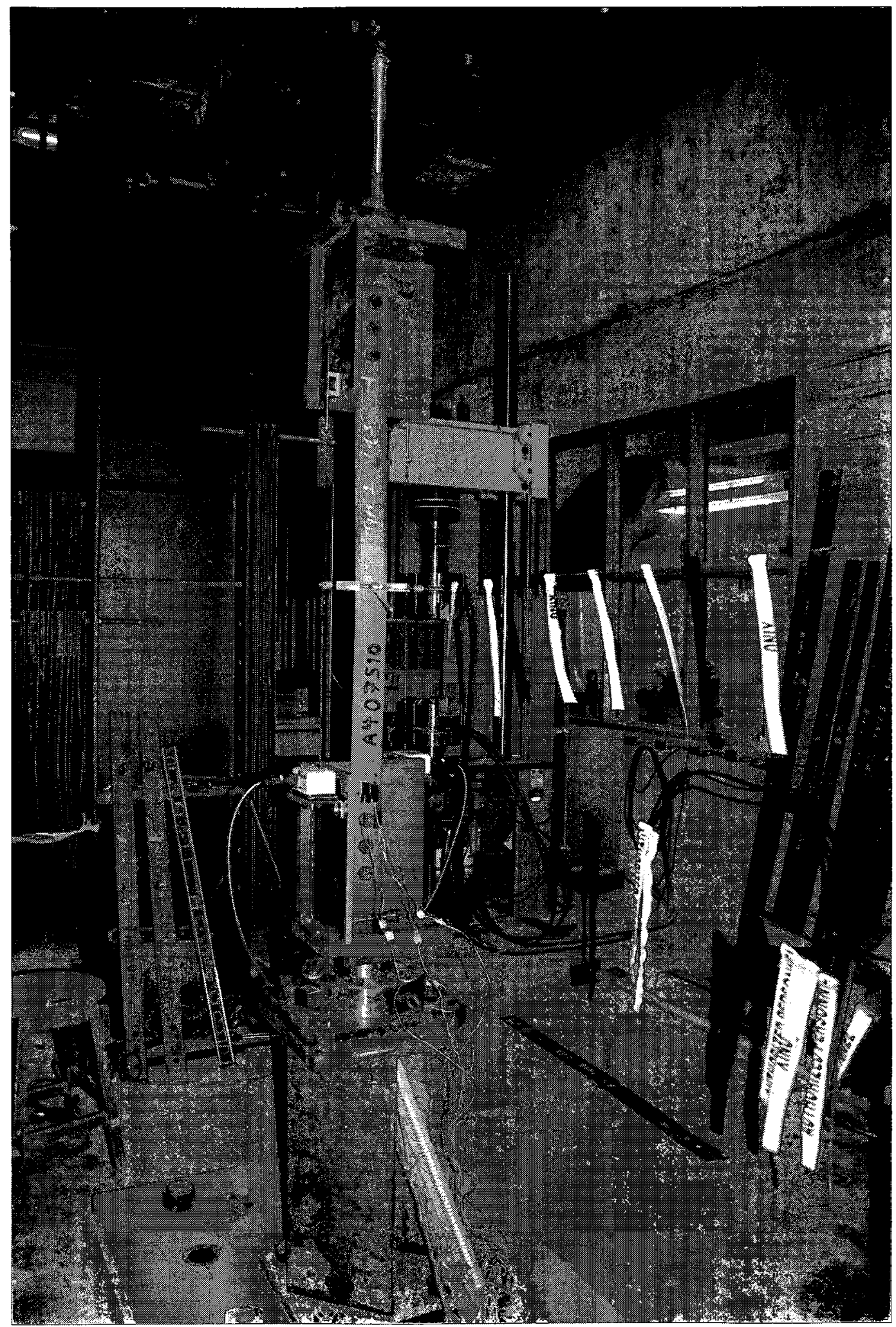

Figure. 3.5 Picture of test setup. 


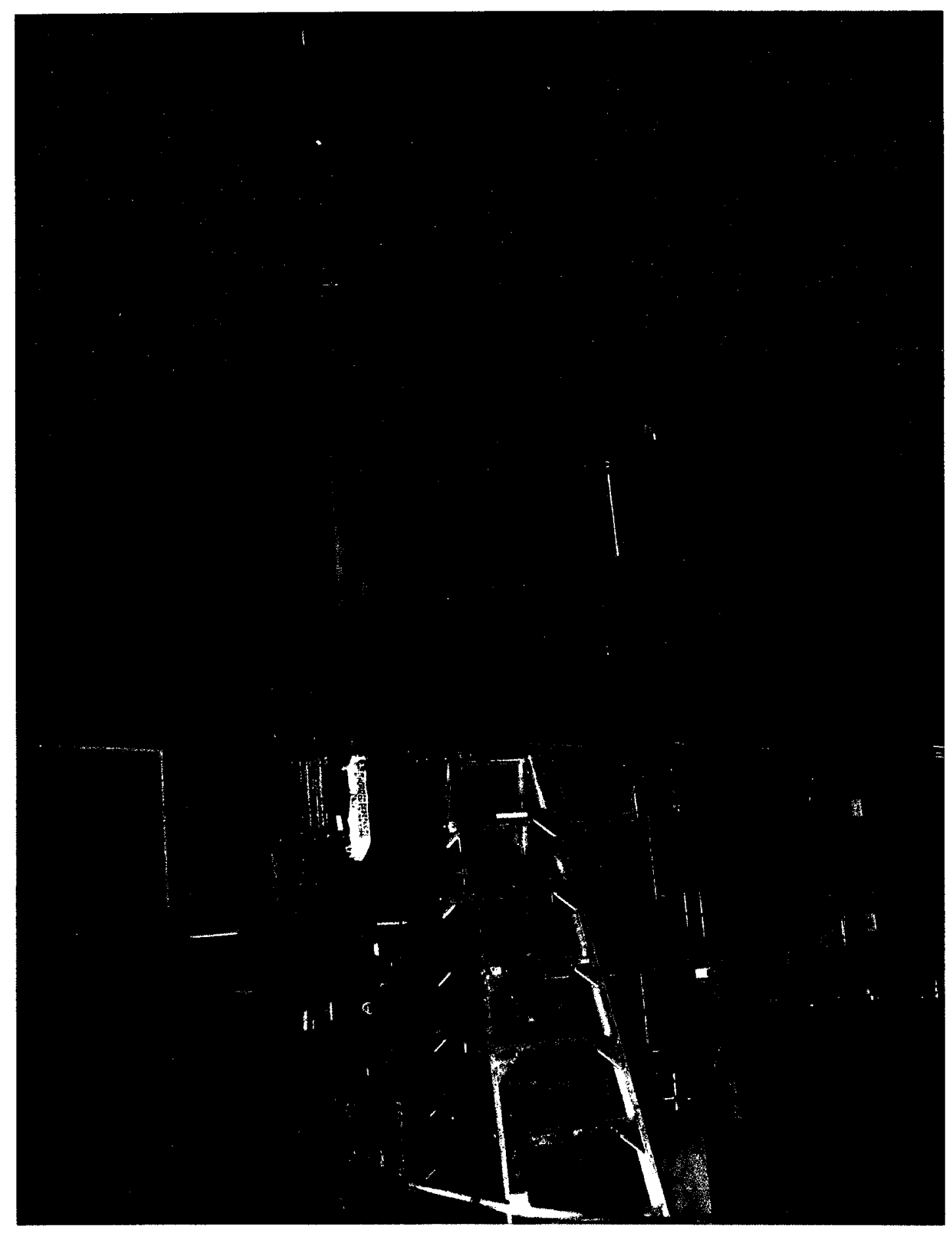

Figure. 3.6 Loading frame. 


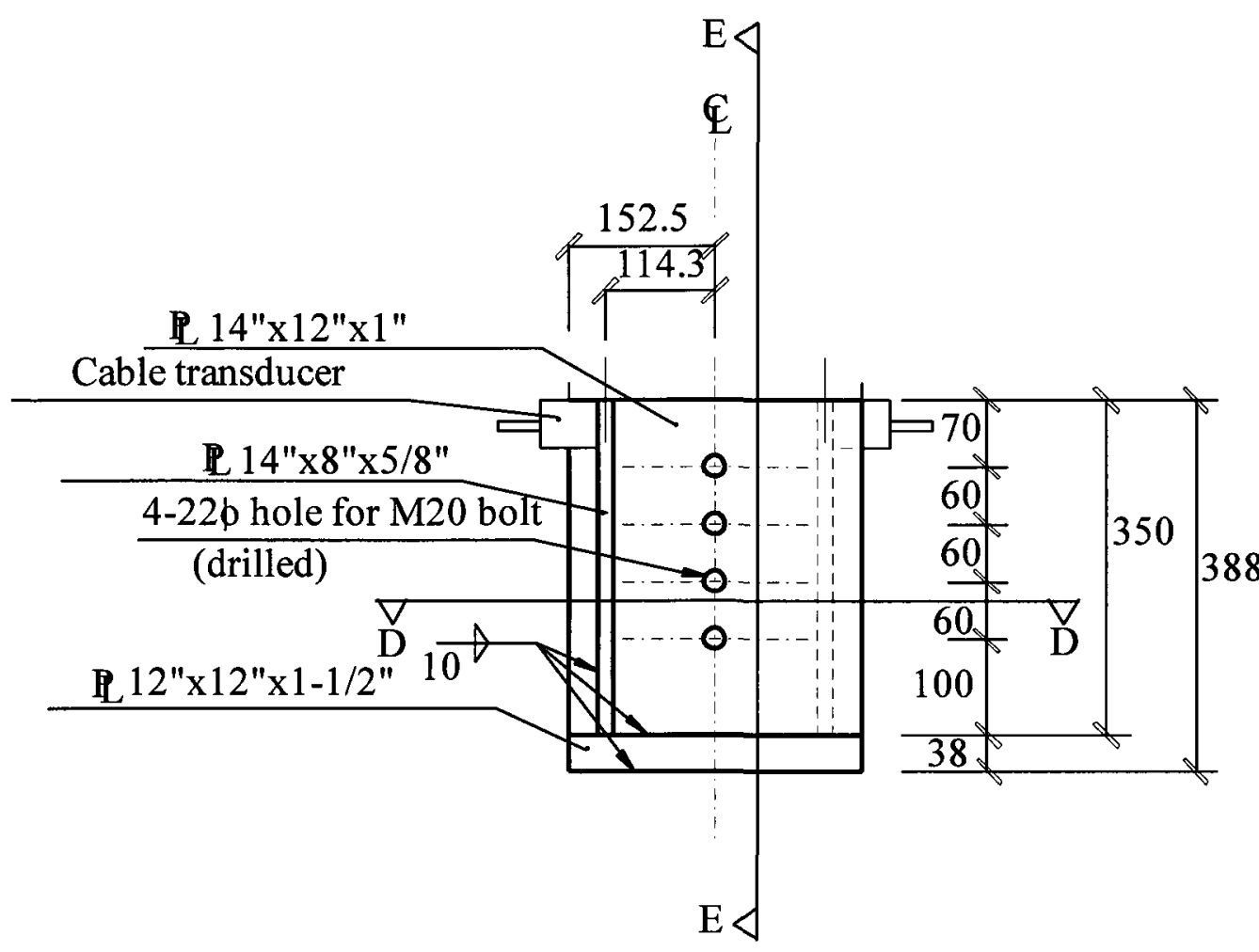

Elevation

All dimensions in $\mathrm{mm}$ unless specified otherwise

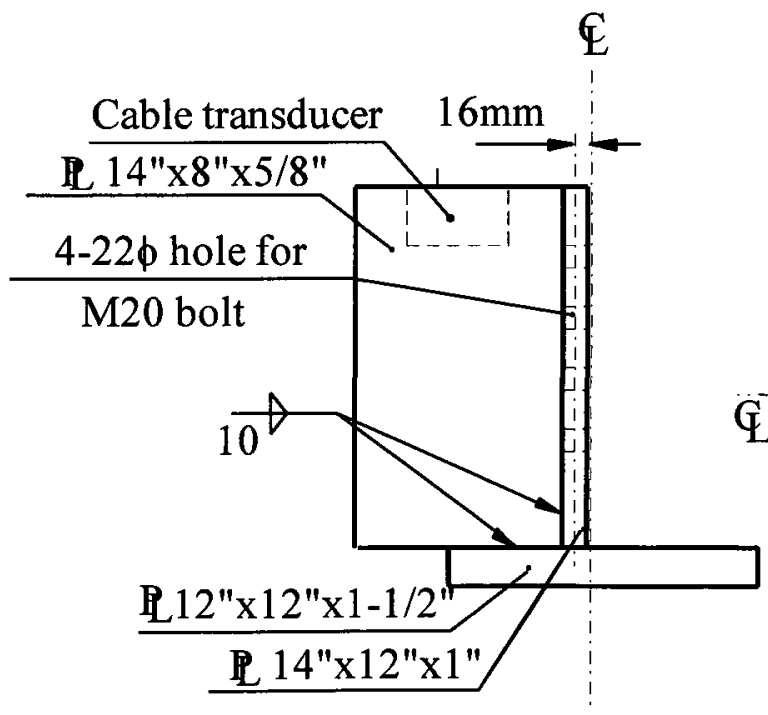

Section E-E

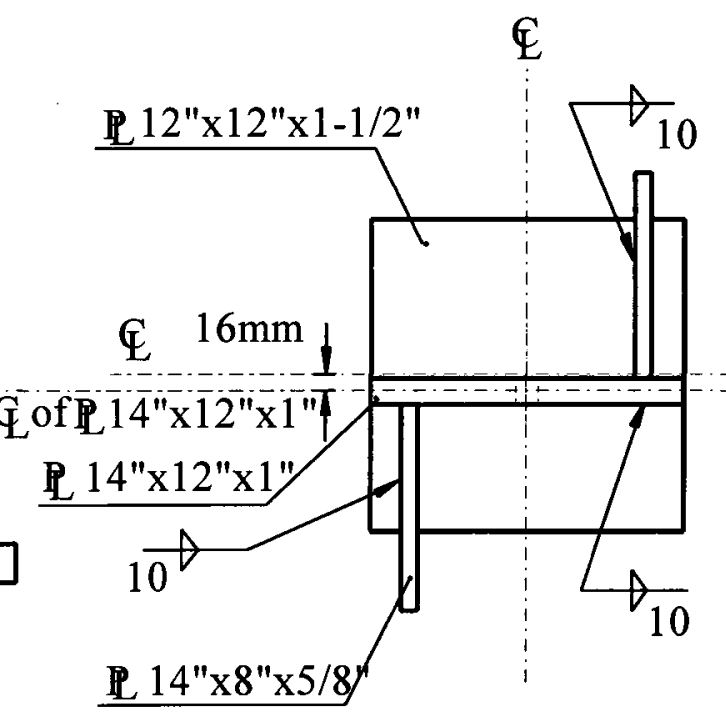

Section D-D

Figure 3.7 Bottom connection. 


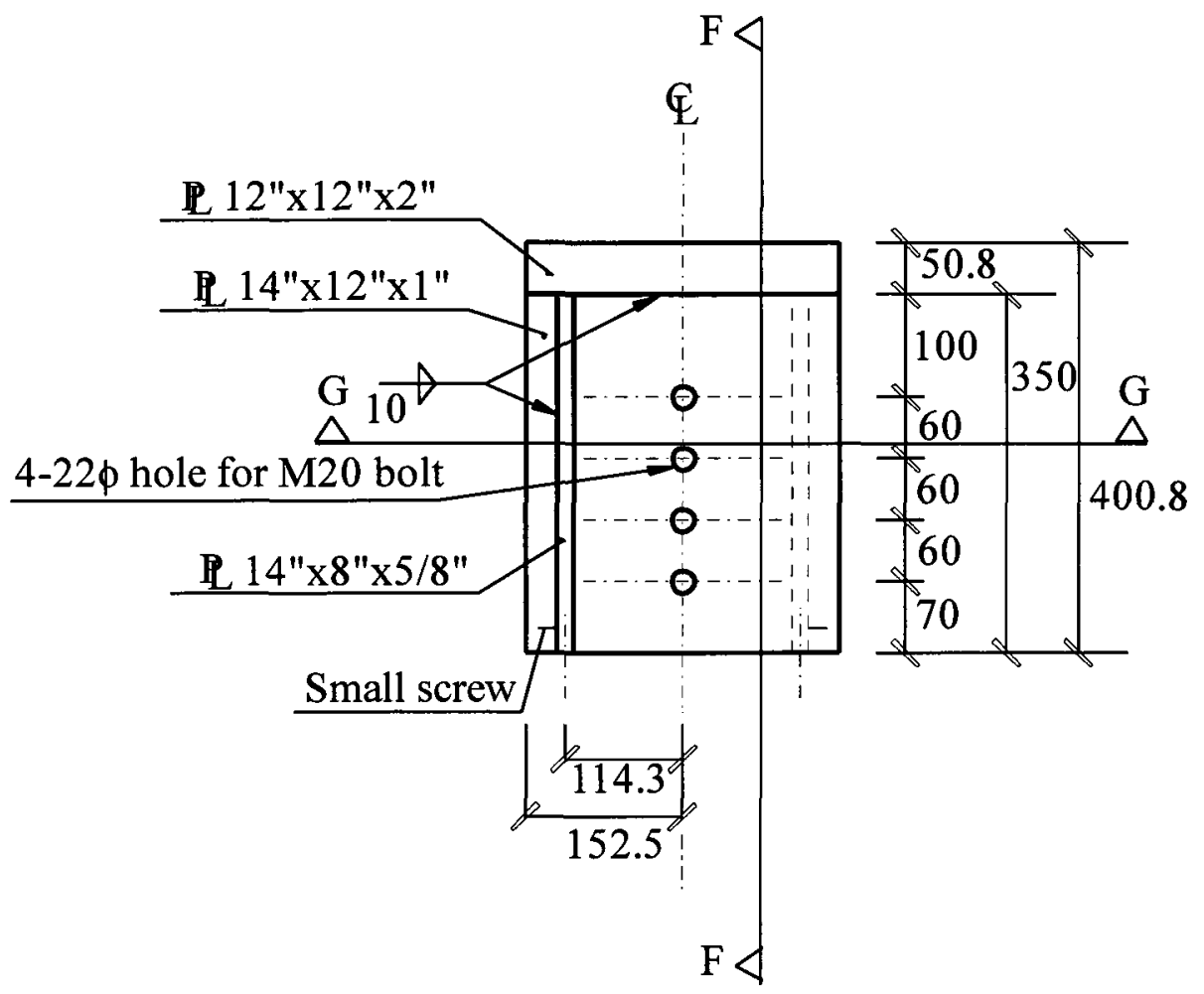

\section{Elevation}

All dimensions in mm unless specified otherwise

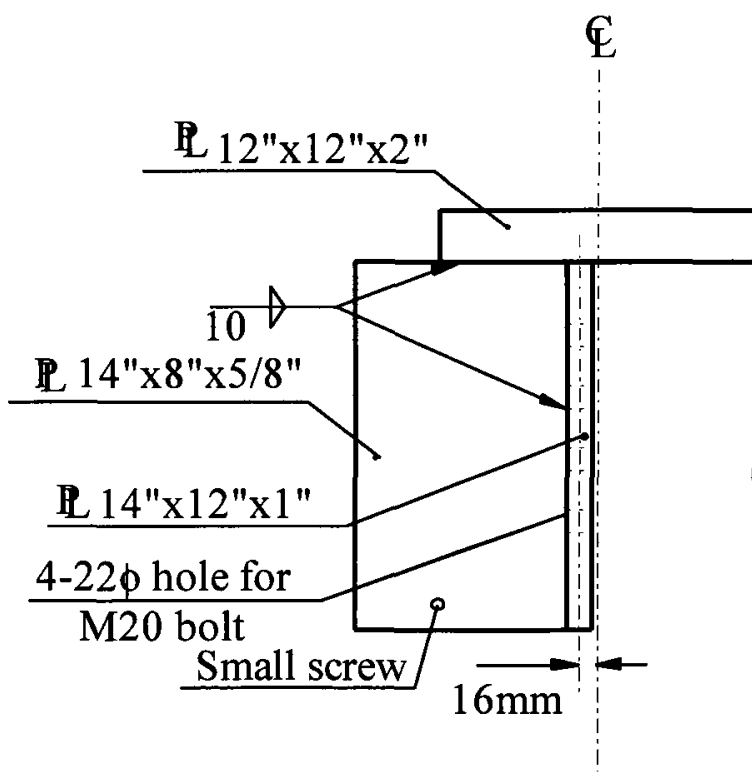

Section F-F

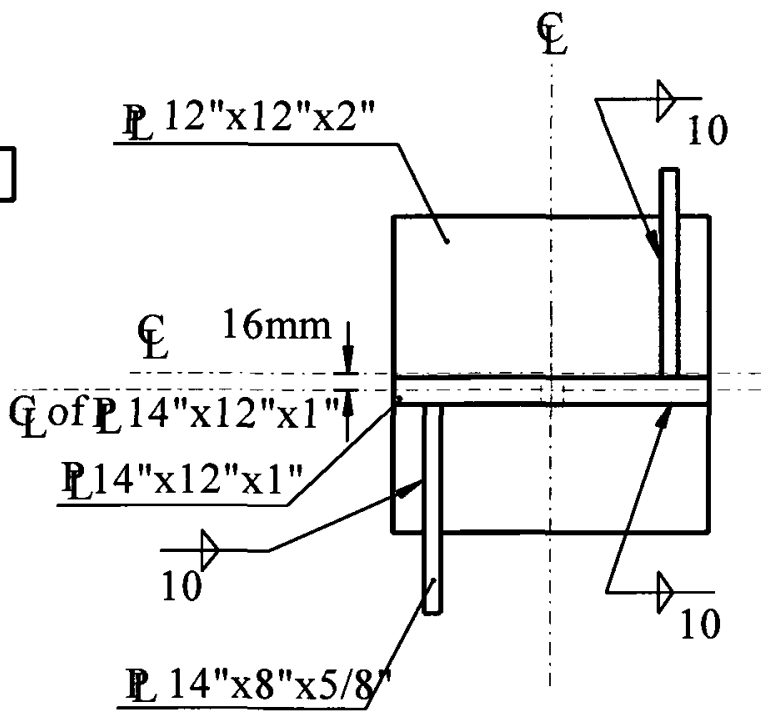

Section G-G

Figure 3.8 Top connection. 


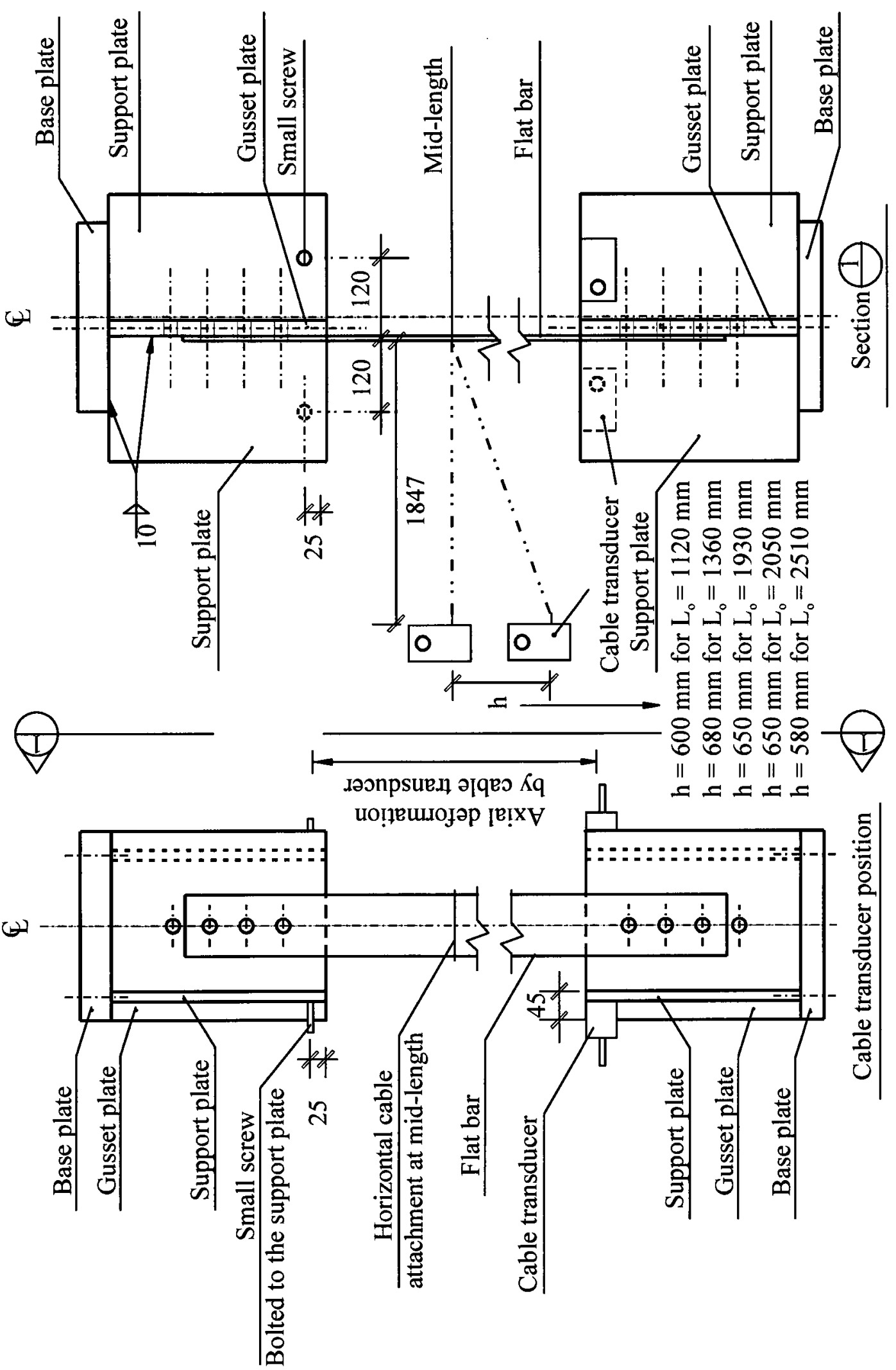

Figure 3.9 Positions of cable transducer. 


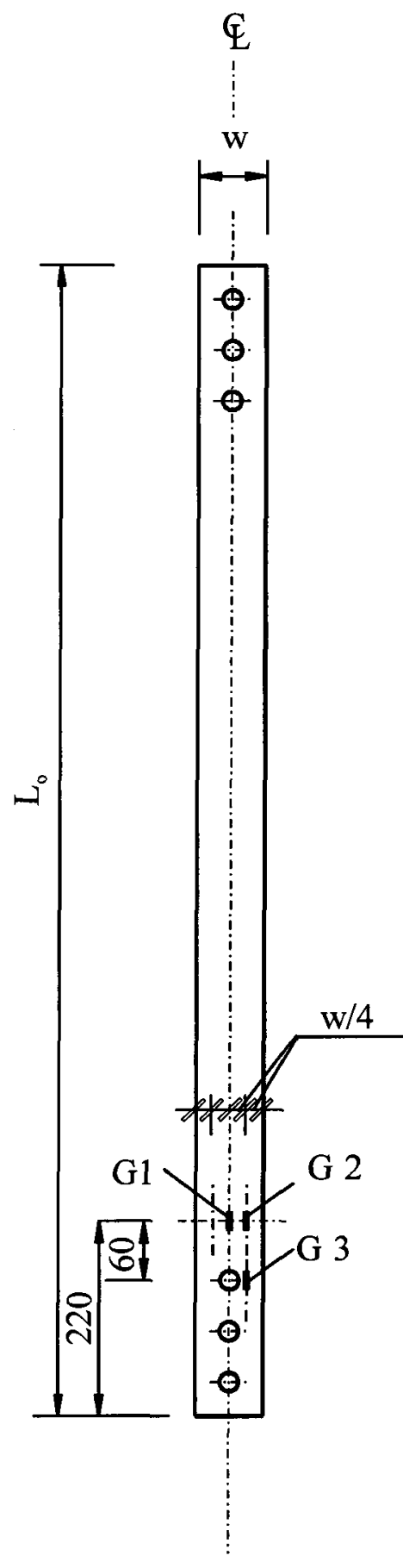

Elevation, Type A

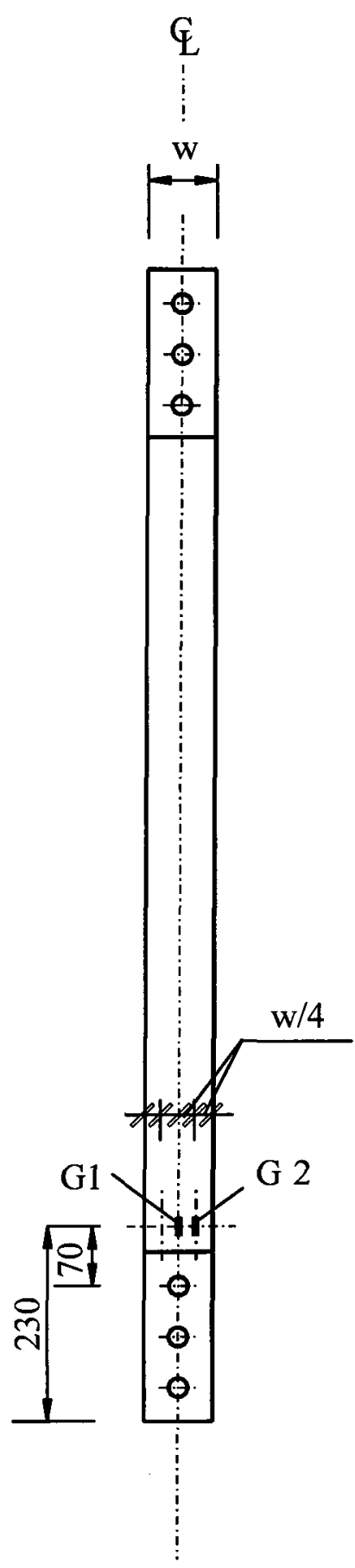

Elevation, Type B

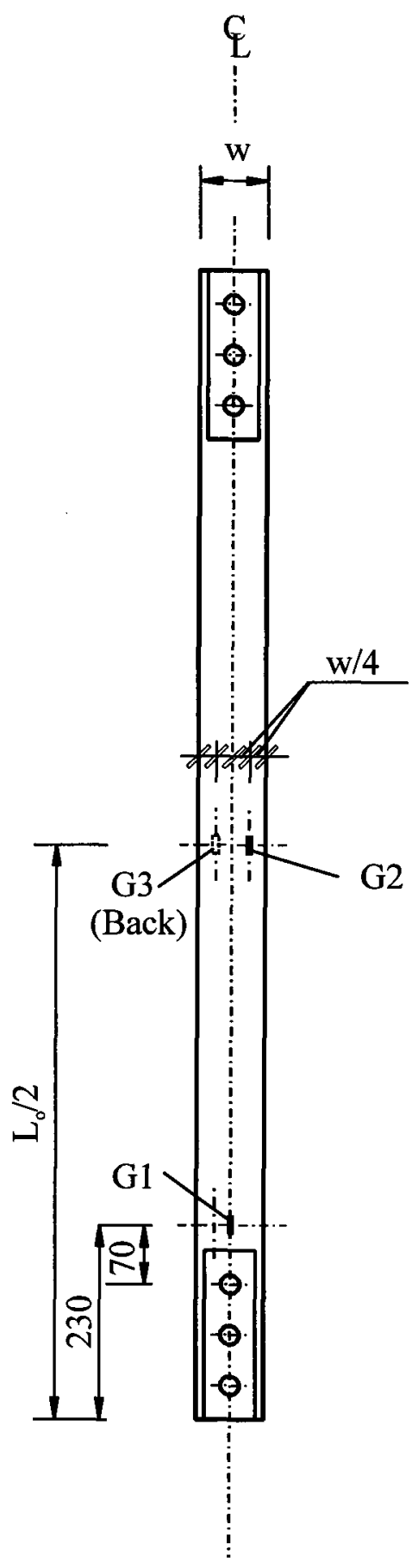

Elevation, Type C

Figure. 3.10 Locations of strain gauges. 


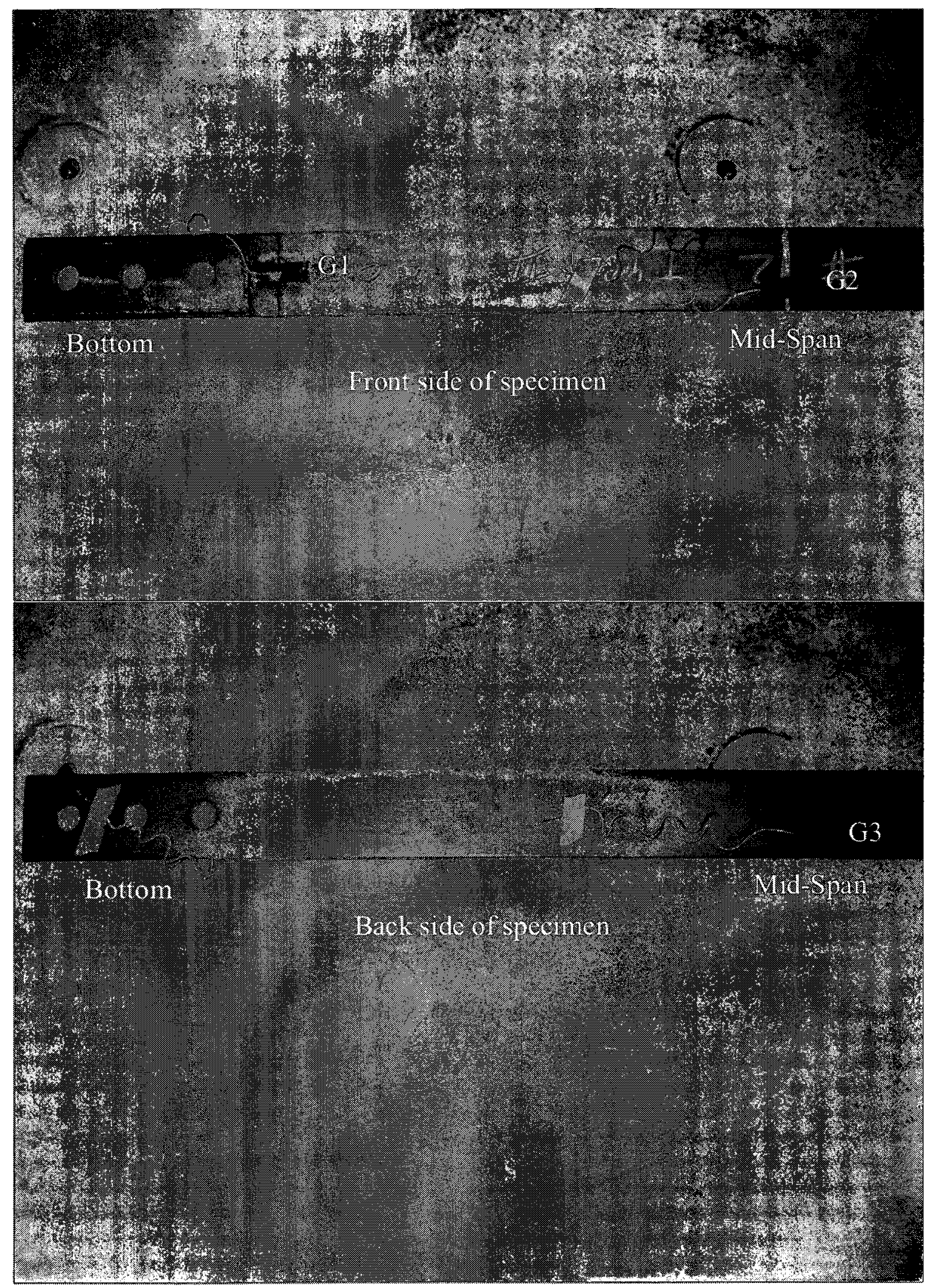

Figure 3.11 Example of a Type $\mathbb{C}$ specimen with strain gauges. 


\section{CHAPTER 4 TEST RESULTS}

Steel straps with various slenderness ratios and connection details have been tested. The response and performance of the strap has been found to change with the slenderness ratio and connection detail. Based on results of the tests, effects of slenderness ratio and connection detail on buckled shape, dissipated energy, load-deformation relationship, location of fracture, and ductility are assessed and discussed. Guidelines and recommendations are also provided on using steel straps as tension-only bracing member in seismic design.

\subsection{Test Results}

Results of the test are summarized in Tables 4.1 and 4.2. The following parameters are adopted for the discussion. In Table 4.1, the hysteretic energy is calculated as the energy dissipated up to fracture or when the test stopped. It is defined as

$$
\mathrm{E}_{\mathrm{h}}=\int \mathrm{Fd} \Delta
$$

where $\mathrm{F}$ is the measured force in the member and $\Delta$ is the average measured displacement from the two axial cable transducers. In order to allow for a better comparison between specimens with different material and length, normalized values of test results similar to Popov and Black (1981) are also presented in Table 4.2. Since the loading rate varied in the test, the static yield strength has been adopted in calculating the normalized value in 
the discussion even though the maximum load in Table 4.1 is the dynamic load. The normalized maximum tension load, $\mathrm{T}_{\max }$ is taken as

$$
\mathrm{T}_{\mathrm{n} \max }=\frac{\mathrm{T}_{\max }}{\mathrm{A}_{\mathrm{g}} \mathrm{F}_{\mathrm{ys}}}
$$

where $T_{\max }$ is the maximum tension force recorded until the test was stopped or the specimen fractured, $A_{g}$ is the measured gross cross-section area of the specimen, and $F_{y s}$ is the measured static yield strength. The normalized maximum extension, $\Delta_{\mathrm{nmax}}$ is defined as

$$
\Delta_{\mathrm{n} \max }=\frac{\Delta_{\max } \mathrm{E}}{\mathrm{F}_{\mathrm{ys}} \mathrm{L}}
$$

where $\Delta_{\max }$ is the maximum extension recorded until the test was stopped or the specimen fractured, $\mathrm{E}$ is the measured elastic modulus and $\mathrm{L}$ is the distance between the middle bolt holes. Finally the normalized hysteretic energy is defined as

$$
E_{n}=\frac{E_{h} E}{A_{g} F_{y s}^{2} L}
$$

The loading strain rate of the test in Table 3.4, which is an average over the specimen length, $L$ ranges from $2 \times 10^{-4}$ to $2 \times 10^{-3}$. From results of the material test shown in Table 3.6, the dynamic to static yield strength rate was found to vary from 1.10 to 1.16 at $10^{-2} \mathrm{~s}^{-1}$. In Table 4.2, the normalized maximum tension load $\left(\mathrm{T}_{\mathrm{nmax}}\right)$ is at least 1.05 for all specimens. However, this dose not imply that gross section yielding has been achieved in all specimens since static yield strength was used in calculating the normalized values. Based on the dynamic material properties, it is difficult to assess conclusively if gross 
section yielding has occurred in the test using $T_{n \max }$ alone when $T_{n \max }$ has a value between 1.10 and 1.16 .

The average net to gross section area and the net section fracture to gross section yielding strength ratios for Type A and B specimens are shown in Table 4.3. Only FB $76 \times 4.8$ specimens have the $\left(A_{n} F_{u} / A_{g} F_{y}\right)$ ratio close to or less than 1.0 . Other specimens have a ratio that is significantly greater than 1.0 even up to a strain rate of $0.5 \mathrm{~s}^{-1}$, and thus would be expected to exhibit considerable ductility in the test. The load versus deformation curves for all tests are shown in Appendix B. There was no deterioration in the load with the increase range in deformation until fracture occurred.

\subsubsection{Direction of Buckling and Fracture Location}

In the test, the specimen can buckle either towards or away from the cable transducers. The direction towards the cable transducers is the direction away from the gusset plate. As shown in Figs 3.5 and 3.8, the specimen was always in between the gusset plate and horizontal cable transducer. Table 4.1 lists the direction of buckling observed in the test, with "+" indicating the direction towards the cable transducer and "-" in the opposite direction. There is no preferred buckling direction observed in the test. In order to ensure and force the buckling to go in one direction, a strut (rod) (not connected to the specimen) was positioned at the mid-length of the specimen as shown in Figs. 4.1 to 4.3. Despite using the strut, buckling direction can still swing back and forth from one 
cycle to another at the late stages of loading.

All Type A specimens fractured across the innermost bolt hole except for A2128c, where fracture occurred across a section close to the end of the gusset plate. Figure 4.4 shows the typical fracture across the innermost bolt hole and that for A2128c. For Type A specimens, the largest cumulative strain due to axial extension occurred at the innermost bolt hole. When the specimen buckled towards the cable transducers and away from the gusset plate, the largest cumulative bending strain due to the buckling and straightening also occurred at the innermost bolt hole. For these reasons, all Type A specimens fractured across the innermost bolt hole when buckling was away from the gusset plate. However, when the specimen buckled towards the gusset plate as in A4075c and A2128c, the largest cumulative bending strain occurred close to the end of the gusset plate instead of innermost bolt hole because the buckled configuration has to go around the gusset plate. Generally, the cumulative strain due to axial extension reduces with a higher $\mathrm{A}_{\mathrm{n}} \mathrm{F}_{\mathrm{u}} / \mathrm{A}_{\mathrm{g}} \mathrm{F}_{\mathrm{y}}$ ratio at the bolt hole. Similarly, the cumulative bending strain due to buckling also reduces with a higher slenderness ratio with other things being equal. For this reason, A4075c, which has a higher slenderness ratio and lower $A_{n} F_{u} / A_{g} F_{y}$ ratio compared to A2128c, fractured across the innermost bolt hole while A2128c fractured close to the end of the gusset plate.

In Type B specimens, the extra plate shifted the location of the largest cumulative bending strain away from the innermost bolt hole to a section close to the end of the reinforcement plate. This increases the ductility of a Type B specimen compared to a 
similar Type A specimen, as can be seen in Table 4.1. While all specimens in B8075 and B2078 series fractured across the innermost bolt hole, some specimens in B2128 series fractured at the mid-length. There is an interplay of many factors, such as clamping force, slenderness ratio, $\mathrm{A}_{\mathrm{n}} \mathrm{F}_{\mathrm{u}} / \mathrm{A}_{\mathrm{g}} \mathrm{F}_{\mathrm{y}}$ ratio and material properties, that influence where fracture occurs. It is not possible to draw a conclusion on the fracture location based on the limited test results available.

For Type $\mathrm{C}$ specimens with welded plate reinforcement, the stroke limit of the actuator was exceeded in many tests before fracture occurred due to the higher ductility compared to Type A and B specimens. Since the section at the bolt hole was no longer the weakest, fracture occurred in these specimens either at the mid-length or close to the end of the reinforcement plate. Figure 4.5 shows the typical fracture locations of Type $\mathrm{C}$ specimens of either close to the end of the reinforcement plate in C2078a or at the mid-length for C2108a. Pictures of fracture location and/or buckling shape for all specimens are shown in Appendix C.

\subsubsection{Out-of-plane Deformation of a Buckled Strap}

The out-of-plane elastic buckling deformation is given by Fig. 4.6 for fixed end condition and Fig. 4.7 for pinned end condition. Based on the assumed deformation shapes in Figs. 4.6 and 4.7, the maximum out-of-plane deflection for both fixed and pinned end conditions can be simplified to 


$$
a=0.64 \sqrt{\left(b_{o}-b\right) b}
$$

where $a$ is the maximum out-of-plane or lateral deflection, $b_{0}$ is the relaxed length at zero load and $b$ is the deformed length. Equation (4.5) is similar to that derived by Tremblay (2002) for fixed end condition, but differs for pinned end condition. In an actual buckling, the end condition is between fixed and pinned. Thus, Eq. (4.5) appears to be the particularly suitable to estimate the maximum out-of-plane buckling deformation. Three relaxed lengths may be considered in using Eq. (4.5). Assuming that all deformations are elastic, the relaxed length can be assumed to be equal to the original undeformed length as

$$
\begin{aligned}
& \mathrm{b}_{\mathrm{o}}=\mathrm{L}_{\mathrm{d}} \quad \text { with } \\
& \mathrm{b}_{\mathrm{o}}-\mathrm{b}=-\Delta
\end{aligned}
$$

where $\mathrm{L}_{d}$ is the undeformed centre-to-centre distance of the innermost bolt holes for Type A specimens and the inner distance between ends of reinforcement plate for Type C specimens, and $\Delta$ is the axial deformation from the original undeformed position taking as negative in compression. If the maximum extension up to the time of consideration is assumed to be fully plastic, the relaxed length can be taken as

$$
\begin{aligned}
& \mathrm{b}_{\mathrm{o}}=\mathrm{L}_{\mathrm{d}}+\Delta_{\mathrm{m}} \quad \text { with } \\
& \mathrm{b}_{\mathrm{o}}-\mathrm{b}=\Delta_{\mathrm{m}}-\Delta
\end{aligned}
$$

where $\Delta_{\mathrm{m}}$ is the maximum extension up to the time of consideration. Finally, the maximum extension up to the time of consideration can be assumed to include some elastic deformation associated with the maximum tension force experienced by the strap 
up to then. This gives the relaxed length as

$$
\begin{aligned}
& \mathrm{b}_{\mathrm{o}}=\mathrm{L}_{\mathrm{d}}+\Delta_{\mathrm{m}}-\frac{\mathrm{F}_{\mathrm{m}}\left(\mathrm{L}_{\mathrm{d}}+\Delta_{\mathrm{m}}\right)}{\mathrm{A}_{\mathrm{g}} \mathrm{E}} \text { with } \\
& \mathrm{b}_{\mathrm{o}}-\mathrm{b}=\Delta_{\mathrm{m}}-\Delta-\frac{\mathrm{F}_{\mathrm{m}}\left(\mathrm{L}_{\mathrm{d}}+\Delta_{\mathrm{m}}\right)}{\mathrm{A}_{\mathrm{g}} \mathrm{E}}
\end{aligned}
$$

where $F_{m}$ is the maximum tension force up to the time of consideration, $A_{g}$ is the gross section area of the strap and $E$ is the elastic modulus. Predicted values based on Eqs. (4.6) to (4.8) are compared to the measured deformations for some of the tests in Table 4.4. Clearly, Eq. (4.8) gives the most accurate overall predicted deflection with the accuracy improving at a larger cyclic loading range. The predicted deformation by Eq. (4.8) is within $10 \%$ of the measured values in Table 4.4, except for A4075a at a low deformation range of $\delta=\delta_{\mathrm{y}}$. Equation (4.6) generally underestimates and Eq. (4.7) overestimates the deformation. As expected, since Eq. (4.6) assumes fully elastic extension while Eq. (4.7) assumes fully plastic extension, the accuracy of Eq. (4.6) deteriorates as the loading range increases and the reverse applies to Eq. (4.7).

\subsubsection{Comparisons of Monotonic and Cyclic Tests}

Monotonic tests were carried out for A2078 (FB 76x4.8) and A2128 (FB 127x7.9) specimens in addition to the cyclic tests. As can be seen in Table 4.3 , both specimen groups have a comparable capacity $\left(\mathrm{A}_{n} \mathrm{~F}_{\mathrm{u}} / \mathrm{A}_{\mathrm{g}} \mathrm{F}_{\mathrm{y}}\right)$ ratio, but $\mathrm{A} 2128$ specimens have a higher cross section $A_{n} / A_{g}$ ratio. This implies that the side of the $A 2128$ extends further out from 
the centerline than A2078, which translates to a higher stress concentration or a more non-uniform stress and strain distributions across the section at the bolt hole for A2128. Table 4.5 shows results of monotonic tests as compared to the ideal net section capacity at various strain rates. Based on the loading rate of $5 \mathrm{~mm} / \mathrm{min}$, the monotonic test has a overall loading strain rate of around $0.00009 \mathrm{~s}^{-1}$. A2078 specimens achieved the ideal full net section capacity for the strain rate of $10^{-4} \mathrm{~s}^{-1}$, but the capacity for A2128 specimens was about $5 \%$ lower. This can be attributed to the higher stress concentration at the bolt hole for A2128 that causes the specimens to fail before the ideal net section capacity is reached.

Comparisons of monotonic and cyclic test results are shown in Table 4.6. Values from A2128c have been excluded because the specimen buckled away from the cable transducers that have resulted in a less severe strain accumulation at the bolt hole. Figures 4.8 and 4.9 show the load versus deformation curves for one each of the monotonic and cyclic specimens. It can be seen in Figs. 4.8 and 4.9 that the load versus deformation curve for the monotonic test forms the upper envelope and provides a good estimate of the tension half of the load versus deformation curve for the cyclic test. Shown in Table 4.6, the maximum tension load in the cyclic test is $5 \%$ lower than the monotonic test for A2128 and 11\% lower for A2078, following the same trend as the comparison of the maximum monotonic tension to the ideal net section capacity between the two specimen groups. It is expected that the difference between the maximum monotonic and cyclic tension load to reduce as the slenderness ratio increases. On average, the maximum 
extension for A2078 in the cyclic test was about the same as the monotonic test, but it was about $25 \%$ lower in the cyclic test for A2128. This may be attributed partly to the higher stress concentration at the bolt hole for A2128 compared to A2078 due to the difference in the specimen width or $A_{n} / A_{g}$ ratio.

\subsubsection{Effects of $A_{n} / A_{g}$ and $A_{n} F_{u} / A_{g} F_{y}$ Ratios}

For the same material, the ductility of the strap is expected to increase with the net to gross section area ratio $\left(\mathrm{A}_{\mathrm{n}} / \mathrm{A}_{\mathrm{g}}\right)$ or the net section fracture to the gross section yielding ratio $\left(A_{n} F_{u} / A g F y\right)$. However, this may not be completely true for straps with different material properties. Excluding tests that buckled away from the cable transducers and loaded monotonically, the average normalized maximum extension and hysteretic energy results for Type A specimens are summarized in Table 4.7.

Due to different material properties, the $\mathrm{A}_{n} \mathrm{~F}_{\mathrm{u}} / \mathrm{AgFy}$ ratio for all $7.9 \mathrm{~mm}$ thick straps (Axxx8) turns out to be about equal, and is significantly higher than 1.0 even though the $A_{n} / A_{g}$ ratio is different. On the other hand, the $A_{n} F_{u} / A_{g} F_{y}$ ratio for $4.8 \mathrm{~mm}$ thick straps (Axxx5) is close to 1.0 up to the strain rate of $10^{-4} \mathrm{~s}^{-1}$. In general, the actual $\mathrm{A}_{\mathrm{n}} \mathrm{F}_{\mathrm{u}} / \mathrm{A}_{\mathrm{g}} \mathrm{F}_{\mathrm{y}}$ ratio is significantly different than the nominal and expected net section fracture to gross section yielding strength ratios in Table 3.3. It can be seen in Table 4.7, A2078 and A2108 achieved roughly the same $\Delta_{n \max }$ and $E_{n}$ while $\Delta_{n \max }$ and $E_{n}$ for A2128 are about $20 \%$ higher, even as all these three Type A specimen series have roughly the 
same $\mathrm{A}_{\mathrm{n}} \mathrm{F}_{\mathrm{u}} / \mathrm{A}_{\mathrm{g}} \mathrm{F}_{\mathrm{y}}$ ratio. The same can be concluded for $\mathrm{A} 4078, \mathrm{~A} 4108$, and $\mathrm{A} 4128$. Unlike $\mathrm{A} 4078, \mathrm{~A} 4108$ and $\mathrm{A} 4128$, the $\mathrm{A}_{\mathrm{n}} \mathrm{F}_{\mathrm{u}} / \mathrm{A}_{\mathrm{g}} \mathrm{F}_{\mathrm{y}}$ ratio for $\mathrm{A} 4075$ is only around 1.0. As a result, A4075 has a much lower ductility. This is also reflected in the much smaller $\Delta_{\max }$ and $\mathrm{E}_{\mathrm{n}}$ in $\mathrm{A} 4075$ as compared to any of the $7.9 \mathrm{~mm}$ thick straps. As expected, the $\mathrm{A}_{\mathrm{n}} \mathrm{F}_{\mathrm{u}} / \mathrm{A}_{\mathrm{g}} \mathrm{F}_{\mathrm{y}}$ ratio can be a good overall indicator on the ductility and energy dissipating capacity of the strap, but not a definitive one.

\subsubsection{Influence of Connection Details}

Three types of connection details were considered in the test program. Type A detail, having a $A_{n} / A_{g}$ ratio of less than 1.0 , was expected to be the least ductile. This is followed by Type B detail (clamped with an extra plate), which shifts the largest cumulative bending strain from the innermost bolt hole to a section close to the end of the reinforcement plate while the $A_{n} / A_{g}$ ratio is still below 1.0. Type $C$ detail will be the most ductile since the $A_{n} / A_{g}$ ratio is 1.0 . Tables 4.8 and 4.9 show the comparisons of the average normalized maximum extension and hysteretic energy for various connection details. Type A and B specimens that buckled away from the cable transducers, monotonic tests, and C4075a that has loading control problem have been excluded. All specimens in Tables 4.8 and 4.9 fractured in the test except for C8075 and C4078. It can be seen that the ductility and hysteretic energy improved from Type A to Type B connection detail. The improvement is especially great for A8075 specimen that has a 
low normalized maximum extension. Further significant improvement in the ductility and hysteretic energy were achieved from Type B to Type C connection detail. The improvement in the ductility and hysteretic energy by switching from Type A to Type C connection detail increases with the slenderness ratio from $x 2078(\mathrm{KL} / \mathrm{r}=200)$ to $\times 4078$ $(\mathrm{KL} / \mathrm{r}=400)$. A similar comparison cannot be made for $\mathrm{x} 4075$ and $\mathrm{x} 8075$ specimens because tests for $\mathrm{C} 8075$ were stopped too prematurely due to the actuator stroke limit.

Based on the storey drift limit of $2.5 \%$ in NBCC 2005 (NRCC 2005), the ductility requirement for bracing at $45^{\circ}$ angle is approximately equal to a normalized maximum extension $\left(\Delta_{\operatorname{nmax}}\right)$ of 8.3 for a yield strength of $300 \mathrm{MPa}$, or a $1.25 \%$ strain in the brace. From Table 4.2, all Type $\mathrm{C}$ specimens achieved $\Delta_{\text {nmax }}$ greater than 30 . This means that all Type C specimens will satisfy the ductility demand for a Seismic Force Resisting System. Although most of Type A and B specimens achieved $\Delta_{\text {nmax }}$ greater than 8.3, some specimens fractured much earlier. For Type A and B specimens, the ductility is greatly influenced by the $A_{n} F_{u} / A_{g} F_{y}$ ratio.

\subsubsection{Effects of Slenderness Ratio}

There are two ways to change the slenderness ratio of the strap. One is by changing the length and the other is by changing the thickness. In this study, the length of the specimen was changed to achieve the different slenderness ratio.

Comparisons of normalized maximum tension load and extension versus nominal 
slenderness ratio are shown together with the trend lines for Type A specimens in Figs. 4.10 and 4.11, and for Type C specimens in Figs. 4.12 and 4.13. Figures 4.10 and 4.11 exclude data from specimens that buckled away from cable transducers and monotonic tests. Data from Cx075 series of specimens were also not included in Figs. 4.12 and 4.13 because some of the tests in that series were stopped too prematurely due to actuator stroke limit to make any comparison useful. Even though $\mathrm{C} 4 \mathrm{xx} 8(\mathrm{KL} / \mathrm{r}=400)$ specimens did not fracture during the test, they are included in the comparisons because the normalized maximum extension that can be applied was much higher than the normalized maximum extension achieved in the $\mathrm{C} 2 \mathrm{xx} 8(\mathrm{KL} / \mathrm{r}=200)$ specimens.

As shown in Figs. 4.10 and 4.12, the normalized maximum tension load $\left(T_{\text {nmax }}\right)$ increases slightly with the slenderness ratio for both Type A and C specimens. This is probably due to the reduction in the compression load as the slenderness ratio increases, which in turn induces less plastic stress reversal in compression. The normalized maximum extension $\left(\Delta_{\max }\right)$ was also found to increase with the slenderness ratio for Type C specimen. As can be seen in Fig. 4.13, $\Delta_{n \max }$ almost double as the nominal slenderness ratio increases from 200 to 400 . However, this may be a little misleading because after $\delta=50 \delta_{\mathrm{y}}$, the loading range increment rate was changed from $\delta_{\mathrm{y}}$ to $50 \delta_{\mathrm{y}}$. Nevertheless, there is a significant increase in the ductility. This increase can partly be attributed to the lower bending strain being generated with a higher slenderness ratio for the same applied normalized deformation. However, $\Delta_{n \max }$ is shown in Fig. 4.11 to decrease with the slenderness ratio for Type A specimens. Unlike Type $\mathrm{C}$ specimens, the 
net section area for Type $A$ specimens is less than the gross section area. Thus, any increase in the deformation will localize more at the bolt hole rather than being distributed evenly over the whole member. For the same normalized extension, a longer Type A specimen will experience a higher strain at the bolt hole than a shorter specimen. This is probably the reason why the normalized maximum extension of Type A specimens decreases as the slenderness ratio increases as the slenderness ratio increase was achieved through using a longer specimen. However, if the material properties and length are identical, it would be expected that the ductility will improve with a higher slenderness ratio by changing the thickness. Similar to the normalized maximum extension, Table 4.9 shows that the normalized hysteretic energy increases with the slenderness ratio in Type C specimens, but reduces in Type A specimens.

\subsection{Guidelines and Recommendations on Using Strap Tension-only Brace in SFRS}

Since objectives of the experimental study were only to investigate the behavior of high slenderness flat bar braces, and provide data for the validation of the finite element analysis models to be developed for the parametric study, only some basic guidelines and recommendations will be provided here. A more comprehensive guidelines and recommendations will be provided through the finite element analysis parametric study that is to be conducted separately. 
For a Seismic Force Resisting System (SFRS), it is important that the member has the ability to go through a number of inelastic load reversal cycles without a significant loss of strength. In the test every specimen achieved a higher tension load with increase range of deformation until the last leg of the loading cycle before fracture occurred. This means that the strap tension-only brace will only require to meet the ductility requirement since there is no deterioration of tension strength.

In NBCC 2005 (NRCC 2005), a normal building is required to have a strorey drift of less than $2.5 \%$ during an earthquake. This translates to a deformation of a 0.0125 strain for a brace at $45^{\circ}$, which is $\delta=8.3 \delta_{\mathrm{y}}$ for $\mathrm{F}_{\mathrm{y}}=300 \mathrm{MPa}$ or the normalized maximum extension $\Delta_{n \max }=8.3$. The strap can be considered to have satisfied the ductility requirement if the $\Delta_{\text {nmax }}$ exceeds 8.3 under the ATC-40 loading protocol. The ductility demand is less if the brace is at an angle of inclination other than $45^{\circ}$.

Based on $\Delta_{\max }$ from the tests, any brace with Type $\mathrm{C}$ connection detail and slenderness ratio of greater than 200 can be used safely in SFRS. Although not studied, it would be expected any reinforcement plate with the same grade and thickness as the strap that meets the edge and end distance limits for the bolted connection will satisfy the Type $\mathrm{C}$ detail requirement. With the significant excess ductility exhibited by the specimens at $\mathrm{KL} / \mathrm{r}=200$, the ductility requirement can probably still be met at a much lower $\mathrm{KL} / \mathrm{r}$ ratio. This limit will be established through the finite element analysis parametric study, which is outside the scope of this thesis. Conservatively, Eq. (2.1) by Tremblay et al. (2003) can be used to estimate the limit. 
Unlike Type C specimens, the ductility of Type A and B specimens are dependent on the member length, $\mathrm{A}_{n} \mathrm{~F}_{\mathrm{u}} / \mathrm{A}_{\mathrm{g}} \mathrm{F}_{\mathrm{y}}$ and slenderness ratios. The calculated $\mathrm{A}_{\mathrm{n}} \mathrm{F}_{\mathrm{u}} / \mathrm{A}_{\mathrm{g}} \mathrm{F}_{\mathrm{y}}$ ratio at various strain rates is shown in Table 4.3. Three of the flat bar specimen groups have the static $\mathrm{A}_{\mathrm{n}} \mathrm{F}_{\mathrm{u}} / \mathrm{A}_{\mathrm{g}} \mathrm{F}_{\mathrm{y}}$ ratio greater than 1.2 achieved the required ductility, while the one specimen group with the static $\mathrm{A}_{\mathrm{n}} \mathrm{F}_{\mathrm{u}} / \mathrm{A}_{\mathrm{g}} \mathrm{F}_{\mathrm{y}}$ ratio close to 1.0 only managed to achieve limited ductility. Two of the flat bar specimen groups sized with the expected $\mathrm{A}_{n} \mathrm{~F}_{\mathrm{u}} / \mathrm{Ag}_{\mathrm{g}} \mathrm{F}_{\mathrm{y}}$ ratio greater than 1 , as shown in Table 3.3, also achieved the required ductility. However, the performance of the specimen groups that satisfied the ductility requirement still need to be investigated for a longer length. There are insufficient test data to provide any definitive guideline and recommendation for a brace designed with the Type $\mathrm{B}$ or $\mathrm{C}$ detail. It is possible that the ductility requirement can be met if the brace is designed with the $\mathrm{A}_{\mathrm{n}} \mathrm{F}_{\mathrm{u}} / \mathrm{A}_{\mathrm{g}} \mathrm{F}_{\mathrm{y}}$ ratio greater than 1.2 or the expected $\mathrm{A}_{\mathrm{n}} \mathrm{F}_{\mathrm{u}} / \mathrm{A}_{\mathrm{g}} \mathrm{F}_{\mathrm{y}}$ ratio greater than 1 . The actual $\mathrm{A}_{\mathrm{n}} \mathrm{F}_{\mathrm{u}} / \mathrm{A}_{\mathrm{g}} \mathrm{F}_{\mathrm{y}}$ provided can be checked using the mill certificate of the strap.

From the material tests in the experimental study, the yield strength of five flat bars at the strain rate $0.5 \mathrm{~s}^{-1}$ was found to exceed the expected yield strength of $385 \mathrm{MPa}$ prescribed in CSA-S16-01 (CSA 2005) for the design. There was only one flat bar that has a yield strength close to $385 \mathrm{MPa}$ at the $0.5 \mathrm{~s}^{-1}$ strain rate. Thus, a higher expected yield strength may have to be used in the design if a strain rate of close to or greater than $0.5 \mathrm{~s}^{-1}$ can be expected during an earthquake. 
Table 4.1 Test results.

\begin{tabular}{|c|c|c|c|c|c|c|c|}
\hline \multirow{2}{*}{$\begin{array}{c}\text { Specimen } \\
\text { no. }\end{array}$} & \multirow{2}{*}{$\begin{array}{c}\text { Max. } \\
\text { tension } \\
\text { load, } \\
\mathrm{T}_{\max }, \\
(\mathrm{kN})\end{array}$} & \multirow{2}{*}{$\begin{array}{c}\text { Max. } \\
\text { extension, } \\
\Delta_{\max },(\mathrm{mm})\end{array}$} & \multirow{2}{*}{$\begin{array}{c}\text { Hysteretic } \\
\text { energy, } \\
\mathrm{E}_{\mathrm{h}},(\mathrm{kJ})\end{array}$} & \multicolumn{2}{|c|}{$\begin{array}{c}\text { Last loading } \\
\text { cycle }\end{array}$} & \multirow{2}{*}{$\begin{array}{l}\text { Fracture } \\
\text { location }\end{array}$} & \multirow{2}{*}{$\begin{array}{c}\text { Direction } \\
\text { of } \\
\text { buckling }\end{array}$} \\
\hline & & & & $\begin{array}{c}\text { Half } \\
\text { cycle } \\
\text { no. }\end{array}$ & $\frac{\delta}{\delta_{y}}$ & & \\
\hline $\mathrm{A} 8075 \mathrm{a}$ & 120 & 11.31 & 2.36 & 47 & 5 & Top $^{2}$ & + \\
\hline $\mathrm{A} 8075 \mathrm{~b}$ & 114 & 9.36 & 1.79 & 43 & 4 & Top ${ }^{2}$ & + \\
\hline $\mathrm{A} 6075 \mathrm{a}$ & 118 & 7.52 & 1.31 & 43 & 4 & Top $^{2}$ & + \\
\hline $\mathrm{A} 6075 \mathrm{~b}$ & 116 & 8.30 & 1.63 & 47 & 5 & Top $^{2}$ & + \\
\hline $\mathrm{A} 4075 \mathrm{a}$ & 116 & 9.14 & 2.21 & 55 & 7 & Top $^{2}$ & + \\
\hline $\mathrm{A} 4075 \mathrm{~b}$ & 117 & 6.74 & 1.50 & 51 & 6 & Top $^{2}$ & + \\
\hline $\mathrm{A} 4075 \mathrm{c}$ & 117 & 10.60 & 2.65 & 57 & 7 & Top $^{2}$ & $+/-^{3}$ \\
\hline $\mathrm{A} 4078 \mathrm{a}$ & 247 & 37.83 & 23.5 & 91 & 16 & Top $^{2}$ & + \\
\hline $\mathrm{A} 4078 \mathrm{~b}$ & 240 & 34.09 & 20.4 & 87 & 15 & Top $^{2}$ & + \\
\hline A2078a & 231 & 23.95 & 26.1 & 107 & 20 & Top $^{2}$ & + \\
\hline $\mathrm{A} 2078 \mathrm{~b}$ & 231 & 26.48 & 30.1 & 115 & 22 & Top $^{2}$ & + \\
\hline $\mathrm{A} 2078 \mathrm{c}$ & 240 & 28.96 & 41.9 & 117 & 22 & Top $^{2}$ & + \\
\hline A2078d & 246 & 29.47 & 5.66 & NA & $\mathrm{NA}$ & Top $^{2}$ & NA \\
\hline $\mathrm{A} 2078 \mathrm{e}$ & 245 & 20.32 & 4.46 & NA & $\mathrm{NA}$ & Top $^{2}$ & NA \\
\hline $\mathrm{A} 4108 \mathrm{a}$ & 350 & 42.48 & 34.4 & 99 & 18 & Top $^{2}$ & + \\
\hline $\mathrm{A} 4108 \mathrm{~b}$ & 357 & 46.84 & 41.2 & 107 & 20 & Top $^{2}$ & + \\
\hline $\mathrm{A} 2108 \mathrm{a}$ & 331 & 28.00 & 45.2 & 125 & 24 & Top $^{2}$ & + \\
\hline $\mathrm{A} 2108 \mathrm{~b}$ & 337 & 29.13 & 47.7 & 127 & 25 & Top $^{2}$ & + \\
\hline $\mathrm{A} 4128 \mathrm{a}$ & 372 & 54.87 & 54.1 & 119 & 23 & Top $^{2}$ & -4 \\
\hline $\mathrm{A} 4128 \mathrm{~b}$ & 376 & 53.19 & 53.7 & 119 & 23 & Top $^{2}$ & + \\
\hline $\mathrm{A} 2128 \mathrm{a}$ & 358 & 32.82 & 65.3 & 139 & 28 & Top $^{2}$ & + \\
\hline $\mathrm{A} 2128 \mathrm{~b}$ & 355 & 34.62 & 67.9 & 143 & 29 & Top $^{2}$ & + \\
\hline A2128c & 359 & 48.90 & 151.4 & 195 & 42 & Top $^{5}$ & $+/-^{3}$ \\
\hline $\mathrm{A} 2128 \mathrm{~d}$ & 349 & 32.17 & 59.5 & 137 & 27 & Top $^{2}$ & + \\
\hline $\mathrm{A} 2128 \mathrm{e}$ & 402 & 42.26 & 14.6 & NA & NA & Bottom $^{2}$ & NA \\
\hline A2128f & 394 & 43.26 & 14.3 & $\mathrm{NA}$ & NA & Top $^{2}$ & NA \\
\hline
\end{tabular}


Table $4.1 \quad$ Continue.

\begin{tabular}{|c|c|c|c|c|c|c|c|}
\hline \multirow{2}{*}{$\begin{array}{c}\text { Specimen } \\
\text { no. }\end{array}$} & \multirow{2}{*}{$\begin{array}{c}\text { Max. } \\
\text { tension } \\
\text { load, } \\
\mathrm{T}_{\max },(\mathrm{kN})\end{array}$} & \multirow{2}{*}{$\begin{array}{c}\text { Max. } \\
\text { extension, } \\
\Delta_{\max },(\mathrm{mm})\end{array}$} & \multirow{2}{*}{$\begin{array}{c}\text { Hysteretic } \\
\text { energy, } \\
\mathrm{E}_{\mathrm{h}},(\mathrm{kJ})\end{array}$} & \multicolumn{2}{|c|}{$\begin{array}{c}\text { Last loading } \\
\text { cycle }\end{array}$} & \multirow{2}{*}{$\begin{array}{l}\text { Fracture } \\
\text { location }\end{array}$} & \multirow{2}{*}{$\begin{array}{c}\text { Direction } \\
\text { of } \\
\text { buckling }^{1}\end{array}$} \\
\hline & & & & $\begin{array}{c}\text { Half } \\
\text { cycle } \\
\text { no. }\end{array}$ & $\frac{\delta}{\delta_{y}}$ & & \\
\hline $\mathrm{B} 8075 \mathrm{a}$ & 127 & 20.11 & 4.50 & 55 & 7 & Top $^{2}$ & + \\
\hline $\mathrm{B} 8075 \mathrm{~b}$ & 127 & 36.45 & 10.3 & 75 & 12 & Top ${ }^{2}$ & + \\
\hline B2078a & 264 & 32.77 & 52.4 & 139 & 28 & Top $^{2}$ & + \\
\hline $\mathrm{B} 2078 \mathrm{~b}$ & 256 & 31.20 & 47.1 & 133 & 26 & Top ${ }^{2}$ & + \\
\hline $\mathrm{B} 2128 \mathrm{a}$ & 382 & 55.65 & 178.4 & 215 & 47 & Middle & + \\
\hline B2128b & 391 & 55.44 & 180.5 & 213 & 46 & Middle & + \\
\hline $\mathrm{B} 2128 \mathrm{c}$ & 385 & 58.48 & 187.4 & 223 & 49 & Top $^{2}$ & -6 \\
\hline B2128d & 375 & 49.59 & 160.5 & 199 & 43 & Middle & -7 \\
\hline $\mathrm{C} 8075 \mathrm{a}$ & 157 & 219.13 & 304.9 & 299 & 65 & NA & $+^{8}$ \\
\hline $\mathrm{C} 8075 \mathrm{~b}$ & 152 & 219.64 & 309.1 & 299 & 65 & NA & $+^{8}$ \\
\hline $\mathrm{C} 6075 \mathrm{a}$ & 163 & 228.90 & 191.4 & 262 & 90 & NA & $+/-^{9}$ \\
\hline $\mathrm{C} 6075 \mathrm{~b}$ & 159 & 228.63 & 303.6 & 318 & $90^{10}$ & NA & $+/-^{9}$ \\
\hline $\mathrm{C} 4075 \mathrm{a}$ & 158 & 145.09 & 165.5 & 262 & $90^{11}$ & NA & $+/_{-}^{12}$ \\
\hline $\mathrm{C} 4075 \mathrm{~b}$ & 160 & 166.68 & 145.6 & 271 & 105 & Middle & $+/_{-}^{13}$ \\
\hline $\mathrm{C} 4078 \mathrm{a}$ & 333 & 203.01 & 416.1 & 307 & 75 & NA & $+/_{-}^{14}$ \\
\hline $\mathrm{C} 4078 \mathrm{~b}$ & 332 & 199.60 & 418.2 & 307 & 75 & NA & $+/-^{14}$ \\
\hline $\mathrm{C} 4108 \mathrm{a}$ & 444 & 192.22 & 501.6 & 307 & 75 & NA & $+/^{15}$ \\
\hline $\mathrm{C} 4108 \mathrm{~b}$ & 446 & 197.12 & 473.9 & 307 & 75 & NA & $+/_{-}^{14}$ \\
\hline $\mathrm{C} 2078 \mathrm{a}$ & 284 & 48.23 & 111.0 & 191 & 41 & Top $^{16}$ & + \\
\hline $\mathrm{C} 2078 \mathrm{~b}$ & 285 & 54.32 & 131.0 & 209 & 45 & Bottom $^{16}$ & + \\
\hline $\mathrm{C} 2108 \mathrm{a}$ & 385 & 55.00 & 166.0 & 209 & 45 & Middle & $+/-^{17}$ \\
\hline $\mathrm{C} 2108 \mathrm{~b}$ & 380 & 44.98 & 121.9 & 181 & 38 & Top $^{18}$ & + \\
\hline $\mathrm{C} 2108 \mathrm{c}$ & 381 & 45.43 & 121.0 & 181 & 38 & Top $^{18}$ & + \\
\hline
\end{tabular}

Notes:

1 The following sign convention on the buckling direction is adopted; $(+)$ sign means buckling towards cable transducers, (-) sign means buckling away from cable transducers and (+/-) sign represents back and forth buckling.

2 Fractured at the third bolt hole from the end.

3 Forced to buckle away from cable transducers by using a rod. Despite using the regular rod as shown in Fig. 4.1, the specimen continued with back and forth buckling. 
A wide rod as shown in Fig. 4.2 subsequently was used to force buckling away from cable transducers.

4 Buckled away from cable transducers in the first few cycles at the beginning, but it was later forced to buckle towards cable transducers by using a rod as shown in Fig. 4.1.

5 Fractured at a section close to the end of top gusset plate.

6 Buckled towards cable transducers at the beginning. However, it switched to buckling away from the cable transducers after that up to the end of the test.

7 Forced to buckle away from cable transducers by using a rod.

8 Forced to buckle towards cable transducers by using a very wide rod as shown in Figure 4.3.

9 Buckled towards cable transducers for most part of the test, but the buckling switched back and forth at the late stages even with using a wide rod.

${ }^{10}$ Only two cycles were carried out at $\delta=90 \delta_{\mathrm{y}}$. It was subsequently reprogrammed to 30 cycles at $\delta=90 \delta_{\mathrm{y}}$ for $\mathrm{C} 6075 \mathrm{~b}$.

11 There was a problem with the control during the test. The actuator could not extent beyond around $140 \mathrm{~mm}$.

12 Buckled towards cable transducers at the beginning, but switched away from the cable transducers as the test progressed. Subsequently, a wide rod was used to force buckling to occur towards the cable transducers. Despite using the rod, the specimen still buckled back and forth at the late stages of the test.

${ }^{13}$ Buckled towards cable transducers for most part of the test, but buckled away at late stages even by using a wide rod.

14 Forced to buckle towards cable transducers by using a very wide rod. Despite using the rod, the specimen buckled back and forth at late stages of the test.

15 Forced to buckle towards cable transducers by using a wide rod. Despite using the rod, the specimen buckled back and forth at late stages of the test.

${ }^{16}$ Fractured at $5 \mathrm{~mm}$ away from the end of the reinforcement plate.

${ }^{17}$ Forced to buckle away from cable transducers by using a wide rod. Despite using the rod, the specimen buckled back and forth at late stages of the test even by changing 
the position of the rod.

18 Fractured at $10 \mathrm{~mm}$ away from the end of the reinforcement plate. 
Table 4.2 Normalized test results.

\begin{tabular}{|c|c|c|c|c|c|}
\hline $\begin{array}{c}\text { Specimen } \\
\text { no. }\end{array}$ & $\begin{array}{c}\text { Max. } \\
\text { tension } \\
\text { load, } \\
\mathrm{T}_{\max },(\mathrm{kN})\end{array}$ & $\begin{array}{c}\text { Max. } \\
\text { extension, } \\
\Delta_{\max },(\mathrm{mm})\end{array}$ & $\begin{array}{c}\text { Normalized } \\
\text { max. tension } \\
\text { load, } \mathrm{T}_{\text {nmax }}\end{array}$ & $\begin{array}{c}\text { Normalized } \\
\text { max. } \\
\text { extension, } \\
\Delta_{\text {nmax }}\end{array}$ & $\begin{array}{c}\text { Normalized } \\
\text { hysteretic } \\
\text { energy, }\end{array}$ \\
\hline A8075a & 120 & 11.31 & 1.10 & 3.35 & 6.51 \\
\hline A8075b & 114 & 9.36 & 1.05 & 2.77 & 4.91 \\
\hline A6075a & 118 & 7.52 & 1.08 & 2.97 & 4.71 \\
\hline A6075b & 116 & 8.30 & 1.07 & 3.28 & 5.81 \\
\hline A4075a & 116 & 9.14 & 1.06 & 5.40 & 11.8 \\
\hline A4075b & 117 & 6.74 & 1.07 & 3.98 & 8.07 \\
\hline A4075c & 117 & 10.60 & 1.07 & 6.25 & 14.6 \\
\hline A4078a & 247 & 37.83 & 1.29 & 13.18 & 42.7 \\
\hline A4078b & 240 & 34.09 & 1.25 & 11.88 & 37.1 \\
\hline A2078a & 231 & 23.95 & 1.21 & 16.79 & 95.9 \\
\hline A2078b & 231 & 26.48 & 1.21 & 18.57 & 110 \\
\hline A2078c & 240 & 28.96 & 1.26 & 20.30 & 154 \\
\hline A2078d & 246 & 29.47 & 1.28 & 20.62 & 20.8 \\
\hline A2078e & 245 & 20.32 & 1.28 & 14.24 & 16.5 \\
\hline A4108a & 350 & 42.48 & 1.25 & 13.47 & 39.0 \\
\hline A4108b & 357 & 46.84 & 1.28 & 14.85 & 46.7 \\
\hline A2108a & 331 & 28.00 & 1.19 & 17.85 & 103 \\
\hline A2108b & 337 & 29.13 & 1.20 & 18.58 & 109 \\
\hline A4128a & 372 & 54.87 & 1.14 & 18.82 & 57.1 \\
\hline A4128b & 376 & 53.19 & 1.15 & 18.24 & 56.5 \\
\hline A2128a & 358 & 32.82 & 1.11 & 22.67 & 140 \\
\hline A2128b & 355 & 34.62 & 1.11 & 23.90 & 146 \\
\hline A2128c & 359 & 48.90 & 1.11 & 33.78 & 324 \\
\hline A2128d & 349 & 32.17 & 1.09 & 22.20 & 128 \\
\hline A2128e & 402 & 42.26 & 1.23 & 29.19 & 30.9 \\
\hline A2128f & 394 & 43.26 & 1.23 & 29.82 & 30.8 \\
\hline
\end{tabular}


Table 4.2 Continue.

\begin{tabular}{|c|c|c|c|c|c|}
\hline $\begin{array}{c}\text { Specimen } \\
\text { no. }\end{array}$ & $\begin{array}{c}\text { Max. } \\
\text { tension } \\
\text { load, } \\
\mathrm{T}_{\max },(\mathrm{kN})\end{array}$ & $\begin{array}{c}\text { Max. } \\
\text { extension, } \\
\Delta_{\max }, \\
(\mathrm{mm})\end{array}$ & $\begin{array}{c}\text { Normalized } \\
\text { max. tension } \\
\text { load, } \mathrm{T}_{\text {nmax }}\end{array}$ & $\begin{array}{c}\text { Normalized } \\
\text { max. } \\
\text { extension, } \\
\Delta_{\text {nmax }}\end{array}$ & $\begin{array}{c}\text { Normalized } \\
\text { hysteretic } \\
\text { energy, } \mathrm{E}_{\mathrm{n}}\end{array}$ \\
\hline B8075a & 127 & 20.11 & 1.17 & 5.96 & 12.3 \\
\hline B8075b & 127 & 36.45 & 1.17 & 10.79 & 28.0 \\
\hline B2078a & 264 & 32.77 & 1.38 & 22.96 & 192 \\
\hline B2078b & 256 & 31.20 & 1.34 & 21.88 & 173 \\
\hline B2128a & 382 & 55.65 & 1.18 & 38.40 & 380 \\
\hline B2128b & 391 & 55.44 & 1.21 & 38.32 & 387 \\
\hline B2128c & 385 & 58.48 & 1.20 & 40.31 & 403 \\
\hline B2128d & 375 & 49.59 & 1.16 & 34.18 & 342 \\
\hline C8075a & 157 & 219.13 & 1.44 & 64.92 & 830 \\
\hline C8075b & 152 & 219.64 & 1.40 & 65.07 & 846 \\
\hline C6075a & 163 & 228.90 & 1.47 & 90.62 & 685 \\
\hline C6075b & 159 & 228.63 & 1.45 & 90.51 & 1097 \\
\hline C4075a & 158 & 145.09 & 1.45 & 85.71 & 894 \\
\hline C4075b & 160 & 166.68 & 1.46 & 98.47 & 785 \\
\hline C4078a & 333 & 203.01 & 1.74 & 70.77 & 758 \\
\hline C4078b & 332 & 199.60 & 1.73 & 69.62 & 762 \\
\hline C4108a & 444 & 192.22 & 1.59 & 60.98 & 570 \\
\hline C4108b & 446 & 197.12 & 1.60 & 62.50 & 539 \\
\hline C2078a & 284 & 48.23 & 1.47 & 33.94 & 404 \\
\hline C2078b & 285 & 54.32 & 1.48 & 38.14 & 477 \\
\hline C2108a & 385 & 55.00 & 1.38 & 35.11 & 380 \\
\hline C2108b & 380 & 44.98 & 1.36 & 28.68 & 279 \\
\hline C2108c & 381 & 45.43 & 1.37 & 29.00 & 277 \\
\hline
\end{tabular}


Table 4.3 Ratios of average cross-section area and tension capacity for Type A and B specimens.

\begin{tabular}{|c|c|c|c|c|c|c|c|}
\hline \multirow{4}{*}{ Strap } & \multirow{4}{*}{$\mathrm{A}_{\mathrm{g}}$} & \multirow{4}{*}{$A_{n}$} & \multirow{4}{*}{$\frac{A_{n}}{A_{g}}$} & \multicolumn{4}{|c|}{$\frac{A_{n} F_{u}}{A_{g} F_{y}}$} \\
\hline & & & & \multicolumn{4}{|c|}{ Strain rate $\left(\mathrm{s}^{-1}\right)$} \\
\hline & & & & Static & \multicolumn{3}{|c|}{ Dynamic } \\
\hline & & & & 0.0001 & 0.0001 & 0.01 & 0.5 \\
\hline $76 \mathrm{~mm} \times 4.8 \mathrm{~mm}$ & 354.4 & 250.5 & 0.71 & 1.01 & 1.02 & 0.94 & 0.89 \\
\hline $76 \mathrm{~mm} \times 7.9 \mathrm{~mm}$ & 602.0 & 425.5 & 0.71 & 1.23 & 1.20 & 1.14 & 1.12 \\
\hline $102 \mathrm{~mm} \times 7.9 \mathrm{~mm}$ & 802.3 & 628.3 & 0.78 & 1.26 & 1.22 & 1.18 & 1.16 \\
\hline $127 \mathrm{~mm} \times 7.9 \mathrm{~mm}$ & 983.0 & 810.6 & 0.83 & 1.24 & 1.25 & 1.12 & 1.12 \\
\hline
\end{tabular}


Table 4.4 Horizontal deflection.

\begin{tabular}{|c|c|c|c|c|c|c|c|c|}
\hline \multirow{3}{*}{ Specimen } & \multirow{3}{*}{$\begin{array}{c}\text { Cycle } \\
\text { range, } \\
\frac{\delta}{\delta_{y}}\end{array}$} & \multirow{2}{*}{\multicolumn{4}{|c|}{$\frac{\text { Maximum lateral deflection }}{\text { Deflection, a }(\mathrm{mm})}$}} & \multicolumn{3}{|c|}{ Ratio } \\
\hline & & & & & & \multirow{2}{*}{$\frac{\text { Eq.(4.6) }}{\text { Actual }}$} & \multirow{2}{*}{$\frac{\text { Eq.(4.7) }}{\text { Actual }}$} & \multirow{2}{*}{$\frac{\text { Eq.(4.8) }}{\text { Actual }}$} \\
\hline & & Actual & Eq.(4.6) & Eq.(4.7) & Eq.(4.8) & & & \\
\hline \multirow{3}{*}{ A2078a } & 4 & 47.27 & 41.47 & 52.15 & 47.96 & 0.88 & 1.10 & 1.01 \\
\hline & 11 & 90.91 & 70.28 & 95.00 & 92.20 & 0.77 & 1.05 & 1.01 \\
\hline & 18 & 122.13 & 89.78 & 124.91 & 122.65 & 0.74 & 1.02 & 1.00 \\
\hline \multirow{3}{*}{ C2078a } & 4 & 45.45 & 38.13 & 50.26 & 47.68 & 0.84 & 1.11 & 1.05 \\
\hline & 22 & 125.76 & 94.13 & 132.43 & 130.37 & 0.75 & 1.05 & 1.04 \\
\hline & 38 & 173.35 & 125.21 & 180.13 & 178.37 & 0.72 & 1.04 & 1.03 \\
\hline \multirow{3}{*}{ A8075a } & 1 & 45.16 & 49.38 & 65.05 & 46.48 & 1.09 & 1.44 & 1.03 \\
\hline & 2 & 80.29 & 72.67 & 98.71 & 81.10 & 0.91 & 1.23 & 1.01 \\
\hline & 4 & 132.91 & 106.13 & 146.95 & 134.93 & 0.80 & 1.11 & 1.02 \\
\hline \multirow{3}{*}{ C8075a } & 4 & 124.00 & 104.73 & 145.15 & 132.96 & 0.84 & 1.17 & 1.07 \\
\hline & 12 & 240.19 & 186.45 & 263.50 & 256.80 & 0.78 & 1.10 & 1.07 \\
\hline & 20 & 332.33 & 240.44 & 342.71 & 337.23 & 0.72 & 1.03 & 1.01 \\
\hline \multirow{3}{*}{ A6075a } & 1 & 34.79 & 37.02 & 48.89 & 37.94 & 1.06 & 1.41 & 1.09 \\
\hline & 2 & 59.58 & 56.23 & 74.45 & 62.61 & 0.94 & 1.25 & 1.05 \\
\hline & 3 & 80.97 & 69.50 & 94.20 & 84.79 & 0.86 & 1.16 & 1.05 \\
\hline \multirow{3}{*}{ A4075a } & 1 & 21.53 & 24.67 & 31.98 & 25.14 & 1.15 & 1.49 & 1.17 \\
\hline & 3 & 52.03 & 45.89 & 60.82 & 54.86 & 0.88 & 1.17 & 1.05 \\
\hline & 6 & 88.18 & 65.88 & 90.89 & 87.79 & 0.75 & 1.03 & 1.00 \\
\hline \multirow{3}{*}{ A4128b } & 4 & 94.75 & 86.99 & 108.47 & 99.31 & 0.92 & 1.14 & 1.05 \\
\hline & 12 & 198.51 & 151.38 & 207.01 & 201.29 & 0.76 & 1.04 & 1.01 \\
\hline & 21 & 271.17 & 200.80 & 280.60 & 275.94 & 0.74 & 1.03 & 1.02 \\
\hline
\end{tabular}


Table 4.5 Monotonic tests.

\begin{tabular}{|c|c|c|c|c|c|c|}
\hline \multirow{2}{*}{ Specimen } & \multirow{2}{*}{$\begin{array}{c}\text { Maximum } \\
\text { dynamic } \\
\text { load, } \\
\mathrm{kN}\end{array}$} & \multirow{2}{*}{$\begin{array}{c}\text { Maximum } \\
\text { static } \\
\end{array}$} & $\begin{array}{c}\text { load, } \\
\mathrm{kN}\end{array}$ & \multicolumn{4}{|c|}{$\mathrm{A}_{\mathrm{n}} \mathrm{F}_{\mathrm{u}}, \mathrm{kN}$} \\
\cline { 4 - 7 } & & & Static & \multicolumn{4}{|c|}{ Dynamic } \\
\cline { 4 - 7 } & & 240 & 235 & 244 & 249 & 262 \\
\hline $\mathrm{A} 2078 \mathrm{~d}$ & 246 & 238 & 237 & 246 & 251 & 264 \\
\hline $\mathrm{A} 2078 \mathrm{e}$ & 245 & 392 & 406 & 425 & 430 & 454 \\
\hline $\mathrm{A} 2128 \mathrm{e}$ & 402 & 3901 & 0.0001 & 0.01 & 0.5 \\
\hline $\mathrm{A} 2128 \mathrm{f}$ & 394 & 382 & 398 & 416 & 421 & 445 \\
\hline
\end{tabular}


Table 4.6 Comparison of monotonic and cyclic tests.

\begin{tabular}{|c|c|c|c|c|c|c|}
\hline \multirow{2}{*}{ Specimen } & \multicolumn{3}{|c|}{$\begin{array}{c}\text { Average maximum tension } \\
\text { load (non-static), } T_{\max }\end{array}$} & \multicolumn{3}{c|}{ Average maximum extension, $\Delta_{\max }$} \\
\cline { 2 - 7 } & $\begin{array}{c}\text { Cyclic } \\
(\mathrm{kN})\end{array}$ & $\begin{array}{c}\text { Monotonic } \\
(\mathrm{kN})\end{array}$ & $\begin{array}{c}\text { Cyclic/Monotonic } \\
\text { ratio }\end{array}$ & $\begin{array}{c}\text { Cyclic } \\
(\mathrm{mm})\end{array}$ & $\begin{array}{c}\text { Monotonic } \\
(\mathrm{mm})\end{array}$ & $\begin{array}{c}\text { Cyclic/Monotonic } \\
\text { ratio }\end{array}$ \\
\hline $\mathrm{A} 2078$ & 234 & 245 & 0.95 & 26.46 & 24.89 & 1.06 \\
\hline $\begin{array}{c}\mathrm{A} 2128 \\
(\mathrm{exclude} \\
\mathrm{A} 2128 \mathrm{c})\end{array}$ & 354 & 398 & 0.89 & 33.20 & 42.76 & 0.78 \\
\hline
\end{tabular}

Table 4.7 Average normalized maximum extension and hysteretic energy for Type A specimens.

\begin{tabular}{|c|c|c|c|c|c|}
\hline \multirow{3}{*}{ Specimen } & \multirow{3}{*}{$\frac{A_{n}}{A_{g}}$} & & & \multirow{3}{*}{$\begin{array}{c}\text { Average } \\
\Delta_{\text {nmax }}\end{array}$} & \multirow{3}{*}{$\begin{array}{c}\text { Average } \\
E_{n}\end{array}$} \\
\hline & & \multicolumn{2}{|c|}{ Strain rate $\left(\mathrm{s}^{-1}\right)$} & & \\
\hline & & Static & 0.0001 & & \\
\hline A2078 & 0.71 & 1.23 & 1.20 & 18.55 & 119.97 \\
\hline A2108 & 0.78 & 1.26 & 1.22 & 18.22 & 106.00 \\
\hline A2128 & 0.83 & 1.24 & 1.25 & 22.92 & 138.00 \\
\hline A4075 & 0.71 & 1.01 & 1.02 & 4.69 & 9.94 \\
\hline $\mathrm{A} 4078$ & 0.71 & 1.23 & 1.20 & 12.53 & 39.90 \\
\hline A4108 & 0.78 & 1.26 & 1.22 & 14.16 & 42.85 \\
\hline A4128 & 0.83 & 1.24 & 1.25 & 18.24 & 56.50 \\
\hline
\end{tabular}


Table 4.8 Comparison of average normalized maximum extension for various connection details.

\begin{tabular}{|c|c|c|c|c|c|}
\hline \multirow{3}{*}{ Specimen } & \multicolumn{5}{|c|}{ Average normalized maximum extension, $\Delta_{\text {nmax }}$} \\
\cline { 2 - 6 } & \multicolumn{5}{|c|}{ Connection Type } \\
\cline { 2 - 6 } & $\mathrm{A}$ & \multicolumn{2}{|c|}{$\mathrm{B}$} & \multicolumn{2}{c|}{} \\
\cline { 2 - 6 } & $\begin{array}{c}\Delta_{\text {nmax }} \\
\text { (a) }\end{array}$ & $\begin{array}{c}\Delta_{\text {nmax }} \\
\text { (b) }\end{array}$ & $\begin{array}{c}\text { Ratio } \\
\text { (b)/(a) }\end{array}$ & $\begin{array}{c}\Delta_{\text {nmax }} \\
\text { (c) }\end{array}$ & $\begin{array}{c}\text { Ratio } \\
\text { (c)/(a) }\end{array}$ \\
\hline x8075 & 3.06 & 8.38 & 2.74 & 65.00 & 21.24 \\
\hline x4075 & 4.69 & - & - & 98.47 & 21.00 \\
\hline x4078 & 12.53 & - & - & 70.19 & 5.60 \\
\hline $\mathrm{x} 2078$ & 18.55 & 22.42 & 1.21 & 36.04 & 1.94 \\
\hline $\mathrm{x} 2108$ & 18.22 & - & - & 30.93 & 1.70 \\
\hline $\mathrm{x} 2128$ & 22.92 & 38.36 & 1.67 & - & - \\
\hline
\end{tabular}

Table 4.9 Comparison of average normalized hysteretic energy for various connection details.

\begin{tabular}{|c|c|c|c|c|c|}
\hline \multirow{4}{*}{ Specimen } & \multicolumn{5}{|c|}{ Average normalized hysteretic energy, $E_{n}$} \\
\hline & \multicolumn{5}{|c|}{ Connection Type } \\
\hline & A & \multicolumn{2}{|c|}{ B } & \multicolumn{2}{|c|}{$\mathrm{C}$} \\
\hline & $\begin{array}{l}E_{n} \\
\text { (a) }\end{array}$ & $\begin{array}{l}E_{n} \\
\text { (b) }\end{array}$ & $\begin{array}{l}\text { Ratio } \\
\text { (b)/(a) }\end{array}$ & $\begin{array}{l}E_{n} \\
\text { (c) }\end{array}$ & $\begin{array}{l}\text { Ratio } \\
\text { (c)/(a) }\end{array}$ \\
\hline$x 8075$ & 5.71 & 20.15 & 3.53 & 838.00 & 146.76 \\
\hline$x 4075$ & 9.94 & - & - & 785.00 & 78.97 \\
\hline $\mathrm{x} 4078$ & 39.90 & - & - & 760.00 & 19.05 \\
\hline $\mathrm{x} 2078$ & 119.97 & 182.50 & 1.52 & 440.50 & 3.67 \\
\hline $\mathrm{x} 2108$ & 106.00 & - & - & 312.00 & 2.94 \\
\hline$x 2128$ & 138.00 & 383.50 & 2.78 & - & - \\
\hline
\end{tabular}




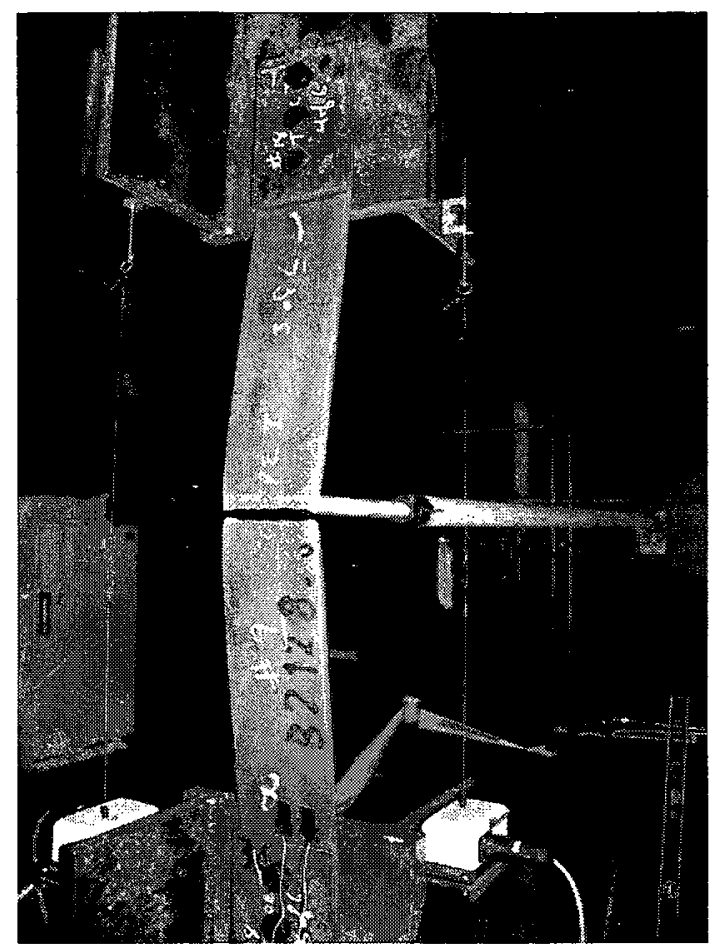

Figure 4.1 Test with a regular rod.

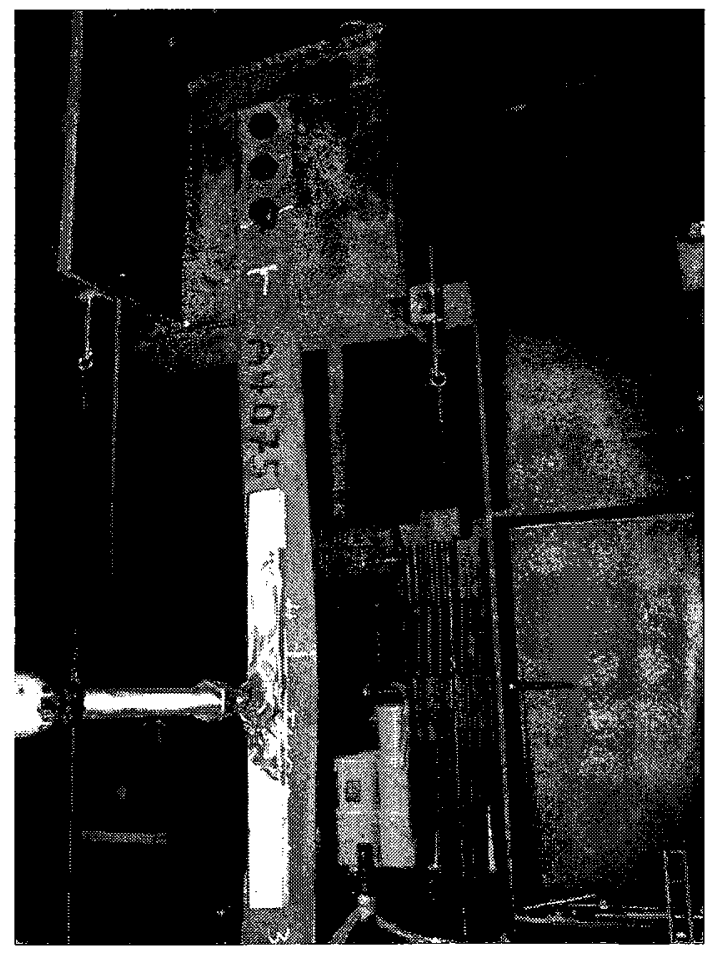

Figure 4.2 Test with a wide rod. 


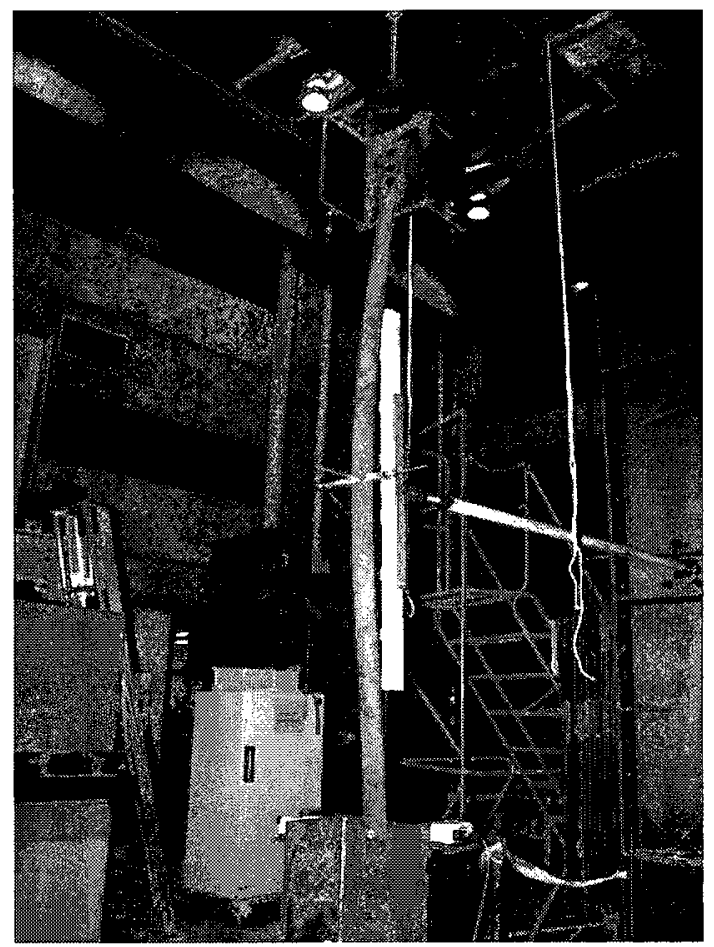

Figure 4.3 Test with a very wide rod. 


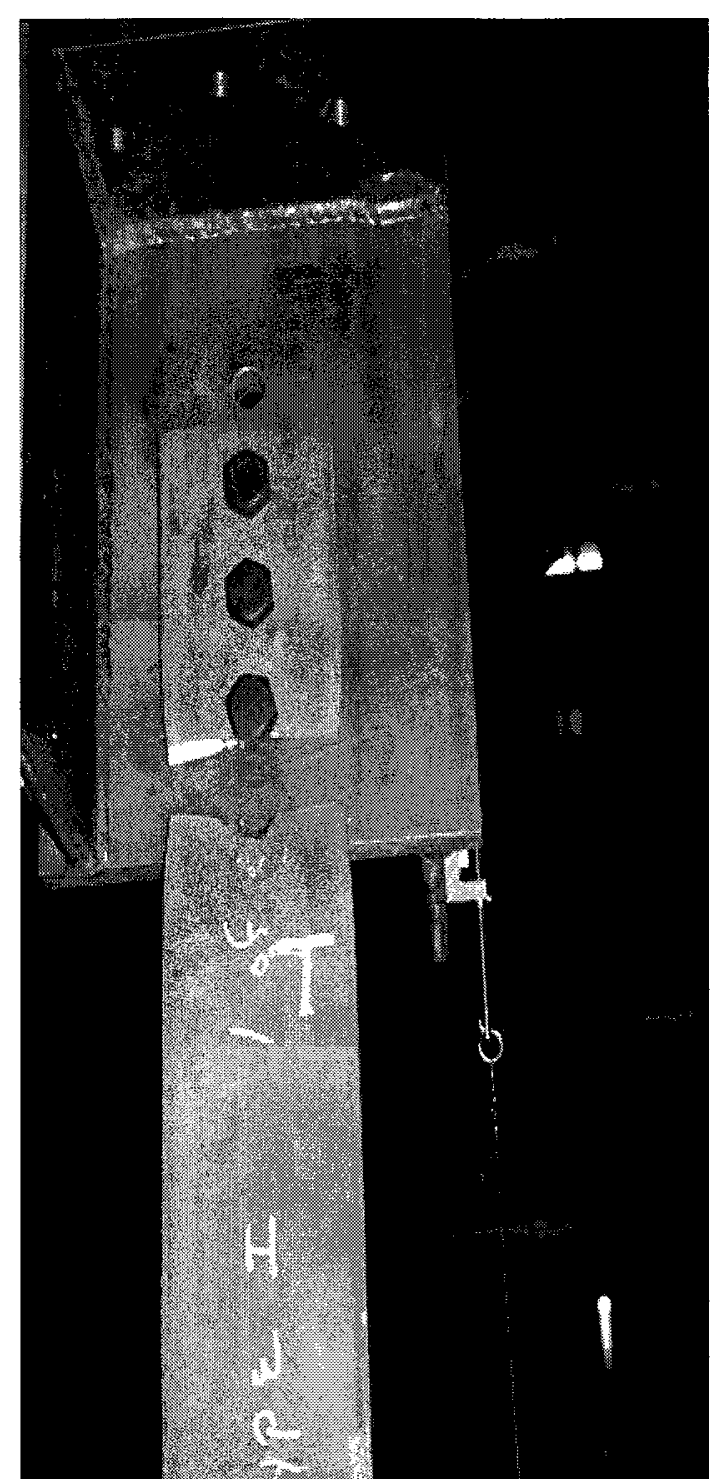

Innermost bolt hole, A2128a.

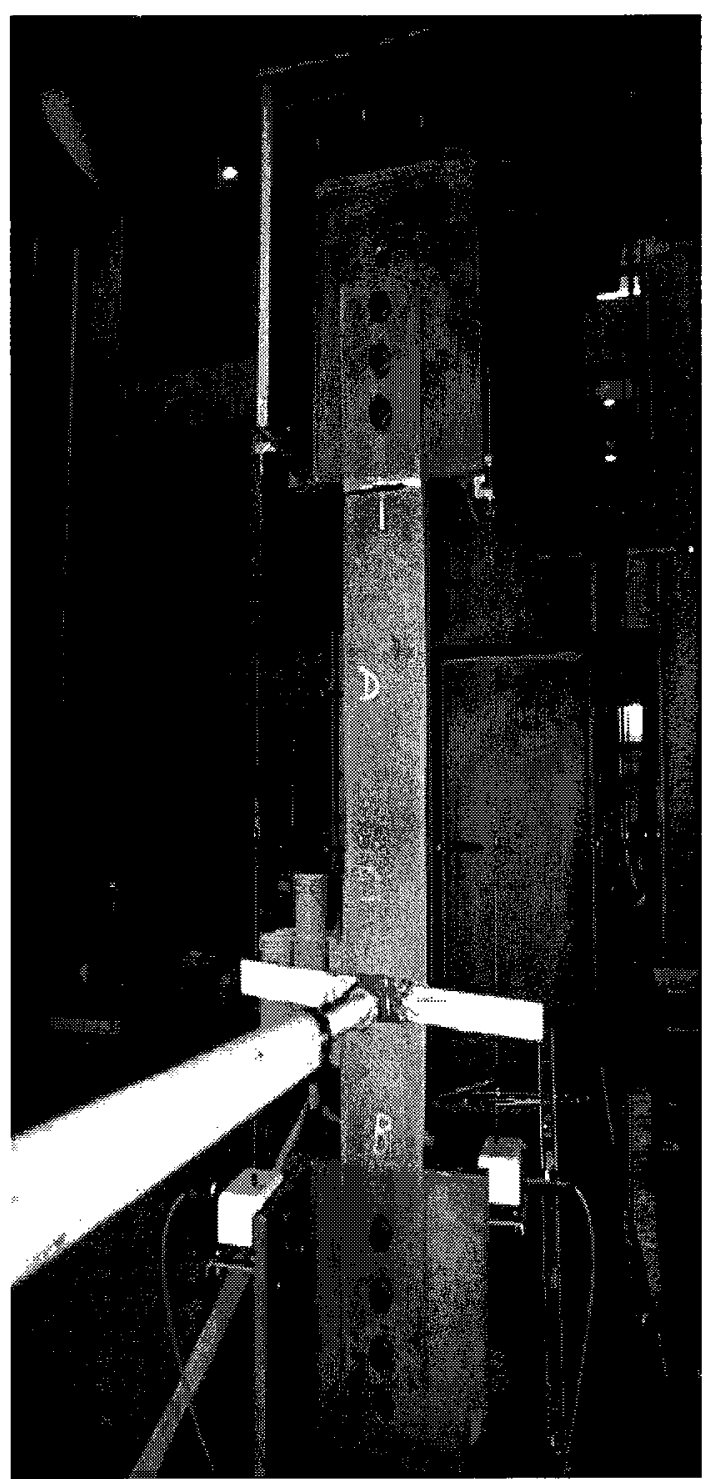

Close to the end of gusset plate, A2128c. Figure 4.4 Fracture for Type A specimens. 


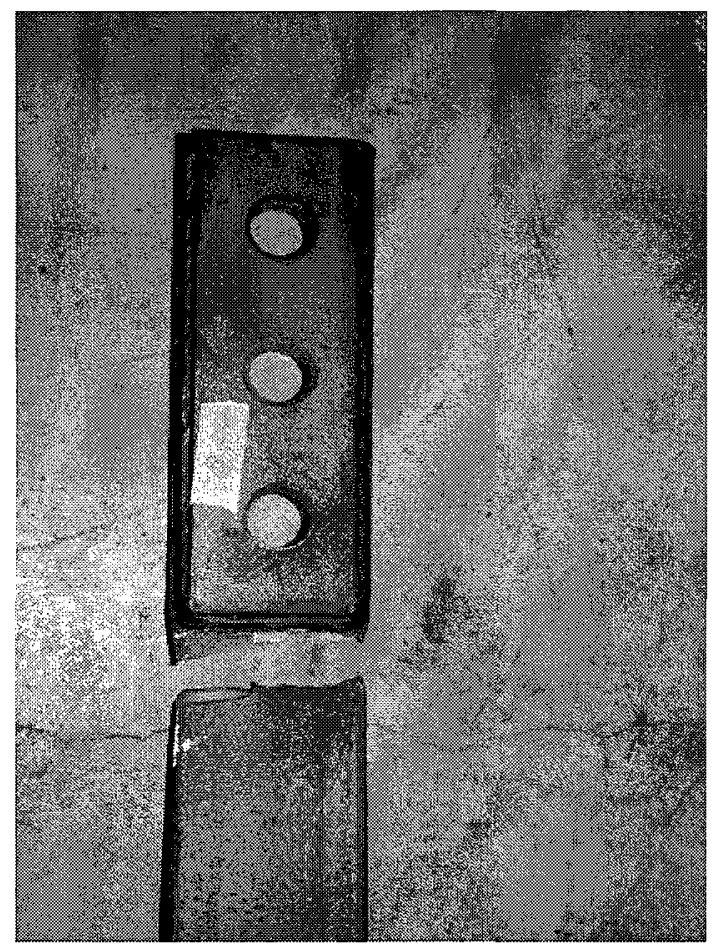

C2078a

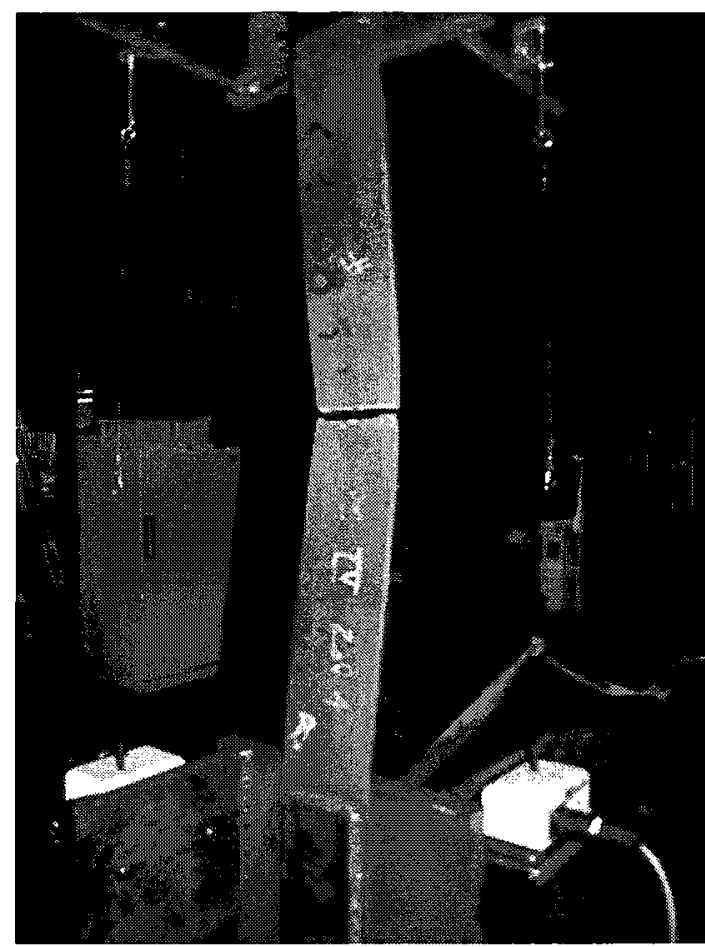

$\mathrm{C} 2108 \mathrm{a}$

Figure 4.5 Fracture of C2078a and C2108a. 


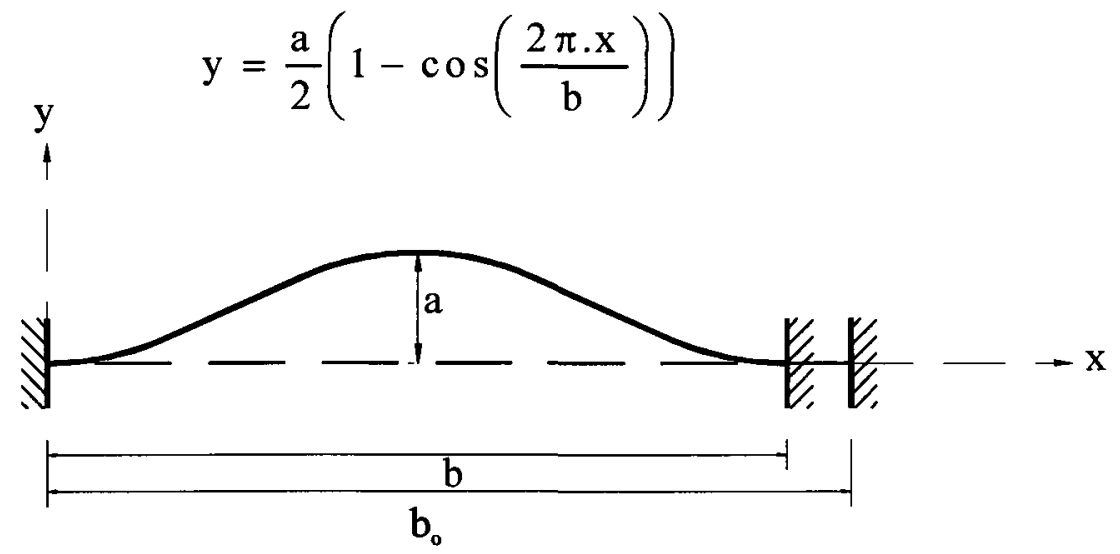

Figure 4.6 Out-of-plane deformation for fixed end elastic buckling.

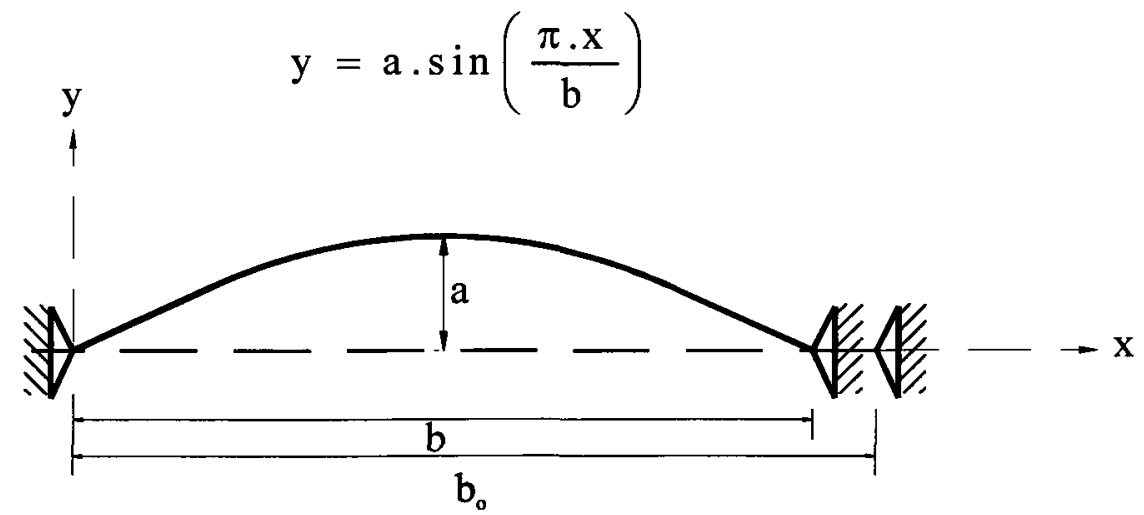

Figure 4.7 Out-of-plane deformation for pinned end elastic buckling. 


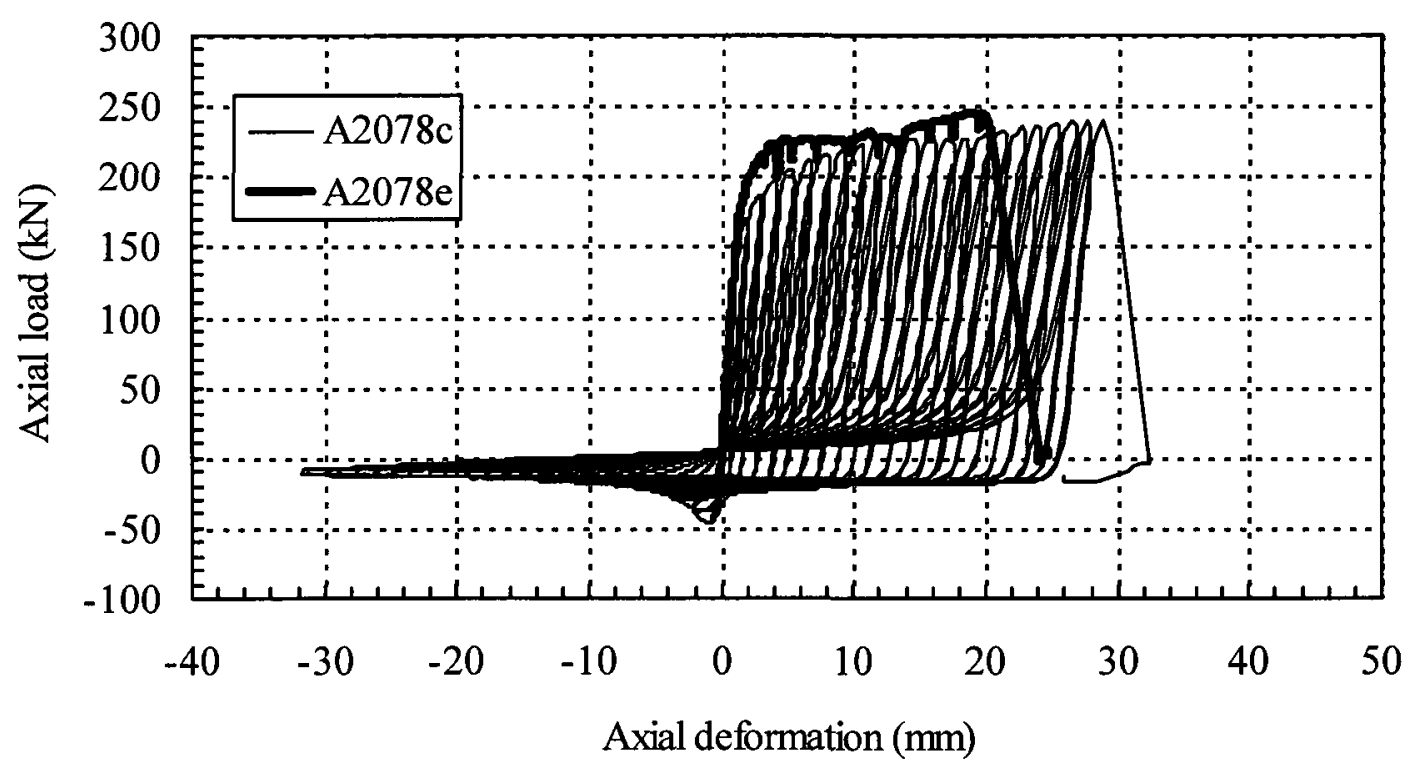

Figure 4.8 Comparison of A2078c (cyclic) and A2078e (monotonic).

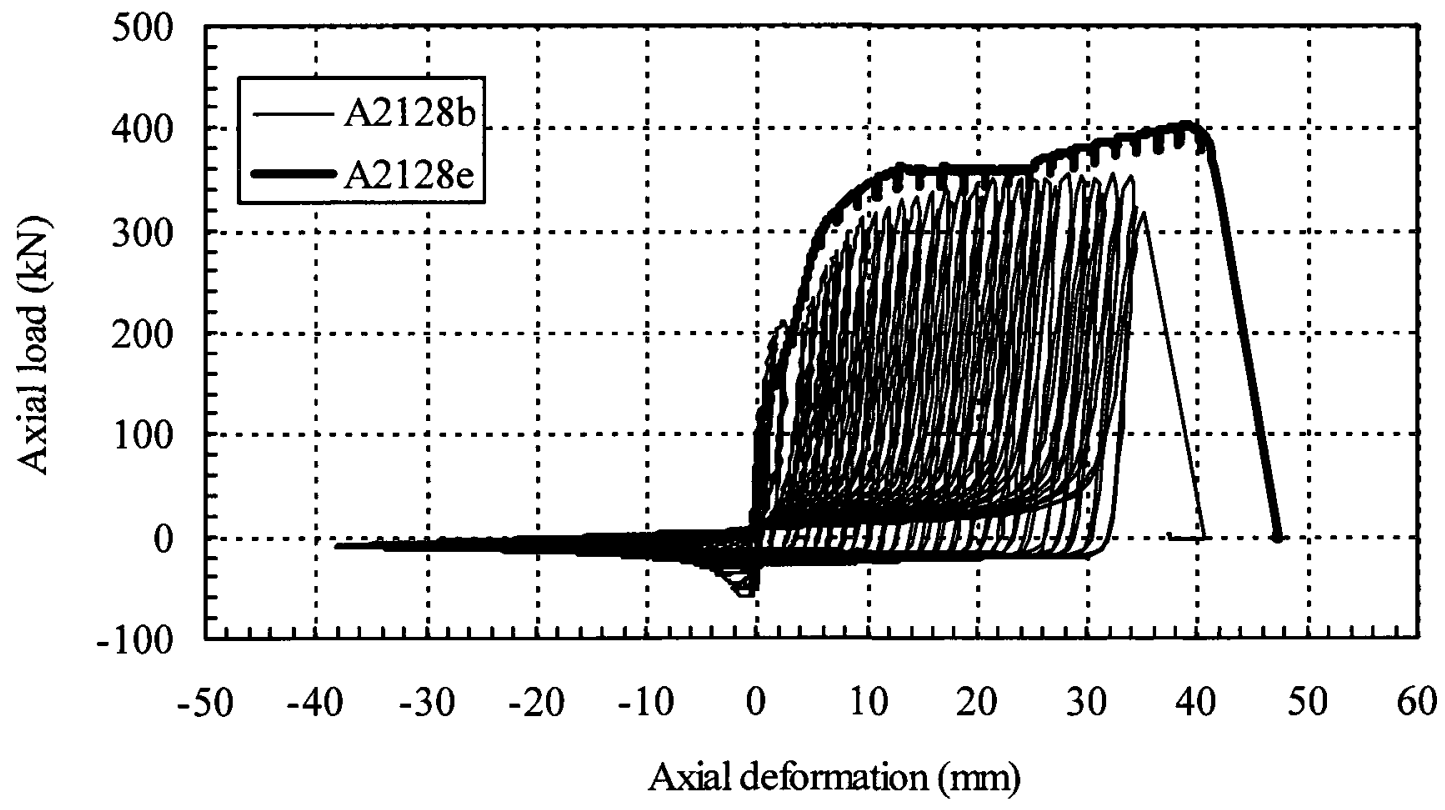

Figure 4.9 Comparison of A2128b (cyclic) and A2128e (monotonic). 


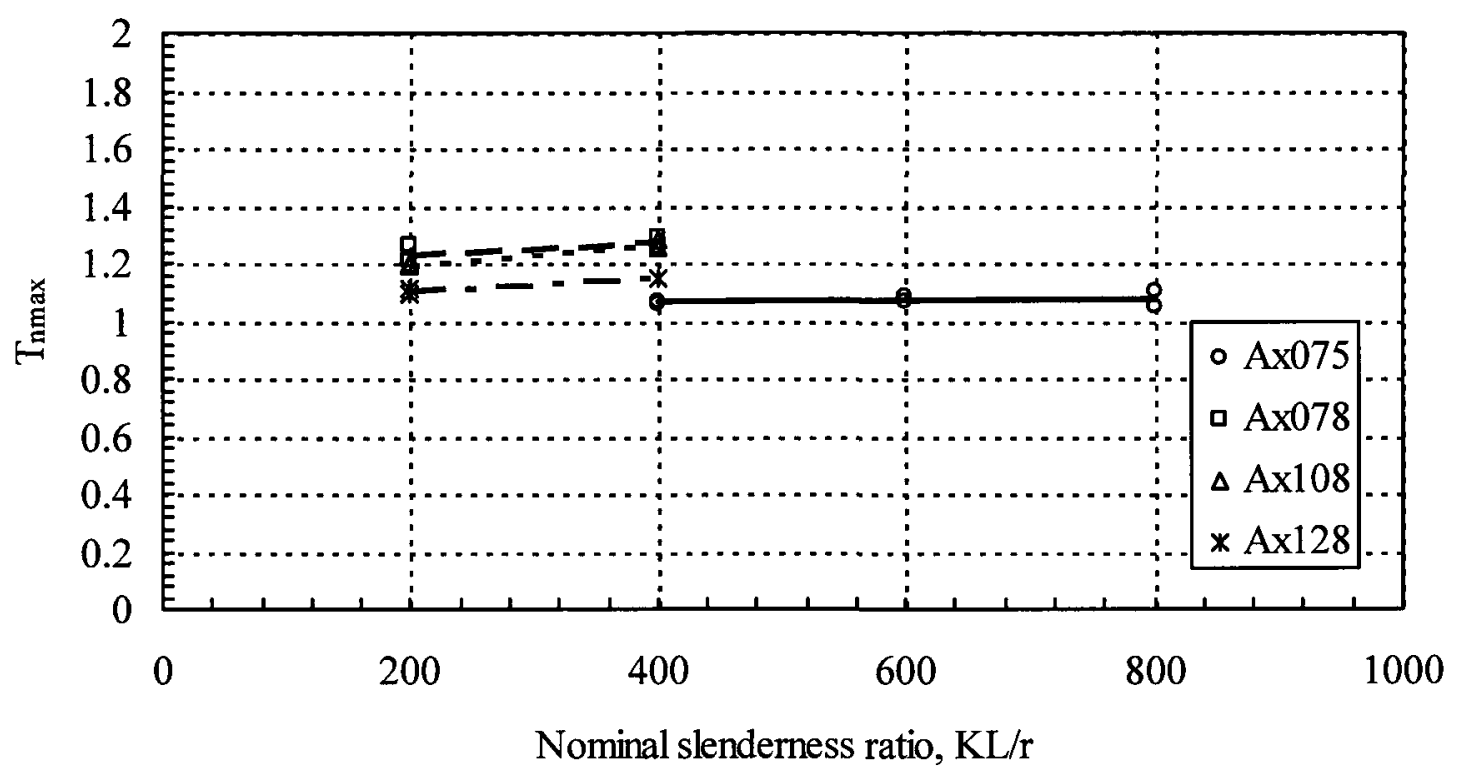

Figure 4.10 Normalized maximum tension load versus slenderness ratio for Type A specimens.

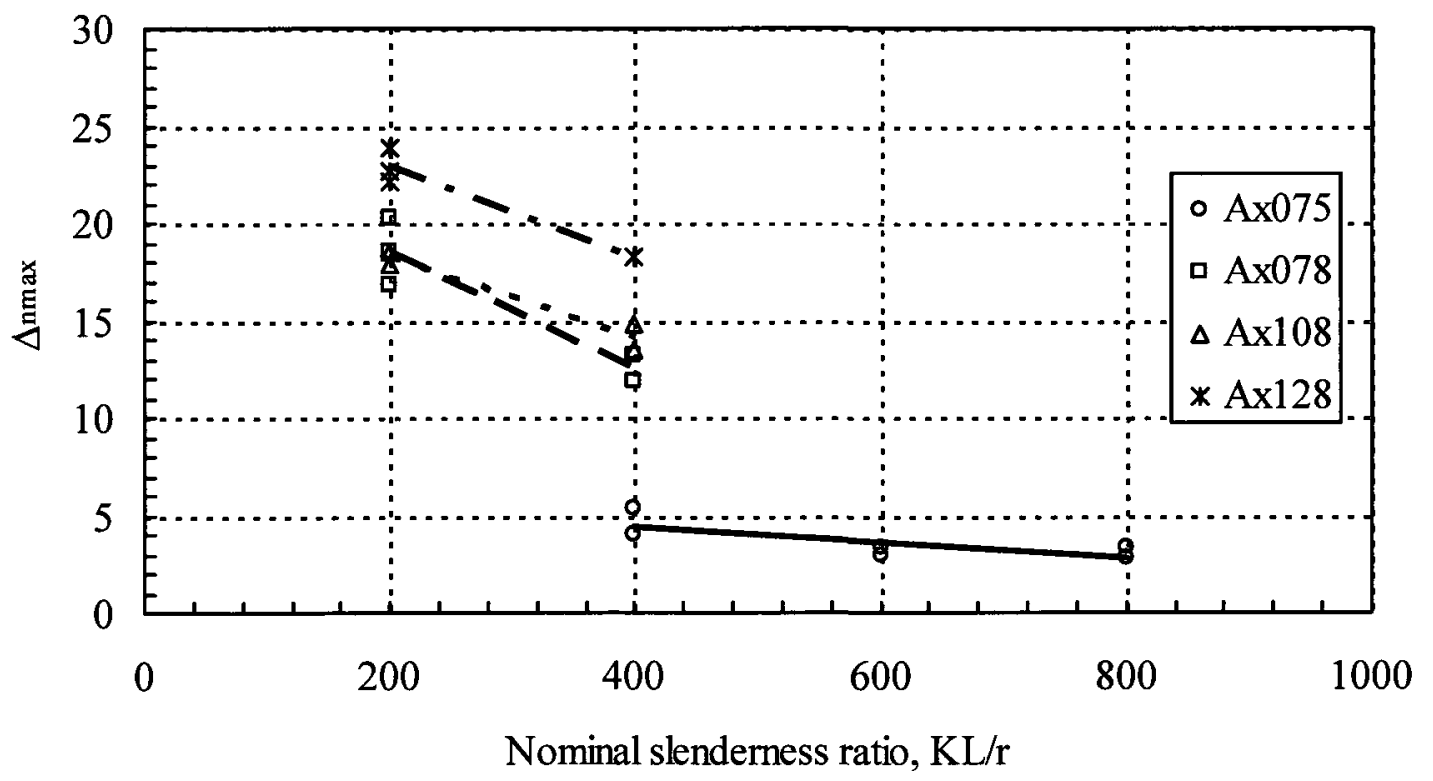

Figure 4.11 Normalized maximum extension versus slenderness ratio for Type A specimens. 


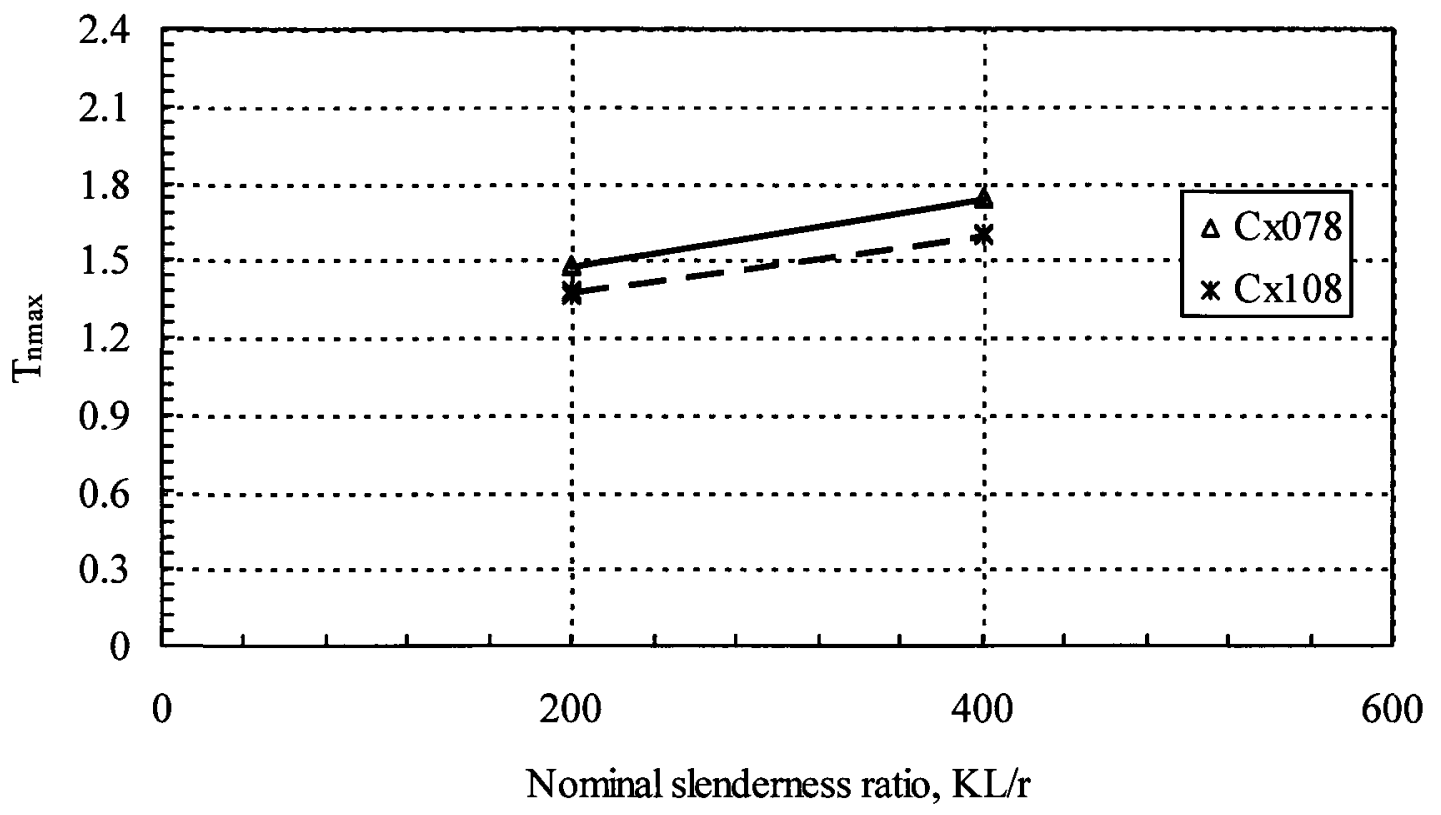

Figure 4.12 Normalized maximum tension load versus slenderness ratio for Type C specimens.

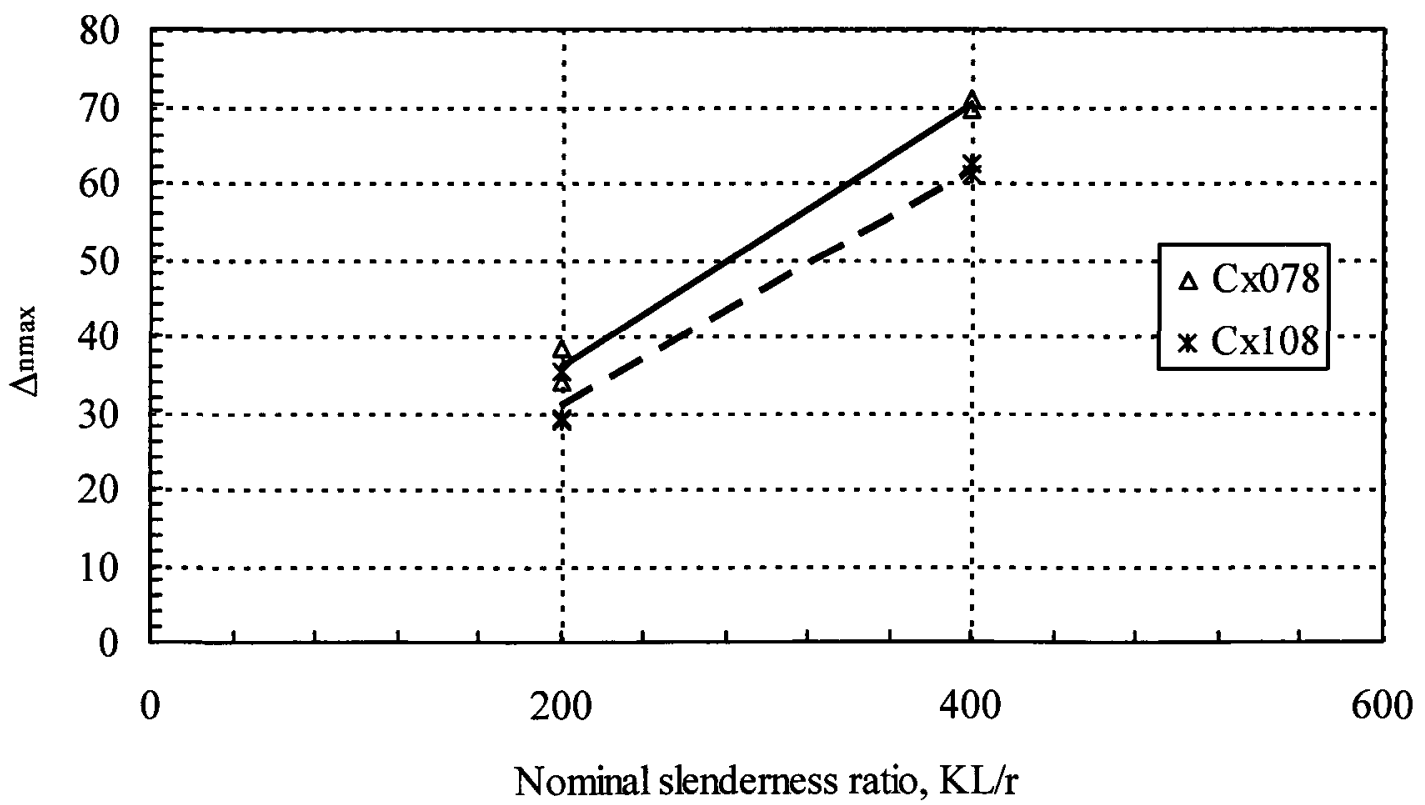

Figure 4.13 Normalized maximum extension versus slenderness ratio for Type C specimens. 


\section{CHAPTER 5 SUMMARY, CONCLUSIONS, AND RECOMMENDATIONS}

\section{$5.1 \quad$ Summary}

A brief review on bracing research and seismic design requirements was presented in Chapter 2. Some previous experimental and numerical studies were discussed. In these studies, slenderness ratio has been found to be one of the main factors that greatly affect the hysteretic behaviour of the bracing member. Most cyclic tests carried out have focused mainly on structural shapes with the slenderness ratio less than 200 . Tests on specimens with the slenderness ratio greater than 200 have mostly been limited to tie-rods and thin cold-formed steel straps. Thus, this experimental study was carried out to study the performance of slender flat bar braces at the slenderness ratio between 200 and 800 .

Forty nine hot-rolled flat bar specimens were tested in this experimental study. All specimens were tested under cyclic loading except for four, which were tested under monotonic tension loading. Four cross-section sizes of flat bar were used. Three connection types, four slenderness and three net to gross section area ratios were considered for the tests. Tension coupon tests have been carried out to obtain material properties of the flat bars. Yield and ultimate strengths at static and three strain rates were obtained.

Test results were analyzed and discussed. Effects of connection detail, slenderness 
ratio, net to gross section area ratio, net section fracture to the gross section yielding strength ratio, dissipated energy, load-deformation relationship, location of fracture, and ductility were discussed. Comparisons of results from monotonic and cyclic tests were made. In order to have a better comparison on test results of specimens with different material and length, the normalized energy, maximum tension force and maximum extension were also calculated. Equations were developed to predict the out-of-plane deflection and validated with the measured test data. Based on the test results, some preliminarily recommendations and guidelines were proposed on using a strap tension-only bracing system in a seismic design with flat bars.

\subsection{Conclusions}

A number of conclusions can be drawn from the results of the experiment.

1) In the test, every specimen achieved a higher tension load with increasing range of deformation until the last leg of the loading cycle before fracture occurred. This means that the largest extension attained in the test can be considered as the useful ductility of the brace.

2) All except one specimens with no reinforcement fractured at the innermost bolt hole. By clamping a reinforcement plate at the connection, the ductility of the brace improved over the one without any reinforcement by shifting the location of the largest bending strain away from the innermost bolt hole to the end of the 
reinforcement plate. A larger ductility improvement proportionally was observed for the specimen without any reinforcement that has a low ductility.

3) The net section fracture to gross section yielding strength $\left(\mathrm{A}_{\mathrm{n}} \mathrm{F}_{\mathrm{u}} / \mathrm{A}_{\mathrm{g}} \mathrm{F}_{\mathrm{y}}\right)$ ratio is a good indicator of the ductility of the brace with no reinforcement, but not a definitive one. The net to gross section area ratio and the shape of the material stress-strain curve may also have some influence on the ductility. In general, the higher the $\left(\mathrm{A}_{\mathrm{n}} \mathrm{F}_{\mathrm{u}} / \mathrm{Ag}_{\mathrm{g}} \mathrm{F}_{\mathrm{y}}\right)$ ratio is above 1 , the greater will the ductility be.

4) All specimens welded with the reinforcement plate achieved a very high ductility. Braces with the welded reinforcement plate and slenderness ratio $\mathrm{KL} / \mathrm{r} \geq 200$ can meet the ductility demand required for NBCC 2005 draft limit.

5) Equations have been developed to predict the out-of-plane deflection of the brace. In most cases, the predicted deflection is within $10 \%$ of the measured deflection. The accuracy of the prediction generally improves at a larger plastic deformation.

6) When changing the slenderness ratio by changing the length, the ductility of the brace with welded reinforcement plate increases with the slenderness ratio while the reverse holds for the brace without reinforcement. Both the length and slenderness ratio are important factors on the ductility of the brace with no reinforcement.

7) A brace with no reinforcement can meet the ductility demand, if a certain $A_{n} F_{u} / A_{g} F_{y}$ ratio is maintained. In the test, specimens sized with the expected $\mathrm{A}_{\mathrm{n}} \mathrm{F}_{\mathrm{u}} / \mathrm{A}_{\mathrm{g}} \mathrm{F}_{\mathrm{y}}$ ratio greater than 1 or specimens with the actual static $\mathrm{A}_{\mathrm{n}} \mathrm{F}_{\mathrm{u}} / \mathrm{A}_{\mathrm{g}} \mathrm{F}_{\mathrm{y}}$ ratio 
greater than 1.2 managed to achieve the required ductility. However, the performance of these specimens still needs to be investigated for a longer length. There is insufficient test data to make any definitive recommendation in the design of a brace with no reinforcement.

\subsection{Recommendations}

1) The testing program was designed to investigate effects of the net section fracture to gross section yielding strength ratio $\left(\mathrm{A}_{n} \mathrm{~F}_{\mathrm{u}} / \mathrm{A}_{\mathrm{g}} \mathrm{F}_{\mathrm{y}}\right)$ through changing the net to gross section area ratio. Due to the difference in the material properties, the $\mathrm{A}_{\mathrm{n}} \mathrm{F}_{\mathrm{u}} / \mathrm{A}_{\mathrm{g}} \mathrm{F}_{\mathrm{y}}$ ratio turned out to be almost the same for three of the flat bar cross-section sizes. A proper variation of $A_{n} F_{u} / A_{g} F_{y}$ ratio can be achieved if the straps are cut from a single plate.

2) From the material tests, the ultimate to yield strength ratio was found to decrease with the increase in the strain (loading) rate. Current tests did not consider effects of loading rate on the performance. Tests should be carried out at various constant strain rates to study effects of the loading rate.

3) The ductility of the brace without reinforcement is greatly affected by the $\mathrm{A}_{\mathrm{n}} \mathrm{F}_{\mathrm{u}} / \mathrm{A}_{\mathrm{g}} \mathrm{F}_{\mathrm{y}}$ ratio and to some extend its length. $\mathrm{A}$ finite element analysis parametric study should be carried out to supplement any additional test in establishing the ductility of the brace without reinforcement for various 
combinations of member length, slenderness ratio, $A_{n} / A_{g}$ ratio, and $A_{n} F_{u} / A_{g} F_{y}$ ratio.

4) Current tests considered only fixed end condition. In an actual structure, the end may not be completely fixed. Other end conditions between pinned and fixed should be investigated.

5) Results of current tests are appropriate for a diagonal bracing system. In a structure, a cross bracing system may be employed. The performance of the flat bar brace in a cross bracing configuration should be investigated.

6) The brace was tested individually in this study. Additional experimental and numerical studies should be carried out to investigate the performance of the brace in a frame under cyclic loading including shaketable tests. 


\section{REFERENCES}

1. AISC. 1997. Seismic Provisions for Structural Steel Buildings. American Institute of Steel Construction, (AISC), Chicago, Illinois.

2. AISC. 2005. ANSI /AISC 341-05, Seismic Provisions for Structural Steel Buildings. American Institute of Steel Construction, (AISC), Chicago, Illinois.

3. Al-Kharat, M., and Rogers, C.A. 2007. Inelastic Performance of Cold-Formed Steel Strap Braced Walls. Journal of Construction Steel Research, 63(4): 460-474.

4. Al-Kharat, M., and Rogers, C.A. 2008. Inelastic Performance of Screw Connected Cold-Formed Steel Strap Braced Walls. Canadian Journal of Civil Engineering, 35(1): 11-26.

5. Astaneh-Asl, A., A.M., Goel, S.C. and Hanson, R.D. 1985. Cyclic Out-of-Plane Buckling of Double-Angle Bracing. Journal of the Structural Engineering, ASCE, 111(5): 1135-1153.

6. ATC. 1992. ATC-24, Guidelines for Cyclic Seismic Testing of Components of Steel Structures. Applied Technology Council (ATC), California.

7. CSA. 2005. Limit States Design of Steel Structures, CAN/CSA-S16-01. Including Supplement S16-05. Canadian Standards Association, Toronto, On, Canada.

8. Davaran, A. 2001. Effective Length Factor for Discontinuous X-Bracing Systems. Journal of Engineering Mechanics, 127(2): 106-112. 
9. DeWolf J.T. and Pelliccione, J.F. 1979. Cross-bracing Design. Journal of the Structural Division, ASCE, 105(7): 1379-1391.

10. El-Tayem, A.A. and Geol, S.C. 1986. Effective Length Factor for the Design of X-bracing Systems. Engineering Journal, AISC, 23(1): 41-45.

11. Filiatrault, A. and Tremblay, R. 1996. Behavior of Tension-only Concentrically Braced Steel Frames under Simulated Earthquake Loads. Proceedings of International Conference on Advances in Steel Structures, Vol. II: 1047-1052.

12. Filiatrault, A. and Tremblay, R. 1998. Design of Tension-only Concentrically Braced Steel Frames for Seismic Induced Impact Loading. Engineering Structures, 20(12): 1087-1096.

13. Goggings, J.M., Broderick, B.M., Elghazouli, A.Y. and Lucas, A.S. 2005. Experimental Cyclic Response of Cold-formed Hollow Steel Bracing Members. Engineering Structures, 27(6): 977-989.

14. Higginbotham, A.B. and Hanson, R.D. 1976. Axial Hysteretic Behavior of Steel Members. Journal of the Structural Division, ASCE, 102(7): 1365-1381.

15. Jain, A.K., Geol, S.C. and Hanson, R.D. 1978. Inelastic Response of Restrained Steel Tubes. Journal of the Structural Division, ASCE, 104(6): 897-910.

16. Kahn, L.F. and Hanson, R.D. 1976. Inelastic Cycles of Axially Loaded Steel Members. Journal of the Structural Division, ASCE, 102(5): 947-959. 
17. Kim, T.W., Wilcoski, J., Foutch, D.A. and Lee, M.S. 2006. Shaketable Tests of a Cold-formed Steel Shear Panel. Journal of the Structural Engineering, ASCE, 28(10): 1462-1470.

18. NRCC. 2005. National Building Code of Canada 2005. National Research Council of Canada, Ottawa, Ontario.

19. Picard, A. and Beaulieu, D. 1987. Design of Diagonal Cross Bracings. Part1: Theoretical Study. Engineering Journal, AISC, 24(3): 122-126.

20. Popov, E.P. and Black, R.G.. 1981. Steel Struts Under Severe Cyclic Loadings. Journal of the Structural Division, ASCE, 107(9): 1857-1881.

21. Prathuangsit, D., Geol, S.C. and Hanson, R.D. 1978. Axial Hysteresis Behavior with End Restrains. Journal of the Structural Division, ASCE, 104(6): 883-896.

22. Sabelli, R. and Hohbach, D. 1999. Design of Cross-braced Frames for Predictable Buckling Behavior. Journal of the Structural Engineering, ASCE, 125(2): 163-168.

23. Shaback, B. and Brown, T. 2003. Behavior of Square Hollow Structural Steel Braces with End Connections Under Reversed Cyclic Axial Loading. Canadian Journal of Civil Engineering, 30(4): 745-753.

24. SSPC (2004). Surface Preparation Specifications No. 1, 2, and 3. Steel Structures Painting Council (SSPC), the Society for Protective Coatings, Pittsburgh, PA, U.S.A. 
25. Tremblay, R. 2000. Influence of Brace Slenderness on the Seismic Response of Concentrically Braced Steel Frames. Behavior of Steel Structures in Seismic Areas. Proceedings of the Third STESSA Conference 2000, Montreal: 527-534.

26. Tremblay, R. 2001. Seismic Behavior and Design of Concentrically Braced Steel Frames. Engineering Journal. AISC, 38(3): 148-166.

27. Tremblay, R. 2002. Inelastic Seismic Response of Steel Bracing Members. Journal of Construction Steel Research, 58(5-8): 665-701.

28. Tremblay, R., Archambault, M.H., and Filiatrault, A. 2003. Seismic Response of Concentrically Braced Steel Frames Made with Rectangular Hollow Bracing Members. Journal of the Structural Engineering, ASCE, 129(12): 1626-1636.

29. Tremblay, R., Robert, N., and Filiatrault A. 1997. Tension-only Bracing: A Viable Earthquake Resistant System for Low-rise Steel Buildings. SDSS’97, Proceedings of 5th International Colloquium on Stability and Ductility of Steel Structures, Vol.II: 1163-1170. 


\section{APPENDIX A: MATERIAL PROPERTIES}

Table A.1 Material ductility and elastic modulus.

\begin{tabular}{|c|c|c|c|c|c|c|c|}
\hline \multirow[t]{2}{*}{ Coupon } & \multirow[t]{2}{*}{$\begin{array}{l}\text { Strain rate } \\
\qquad\left(\mathrm{s}^{-1}\right)\end{array}$} & \multicolumn{2}{|c|}{ Elongation (\%) } & \multicolumn{2}{|c|}{$\frac{A_{o}}{A_{f}}$} & \multicolumn{2}{|c|}{$\begin{array}{c}\text { Elastic modulus, } \\
\mathrm{E}(\mathrm{MPa})\end{array}$} \\
\hline & & & Avg. & & Avg. & & Avg. \\
\hline \multicolumn{8}{|c|}{$76 \mathrm{~mm} \times 4.8 \mathrm{~mm}\left(3^{\prime \prime} \times 3 / 16^{\prime \prime}\right)$} \\
\hline A1 & \multirow{2}{*}{0.0001} & 34.4 & \multirow{2}{*}{34.7} & 2.68 & \multirow{2}{*}{2.71} & 208419 & \multirow{6}{*}{210700} \\
\hline $\mathrm{A} 2$ & & 35.0 & & 2.74 & & 205296 & \\
\hline A3 & \multirow{2}{*}{0.01} & 31.3 & \multirow{2}{*}{31.9} & 2.47 & \multirow{2}{*}{2.52} & 216061 & \\
\hline A4 & & 32.5 & & 2.56 & & 215558 & \\
\hline A5 & \multirow{2}{*}{0.5} & 37.0 & \multirow{2}{*}{38.1} & 2.53 & \multirow{2}{*}{2.55} & 210745 & \\
\hline A6 & & 39.2 & & 2.57 & & 208094 & \\
\hline \multicolumn{8}{|c|}{$76 \mathrm{~mm} \times 7.9 \mathrm{~mm} \quad\left(3^{\prime \prime} \times 5 / 16^{\prime \prime}\right)$} \\
\hline B1 & \multirow{2}{*}{0.0001} & 29.5 & \multirow{2}{*}{28.5} & 2.37 & \multirow{2}{*}{2.33} & 195251 & \multirow{6}{*}{205100} \\
\hline B2 & & 27.4 & & 2.28 & & 198837 & \\
\hline B3 & \multirow{2}{*}{0.01} & 28.7 & \multirow{2}{*}{29.2} & 2.45 & \multirow{2}{*}{2.46} & 204741 & \\
\hline B4 & & 29.7 & & 2.46 & & 204491 & \\
\hline B5 & \multirow{2}{*}{0.5} & 27.4 & \multirow{2}{*}{28.1} & 2.43 & \multirow{2}{*}{2.41} & 217878 & \\
\hline B6 & & 28.7 & & 2.38 & & 209507 & \\
\hline \multicolumn{8}{|c|}{$102 \mathrm{~mm} \times 7.9 \mathrm{~mm}\left(4^{\prime \prime} \times 5 / 16^{\prime \prime}\right)$} \\
\hline $\mathrm{C} 1$ & \multirow{2}{*}{0.0001} & 32.5 & \multirow{2}{*}{31.9} & 2.28 & 244 & 200978 & \\
\hline $\mathrm{C} 2$ & & 31.3 & & 2.60 & 2.44 & 197924 & \\
\hline $\mathrm{C} 3$ & 001 & 30.1 & 307 & 2.57 & 254 & 210597 & 304700 \\
\hline $\mathrm{C} 4$ & 0.01 & 31.3 & 30.1 & 2.51 & 2.34 & 209591 & 204200 \\
\hline $\mathrm{C} 5$ & 05 & 30.5 & 207 & 2.44 & 244 & 214087 & \\
\hline C6 & 0.5 & 30.9 & 30.1 & 2.43 & 2.44 & 192092 & \\
\hline $127 \mathrm{~mm} \times 7.9$ & $(5 " \times 5 / 16 "$ & & & & & & \\
\hline D1 & 0 & 34.1 & 2 & 2.66 & 250 & 194090 & \\
\hline D2 & 0.0001 & 32.9 & כ3.5 & 2.52 & 2.59 & 200428 & \\
\hline D3 & 001 & 31.5 & 312 & 2.54 & 250 & 218418 & 208300 \\
\hline D4 & & 30.9 & & 2.46 & & 215221 & \\
\hline D5 & 05 & 33.7 & 341 & 2.55 & 254 & 215030 & \\
\hline D6 & 0.5 & 34.4 & 34.1 & 2.52 & 2.34 & 206519 & \\
\hline
\end{tabular}


Table A.1 Continue.

\begin{tabular}{|c|c|c|c|c|c|c|c|}
\hline \multirow[t]{2}{*}{ Coupon } & \multirow{2}{*}{$\begin{array}{c}\text { Strain } \\
\text { rate } \\
\left(\mathrm{s}^{-1}\right)\end{array}$} & \multicolumn{2}{|c|}{$\begin{array}{c}\text { Elongation } \\
(\%)\end{array}$} & \multicolumn{2}{|c|}{$\frac{A_{o}}{A_{f}}$} & \multicolumn{2}{|c|}{$\begin{array}{c}\text { Elastic modulus, } \\
\mathrm{E}(\mathrm{MPa})\end{array}$} \\
\hline & & & Avg. & & Avg. & & Avg. \\
\hline \multicolumn{8}{|c|}{$64 \mathrm{~mm} \times 4.8 \mathrm{~mm}(2-1 / 2$ " x 3/16") } \\
\hline E1 & \multirow{2}{*}{0.0001} & 29.1 & \multirow{2}{*}{28.6} & 2.25 & \multirow{2}{*}{2.23} & 217161 & \multirow{6}{*}{212700} \\
\hline E2 & & 28.1 & & 2.21 & & 227968 & \\
\hline E3 & \multirow{2}{*}{0.01} & 30.9 & \multirow{2}{*}{30.9} & 2.43 & \multirow{2}{*}{2.43} & 206694 & \\
\hline E4 & & 30.9 & & 2.43 & & 203004 & \\
\hline E5 & \multirow{2}{*}{0.5} & 32.9 & \multirow{2}{*}{32.3} & 2.42 & \multirow{2}{*}{2.41} & 212600 & \\
\hline E6 & & 31.7 & & 2.40 & & 208579 & \\
\hline \multicolumn{8}{|c|}{$64 \mathrm{~mm} \times 7.9 \mathrm{~mm}(2-1 / 2$ " x 5/16") } \\
\hline F1 & \multirow{2}{*}{0.0001} & 33.7 & \multirow{2}{*}{33.5} & 2.37 & \multirow{2}{*}{2.36} & 212320 & \multirow{6}{*}{213400} \\
\hline $\mathrm{F} 2$ & & 33.3 & & 2.35 & & 212786 & \\
\hline F3 & \multirow{2}{*}{0.01} & 33.5 & \multirow{2}{*}{33.0} & 2.42 & \multirow{2}{*}{2.38} & 216834 & \\
\hline F4 & & 32.5 & & 2.34 & & 215605 & \\
\hline F5 & \multirow{2}{*}{0.5} & 35.4 & \multirow{2}{*}{34.5} & 2.34 & \multirow{2}{*}{2.35} & 212677 & \\
\hline F6 & & 33.5 & & 2.36 & & 210189 & \\
\hline
\end{tabular}


Table A.2 Material yield and ultimate strengths at various loading rates.

\begin{tabular}{|c|c|c|c|c|c|c|c|}
\hline \multirow[t]{2}{*}{ Coupon } & \multirow{2}{*}{$\begin{array}{l}\text { Strain } \\
\text { rate } \\
\left(\mathrm{s}^{-1}\right) \\
\end{array}$} & \multicolumn{2}{|c|}{$\begin{array}{l}\text { Yield strength, } \\
\mathrm{F}_{\mathrm{y}}(\mathrm{MPa})\end{array}$} & \multicolumn{2}{|c|}{$\begin{array}{c}\text { Ultimate strength, } \\
\mathrm{F}_{\mathrm{u}}(\mathrm{MPa})\end{array}$} & \multirow{2}{*}{\begin{tabular}{|l}
$\frac{F_{u}}{F_{y}}$ \\
Avg.
\end{tabular}} & \multirow{2}{*}{$\begin{array}{c}\frac{F_{Y}}{F_{y} \text { (static) }} \\
\text { Avg. }\end{array}$} \\
\hline & & & Avg. & & Avg. & & \\
\hline \multicolumn{8}{|c|}{$76 \mathrm{~mm} \times 4.8 \mathrm{~mm}\left(3^{\prime \prime} \times 3 / 16^{\prime \prime}\right)$} \\
\hline $\mathrm{A} 1$ & \multirow{2}{*}{$\begin{array}{c}\text { Static } \\
(0.0001)\end{array}$} & 308.4 & \multirow{2}{*}{308.0} & 437.9 & \multirow{2}{*}{440.9} & \multirow{2}{*}{1.43} & \multirow{2}{*}{1} \\
\hline $\mathrm{A} 2$ & & 307.6 & & 443.8 & & & \\
\hline $\mathrm{A} 1$ & \multirow{2}{*}{0.0001} & 326.5 & \multirow{2}{*}{326.1} & 464.4 & \multirow{2}{*}{466.6} & \multirow{2}{*}{1.43} & \multirow{2}{*}{1.06} \\
\hline $\mathrm{A} 2$ & & 325.6 & & 468.7 & & & \\
\hline $\mathrm{A} 3$ & \multirow{2}{*}{0.01} & 359.9 & \multirow{2}{*}{356.8} & 473.1 & \multirow{2}{*}{472.3} & \multirow{2}{*}{1.32} & \multirow{2}{*}{1.16} \\
\hline A4 & & 353.6 & & 471.5 & & & \\
\hline A5 & \multirow{2}{*}{0.5} & 385.7 & \multirow{2}{*}{387.2} & 486.8 & \multirow{2}{*}{489.1} & \multirow{2}{*}{1.26} & \multirow{2}{*}{1.26} \\
\hline A6 & & 388.7 & & 491.3 & & & \\
\hline \multicolumn{8}{|c|}{$76 \mathrm{~mm} \times 7.9 \mathrm{~mm} \quad(3 "$ × 5/16") } \\
\hline B1 & \multirow{2}{*}{$\begin{array}{c}\text { Static } \\
(0.0001)\end{array}$} & 316.8 & \multirow{2}{*}{318.2} & 551.8 & \multirow{2}{*}{553.8} & 174 & 1 \\
\hline B2 & & 319.6 & & 555.7 & & 1.14 & 1 \\
\hline B1 & 00001 & 342.5 & 3426 & 576.0 & 5776 & 169 & 108 \\
\hline B2 & 0.0001 & 342.7 & 342.0 & 579.1 & 年, & 1.09 & 1.08 \\
\hline B3 & 001 & 372.8 & 3603 & 590.7 & 5807 & 160 & 116 \\
\hline B4 & 0.01 & 365.7 & 369.3 & 588.7 & 589.1 & 1.60 & 1.10 \\
\hline B5 & 05 & 401.2 & 3043 & 619.6 & 6107 & 157 & 124 \\
\hline B6 & 0.0 & 387.3 & $394 . J$ & 619.7 & 019.1 & 1.51 & 1.24 \\
\hline $102 \mathrm{~mm} \mathrm{x} 7$. & $(4 " \times 5 /$ & & & & & & \\
\hline $\mathrm{C} 1$ & Static & 353.1 & 3481 & 567.8 & 5621 & 161 & 1 \\
\hline $\mathrm{C} 2$ & $(0.0001)$ & 343.1 & 348.1 & 556.3 & 502.1 & 1.01 & 1 \\
\hline $\mathrm{C} 1$ & 00001 & 379.8 & 3751 & 590.3 & 5863 & 156 & 108 \\
\hline $\mathrm{C} 2$ & 0.0001 & 370.4 & $3 / 2.1$ & 582.3 & 580.3 & 1.00 & 1.08 \\
\hline $\mathrm{C} 3$ & 0.01 & 396.5 & 394.8 & 596.3 & 596.9 & 1.51 & 1.13 \\
\hline $\mathrm{C} 4$ & & 393.0 & & 597.4 & & & \\
\hline $\mathrm{C} 5$ & 0 & 431.1 & 1 & 629.0 & & 110 & 1 \\
\hline C6 & $0 . J$ & 414.0 & 422.0 & 626.9 & 020.0 & 1.49 & 1.21 \\
\hline
\end{tabular}


Table A.2 Continue.

\begin{tabular}{|c|c|c|c|c|c|c|c|}
\hline \multirow[t]{2}{*}{ Coupon } & \multirow{2}{*}{$\begin{array}{l}\text { Strain } \\
\text { rate } \\
\left(\mathrm{s}^{-1}\right)\end{array}$} & \multicolumn{2}{|c|}{$\begin{array}{l}\text { Yield strength, } \\
\mathrm{F}_{\mathrm{y}}(\mathrm{MPa})\end{array}$} & \multicolumn{2}{|c|}{$\begin{array}{l}\text { Ultimate strength, } \\
\mathrm{F}_{\mathrm{u}}(\mathrm{MPa})\end{array}$} & \multirow{2}{*}{$\frac{\frac{F_{u}}{F_{y}}}{\text { Avg. }}$} & \multirow{2}{*}{$\frac{\frac{F_{y}}{F_{y}(\text { static })}}{\text { Avg. }}$} \\
\hline & & & Avg. & & Avg. & & \\
\hline \multicolumn{8}{|c|}{$127 \mathrm{~mm} \times 7.9 \mathrm{~mm} \quad\left(5^{\prime \prime} \times 5 / 16^{\prime \prime}\right)$} \\
\hline D1 & \multirow{2}{*}{$\begin{array}{c}\text { Static } \\
(0.0001)\end{array}$} & 329.6 & \multirow{2}{*}{328.5} & 493.0 & \multirow{2}{*}{494.2} & \multirow{2}{*}{1.50} & \multirow{2}{*}{1} \\
\hline D2 & & 327.4 & & 495.4 & & & \\
\hline D1 & \multirow{2}{*}{0.0001} & 346.3 & \multirow{2}{*}{345.9} & 518.1 & \multirow{2}{*}{518.4} & \multirow{2}{*}{1.50} & \multirow{2}{*}{1.05} \\
\hline $\mathrm{D} 2$ & & 345.4 & & 518.6 & & & \\
\hline D3 & \multirow{2}{*}{0.01} & 358.7 & \multirow{2}{*}{361.7} & 522.7 & \multirow{2}{*}{524.2} & \multirow{2}{*}{1.45} & \multirow{2}{*}{1.10} \\
\hline D4 & & 364.7 & & 525.7 & & & \\
\hline D5 & \multirow{2}{*}{0.5} & 411.3 & \multirow{2}{*}{408.7} & 553.5 & \multirow{2}{*}{552.8} & \multirow{2}{*}{1.35} & \multirow{2}{*}{1.24} \\
\hline D6 & & 406.1 & & 552 & & & \\
\hline \multicolumn{8}{|c|}{$64 \mathrm{~mm}$ x $4.8 \mathrm{~mm}\left(2-1 / 2 " \mathrm{c}\right.$ × $\left.3 / 16^{\prime \prime}\right)$} \\
\hline E1 & \multirow{2}{*}{$\begin{array}{c}\text { Static } \\
(0.0001)\end{array}$} & 339.4 & \multirow{2}{*}{337.6} & 492.4 & \multirow{2}{*}{490.7} & & \\
\hline E2 & & 335.7 & & 488.9 & & 1.45 & 1 \\
\hline E1 & & 351.3 & & 514.4 & & & \\
\hline E2 & 0.0001 & 351.7 & 351.5 & 517.1 & 515.8 & 1.47 & 1.04 \\
\hline E3 & & 371.7 & & 521.3 & & & \\
\hline $\mathrm{E} 4$ & 0.01 & 375.2 & 373.5 & 521.8 & 521.6 & 1.40 & 1.11 \\
\hline E5 & & 417.8 & & 546.9 & & & \\
\hline E6 & 0.5 & 418.5 & 418.2 & 548.9 & 547.9 & 1.31 & 1.24 \\
\hline $64 \mathrm{~mm} \times 7.9 \mathrm{r}$ & $(2-1 / 2 " x$ & $\left.16^{\prime \prime}\right)$ & & & & & \\
\hline F1 & Static & 323.6 & & 496.1 & & & \\
\hline $\mathrm{F} 2$ & $(0.0001)$ & 326.8 & 325.2 & 498.6 & 497.4 & 1.53 & 1 \\
\hline $\mathrm{F} 1$ & & 337.6 & & 517.0 & & & \\
\hline F2 & 0.0001 & 342.2 & 339.9 & 520.2 & 518.6 & 1.53 & 1.05 \\
\hline F3 & 001 & 364.6 & 3622 & 527.2 & 5 & 115 & 112 \\
\hline F4 & 0.01 & 361.7 & 363.2 & 528.3 & 52 & 1.43 & 1.12 \\
\hline F5 & 05 & 407.4 & 1073 & 554.2 & 5553 & 136 & 125 \\
\hline F6 & 0.5 & 407.2 & $40 / .3$ & 556.4 & 530.5 & 1.36 & 1.25 \\
\hline
\end{tabular}


Table A.3 Average specimen strength for various loading rates.

\begin{tabular}{|c|c|c|c|c|}
\hline Strap & $\begin{array}{c}\text { Strain } \\
\text { rate } \\
\left(\mathrm{s}^{-1}\right)\end{array}$ & $\begin{array}{c}\text { Average } \\
A_{g} F_{y}(k N)\end{array}$ & $\begin{array}{c}\text { Average } \\
\mathrm{A}_{\mathrm{g}} \mathrm{F}_{\mathrm{u}}(\mathrm{kN})\end{array}$ & $\begin{array}{l}\text { Average } \\
A_{n} F_{u}(k N)\end{array}$ \\
\hline \multirow{4}{*}{$76 \mathrm{~mm} \times 4.8 \mathrm{~mm}$} & $\begin{array}{c}\text { Static } \\
(0.0001)\end{array}$ & 109 & 156 & 110 \\
\hline & 0.0001 & 115 & 165 & 117 \\
\hline & 0.01 & 126 & 167 & 118 \\
\hline & 0.5 & 137 & 173 & 122 \\
\hline \multirow{4}{*}{$76 \mathrm{~mm} \times 7.9 \mathrm{~mm}$} & $\begin{array}{c}\text { Static } \\
(0.0001)\end{array}$ & 192 & 333 & 235 \\
\hline & 0.0001 & 206 & 348 & 245 \\
\hline & 0.01 & 222 & 355 & 251 \\
\hline & 0.5 & 237 & 373 & 263 \\
\hline \multirow{4}{*}{$102 \mathrm{~mm} \times 7.9 \mathrm{~mm}$} & $\begin{array}{c}\text { Static } \\
(0.0001)\end{array}$ & 279 & 451 & 353 \\
\hline & 0.0001 & 301 & 470 & 368 \\
\hline & 0.01 & 317 & 479 & 375 \\
\hline & 0.5 & 339 & 504 & 394 \\
\hline \multirow{4}{*}{$127 \mathrm{~mm} \times 7.9 \mathrm{~mm}$} & $\begin{array}{c}\text { Static } \\
(0.0001)\end{array}$ & 323 & 486 & 401 \\
\hline & 0.0001 & 340 & 510 & 420 \\
\hline & 0.01 & 356 & 515 & 425 \\
\hline & 0.5 & 402 & 543 & 448 \\
\hline
\end{tabular}




\section{APPENDIX B: LOAD VERSUS DEFORMATION CURVES}

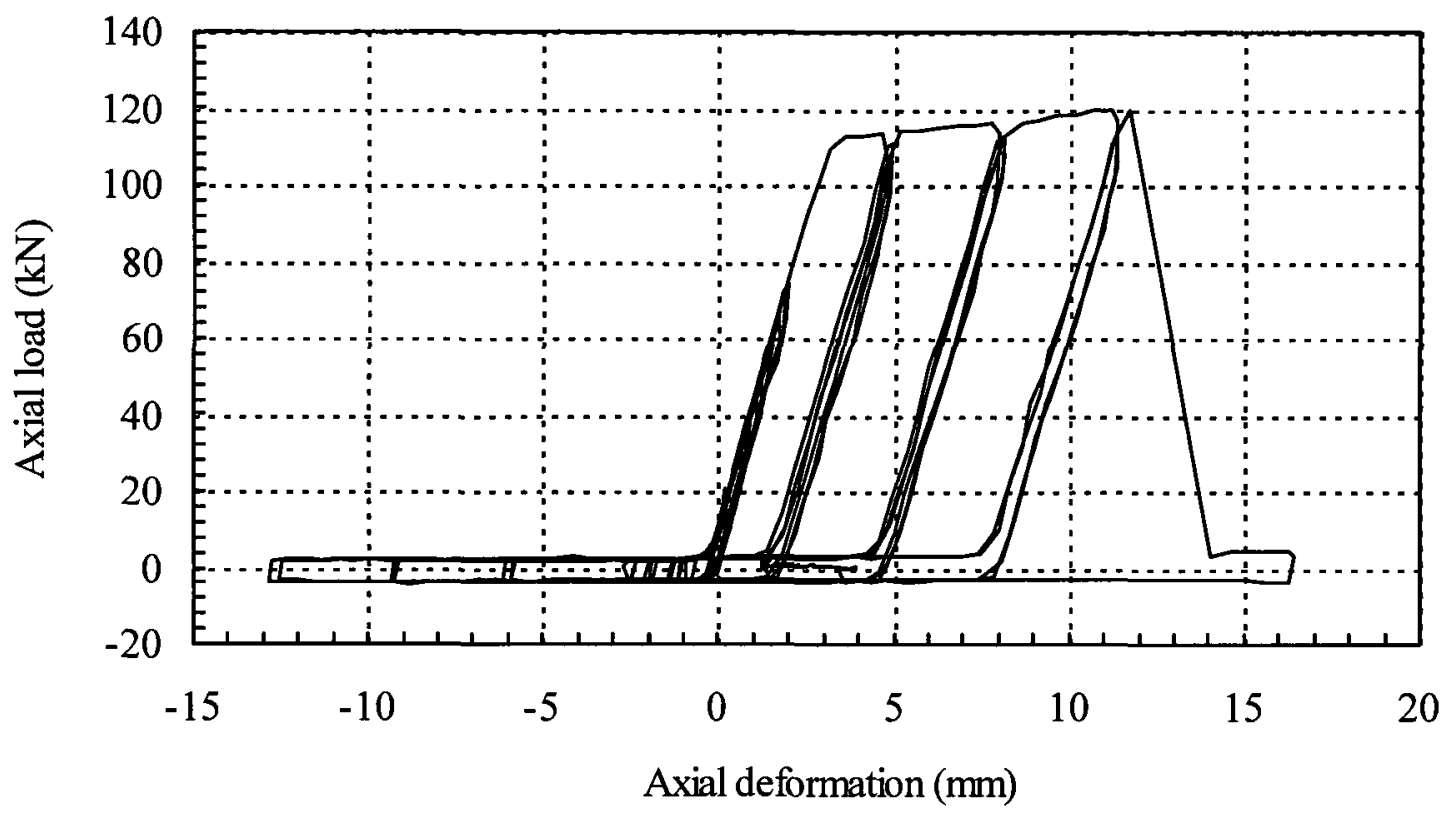

Figure B.1 Axial load versus axial deformation for A8075a specimen.

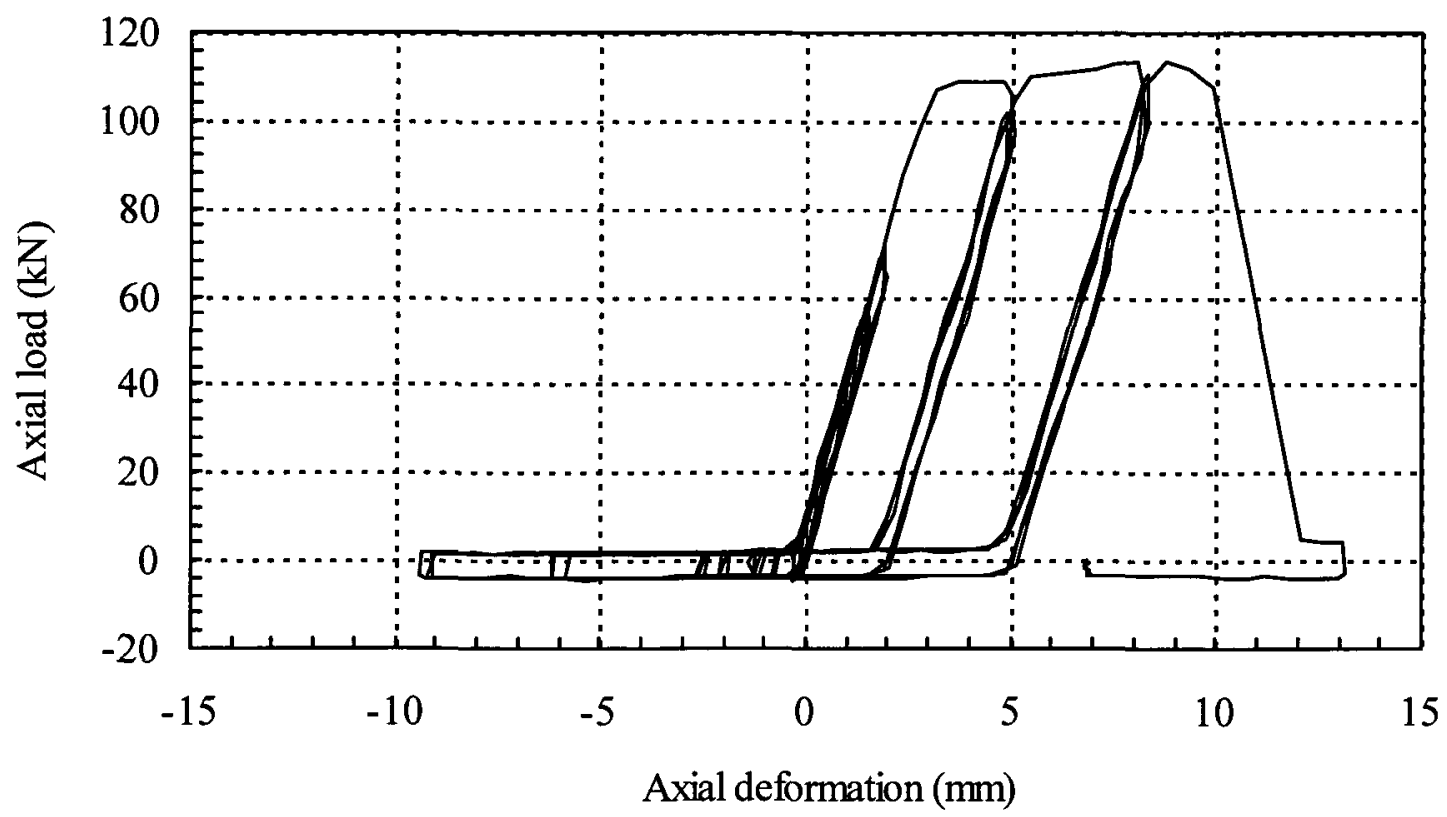

Figure B.2 Axial load versus axial deformation for A8075b specimen. 


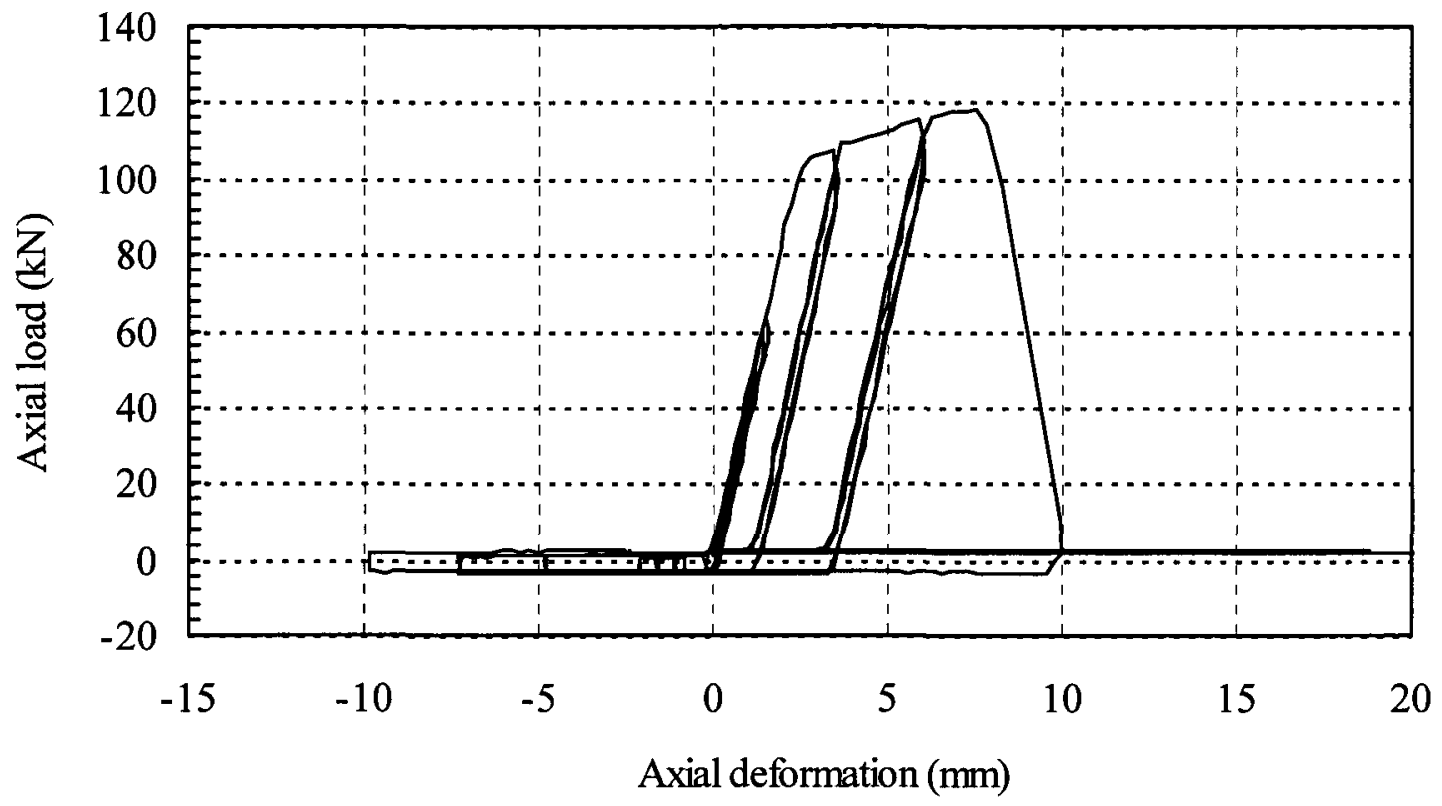

Figure B.3 Axial load versus axial deformation for A6075a specimen.

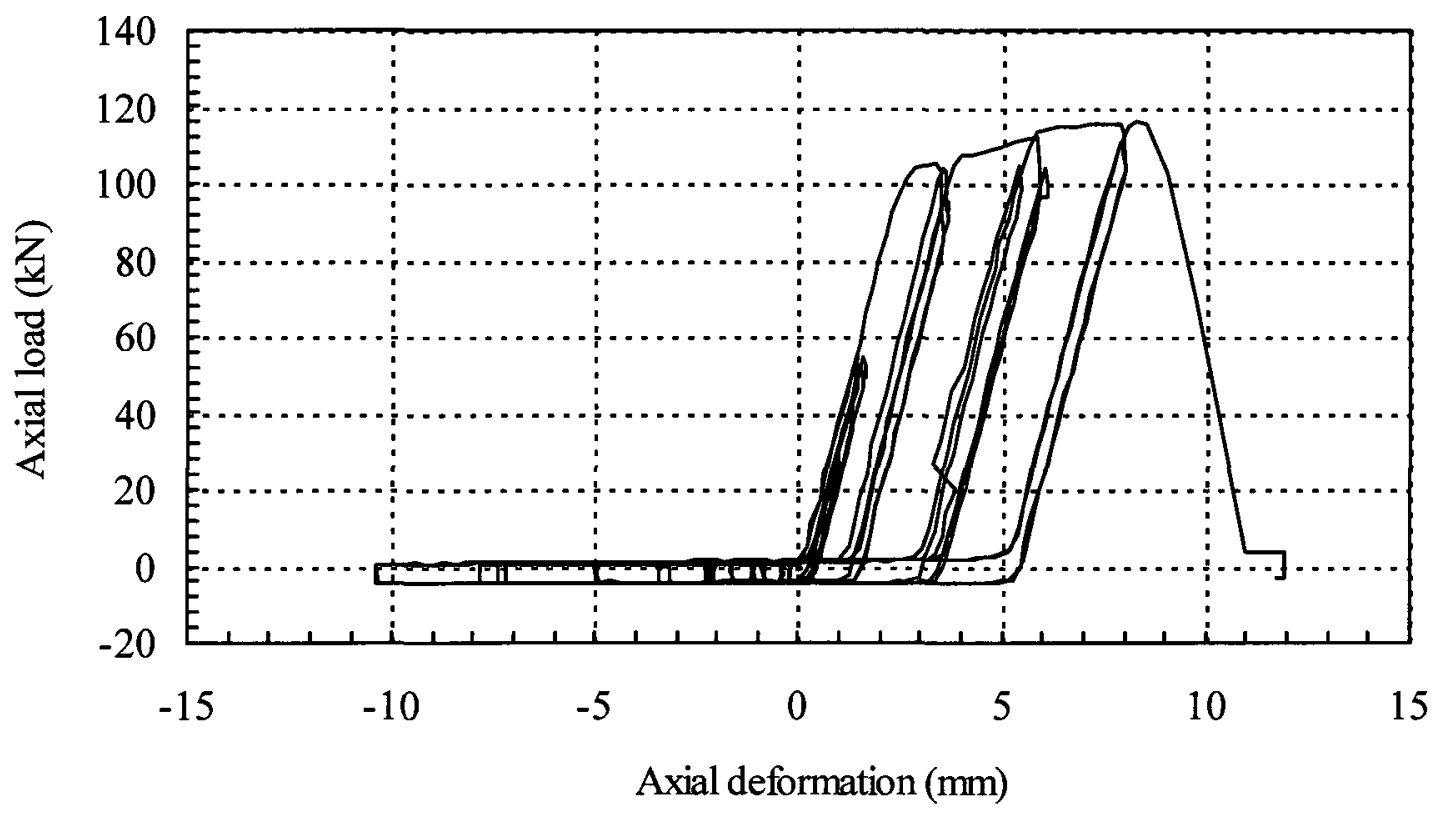

Figure B.4 Axial load versus axial deformation for A6075b specimen. 


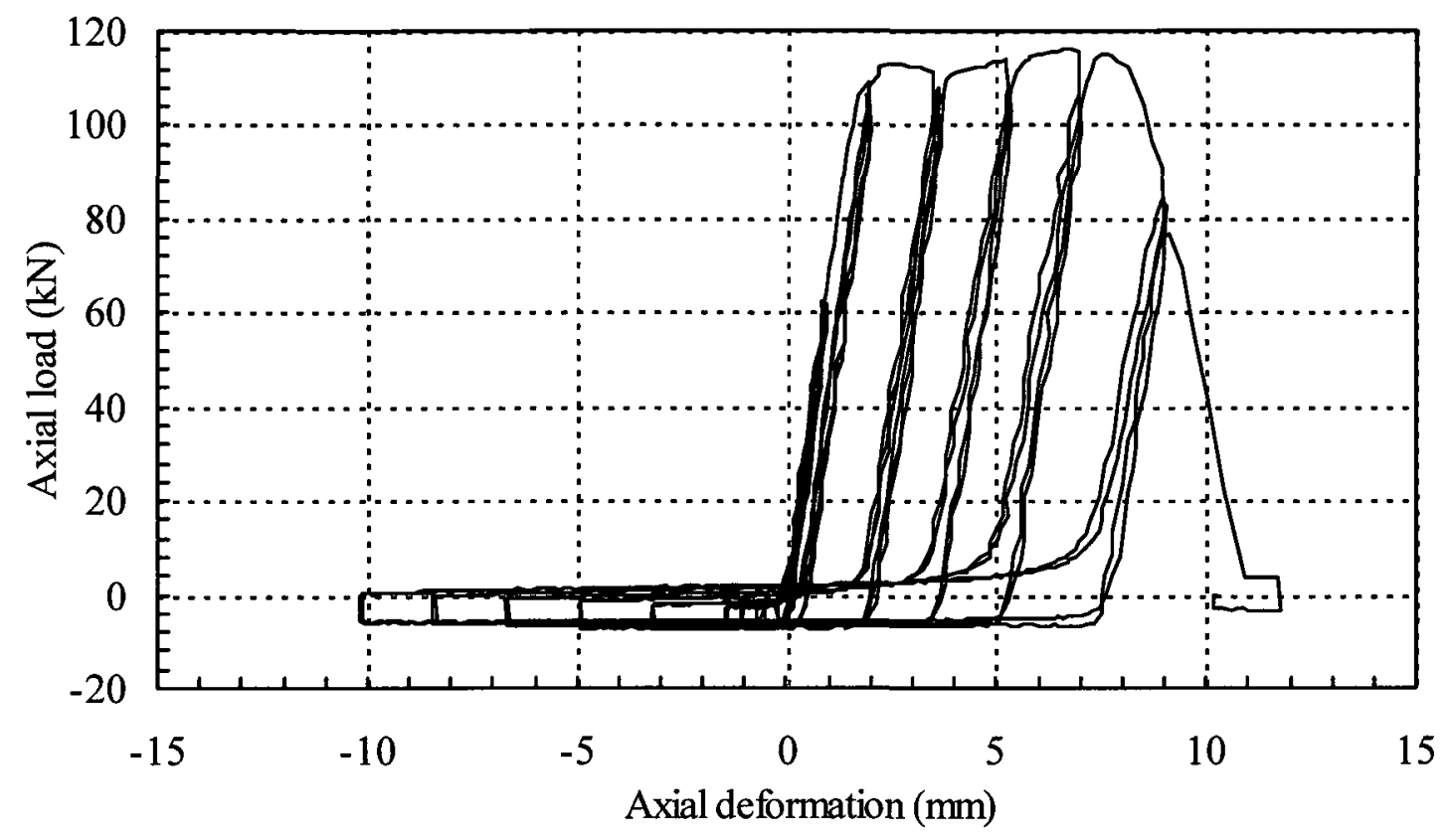

Figure B.5 Axial load versus axial deformation for A4075a specimen.

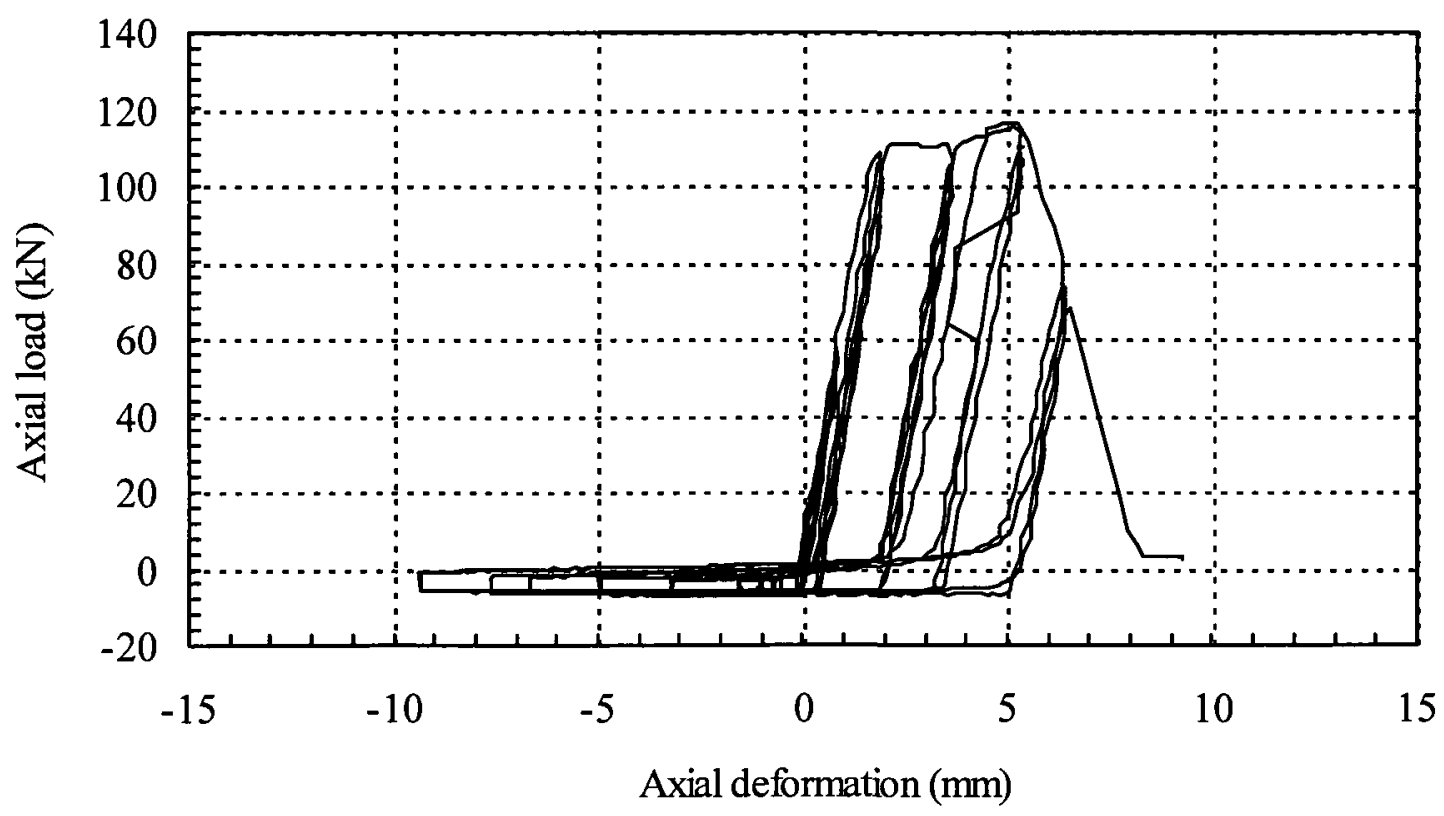

Figure B.6 Axial load versus axial deformation for A4075b specimen. 


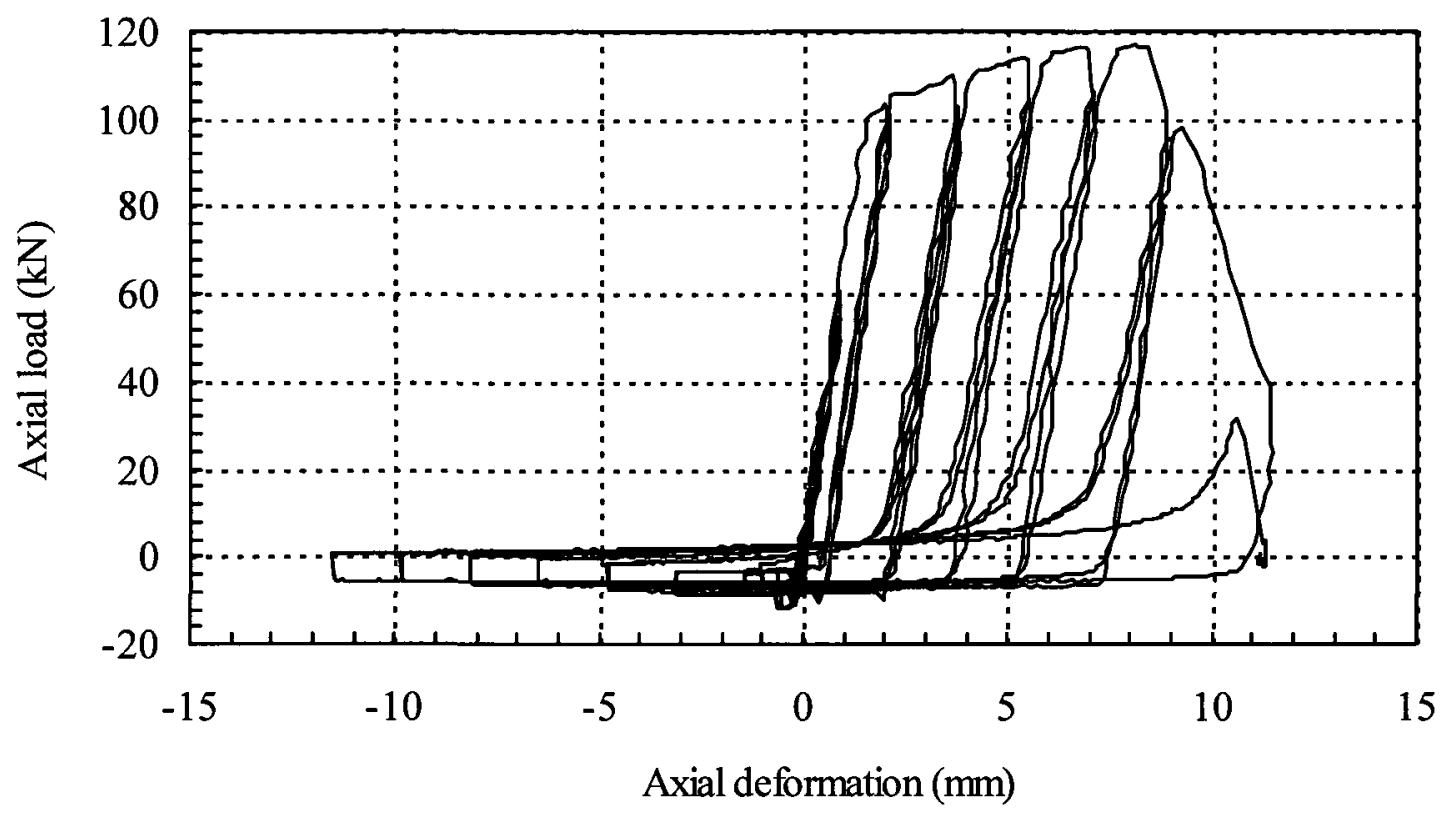

Figure B.7 Axial load versus axial deformation for A4075c specimen.

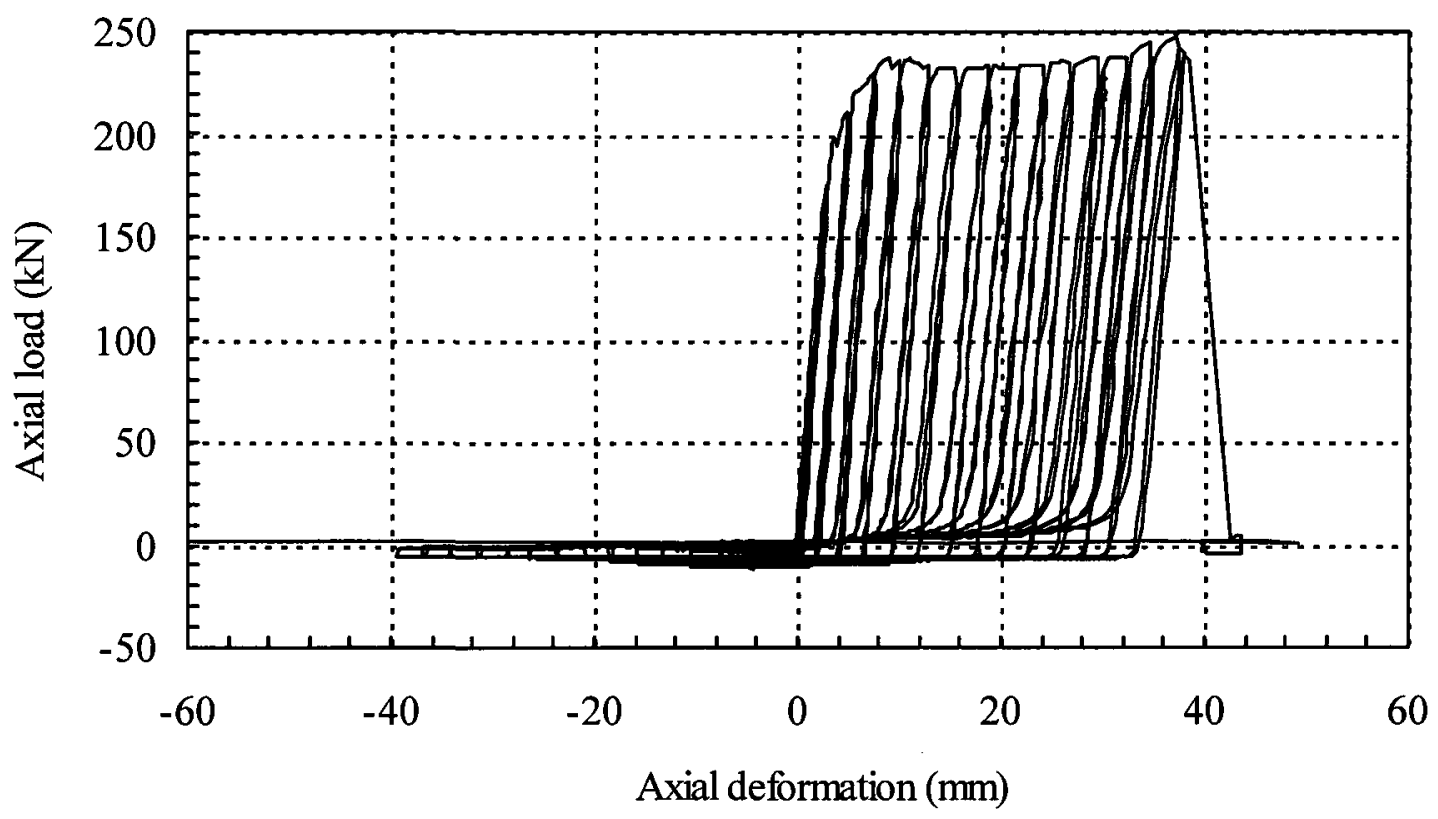

Figure B.8 Axial load versus axial deformation for A4078a specimen. 


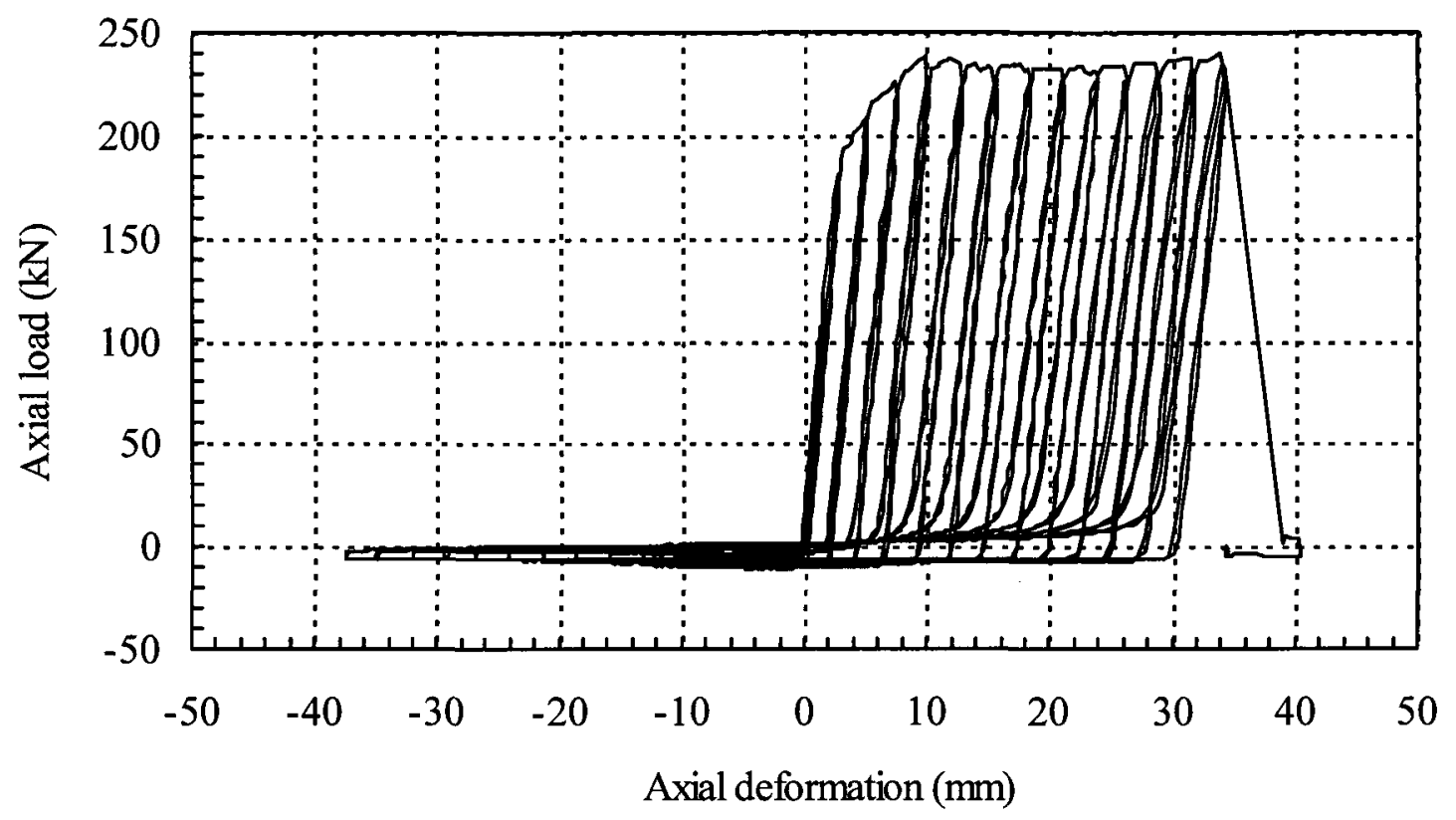

Figure B.9 Axial load versus axial deformation for A4078b specimen.

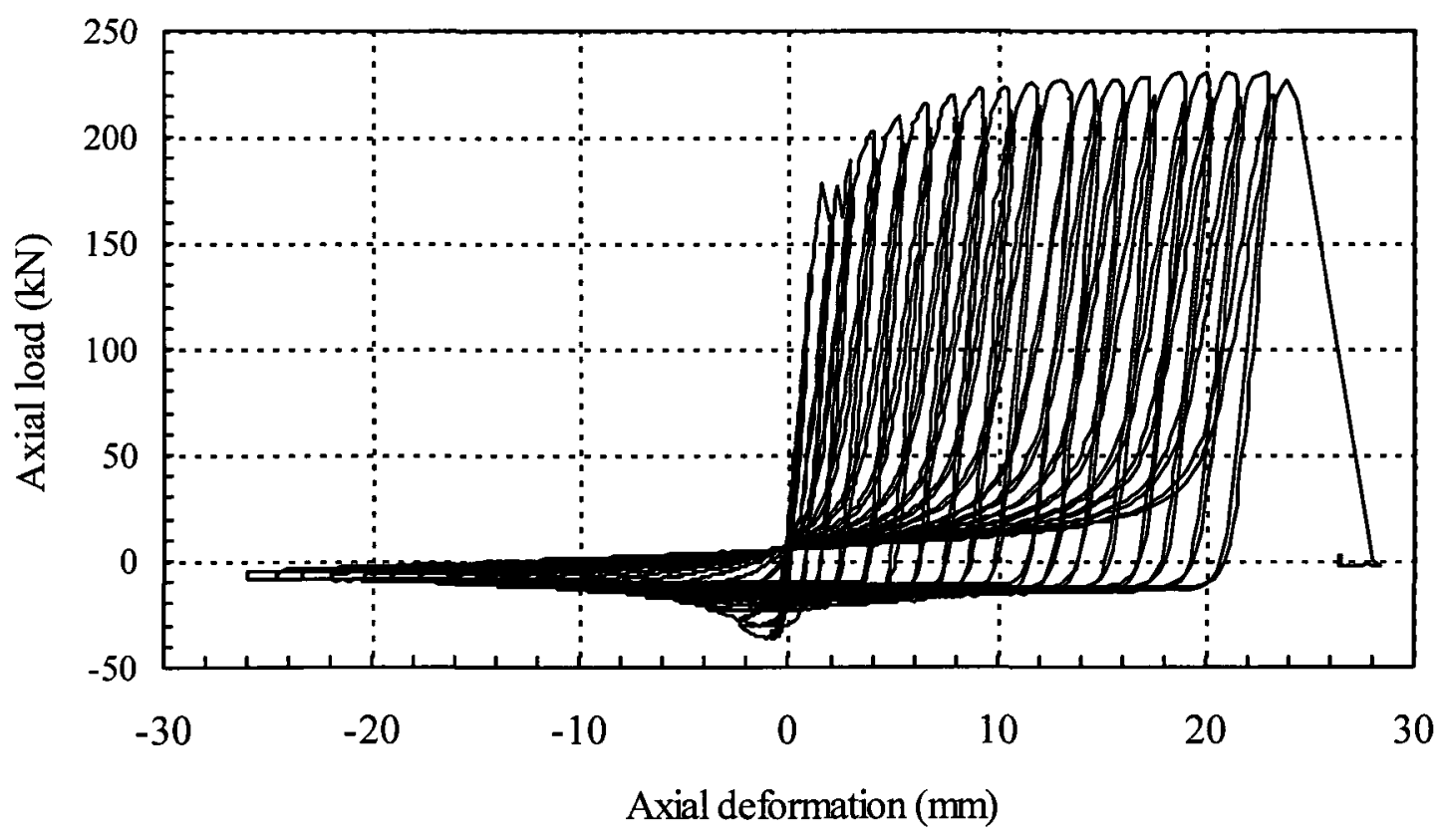

Figure B.10 Axial load versus axial deformation for A2078a specimen. 


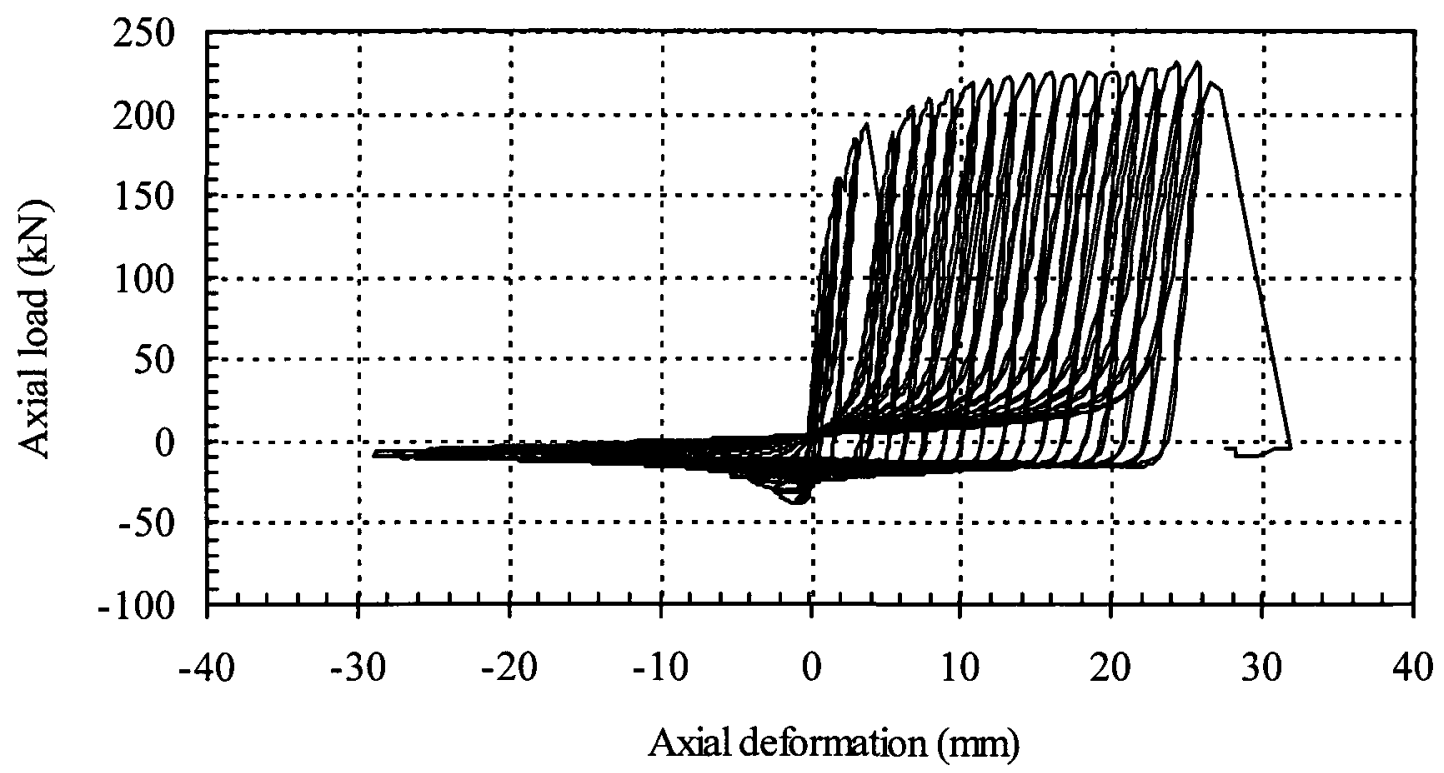

Figure B.11 Axial load versus axial deformation for A2078b specimen.

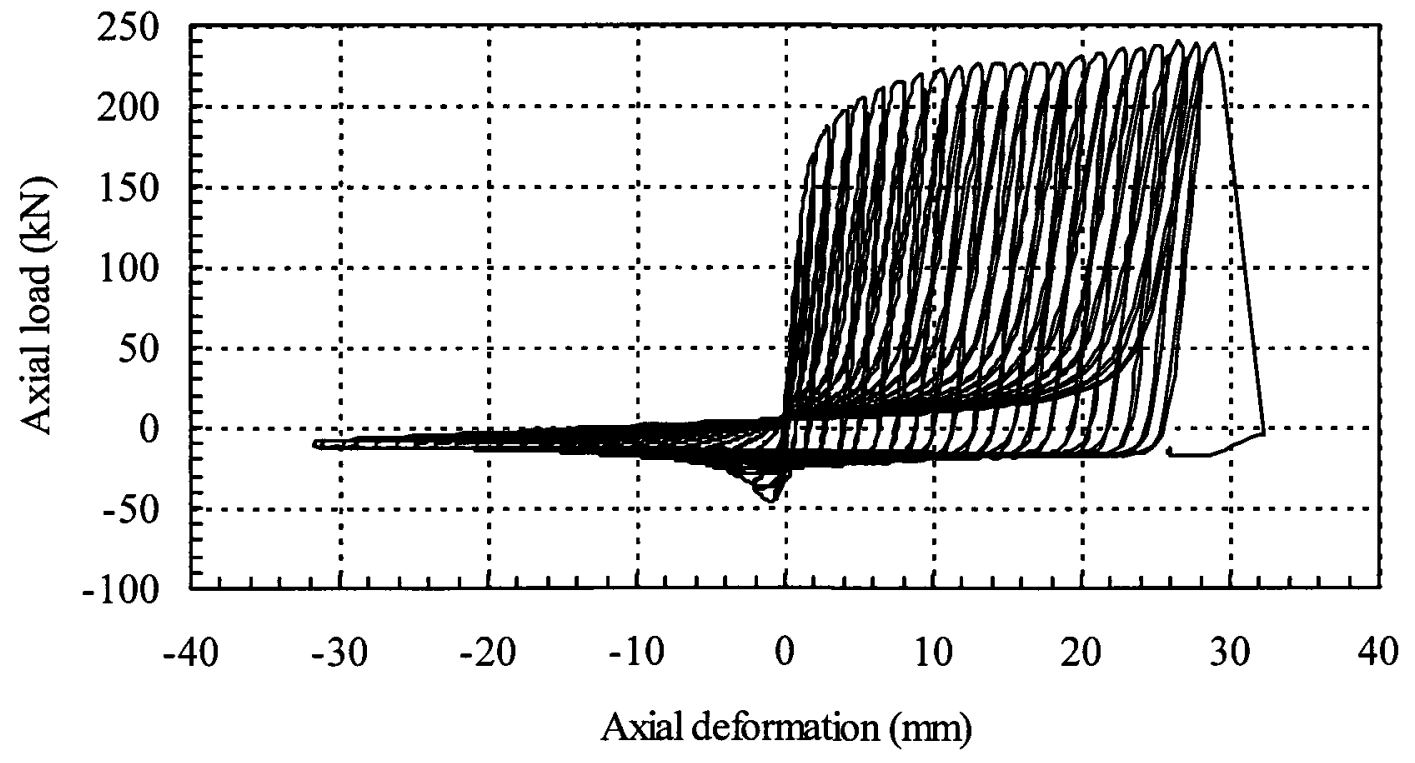

Figure B.12 Axial load versus axial deformation for A2078c specimen. 


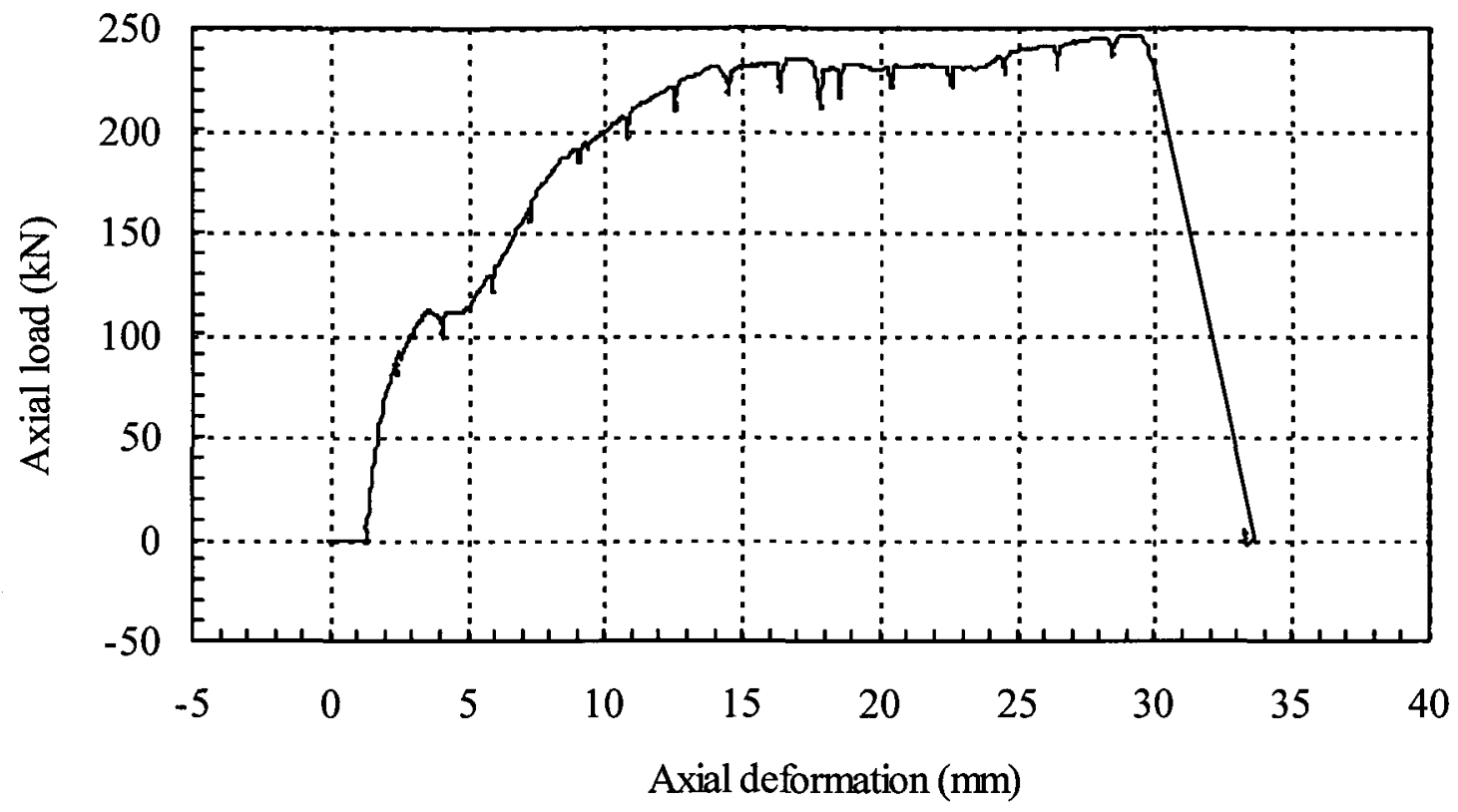

Figure B.13 Axial load versus axial deformation for A2078d specimen.

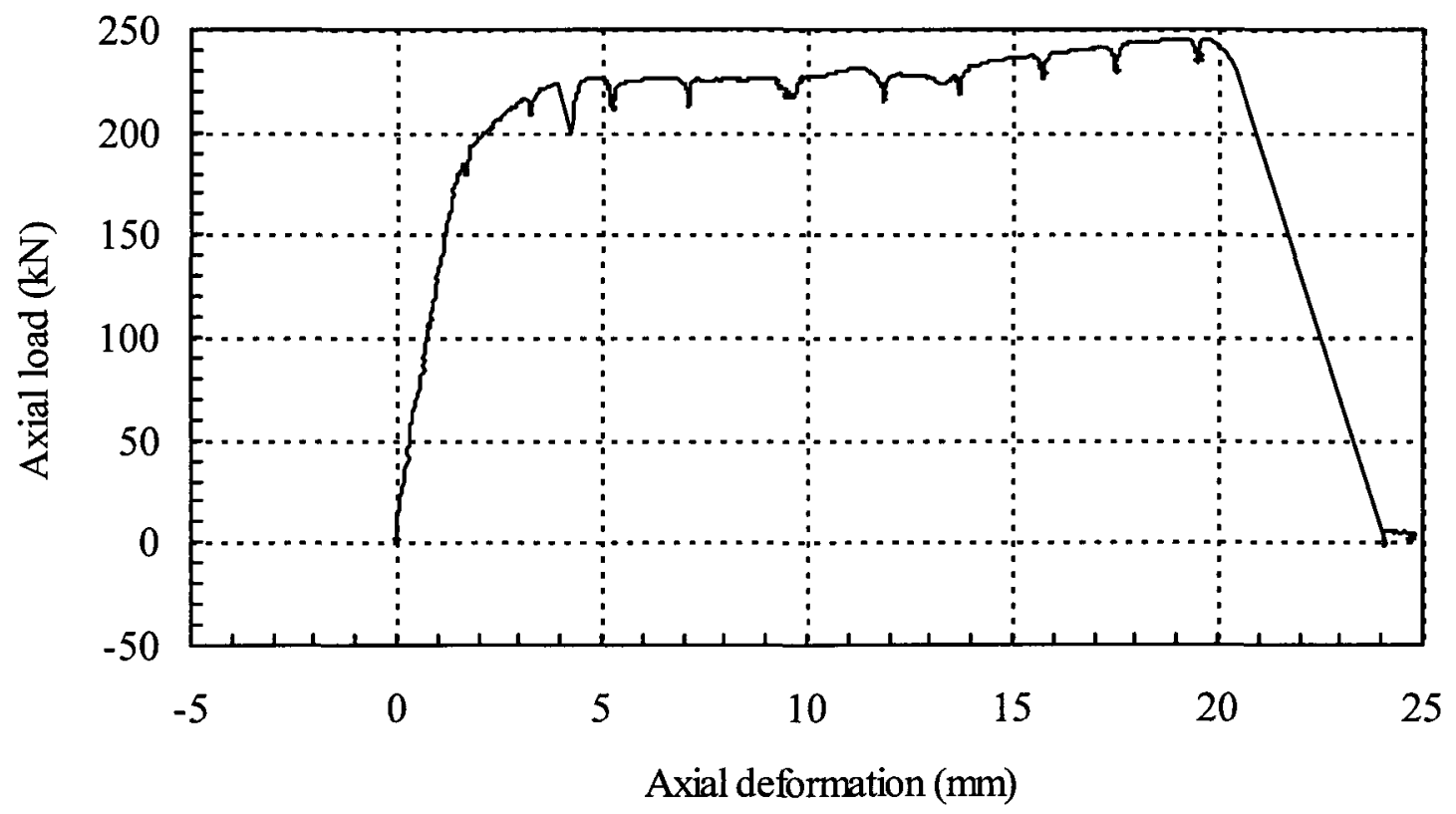

Figure B.14 Axial load versus axial deformation for A2078e specimen. 


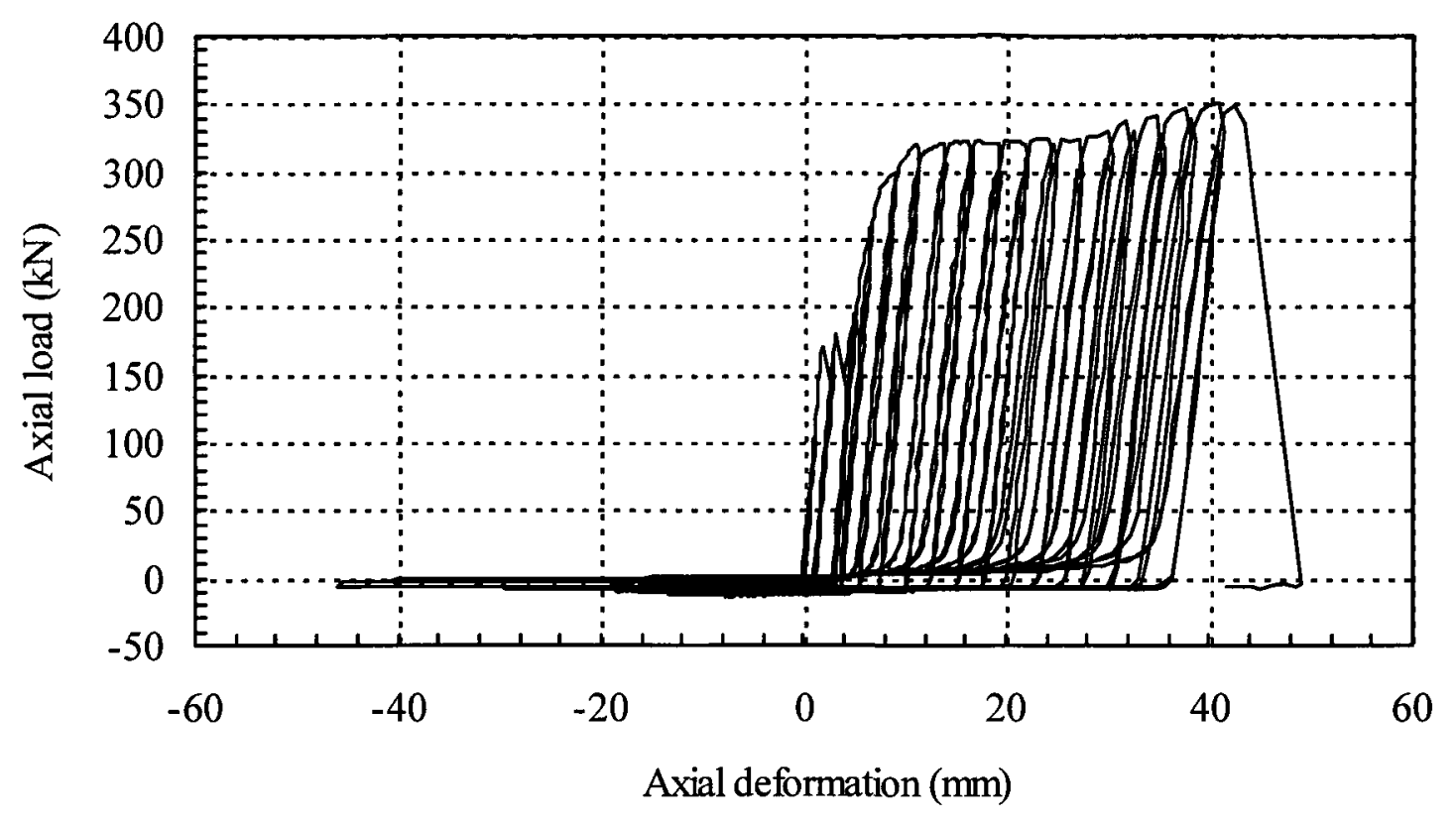

Figure B.15 Axial load versus axial deformation for A4108a specimen.

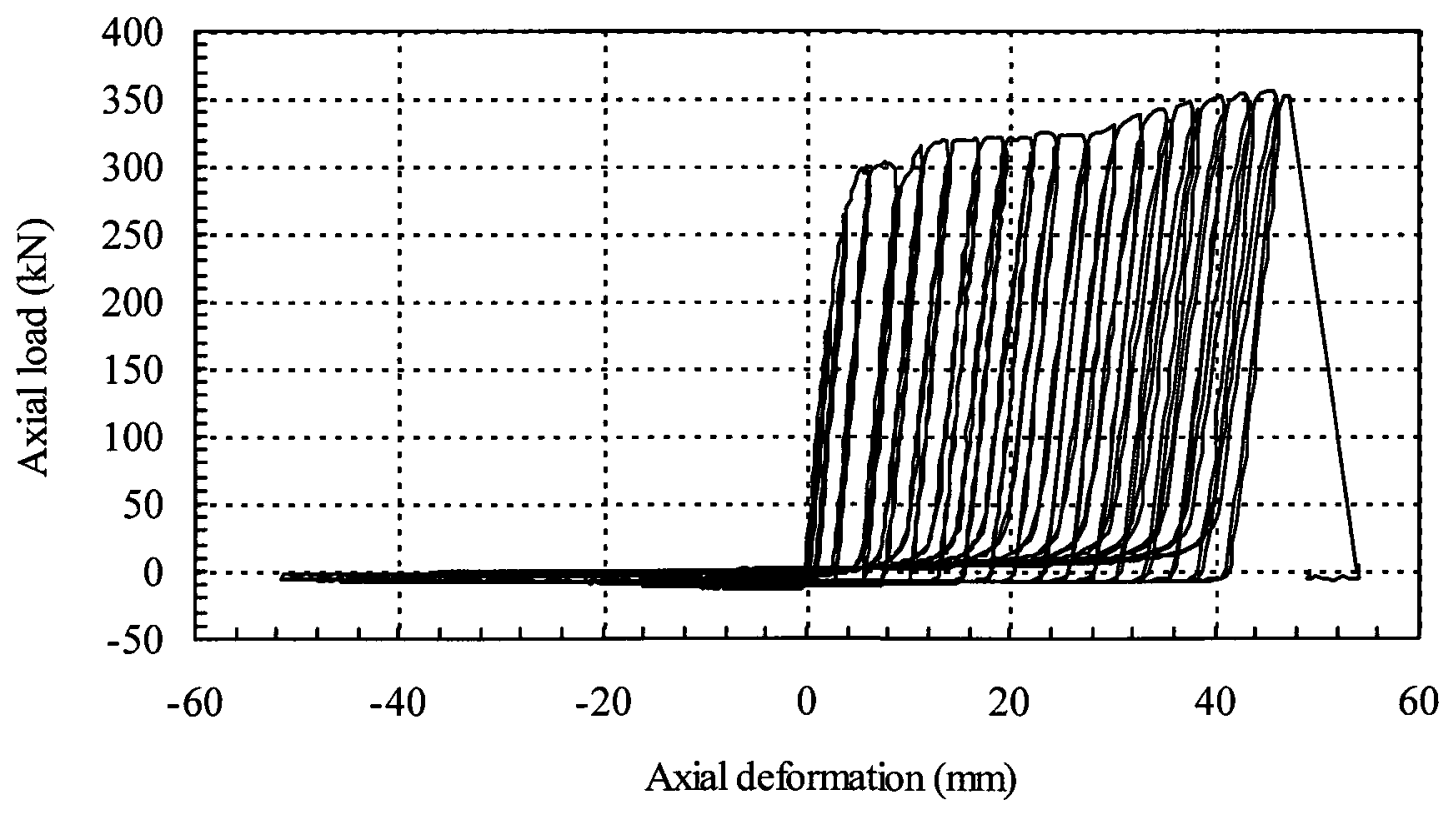

Figure B.16 Axial load versus axial deformation for A4108b specimen. 


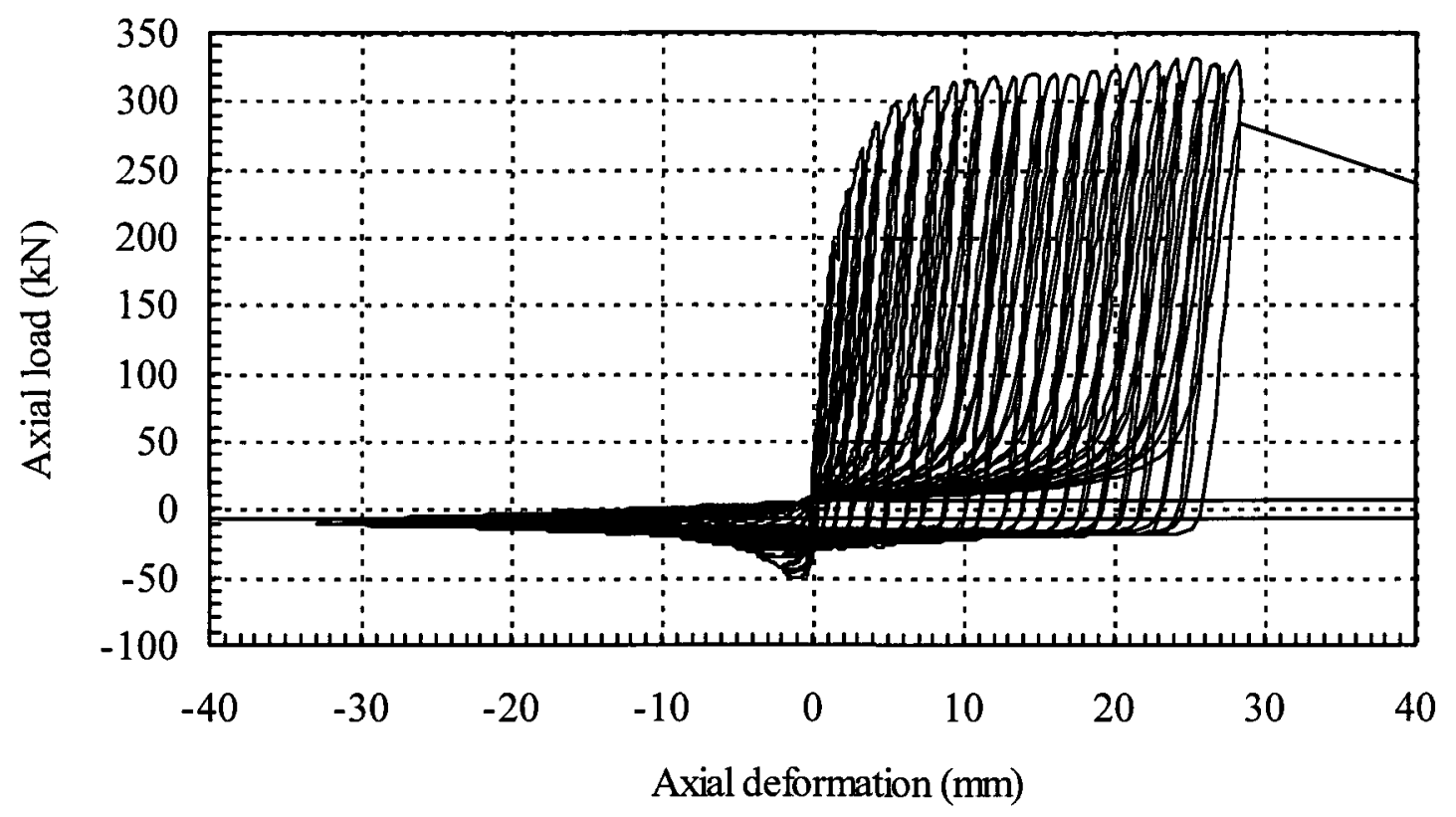

Figure B.17 Axial load versus axial deformation for A2108a specimen.

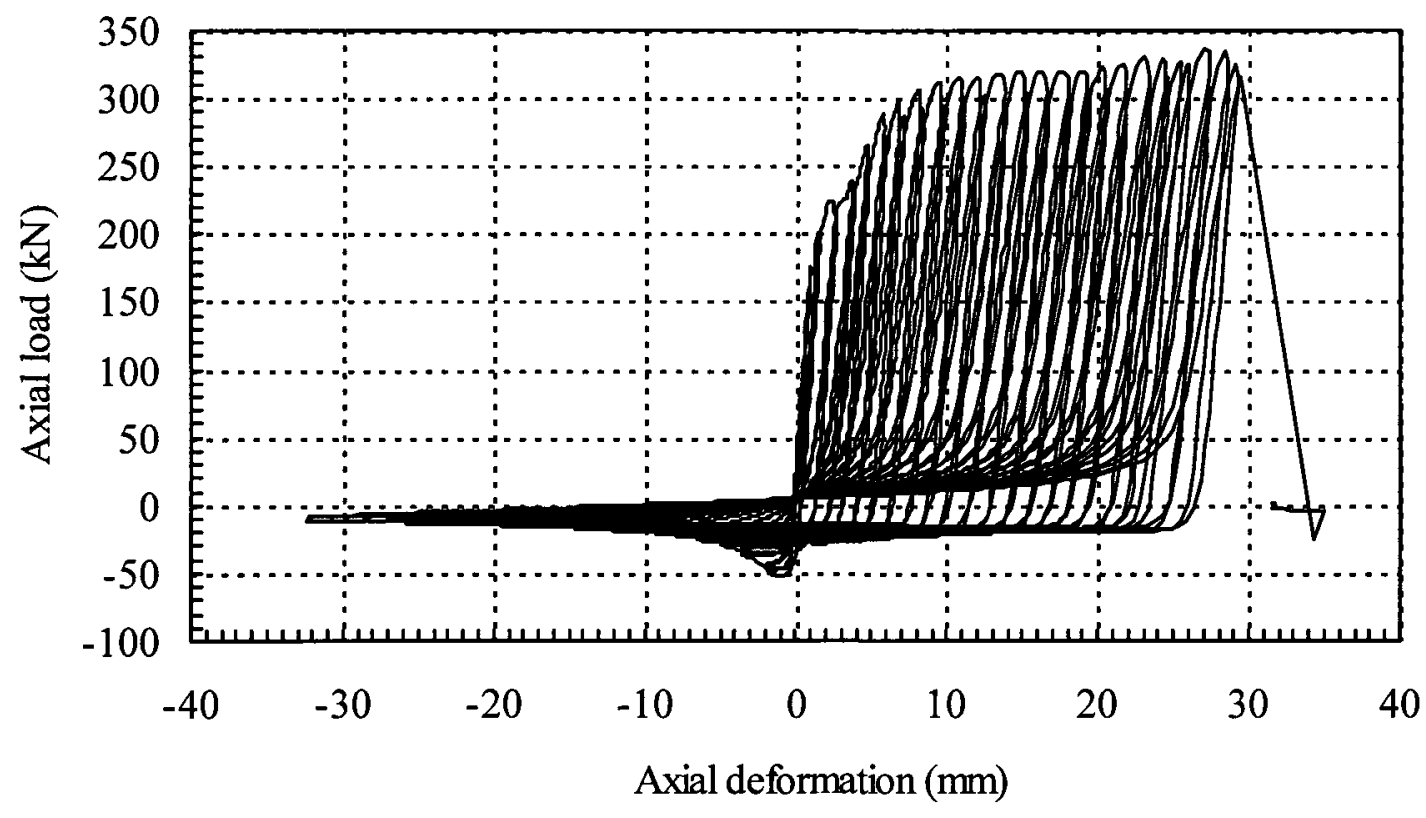

Figure B.18 Axial load versus axial deformation for A2108b specimen. 


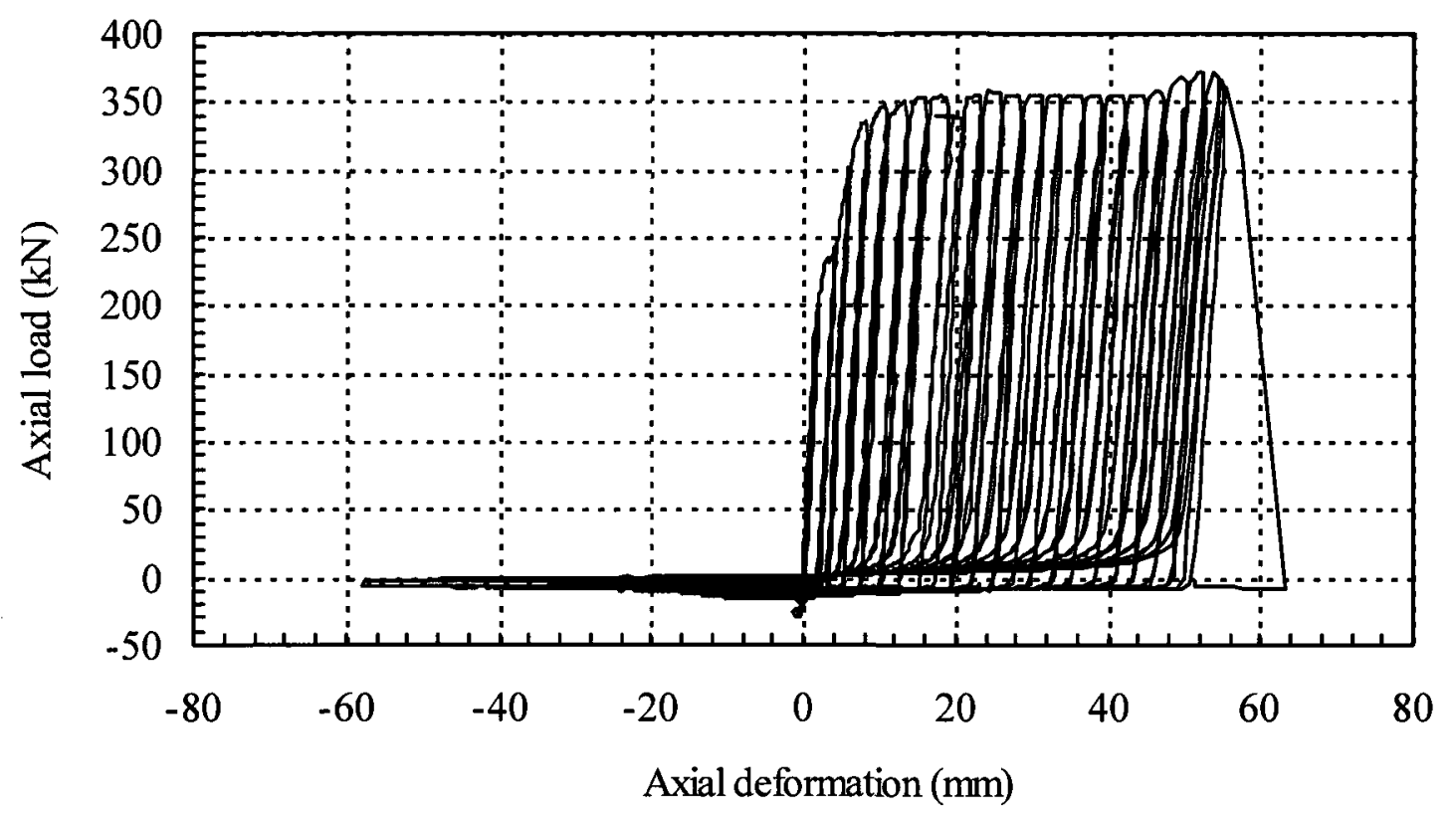

Figure B.19 Axial load versus axial deformation for A4128a specimen.

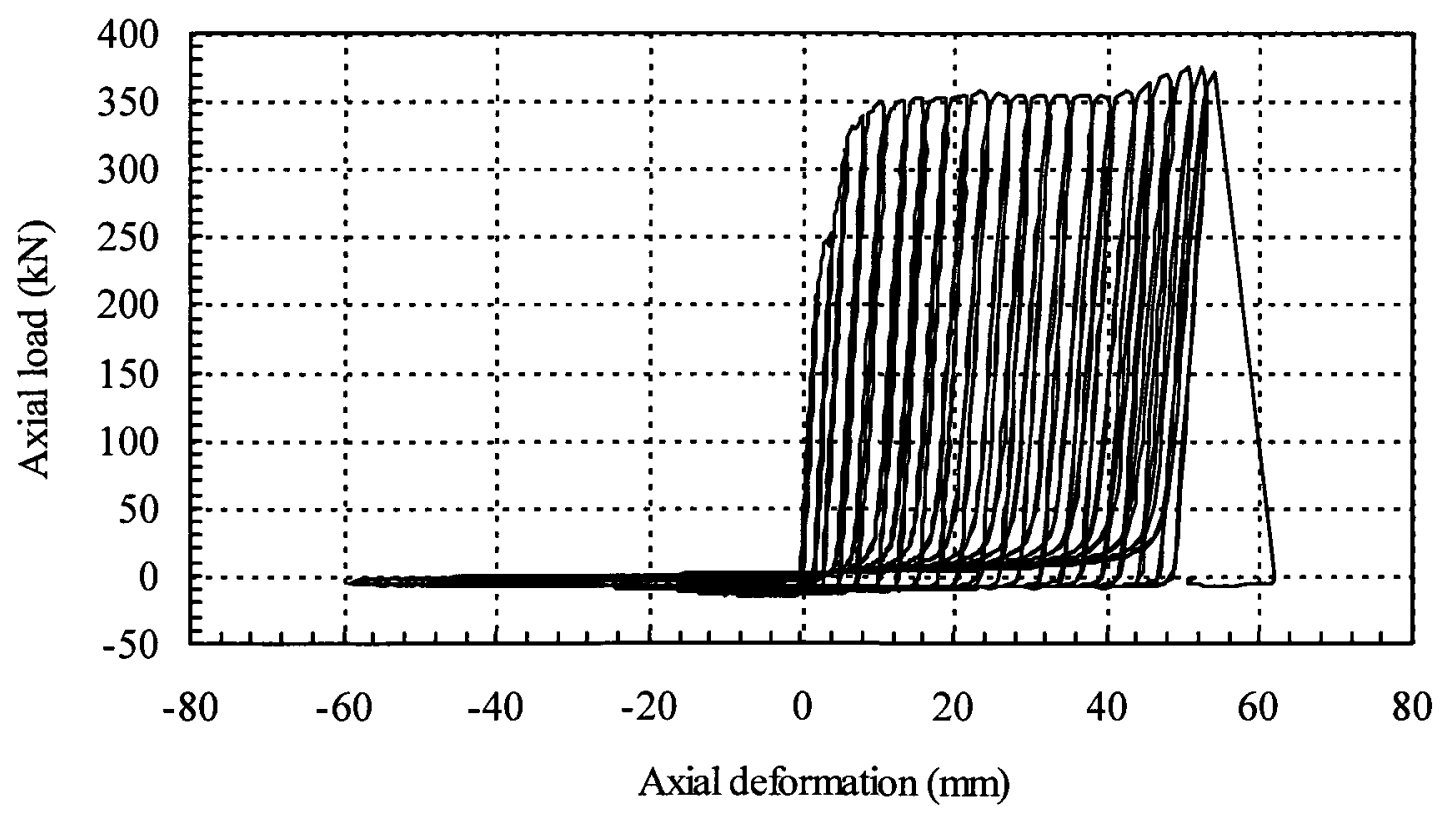

Figure B.20 Axial load versus axial deformation for A4128b specimen. 


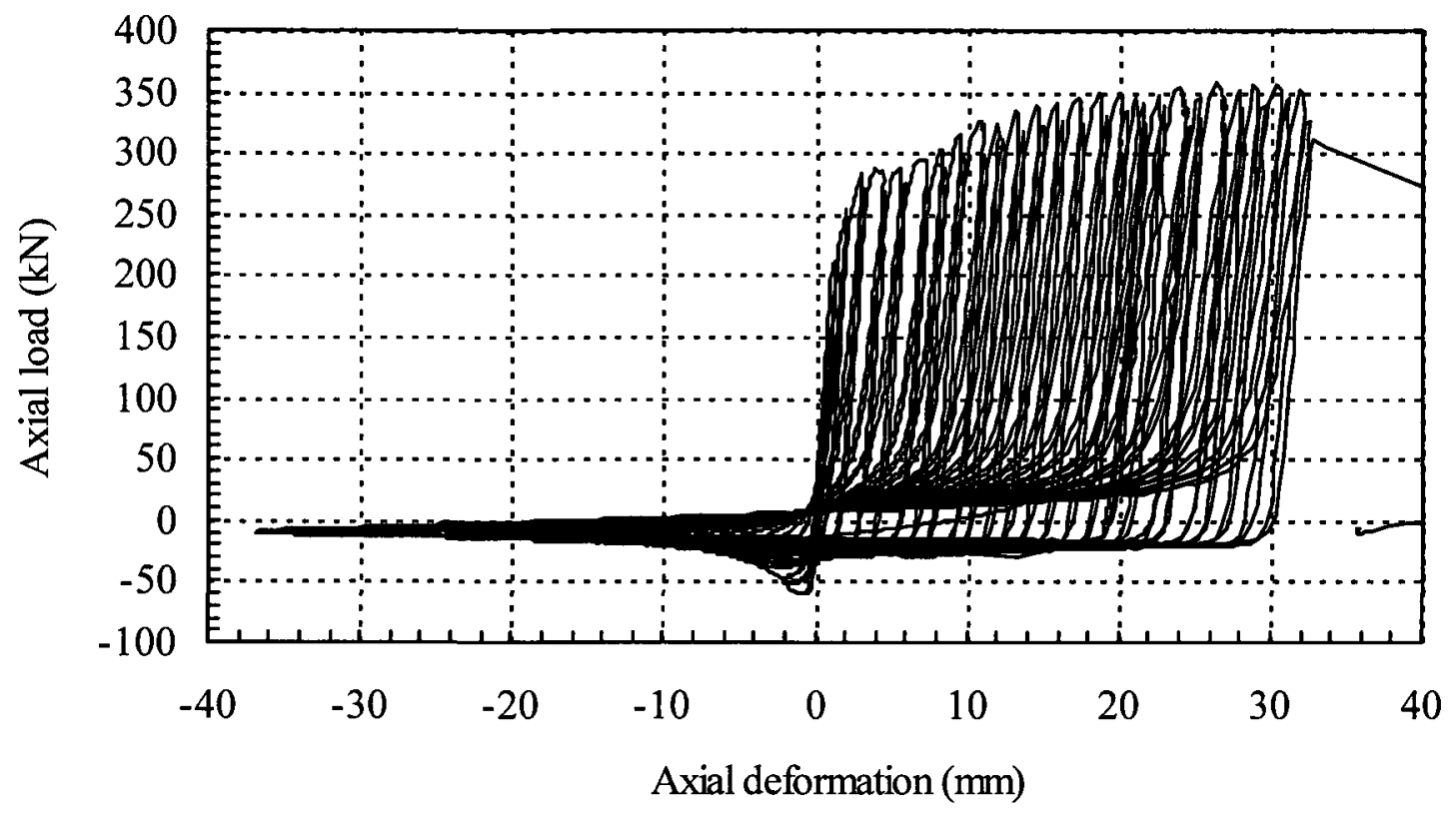

Figure B.21 Axial load versus axial deformation for A2128a specimen.

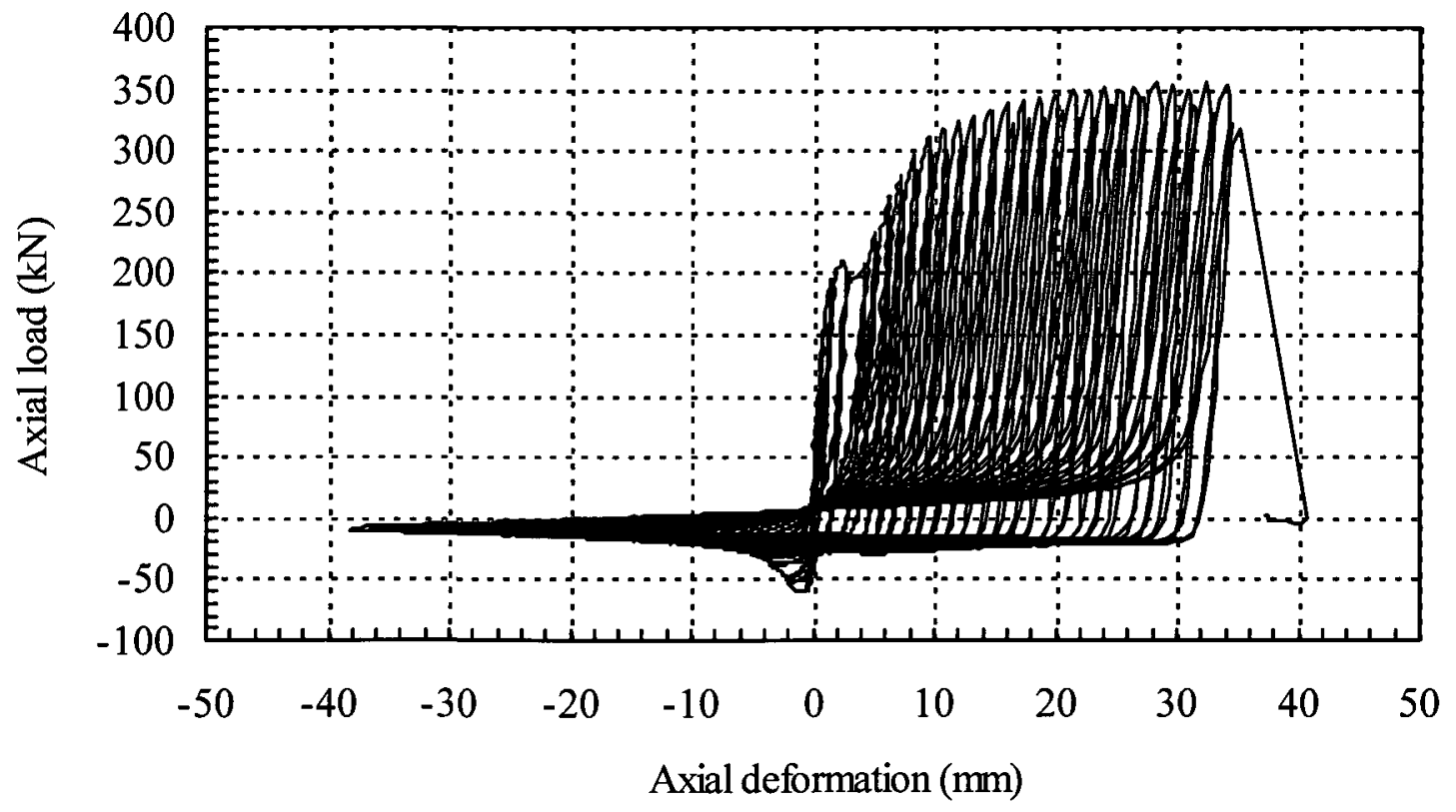

Figure B.22 Axial load versus axial deformation for A2128b specimen. 


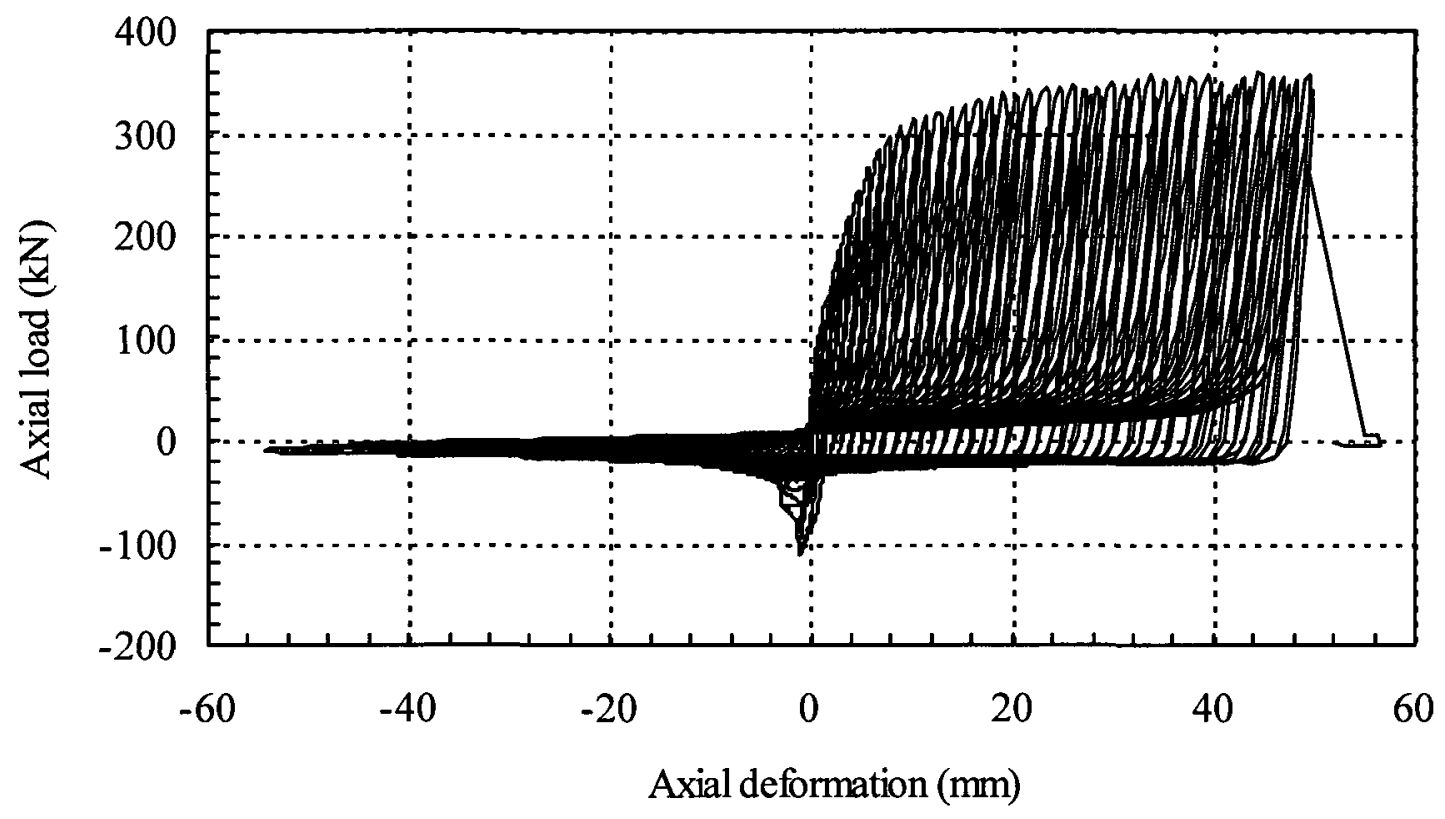

Figure B.23 Axial load versus axial deformation for A2128c specimen.

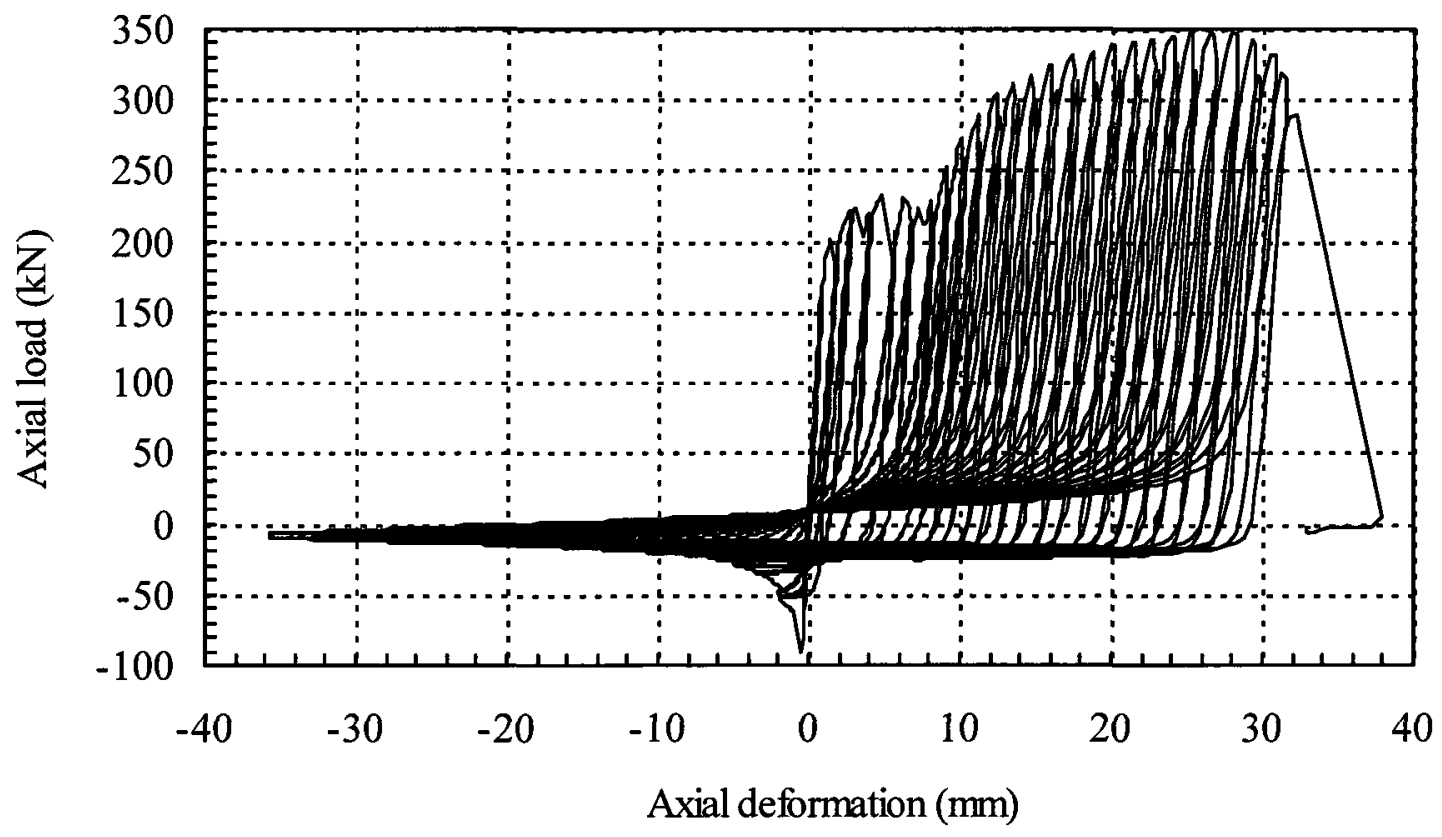

Figure B.24 Axial load versus axial deformation for A2128d specimen. 


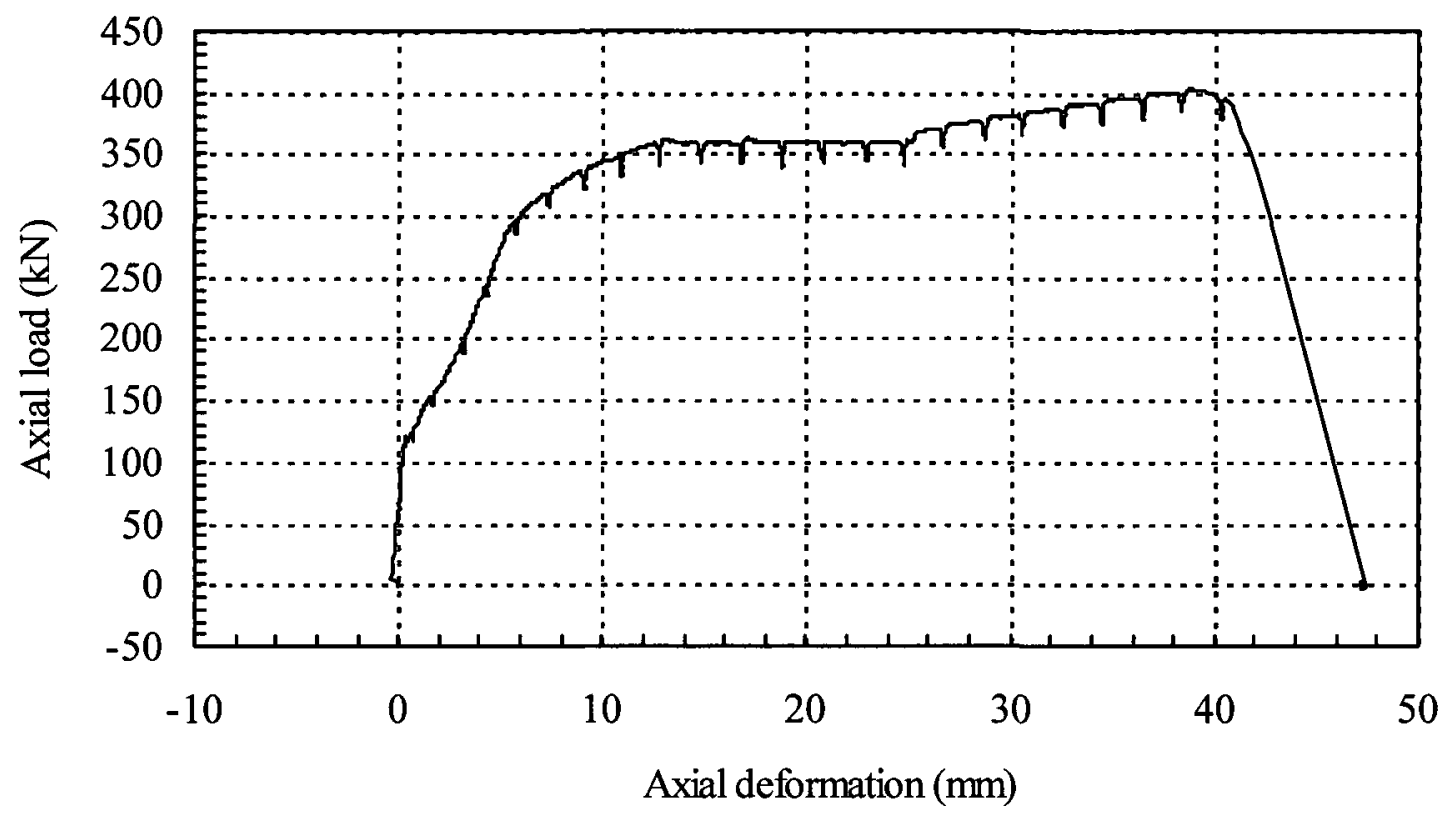

Figure B.25 Axial load versus axial deformation for A2128e specimen.

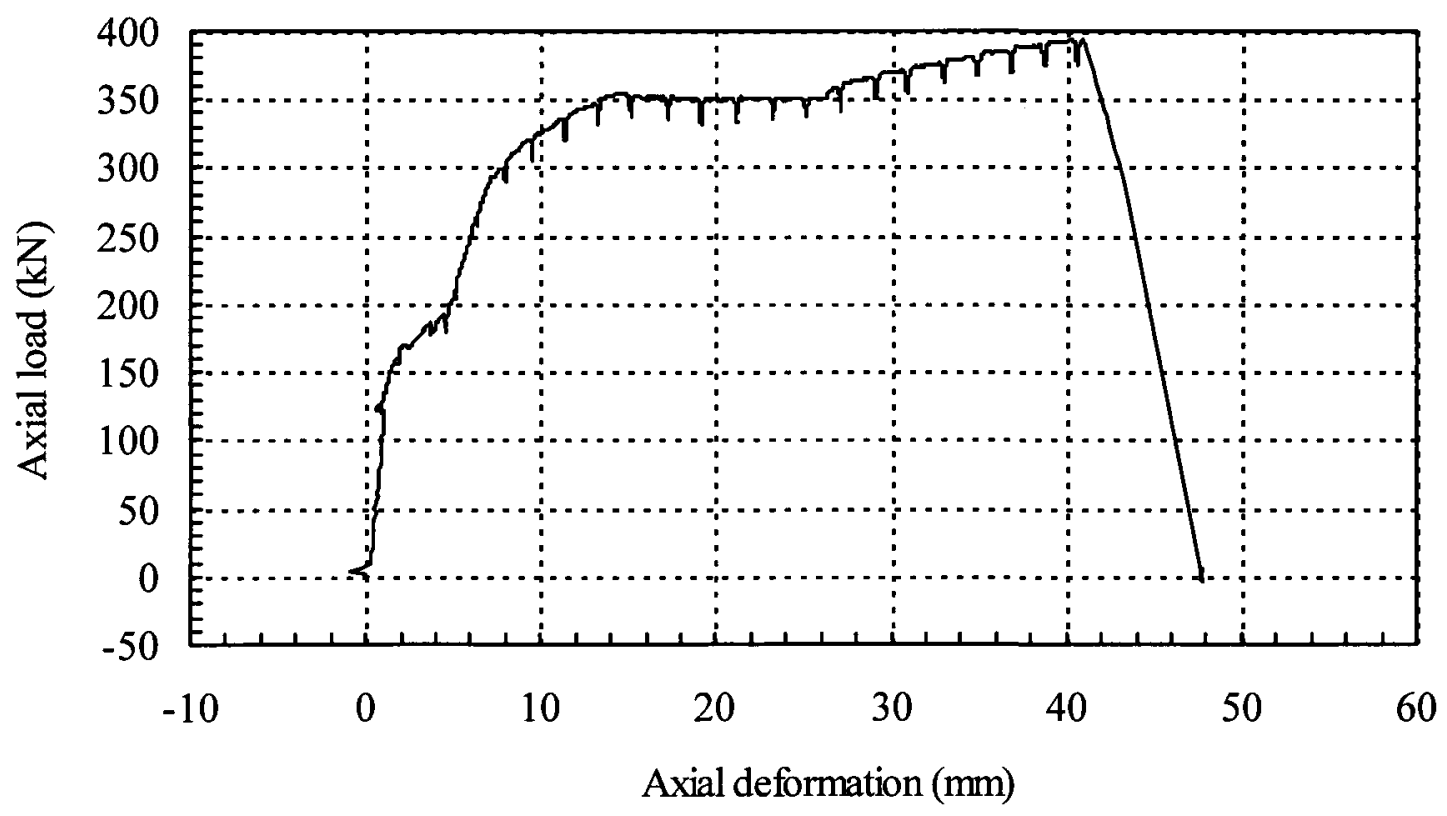

Figure B.26 Axial load versus axial deformation for A2128f specimen. 


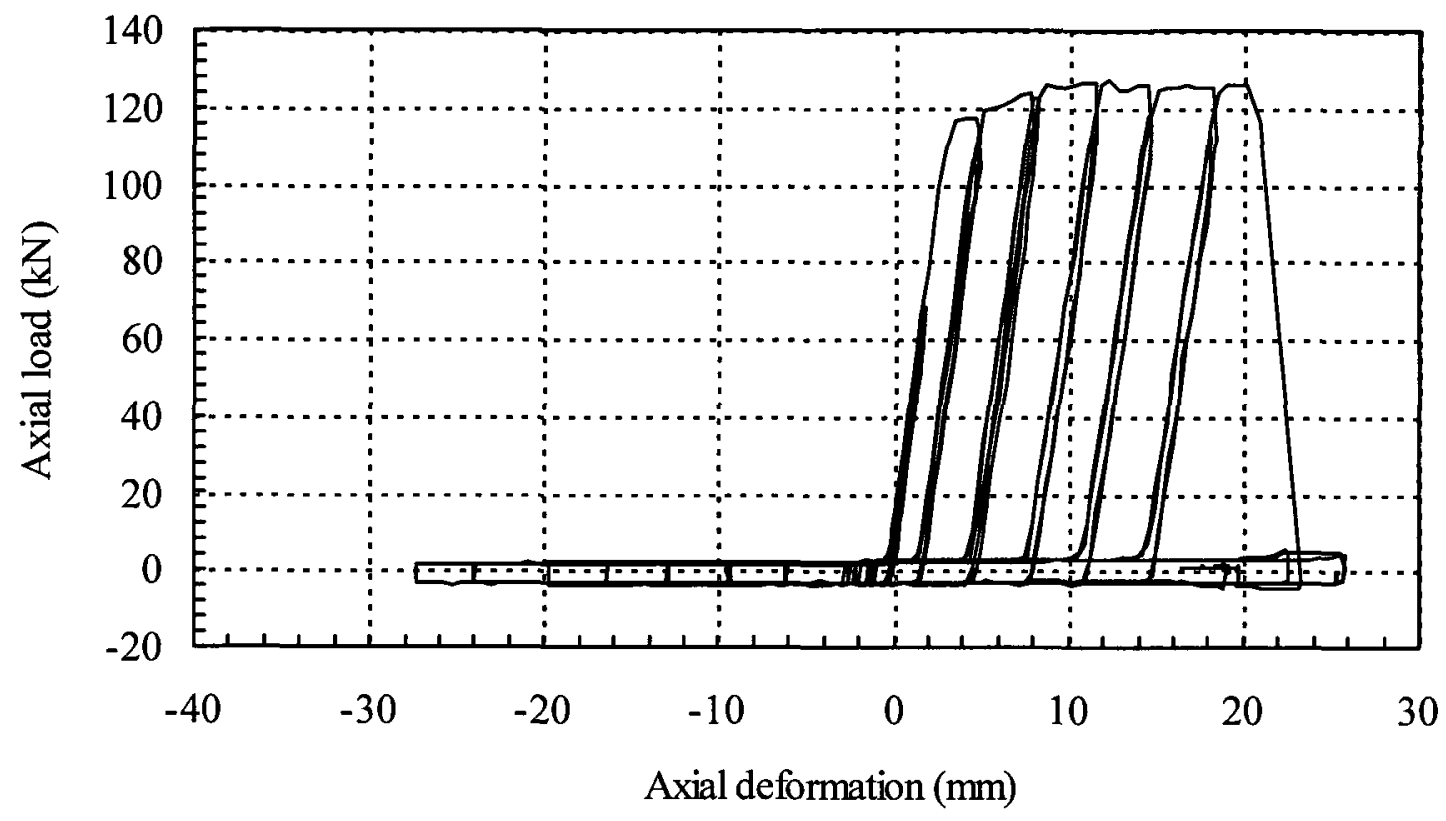

Figure B.27 Axial load versus axial deformation for B8075a specimen.

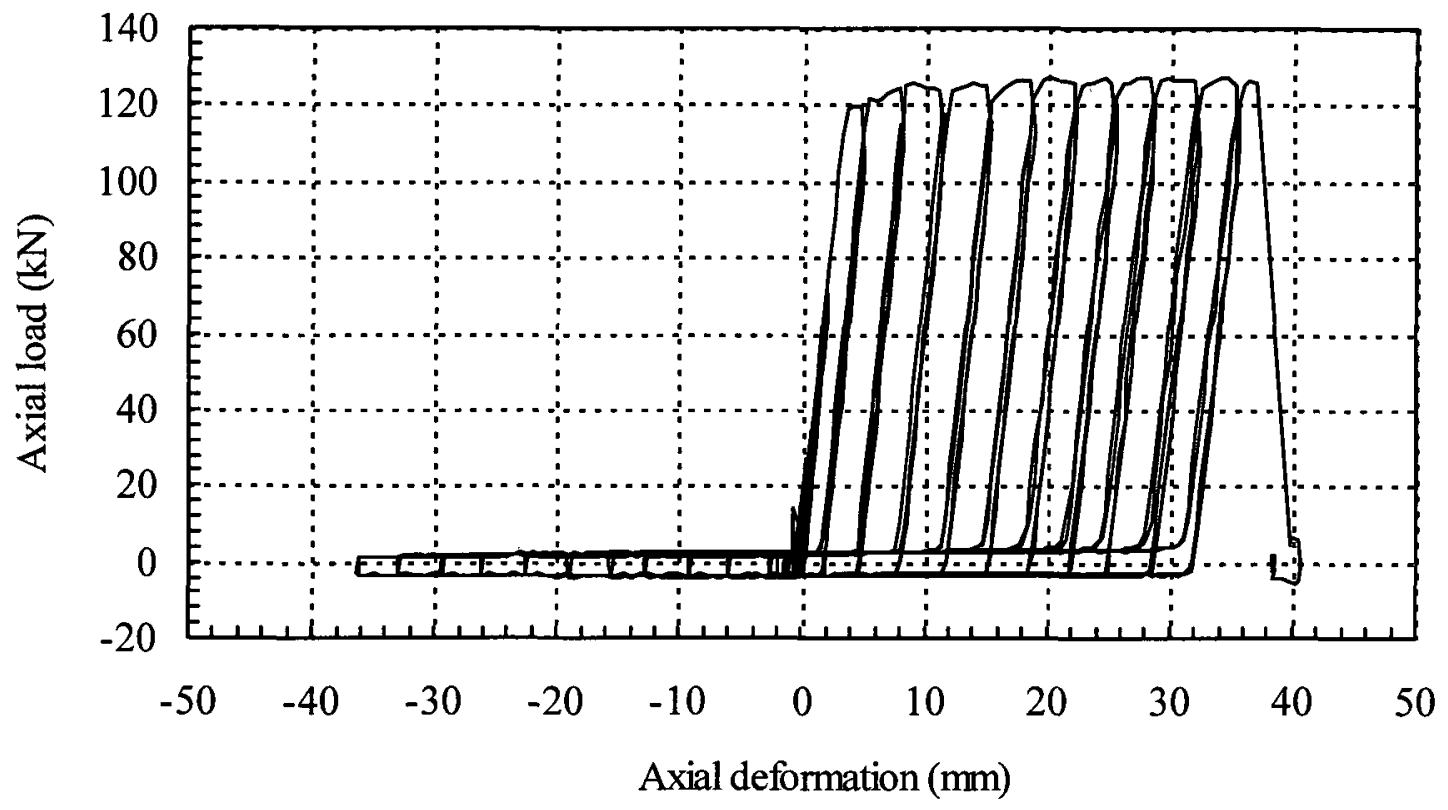

Figure B.28 Axial load versus axial deformation for B8075b specimen. 


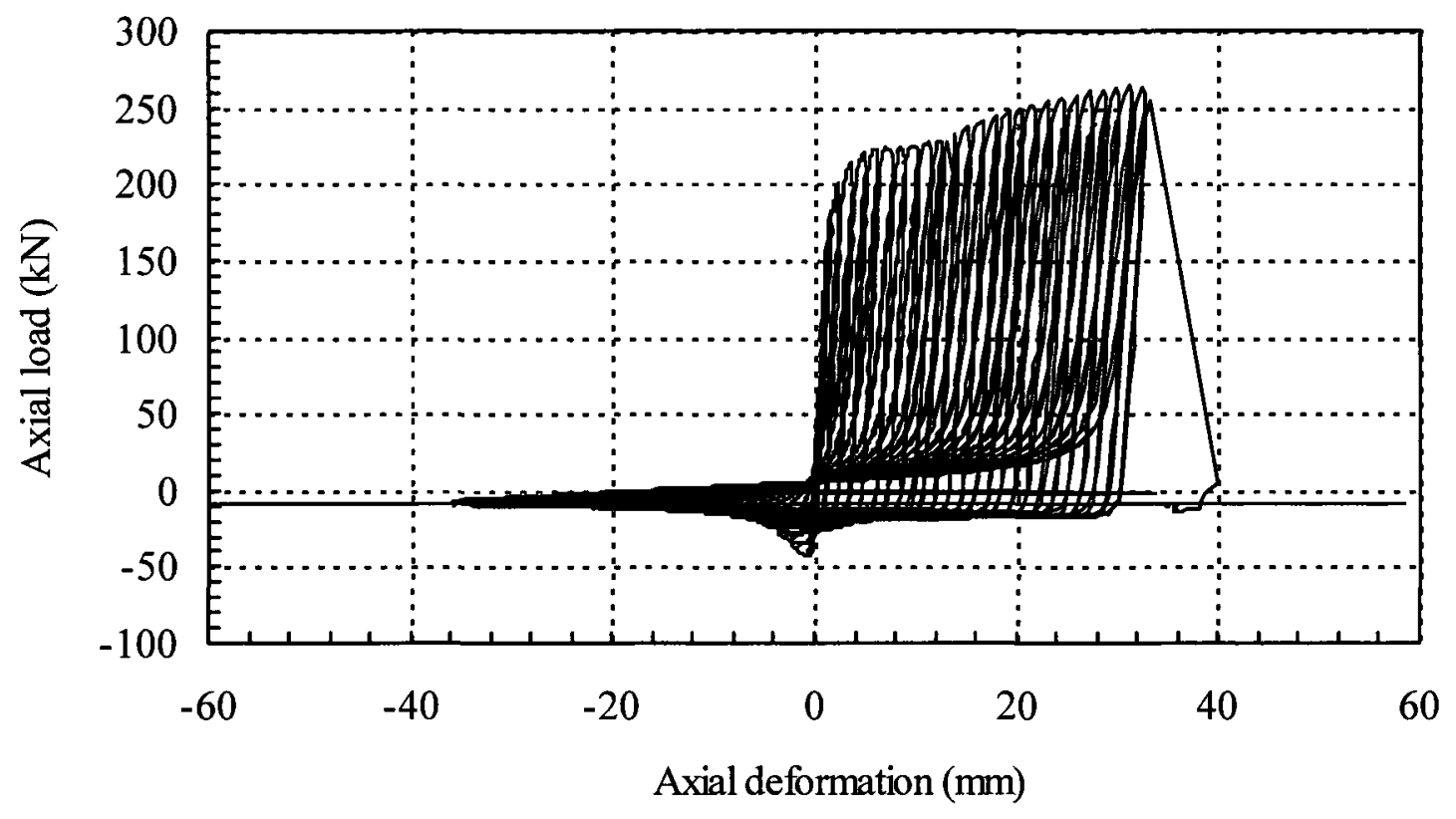

Figure B.29 Axial load versus axial deformation for B2078a specimen.

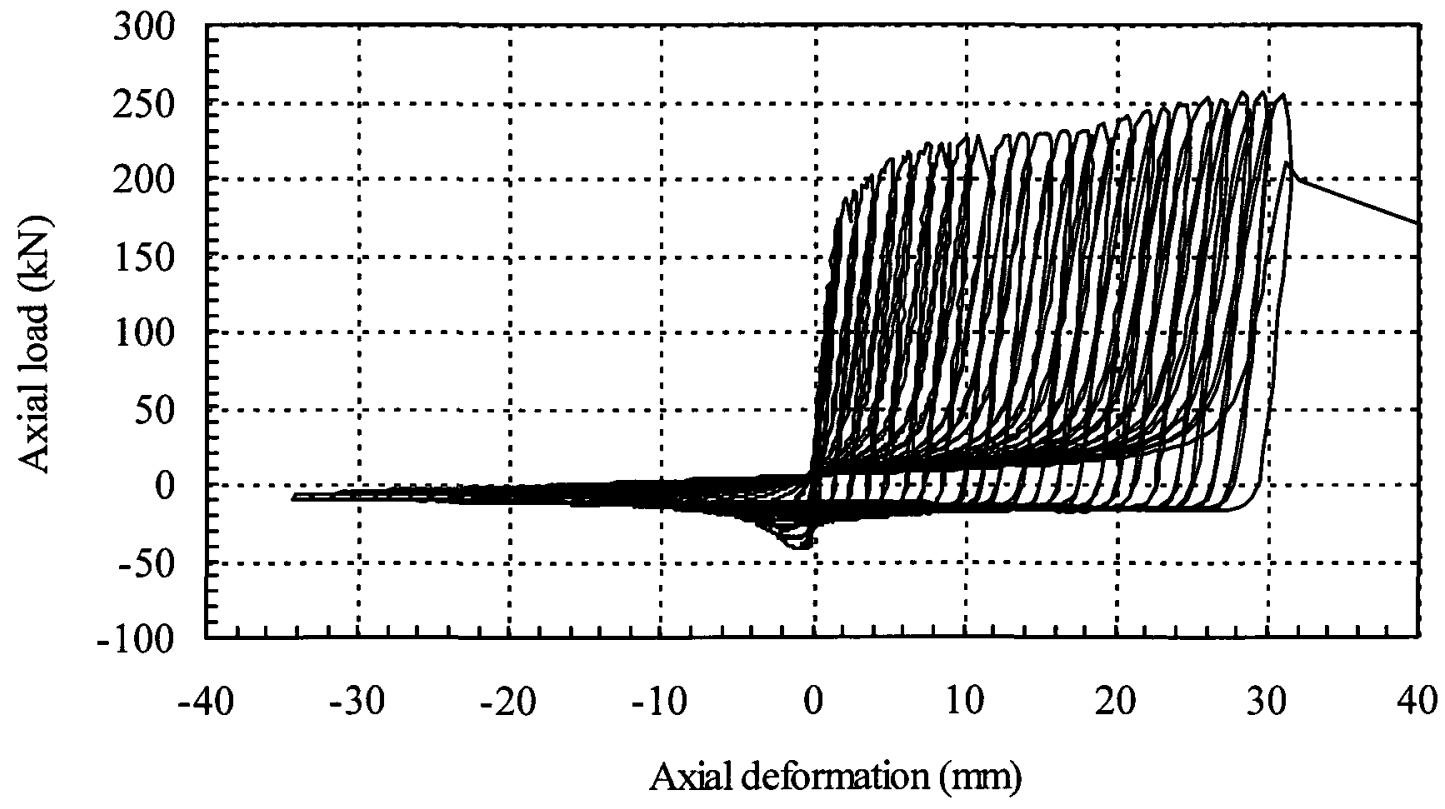

Figure B.30 Axial load versus axial deformation for B2078b specimen. 


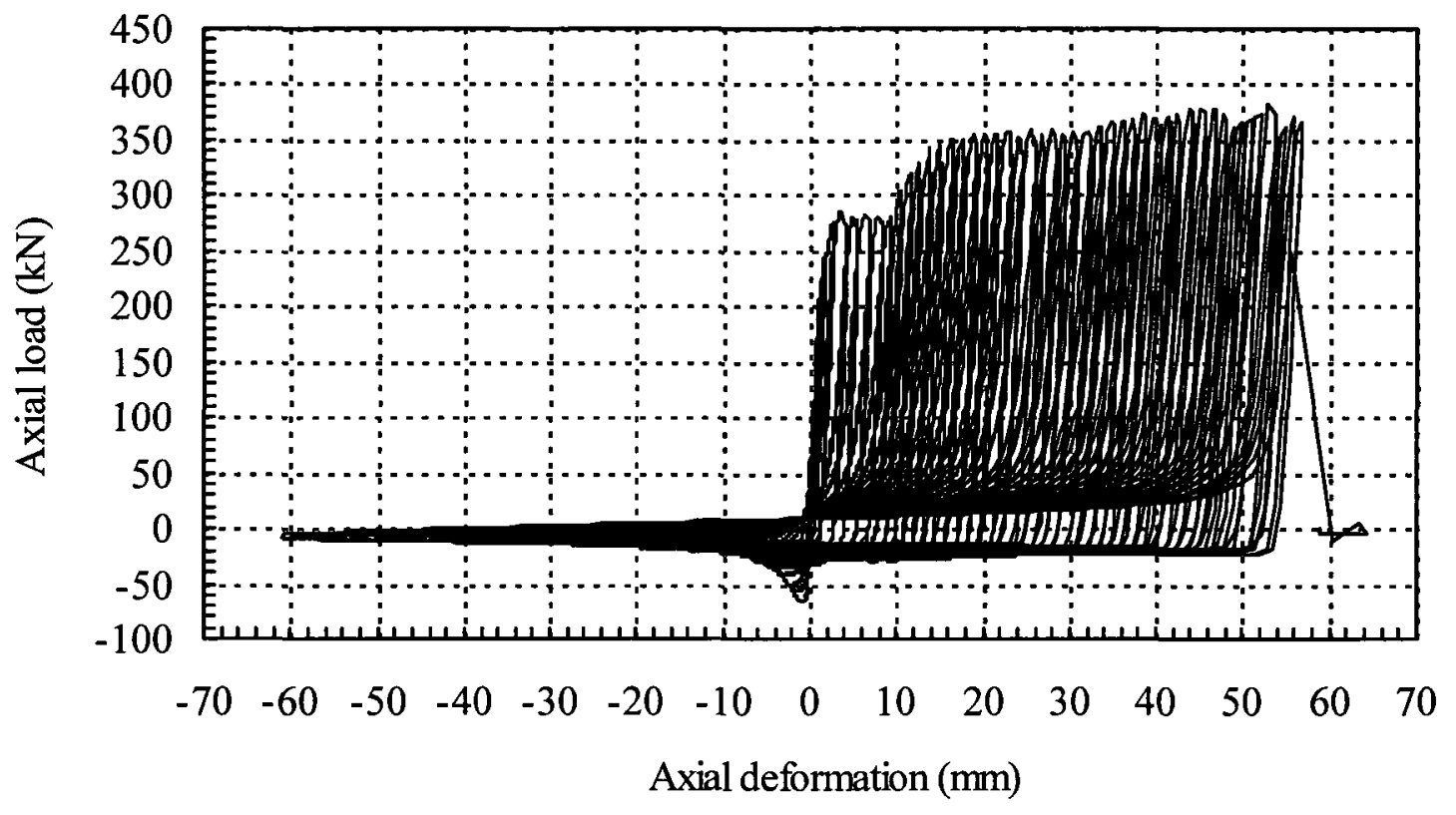

Figure B.31 Axial load versus axial deformation for B2128a specimen.

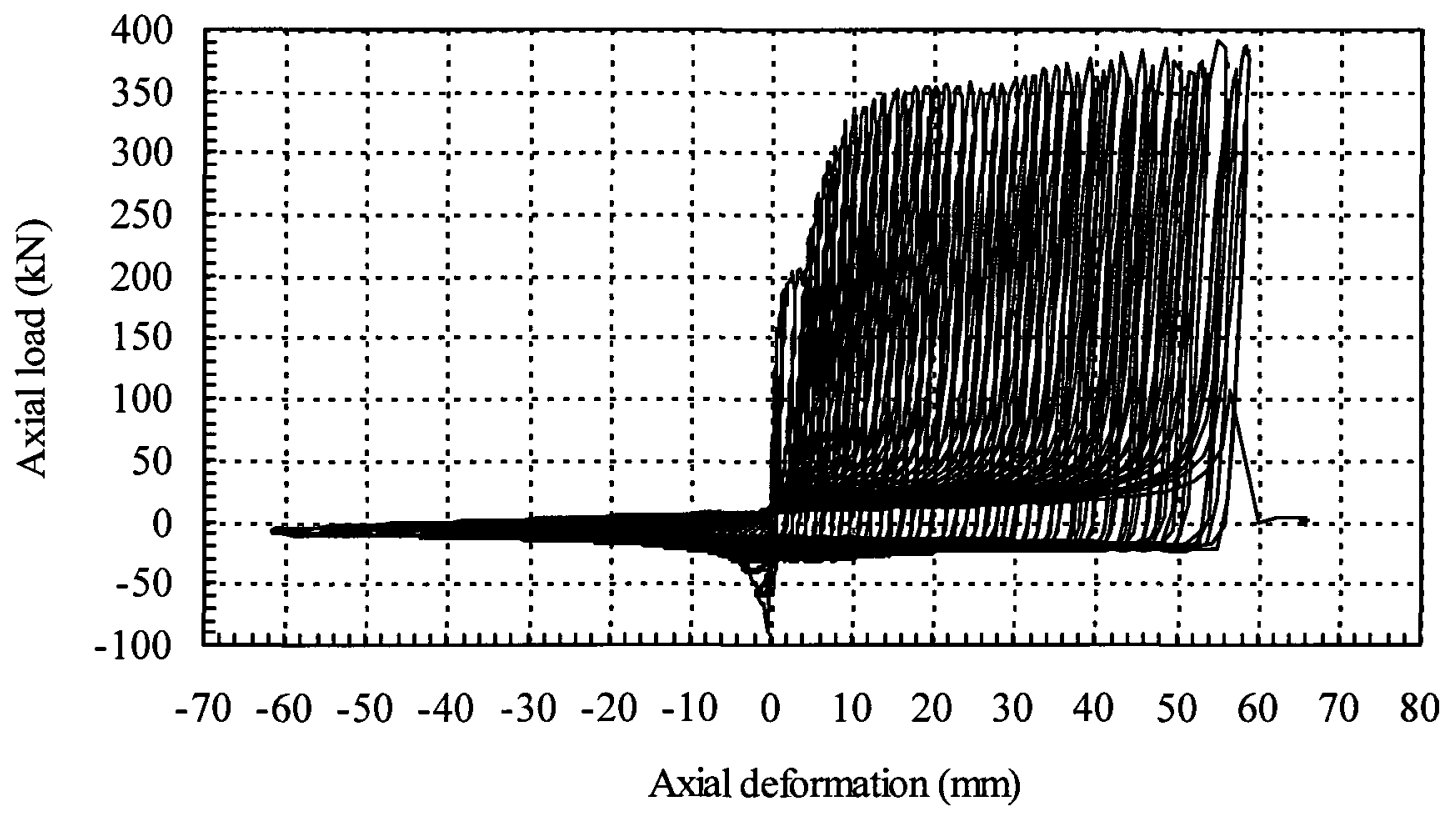

Figure B.32 Axial load versus axial deformation for B2128b specimen. 


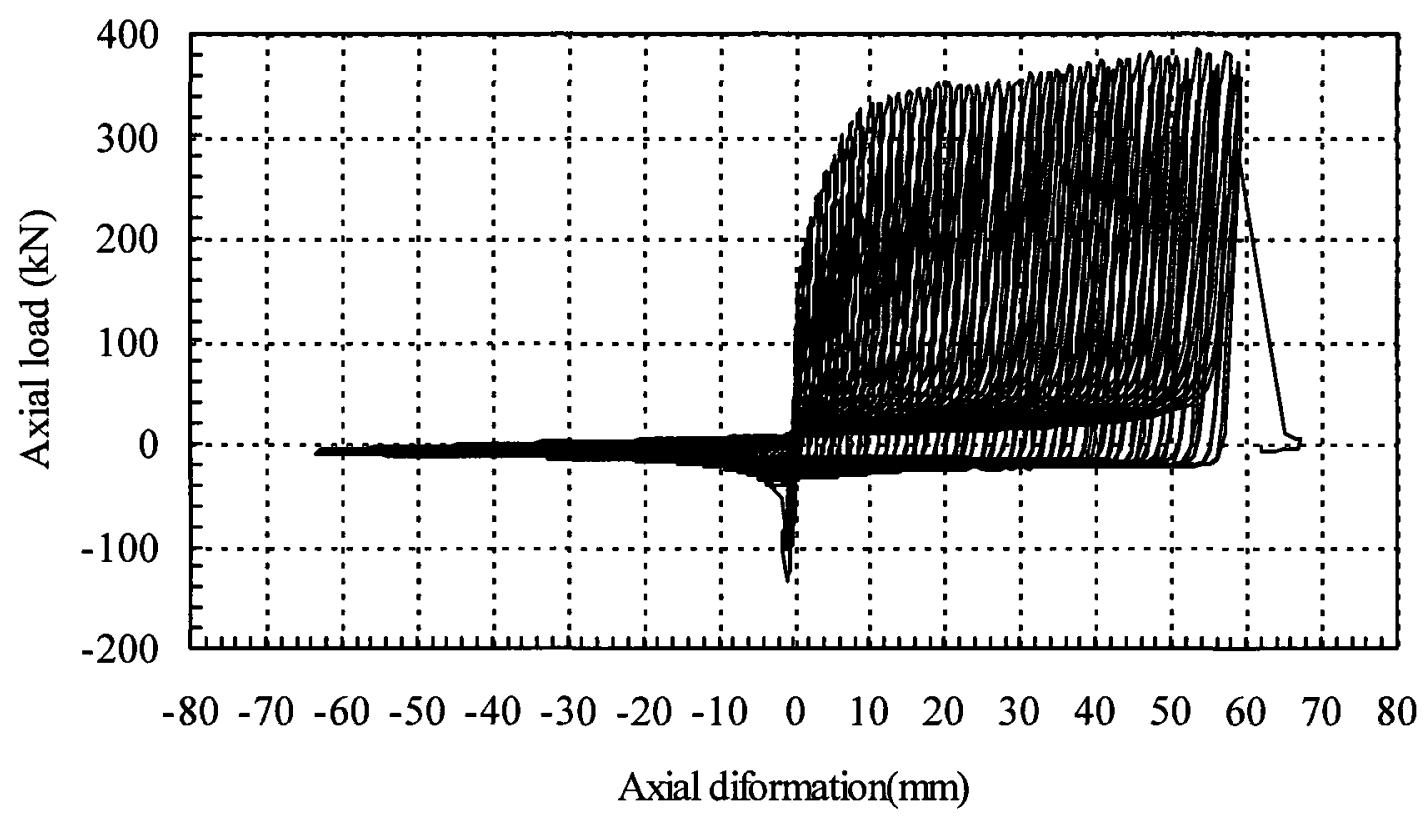

Figure B.33 Axial load versus axial deformation for B2128c specimen.

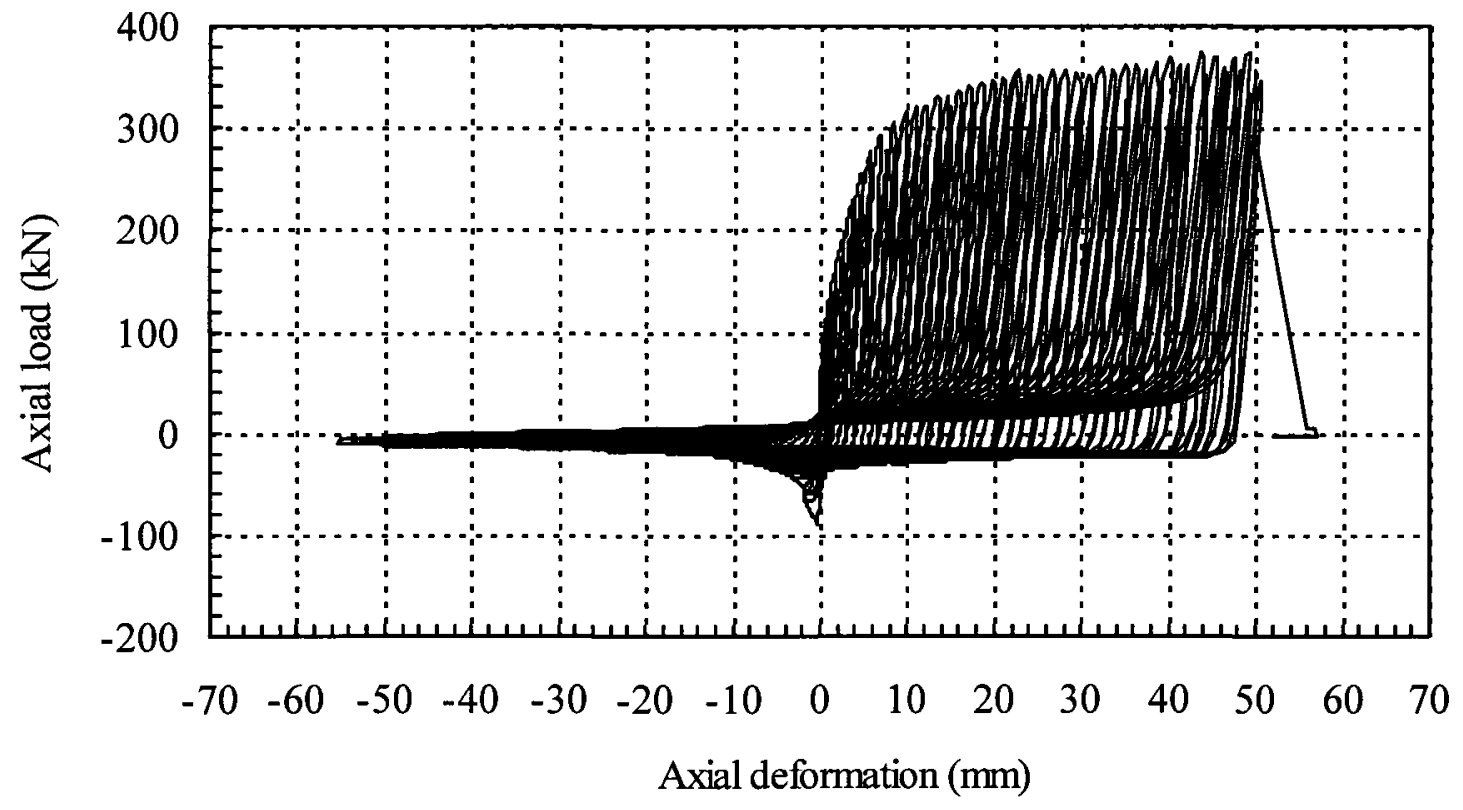

Figure B.34 Axial load versus axial deformation for B2128d specimen. 


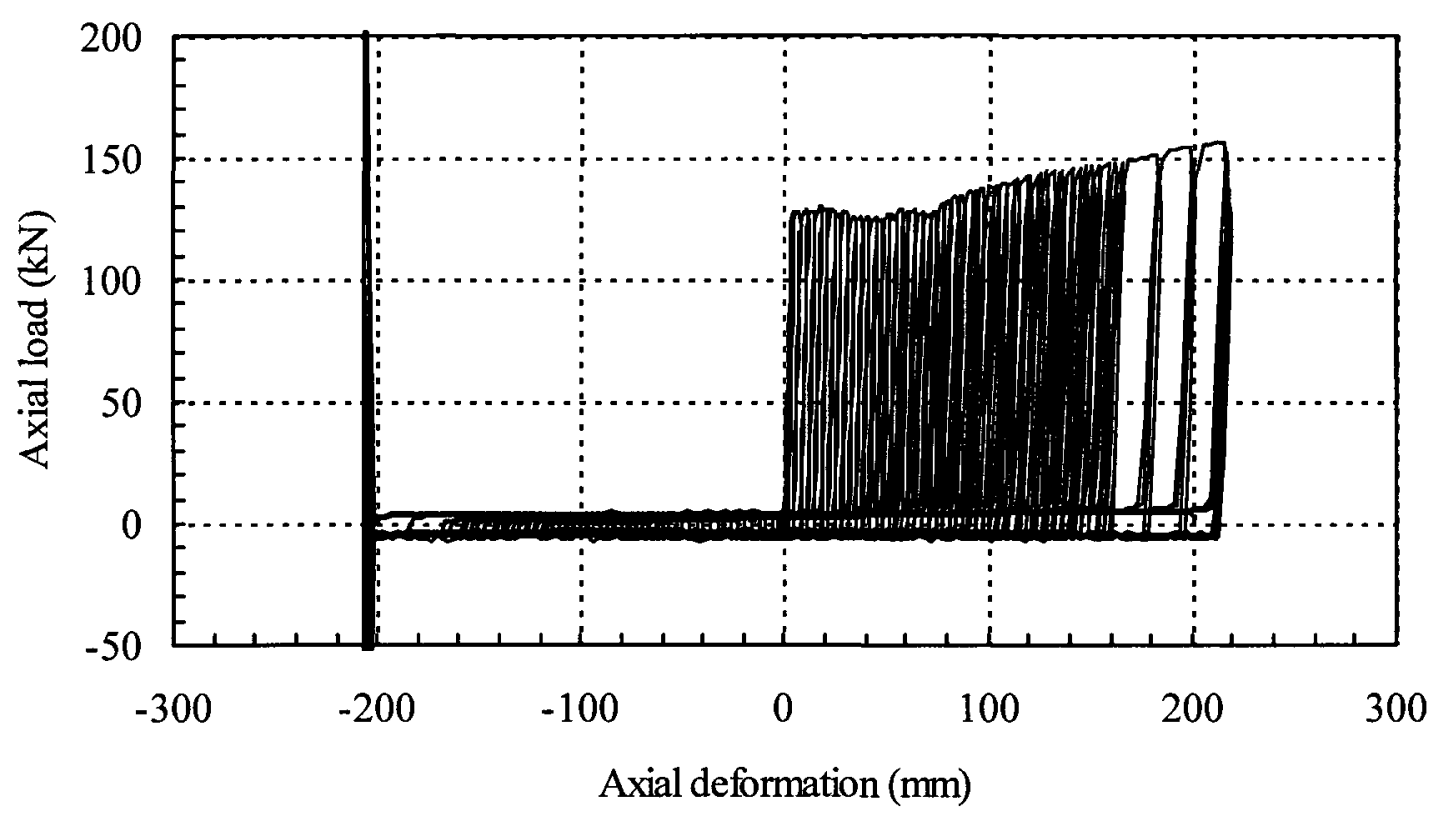

Figure B.35 Axial load versus axial deformation for C8075a specimen.

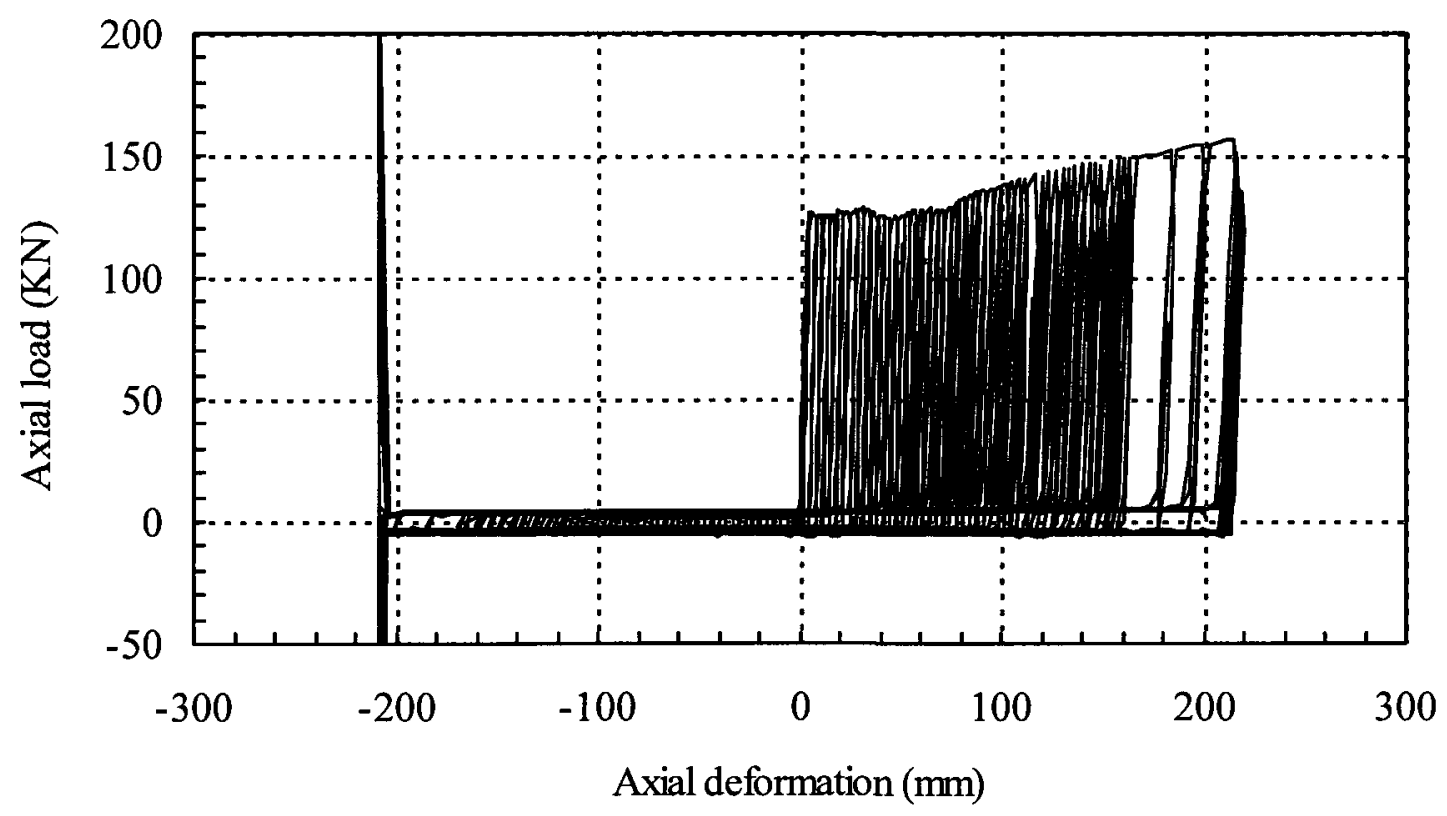

Figure B.36 Axial load versus axial deformation for C8075b specimen. 


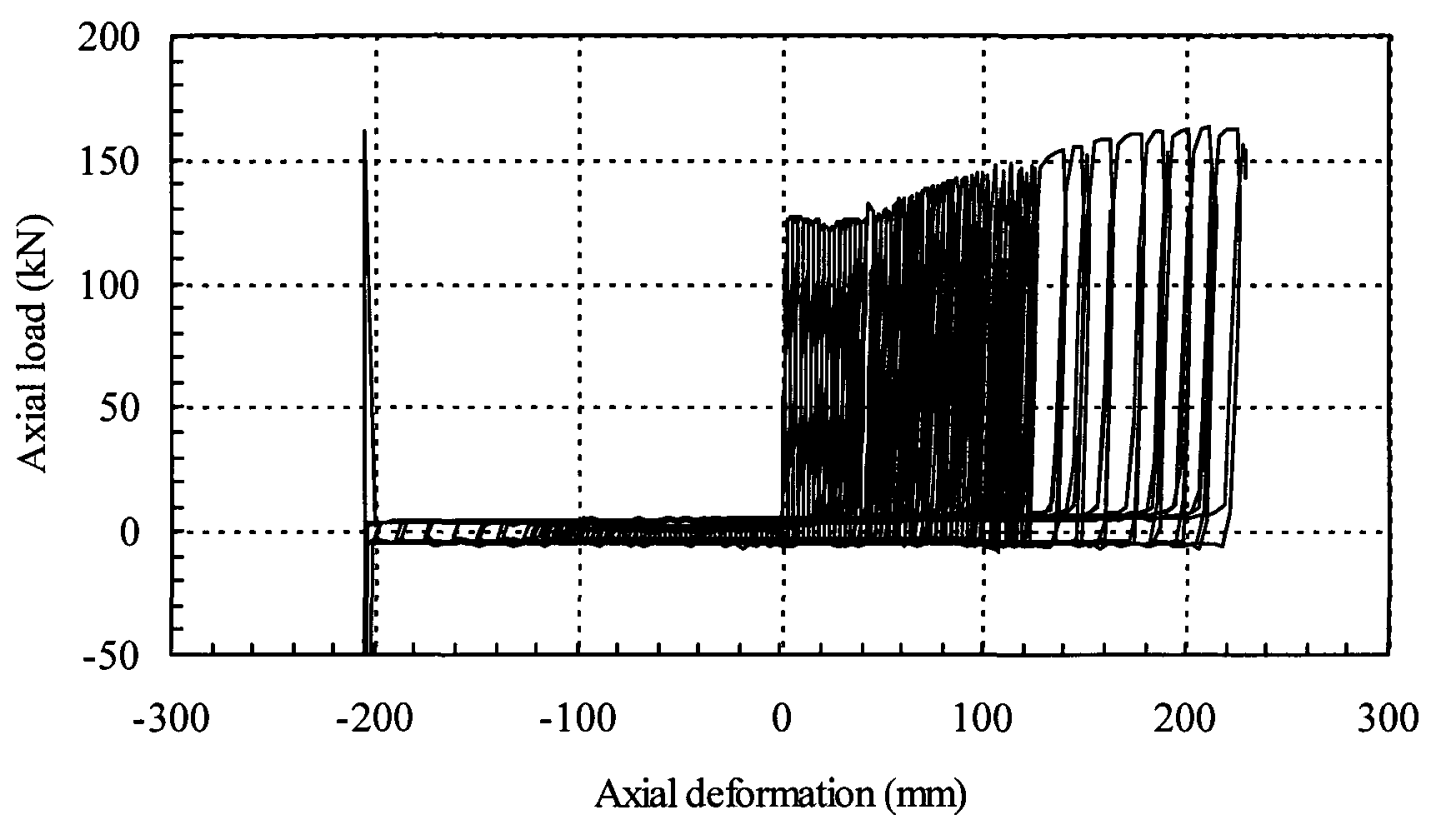

Figure B.37 Axial load versus axial deformation for C6075a specimen.

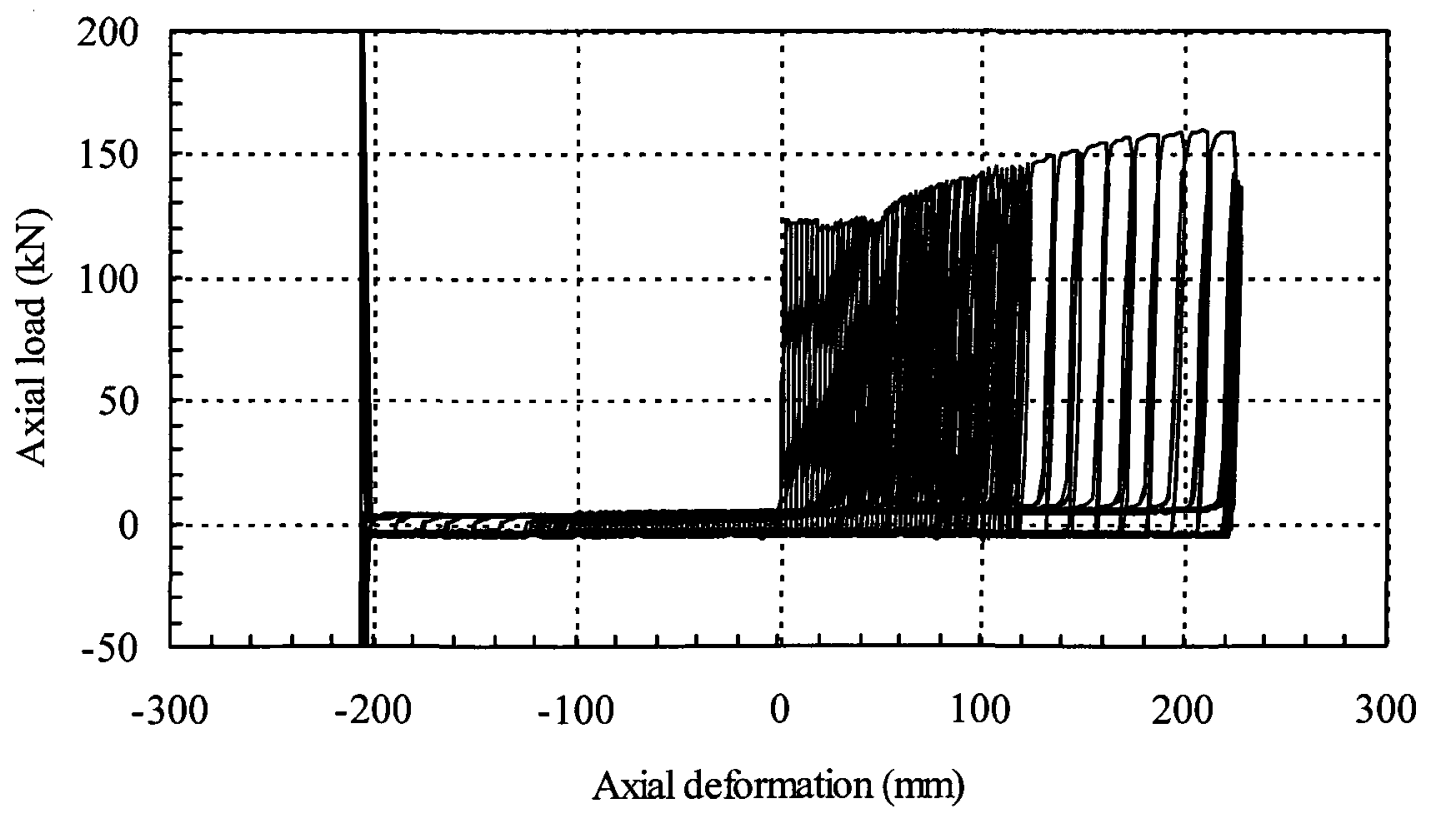

Figure B.38 Axial load versus axial deformation for $\mathrm{C} 6075 \mathrm{~b}$ specimen. 


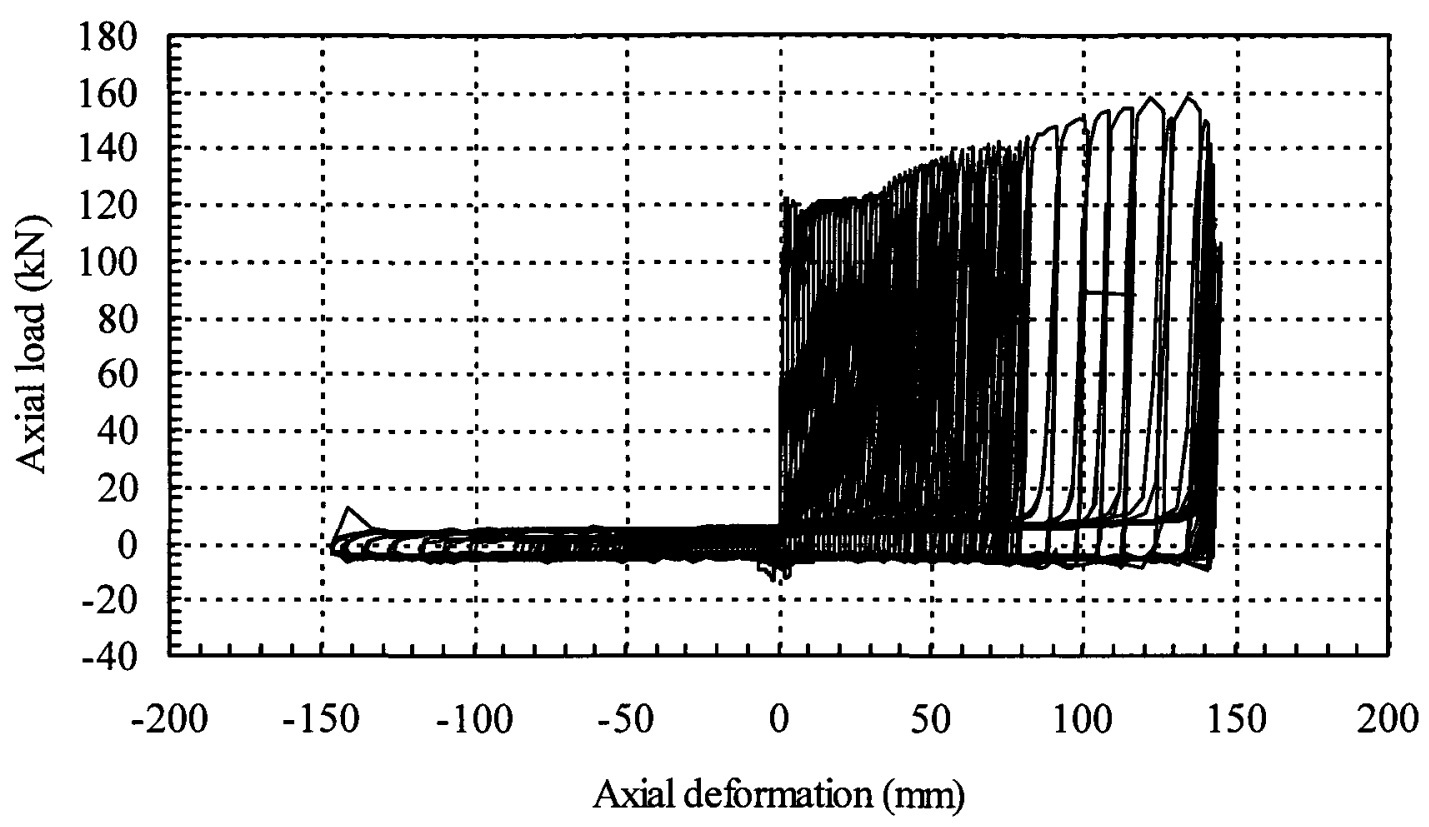

Figure B.39 Axial load versus axial deformation for C4075a specimen.

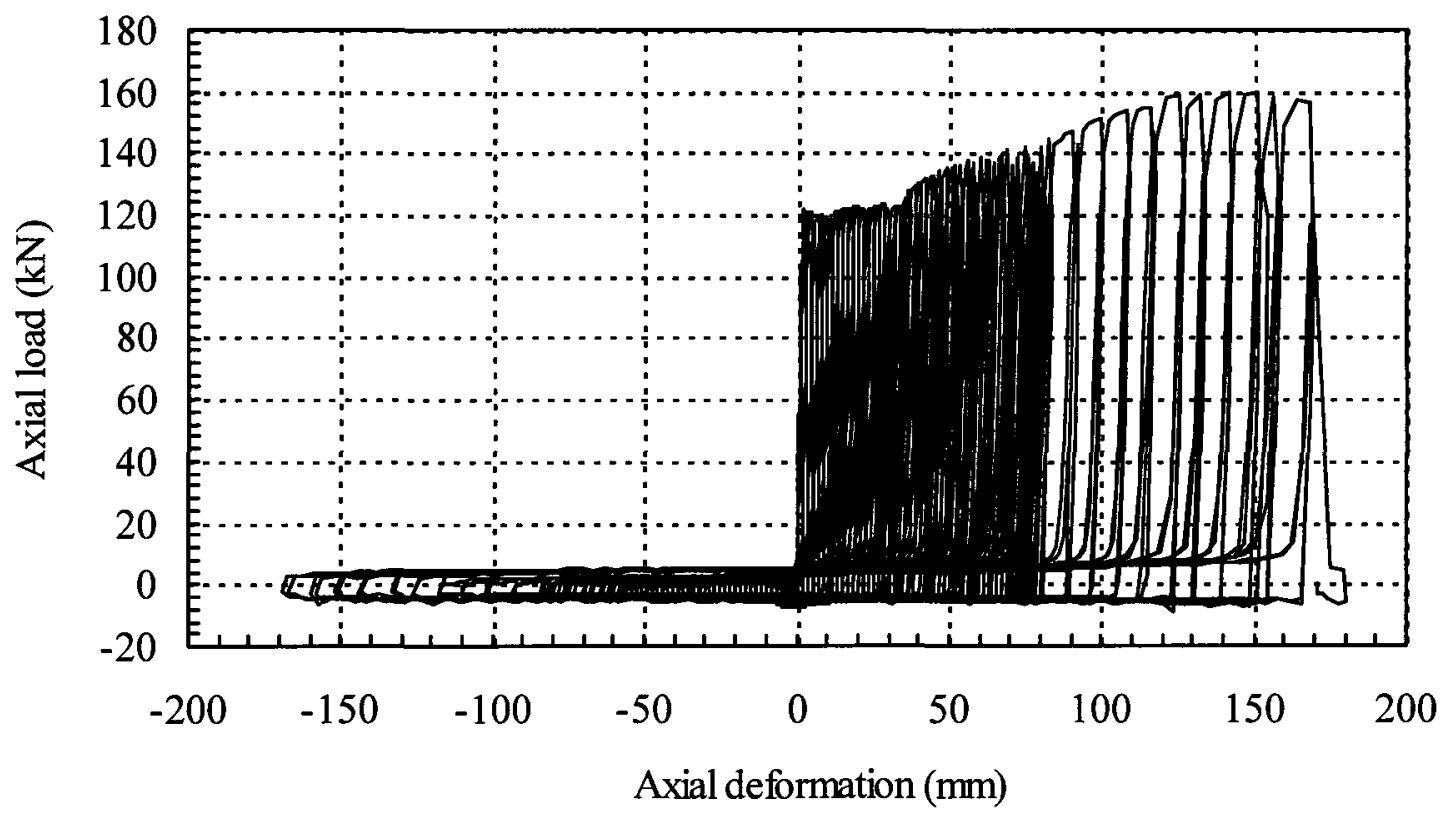

Figure B.40 Axial load versus axial deformation for $\mathrm{C} 4075 \mathrm{~b}$ specimen. 


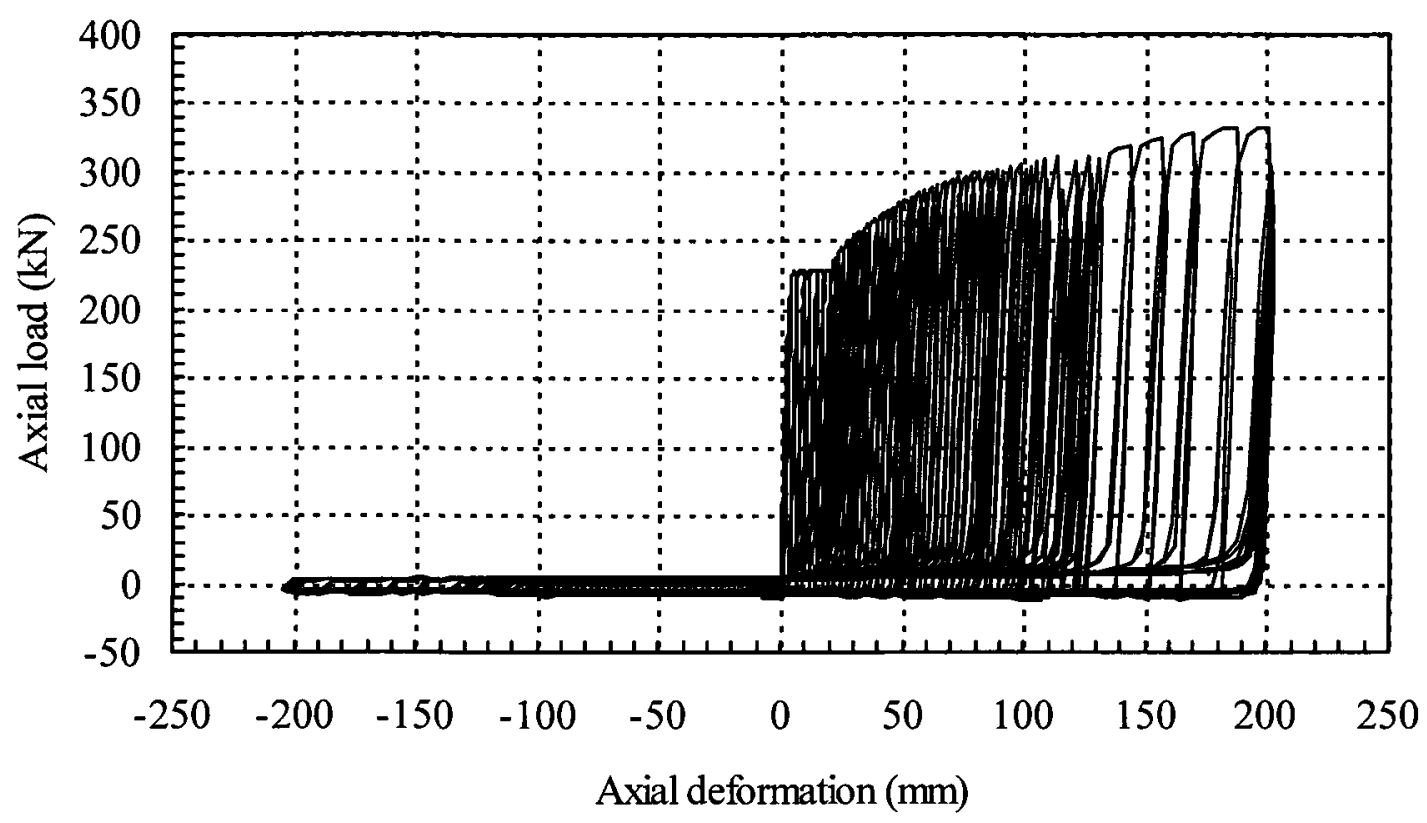

Figure B.41 Axial load versus axial deformation for C4078a specimen.

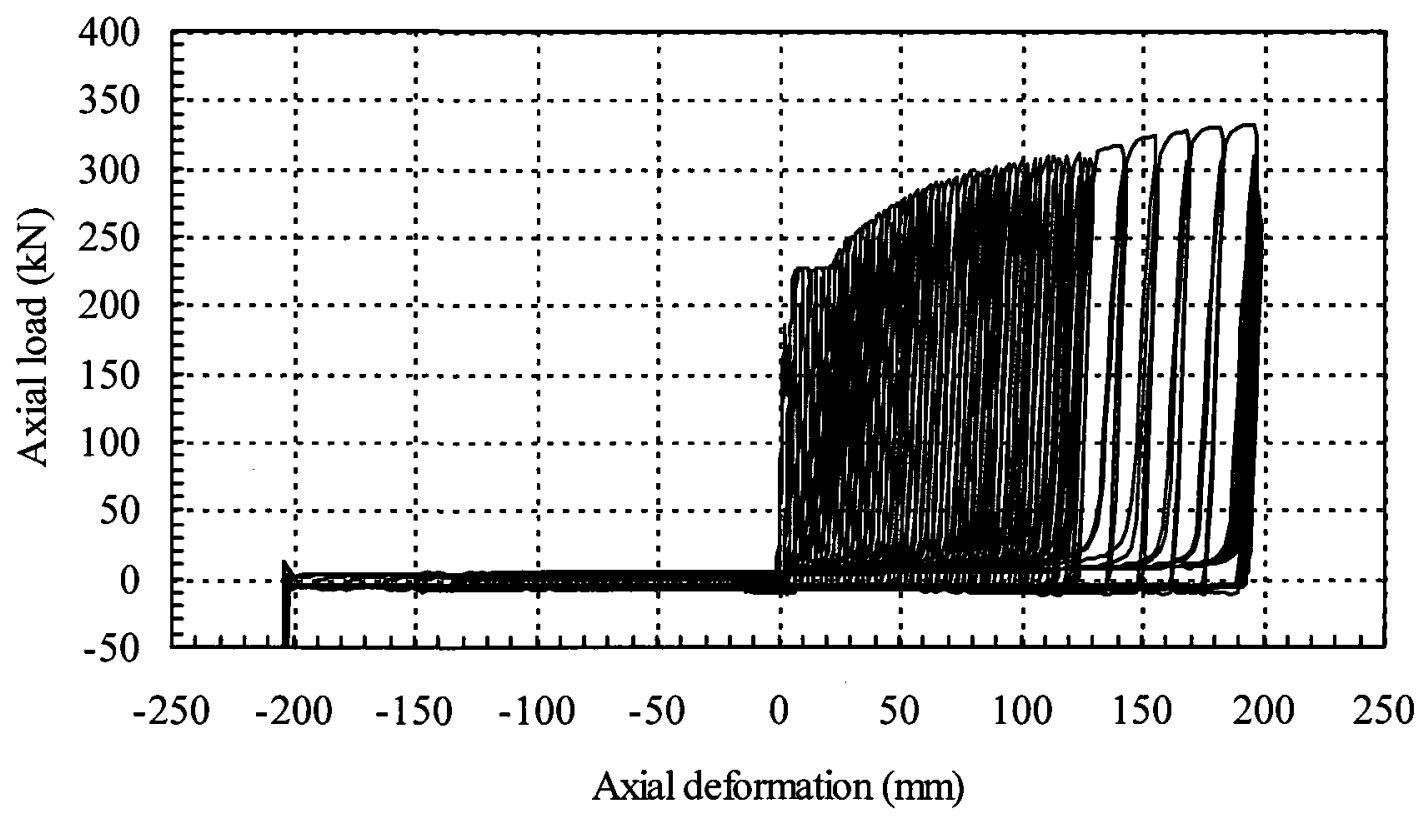

Figure B.42 Axial load versus axial deformation for $\mathrm{C} 4078 \mathrm{~b}$ specimen. 


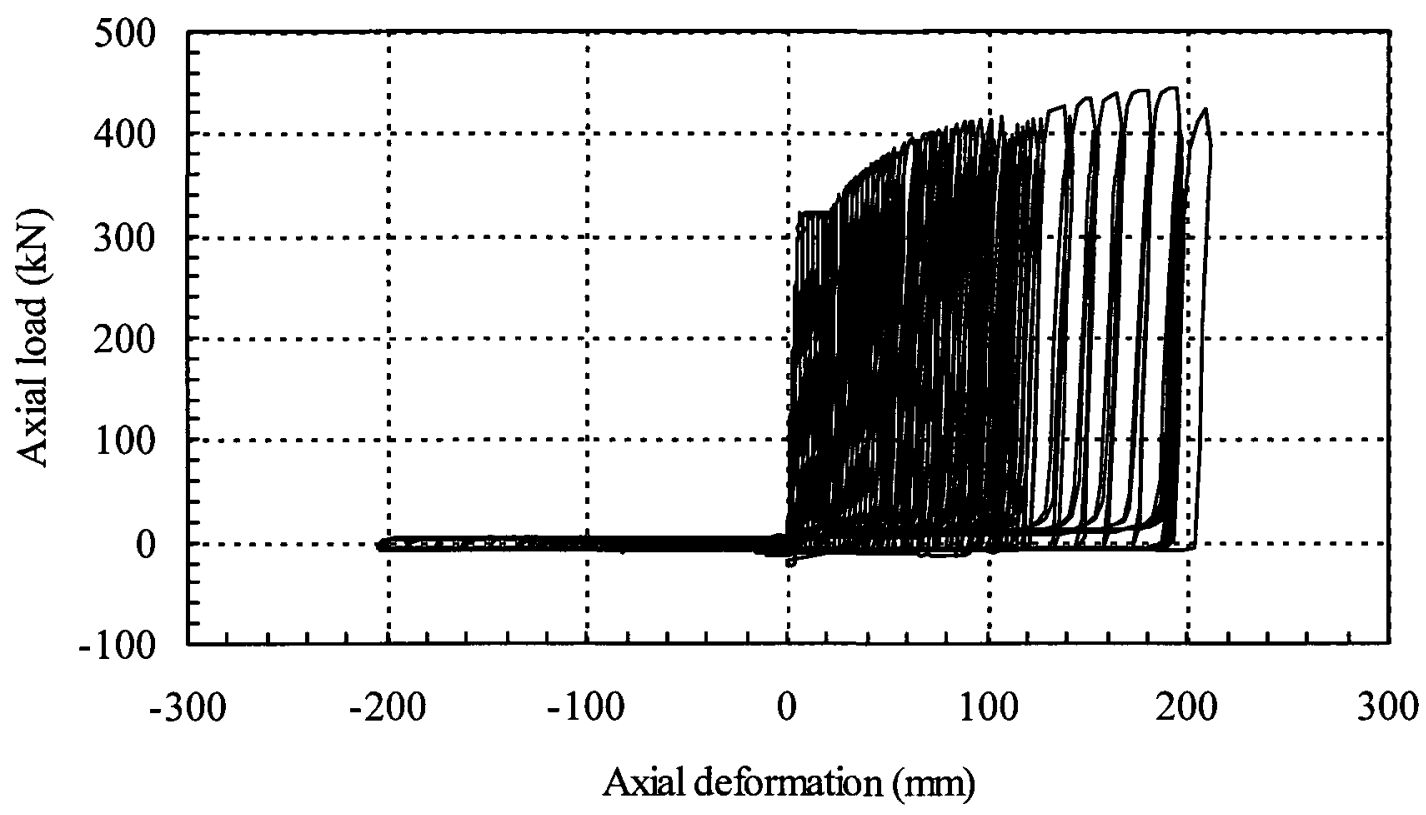

Figure B.43 Axial load versus axial deformation for C4108a specimen.

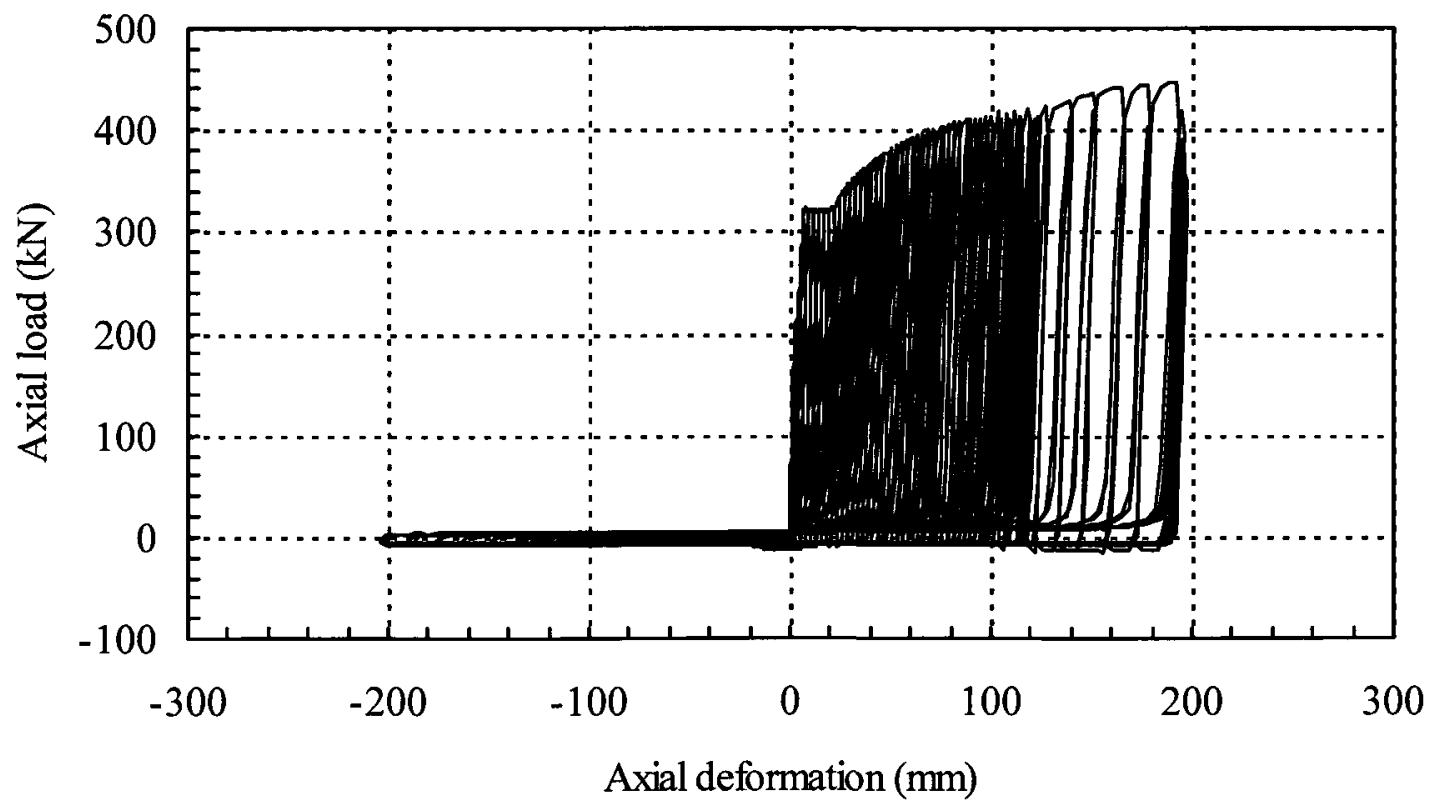

Figure B.44 Axial load versus axial deformation for $\mathrm{C} 4108 \mathrm{~b}$ specimen. 


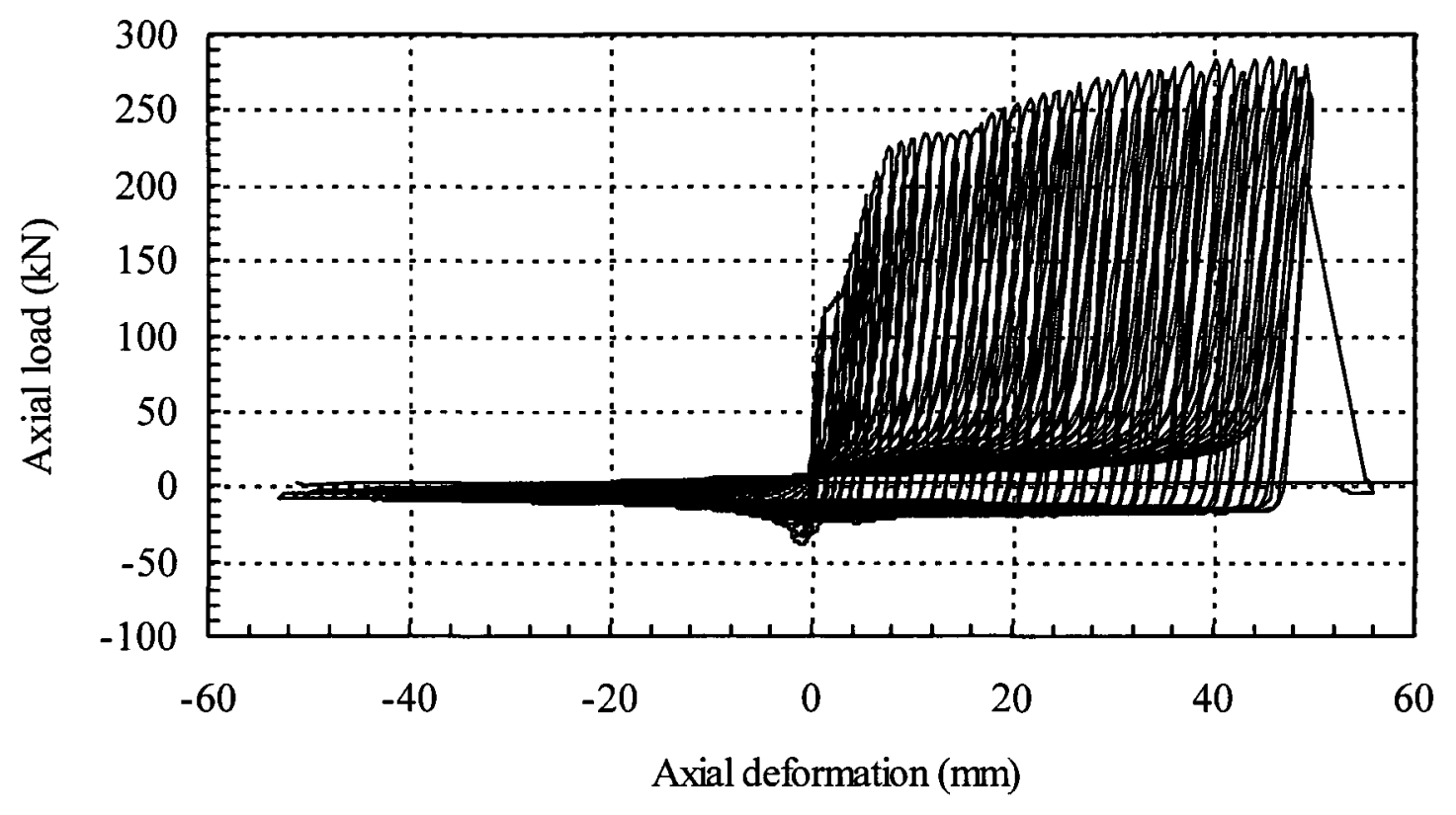

Figure B.45 Axial load versus axial deformation for C2078a specimen.

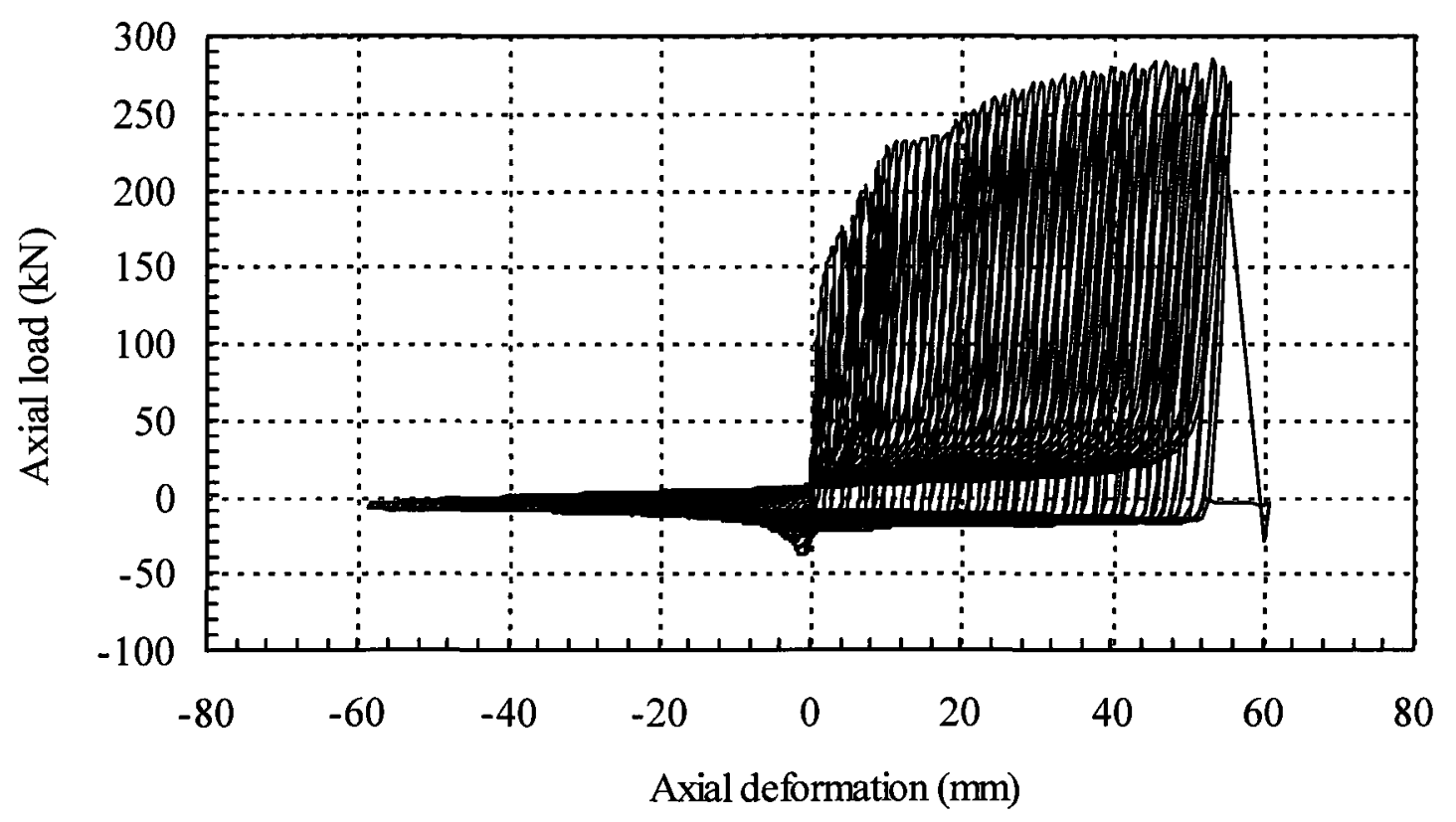

Figure B.46 Axial load versus axial deformation for $\mathrm{C} 2078 \mathrm{~b}$ specimen. 


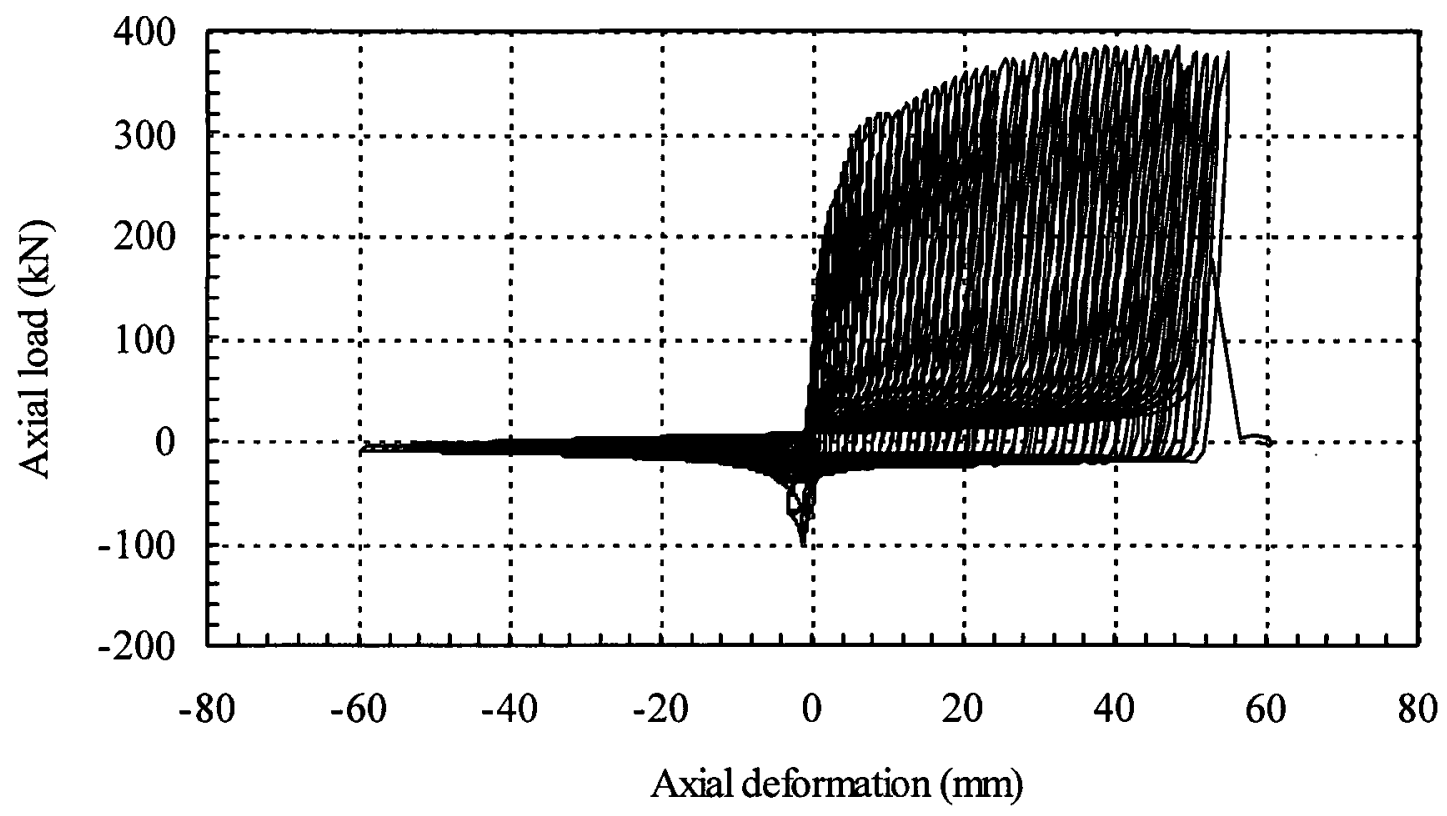

Figure B.47 Axial load versus axial deformation for C2108a specimen.

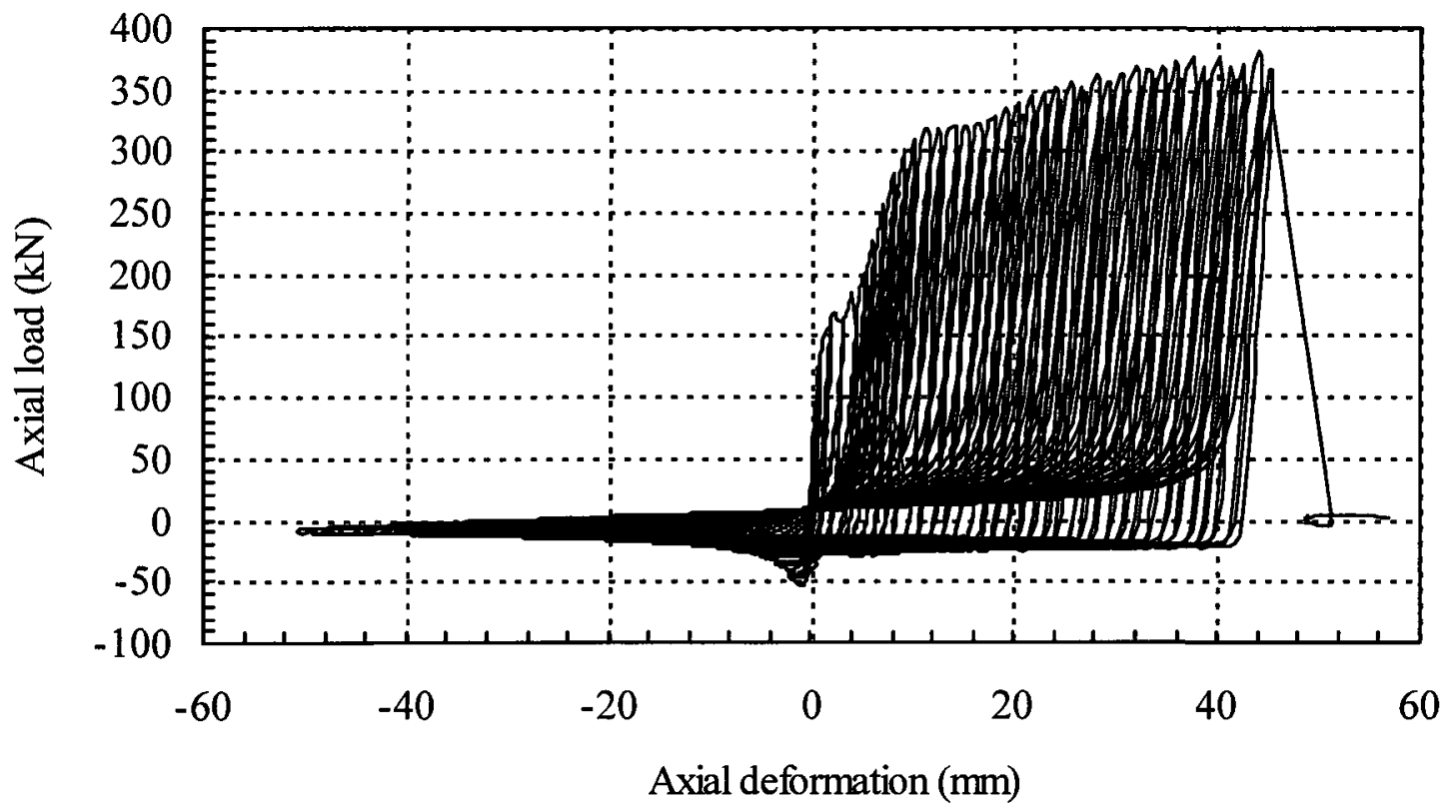

Figure B.48 Axial load versus axial deformation for $\mathrm{C} 2108 \mathrm{~b}$ specimen. 


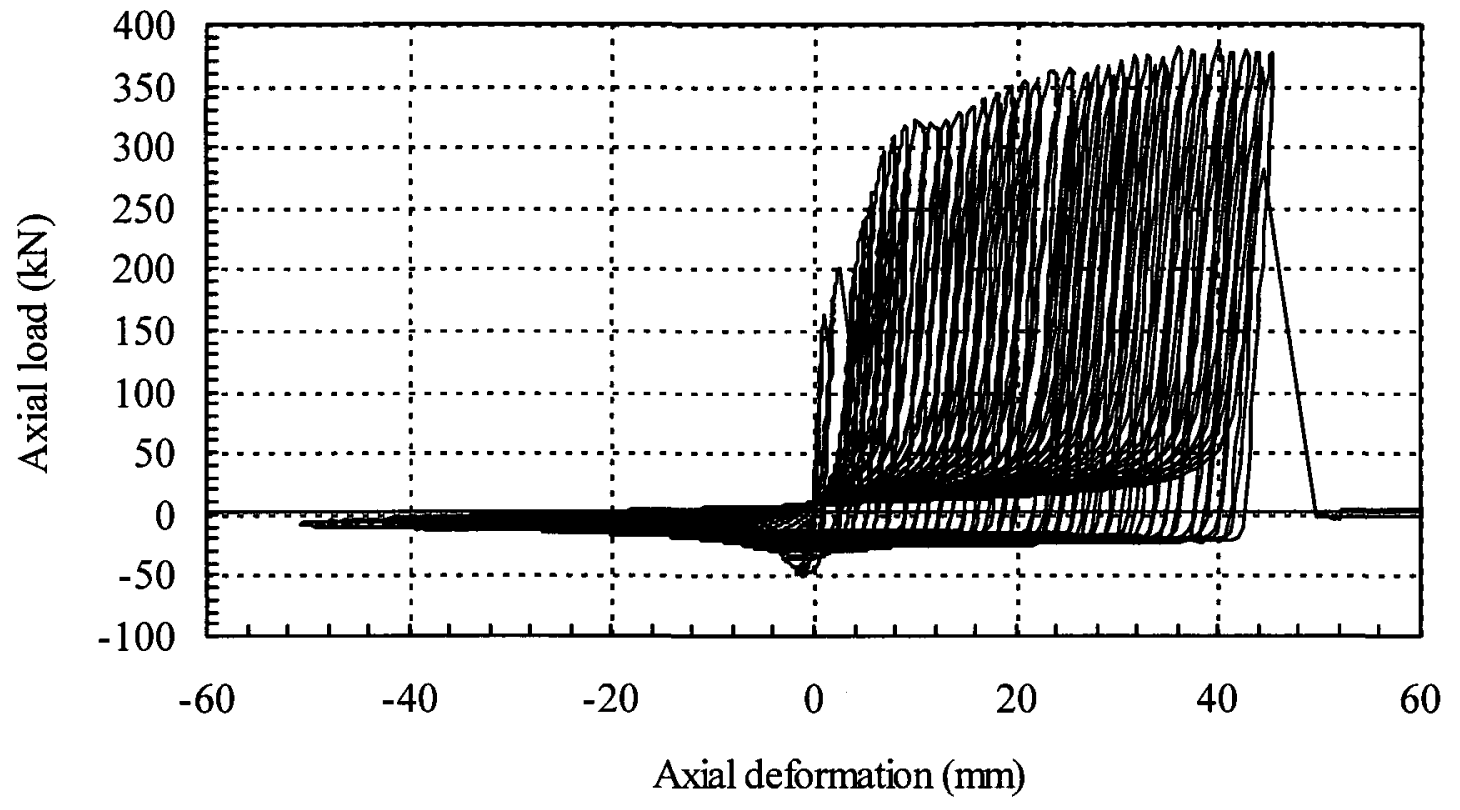

Figure B.49 Axial load versus axial deformation for $\mathrm{C} 2108 \mathrm{c}$ specimen. 
APPENDIX C: PICTURES OF SPECIMEN FRACTURE AND BUCRK TNG

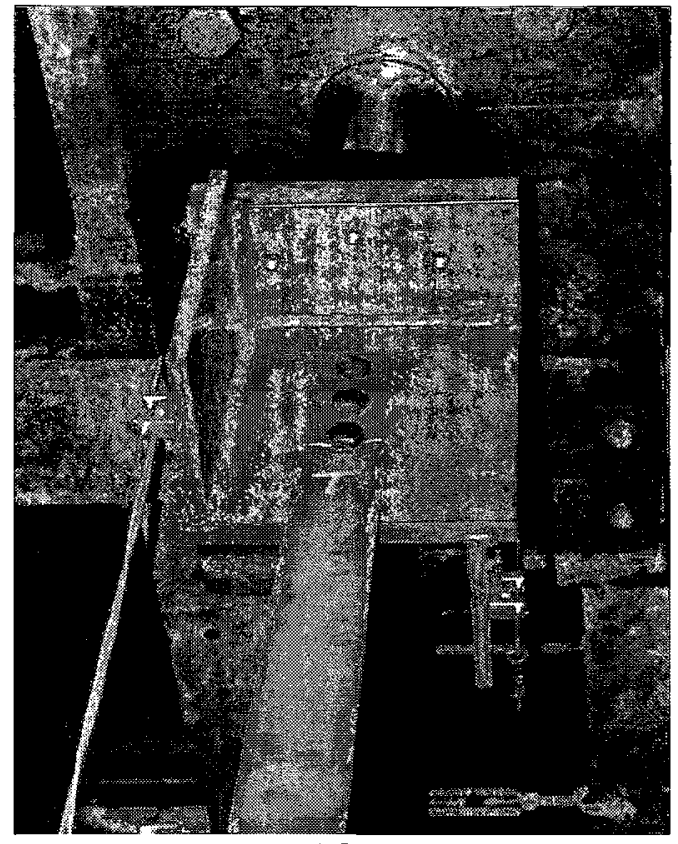

A8075a

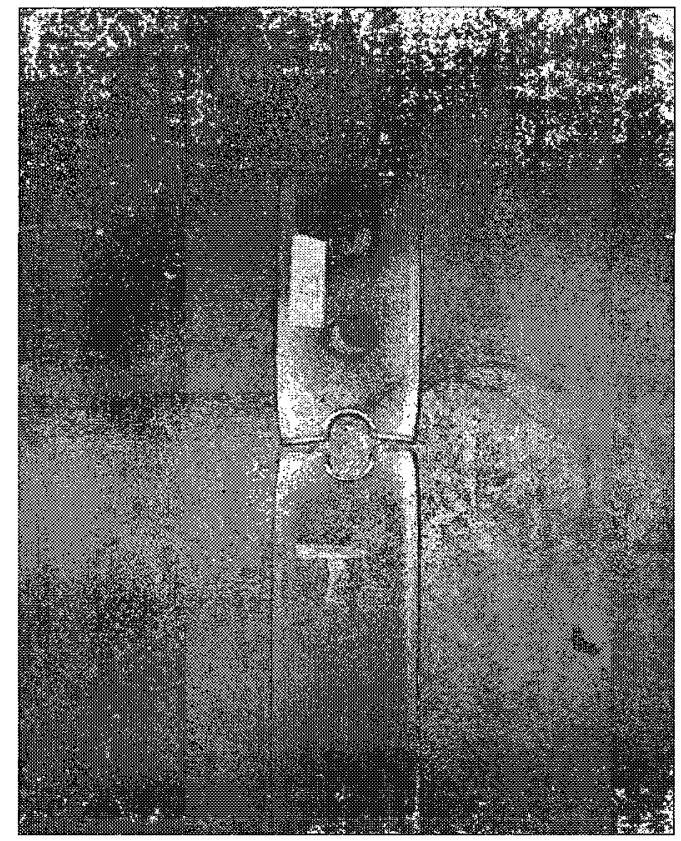

$\mathrm{A} 8075 b$

Figure C.1 Failure of A8075a and A8075b.

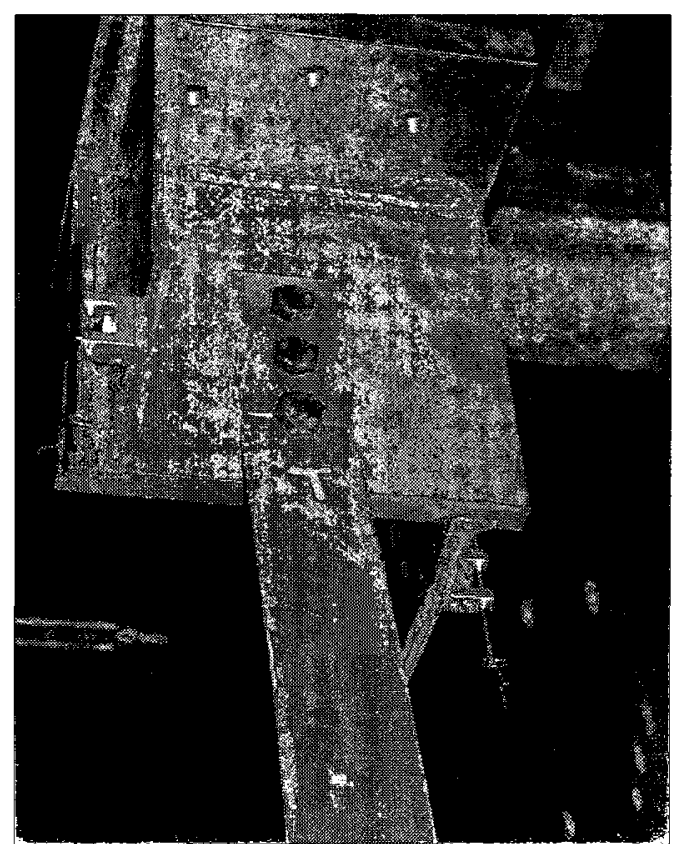

A6075

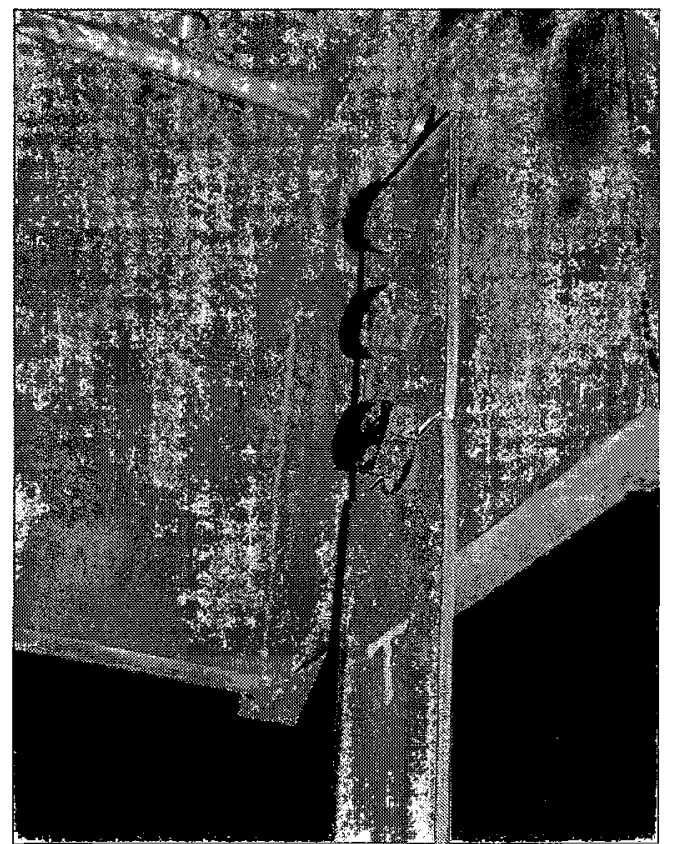

A6075b

Figure $\mathbb{C} .2$ Failure of $\mathbb{A} 6075 a$ and $A 6075 b$. 


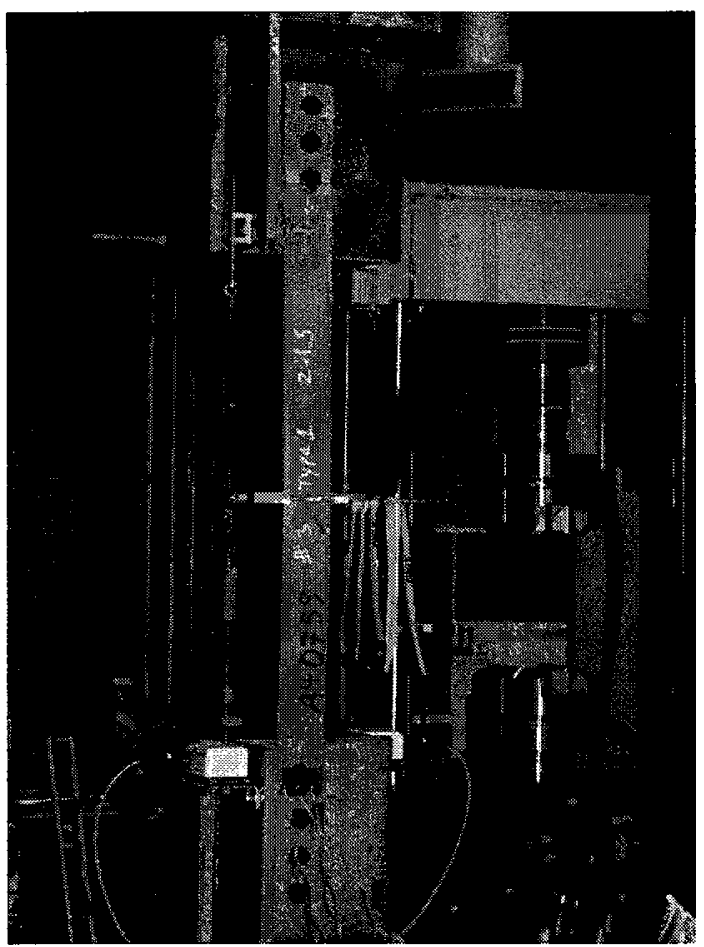

A4075a

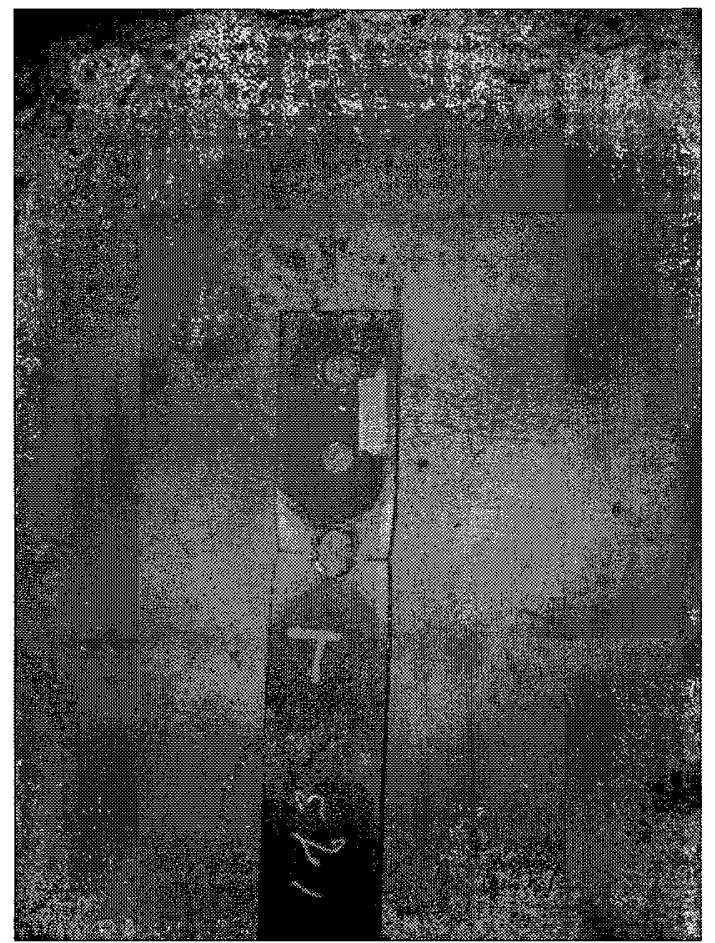

$\mathrm{A} 4075 \mathrm{~b}$

Figure C.3 Failure of A4075a and A4075b.
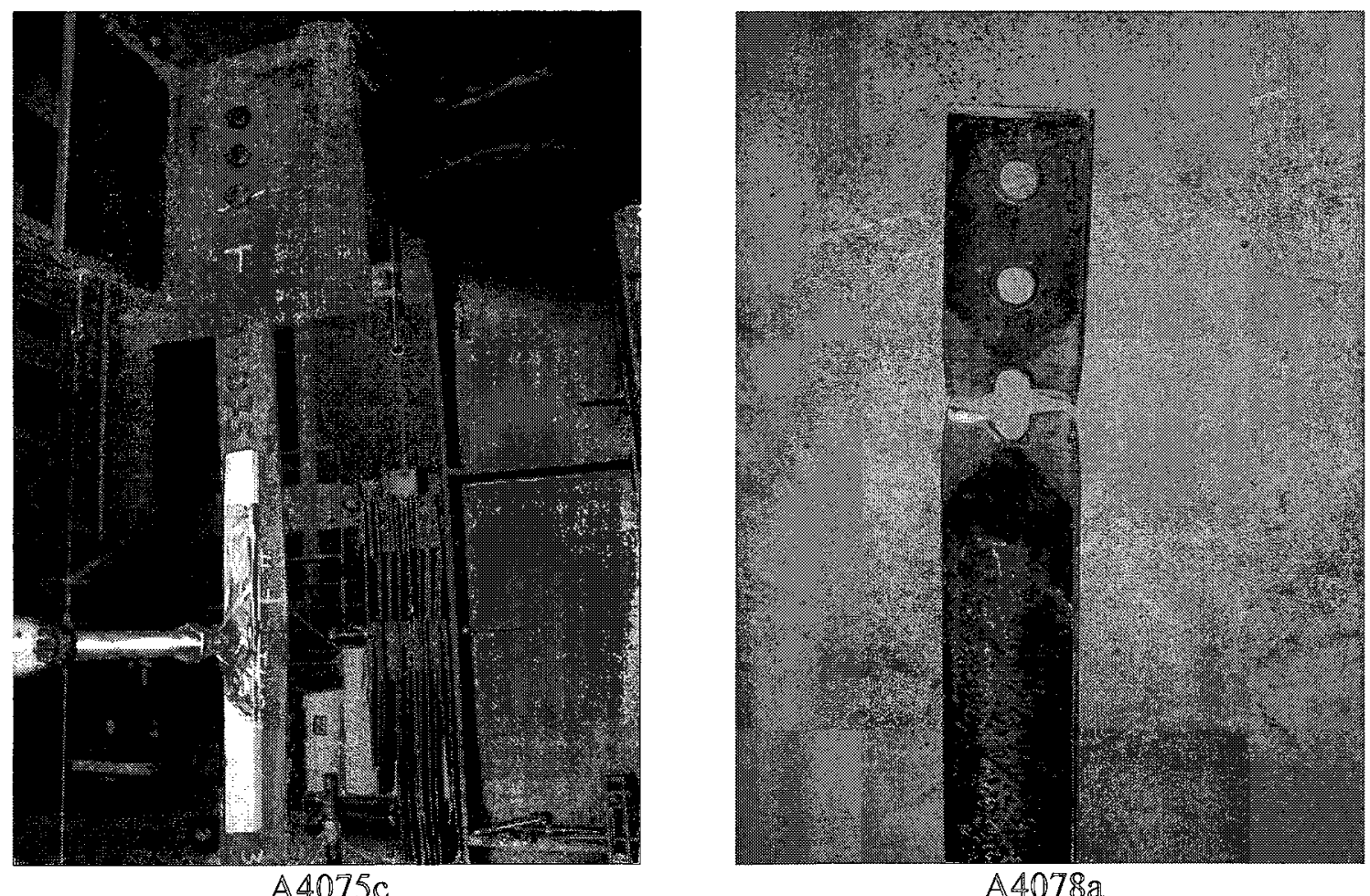

A4078a

Figure $C_{.4}$ Failure of $\mathrm{A} 4075 \mathrm{C}$ and $\mathrm{A} 4078 \mathrm{a}$ 


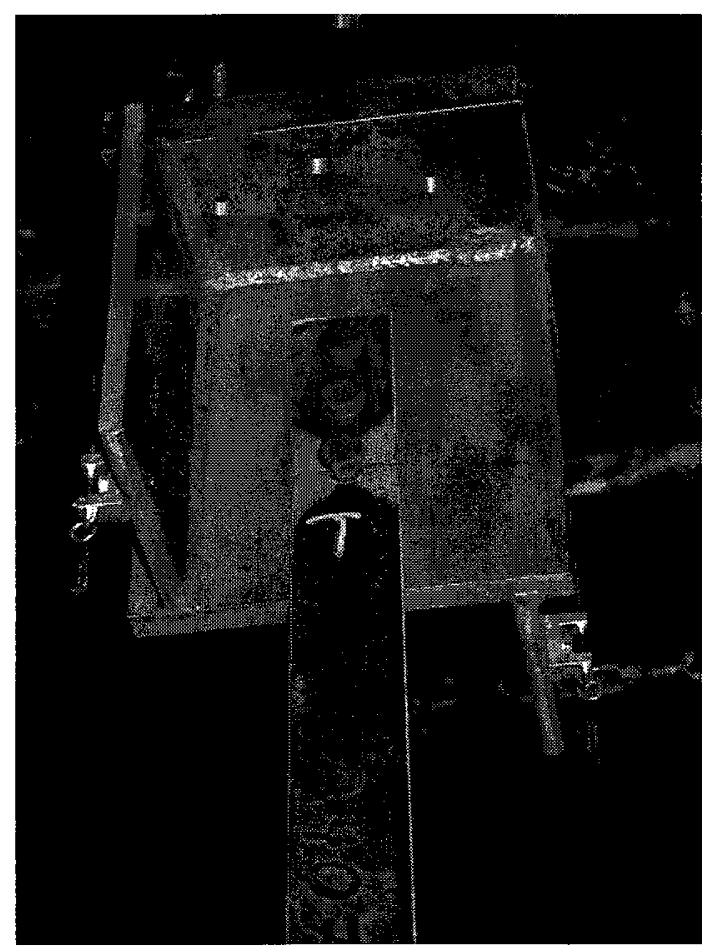

A4078b

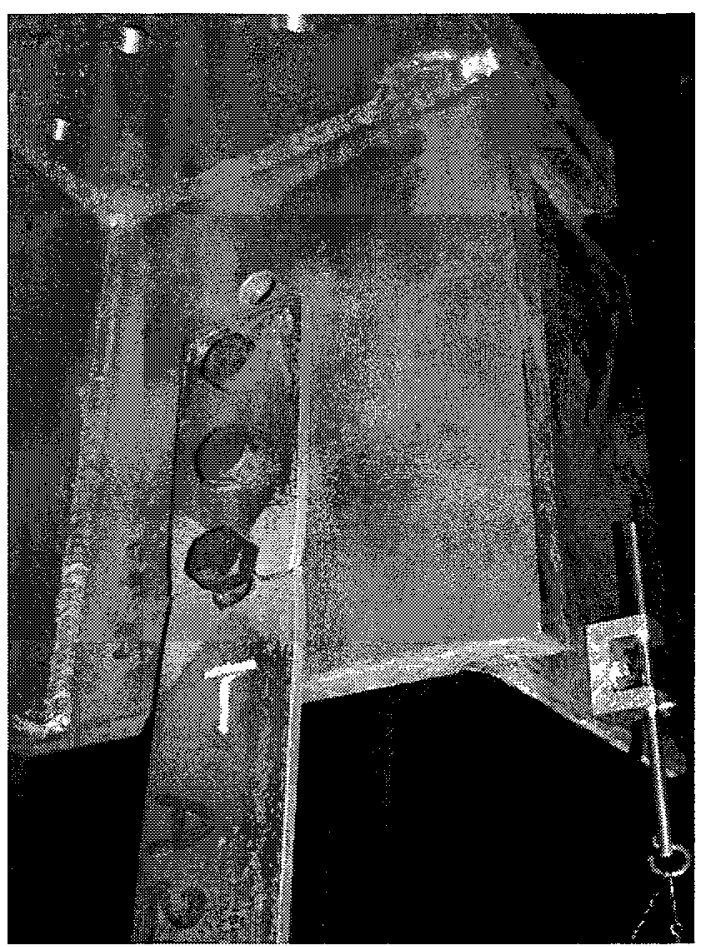

A2078a

Figure C.5 Failure of A4078b and A2078a.

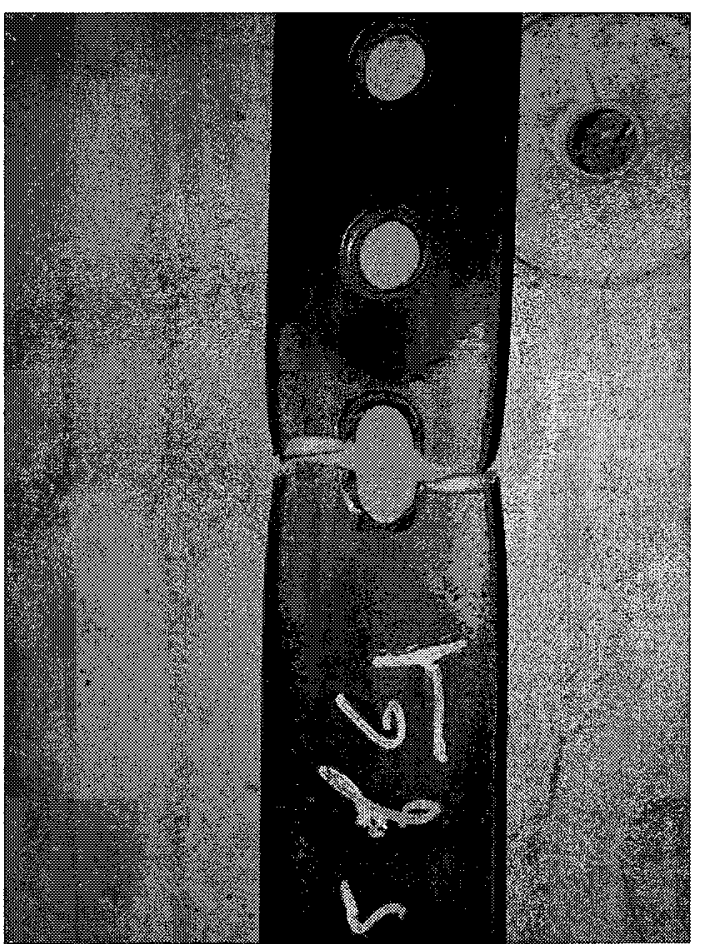

A2078b

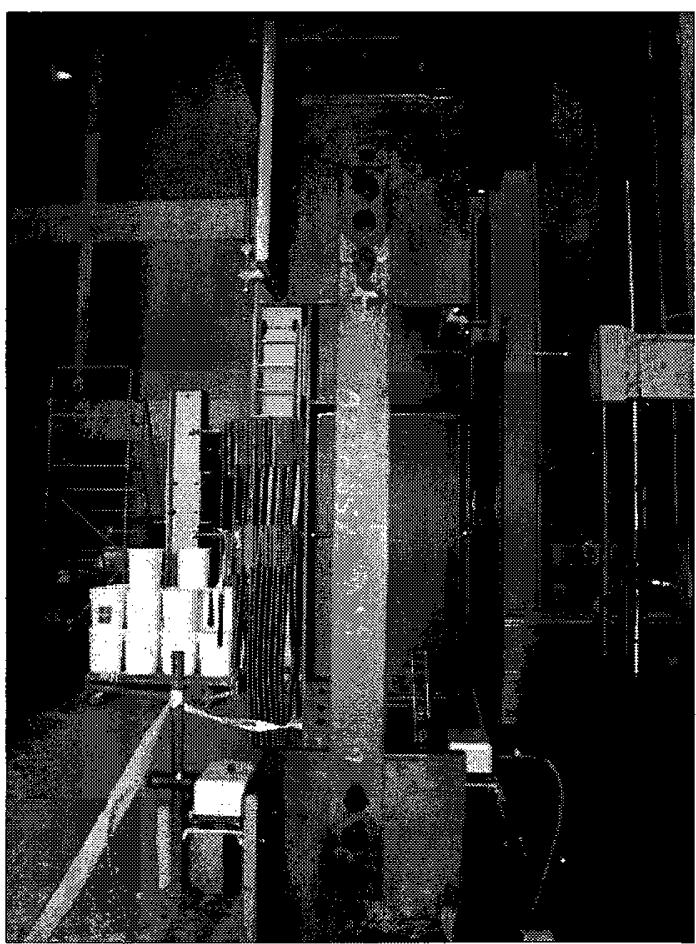

A2078d

Figure C.6 Failure of A2078b and A2078d. 


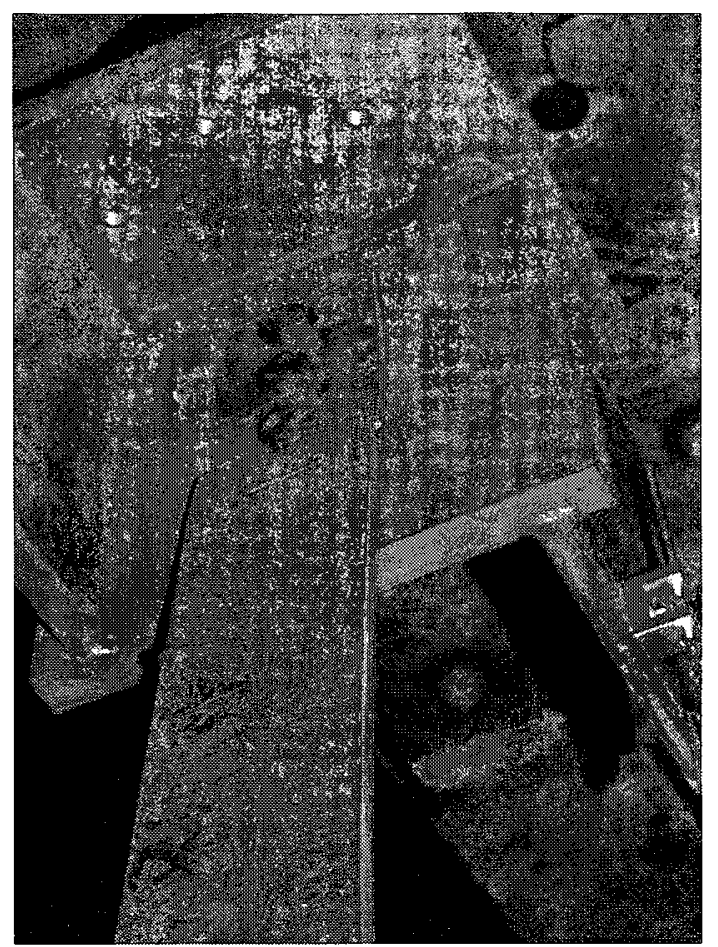

A2078e

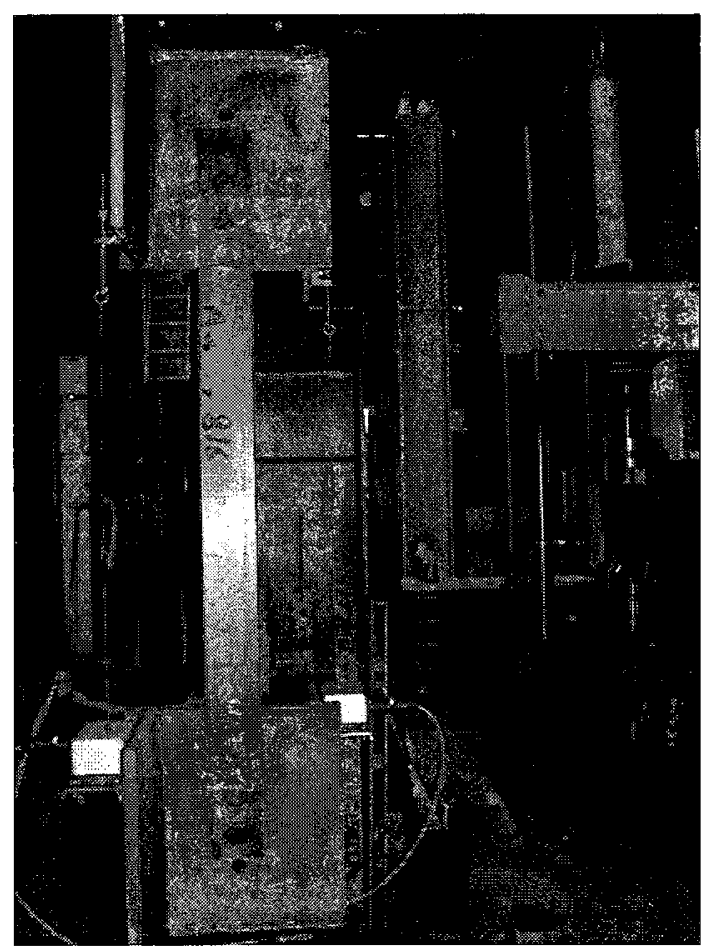

A4108a

Figure C.7 Failure of A2078e and A4108a.

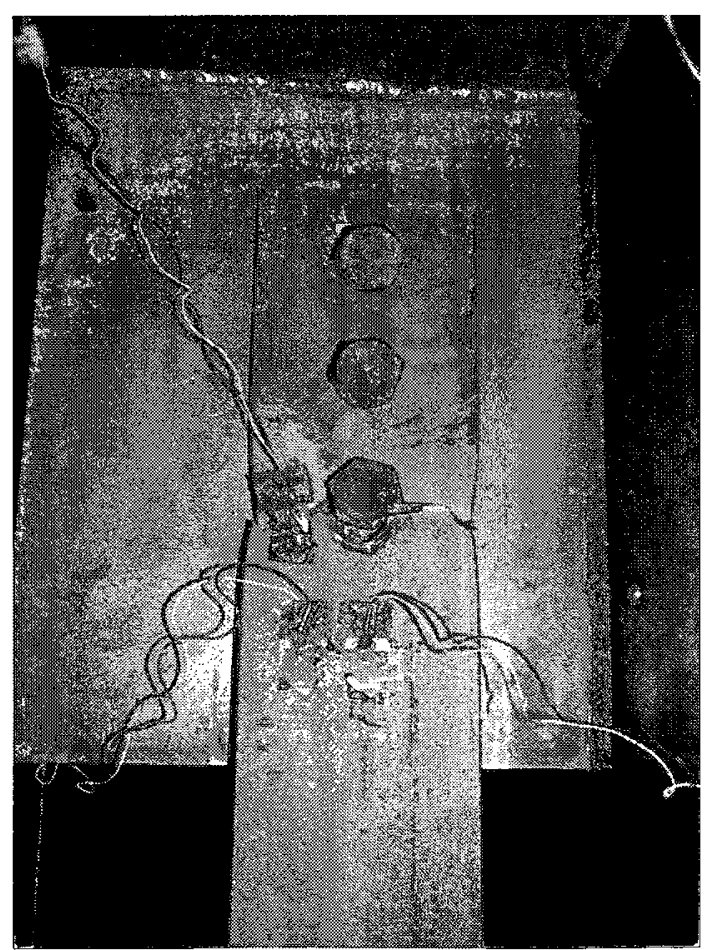

A4108b

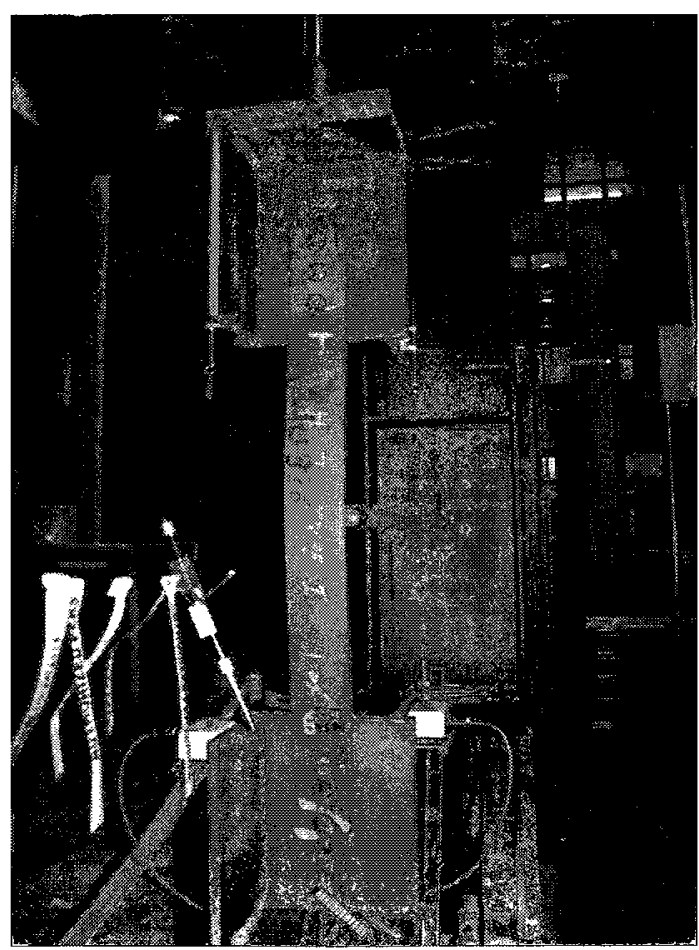

$\mathbb{A} 2108 \mathrm{a}$

Figure $\mathbb{C} .8$ Failure of $A 4108 B$ and $A 2108$. 


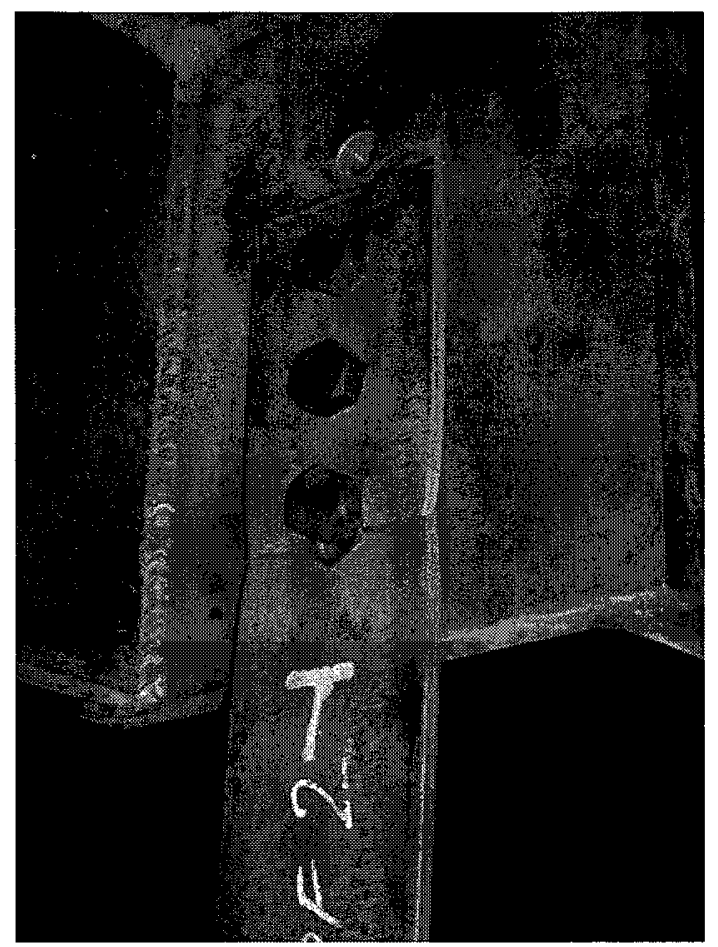

A2108b

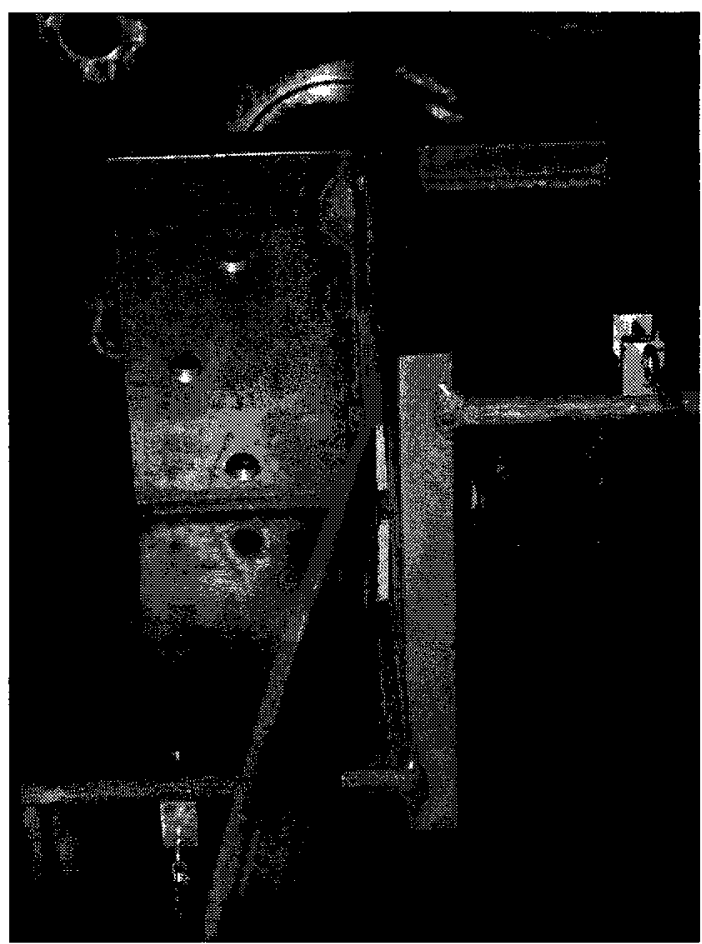

A4128a

Figure C.9 Failure of A2108b and A4128a.

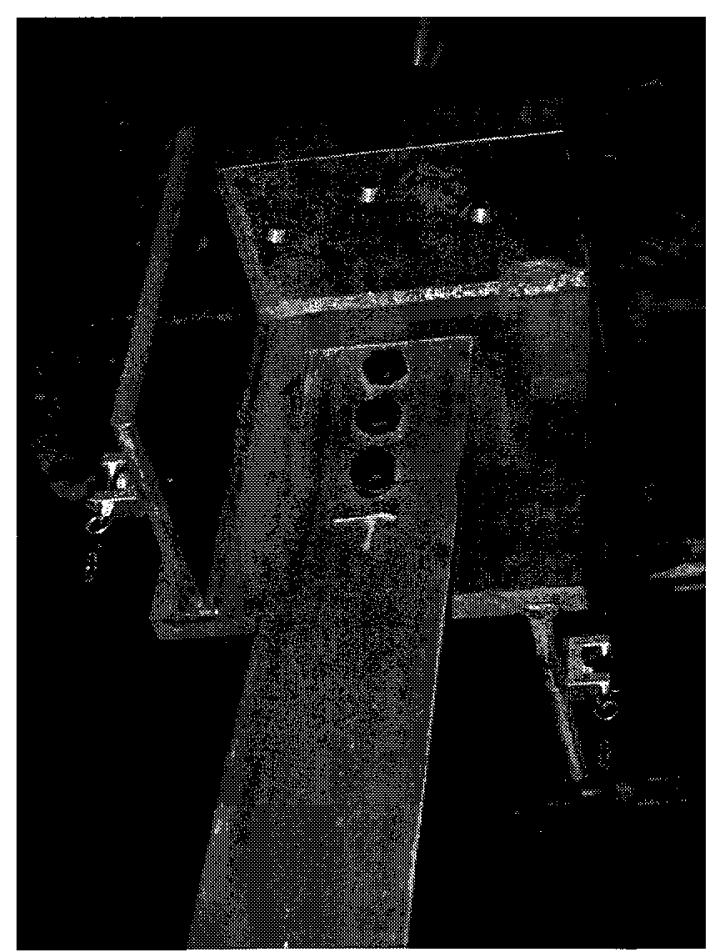

A4128b

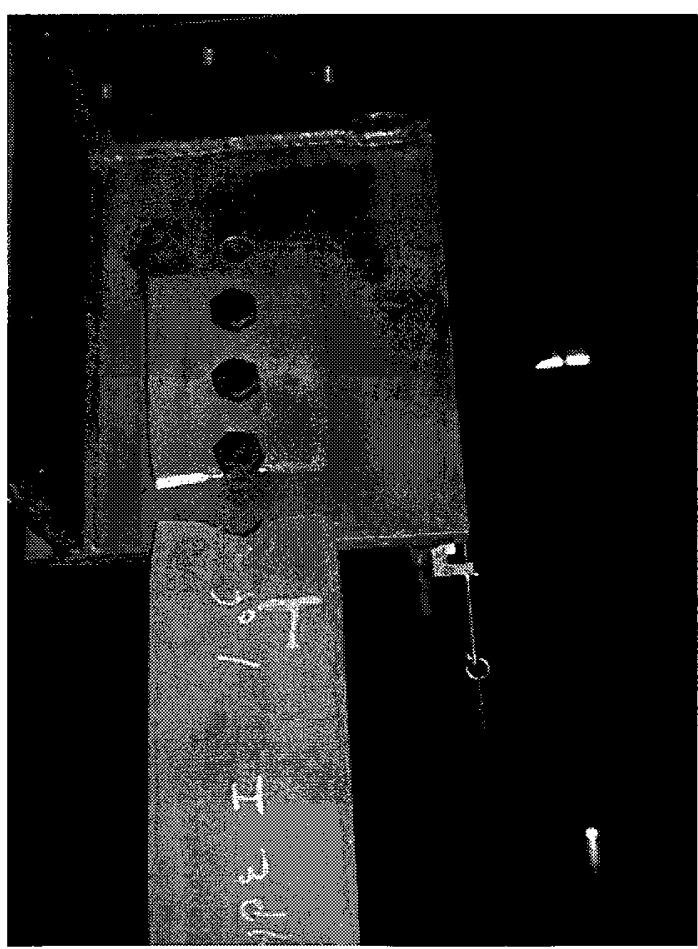

A2128a

Figure C.10 Failure of A4128b and A2128a. 


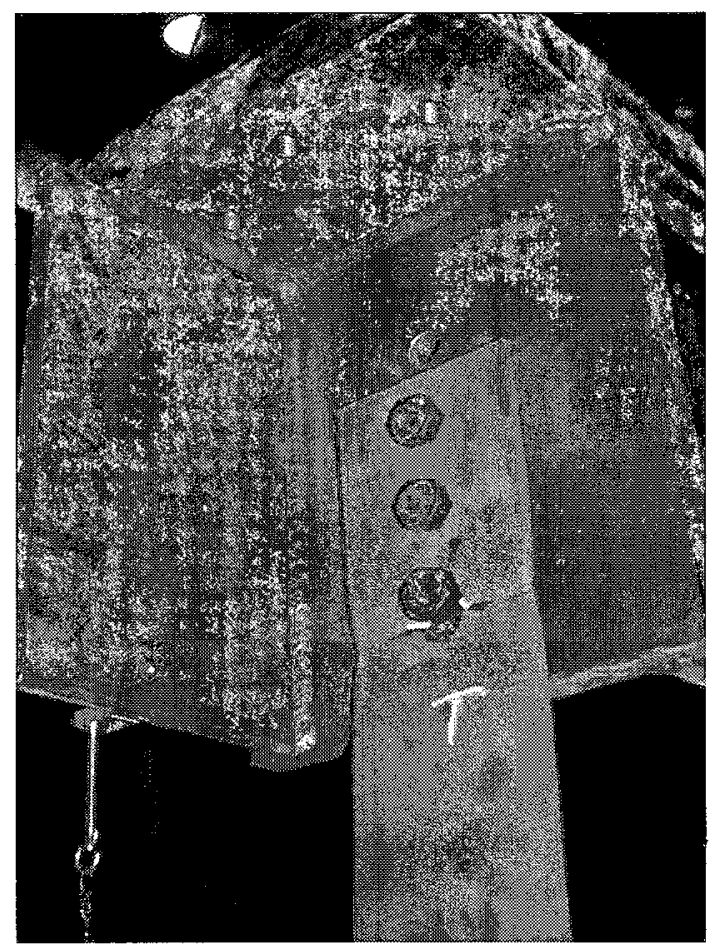

A2128b

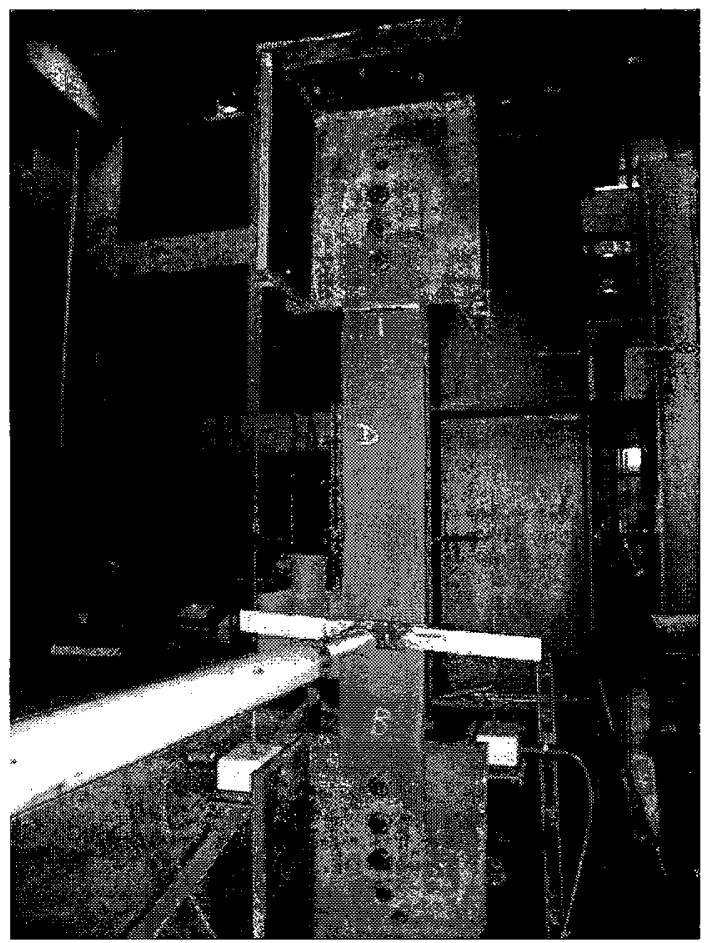

$\mathrm{A} 2128 \mathrm{c}$

Figure C.11 Failure of A2128b and A2128c.

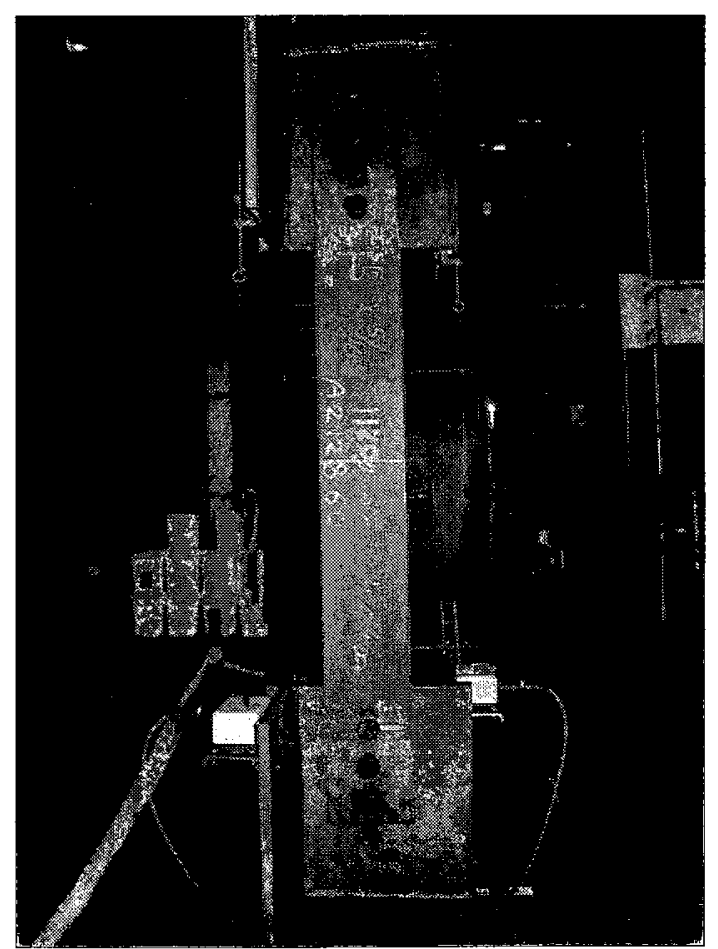

A2128e

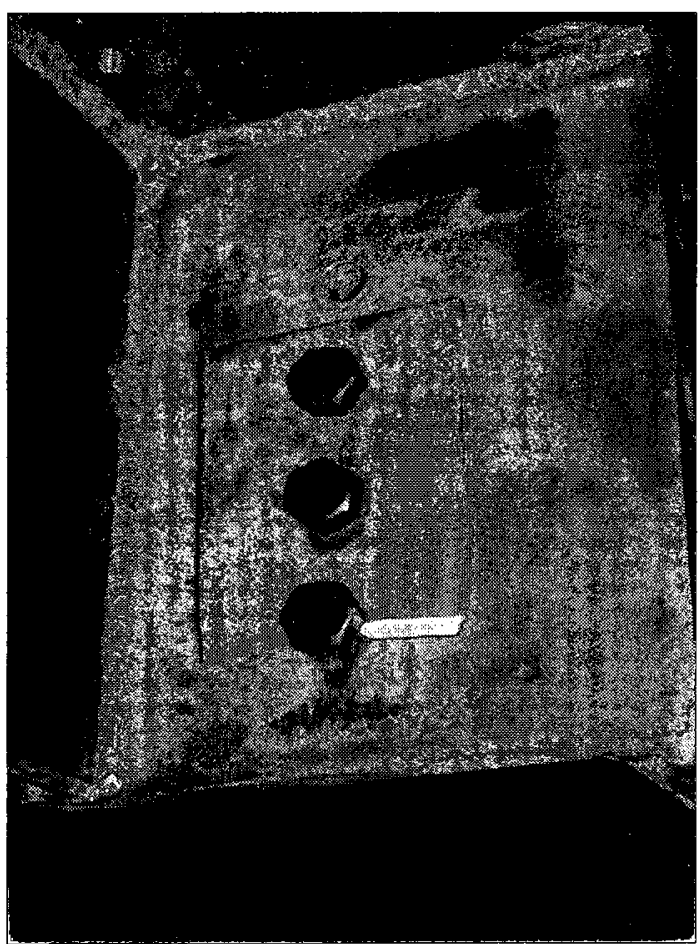

A21281

Figure C.12 Failure of $\mathrm{A} 42128 \mathrm{e}$ and $\mathrm{A} 2128 \mathrm{f}$. 


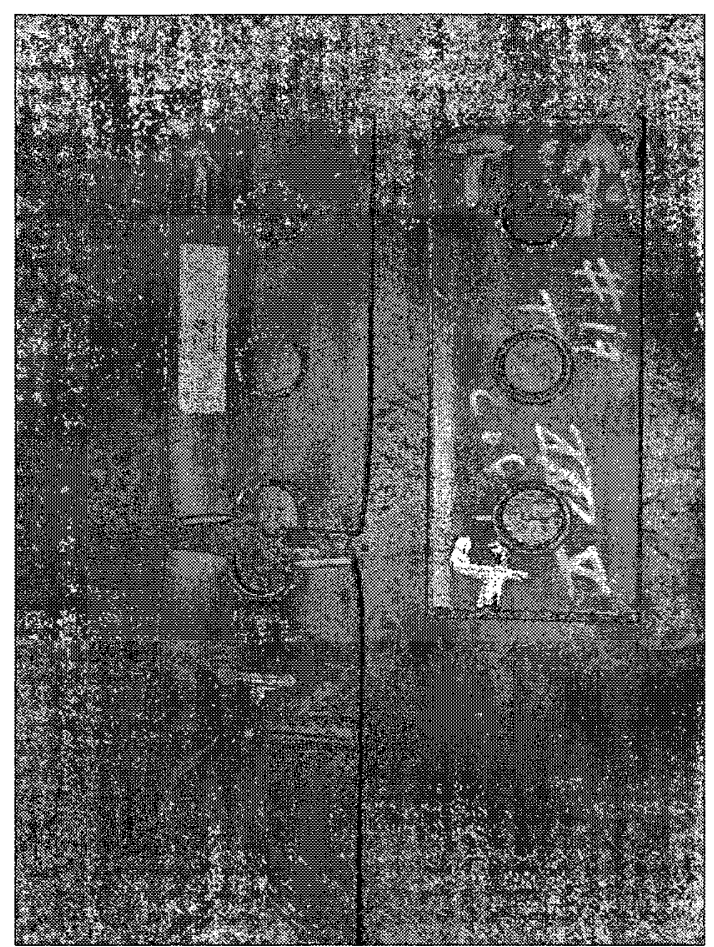

B8075a

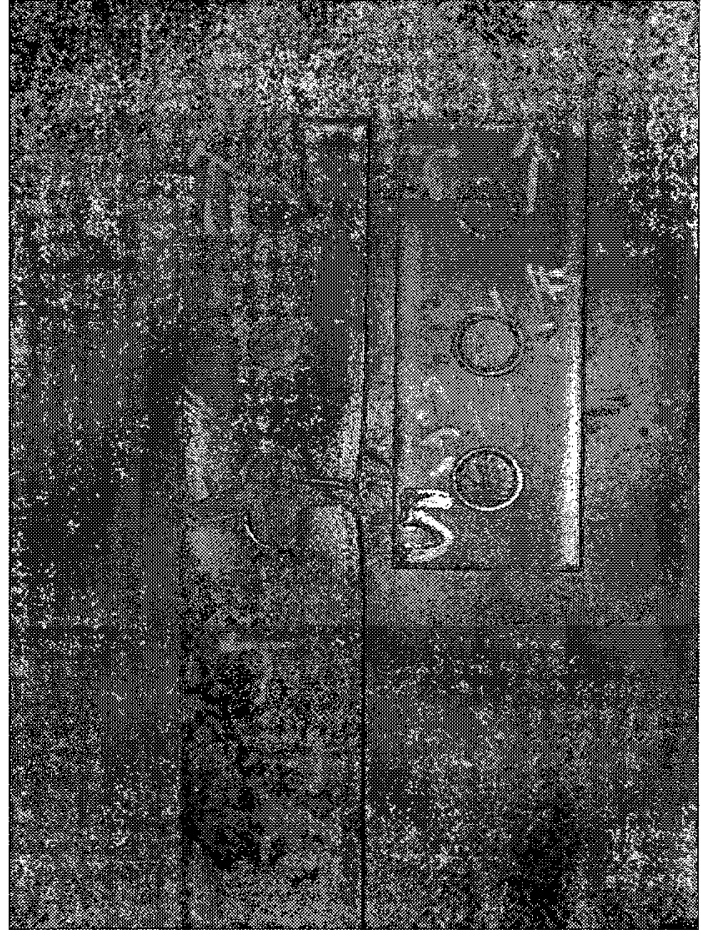

$\mathrm{B} 8075 \mathrm{~b}$

Figure C.13 Failure of B8075a and B8075b.

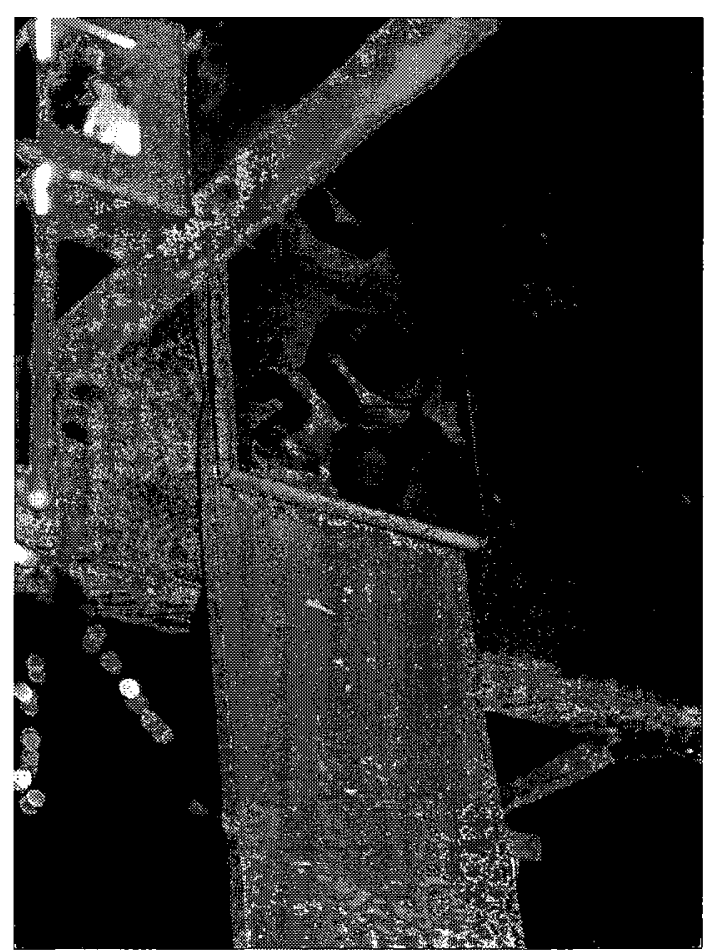

B2078a

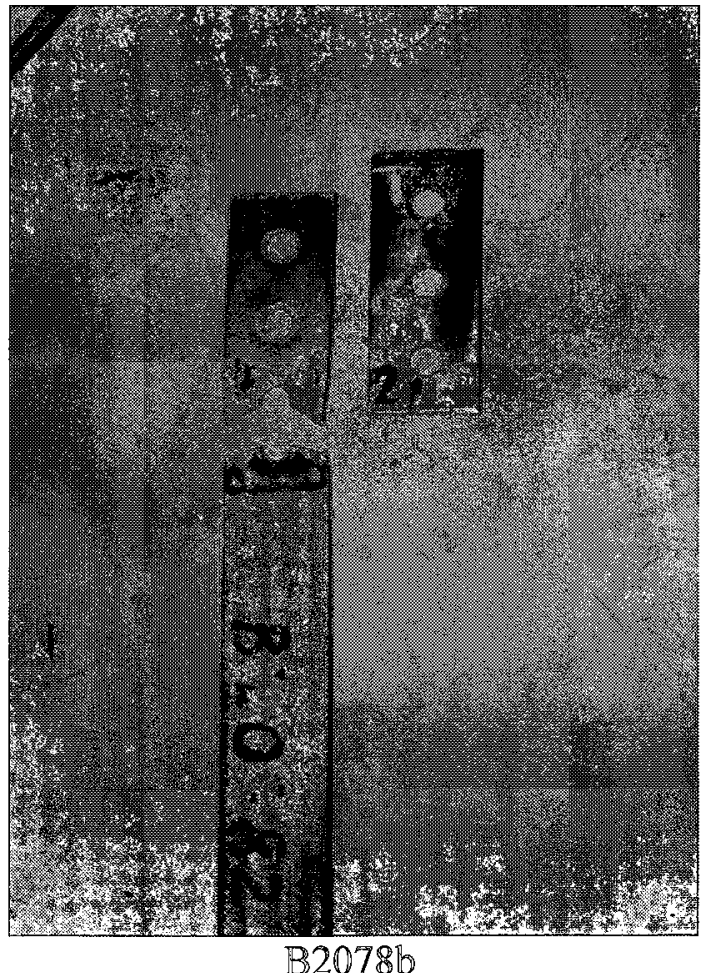

B2078b

Figure C.14 Failure of B2078a and B2078b. 


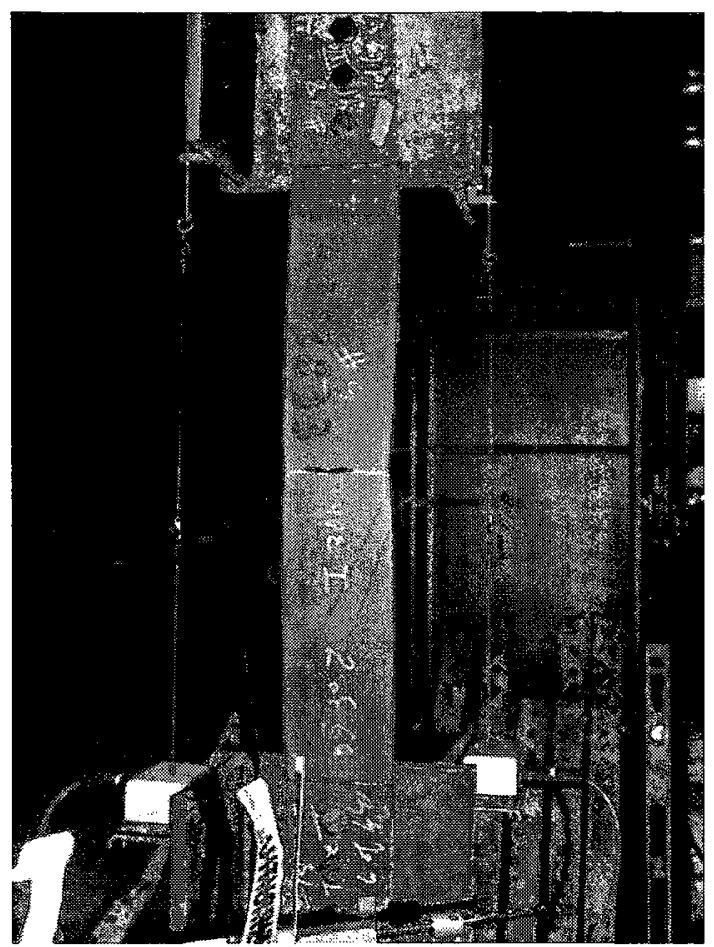

B2128a

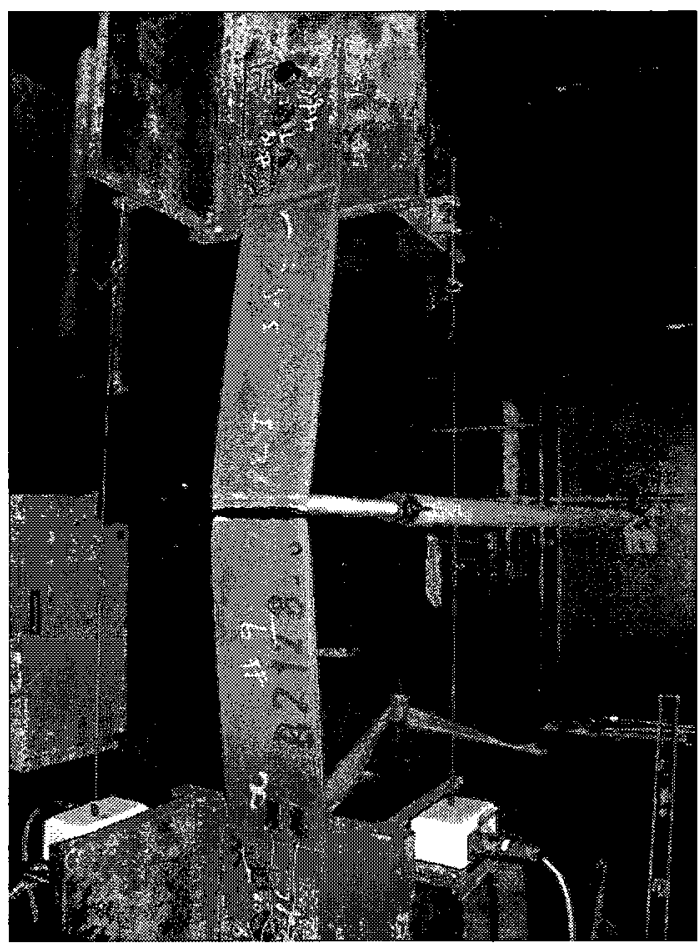

B2128b

Figure C.15 Failure of B2128a and B2128b.

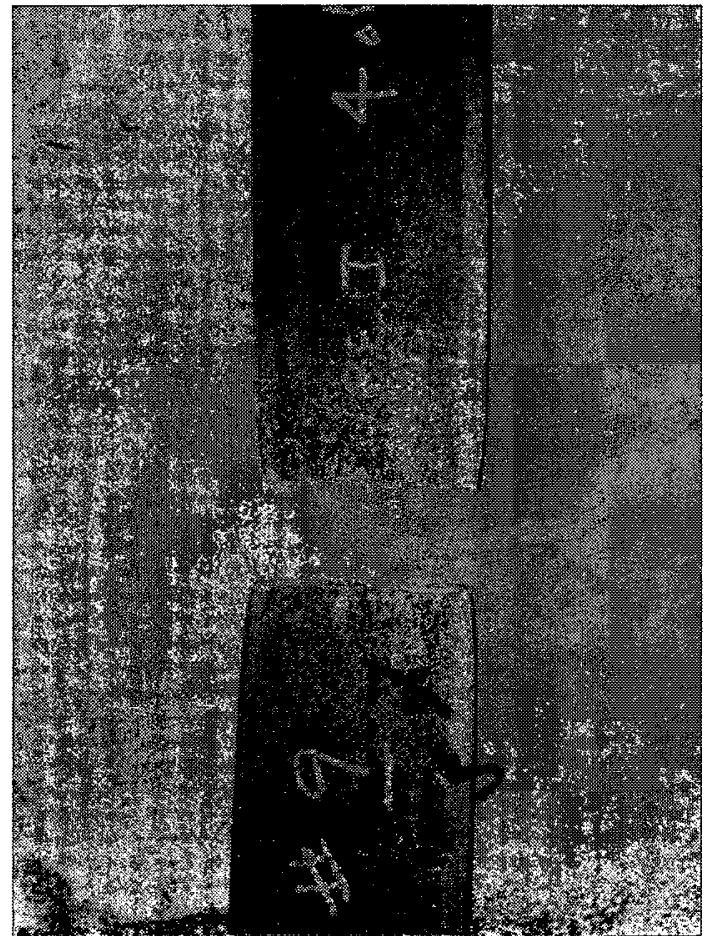

B21280

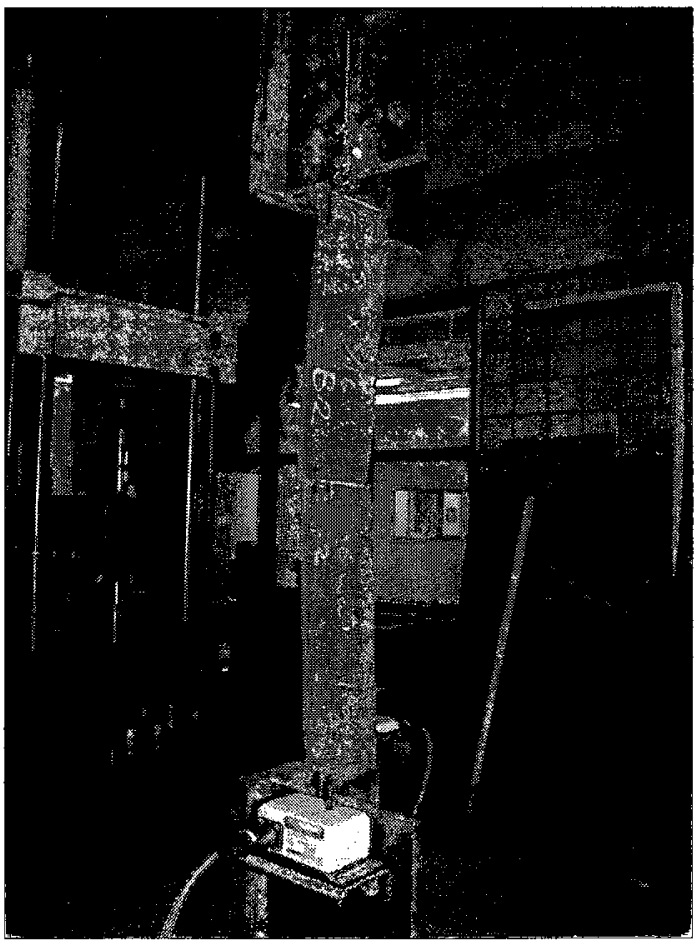

B2128d

Figure $\mathbb{C} .16$ Failure of $B 2128 C$ and $B 2128 d$. 


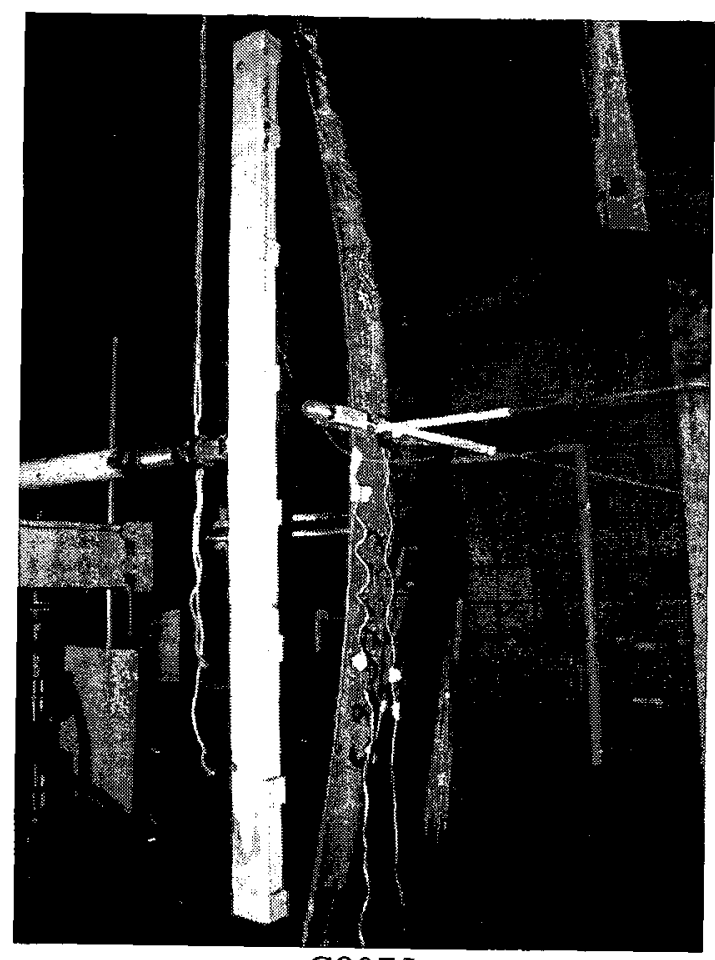

C8075a

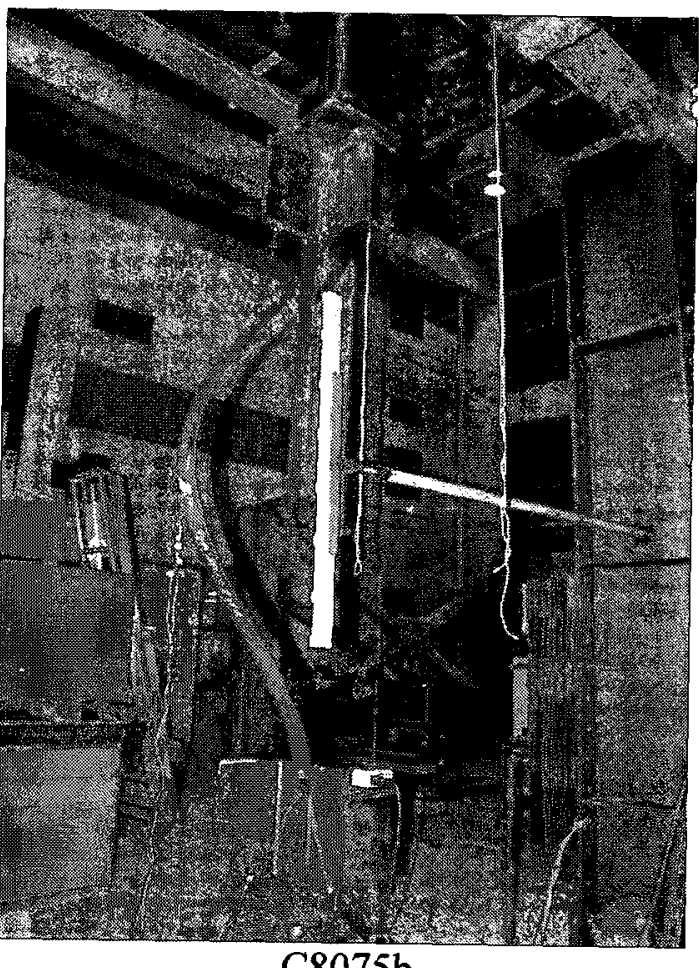

$\mathrm{C} 8075 \mathrm{~b}$

Figure C.17 Buckling of C8075a and C8075b.

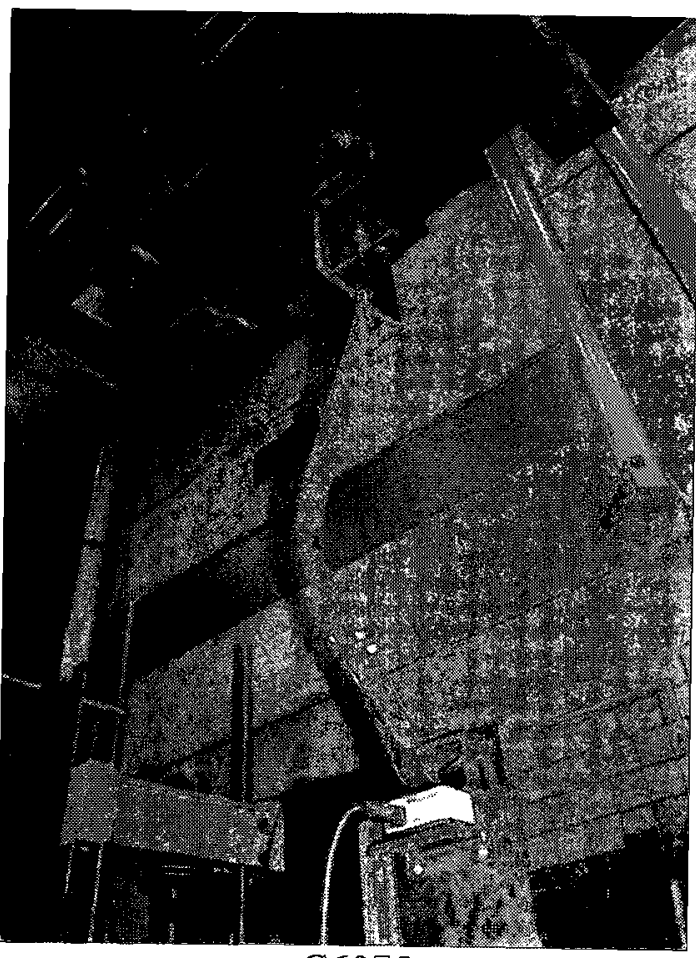

C6075a

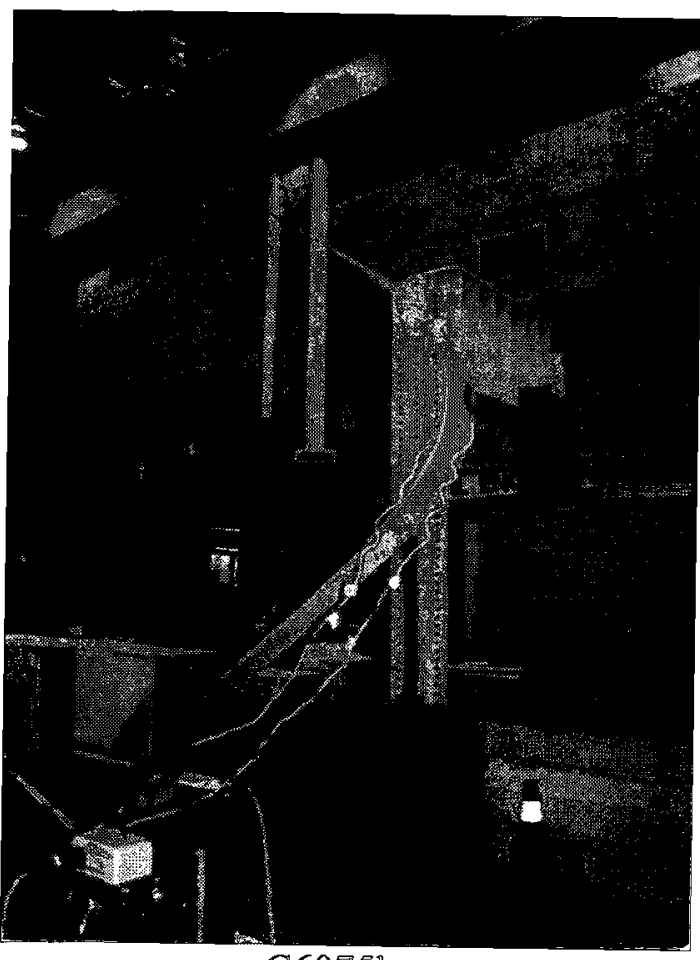

C6075b

Figure C.18 Buckling of C6075a and C6075b. 


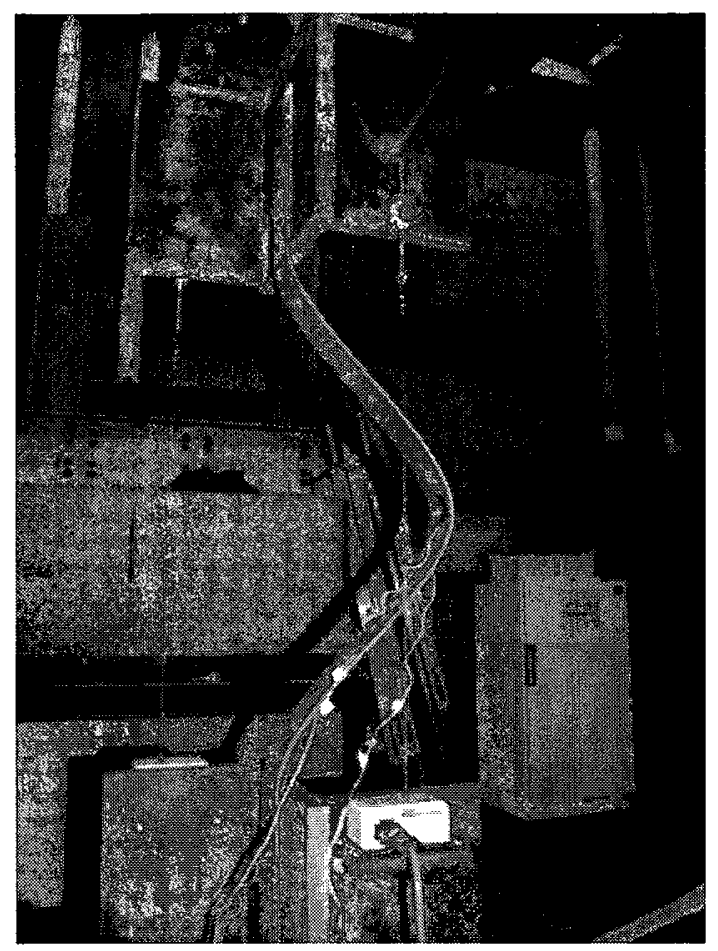

$\mathrm{C} 4075 \mathrm{a}$

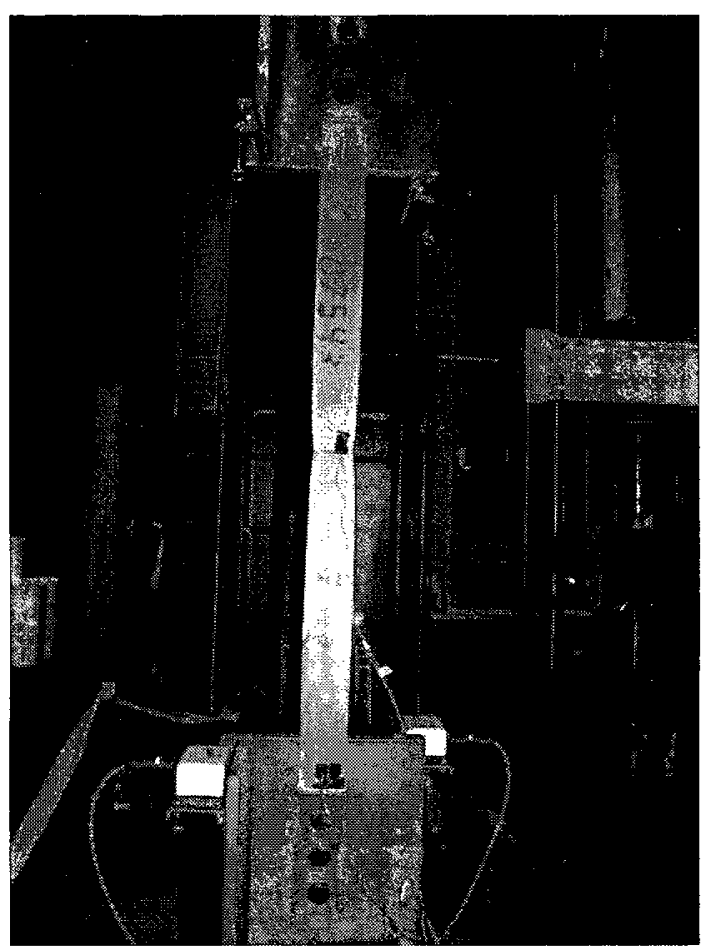

$\mathrm{C} 4075 \mathrm{~b}$

Figure C.19 Buckling of C4075a and C4075b.

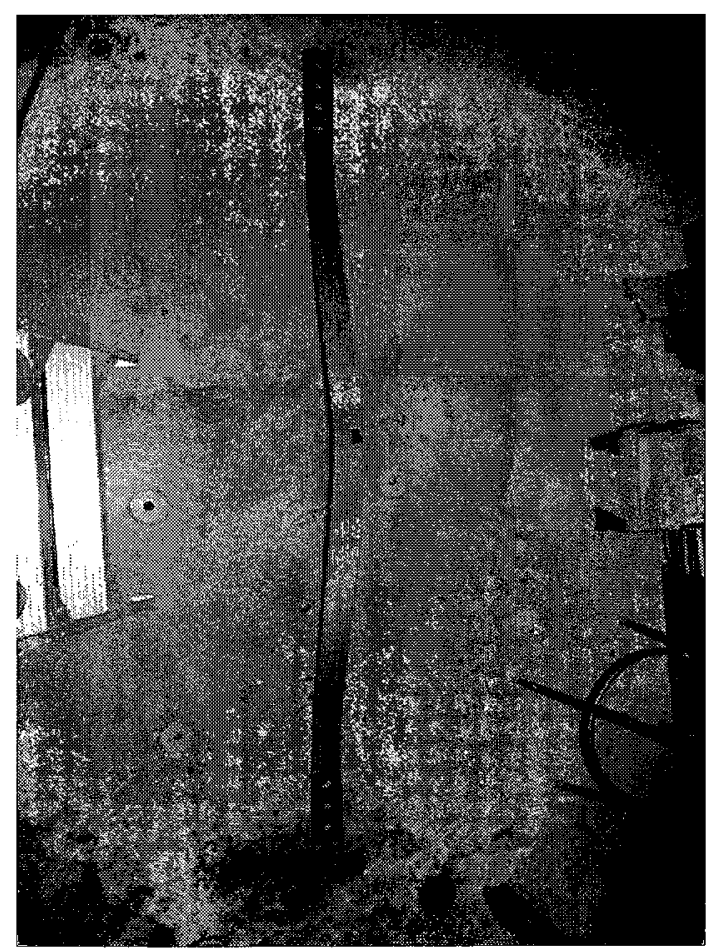

C4078a

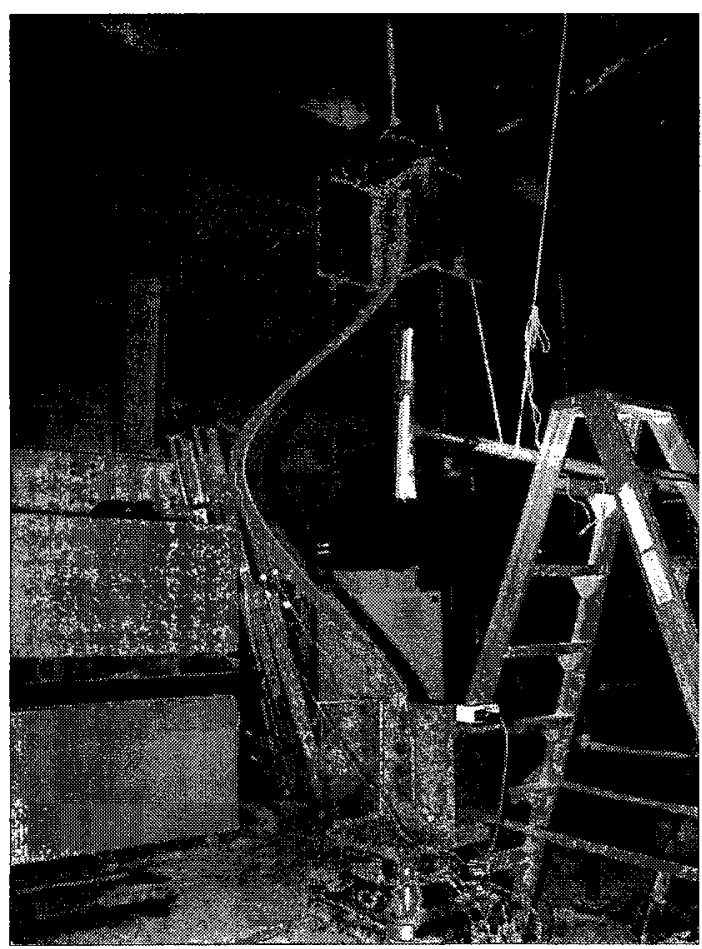

C4078b

Figure C.20 Buckling of C4.07 8 and $\mathrm{C} 40786$. 


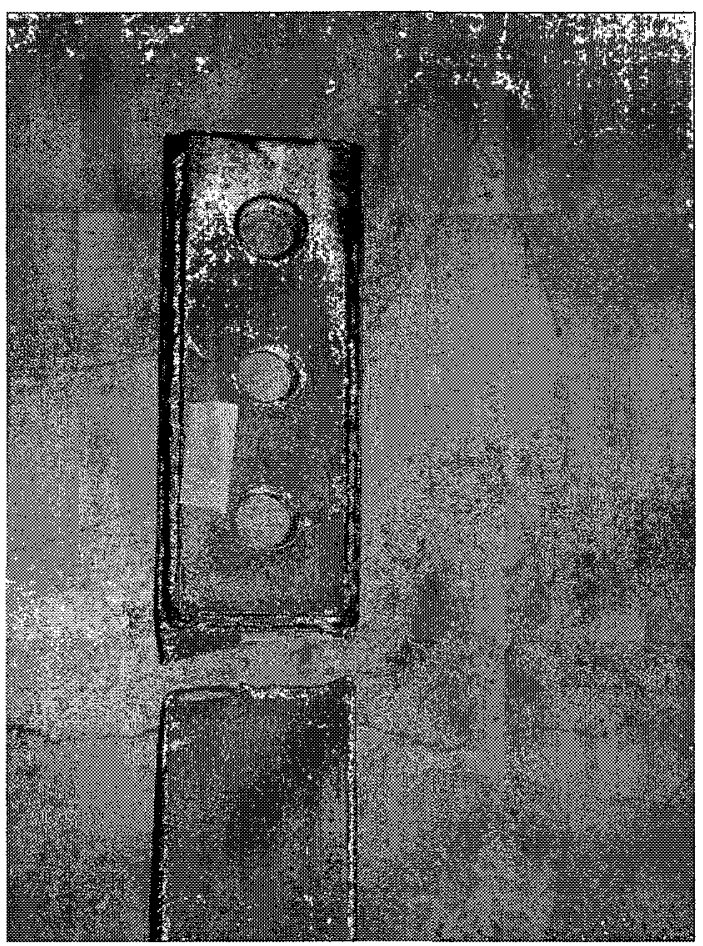

$\mathrm{C} 2078 \mathrm{a}$

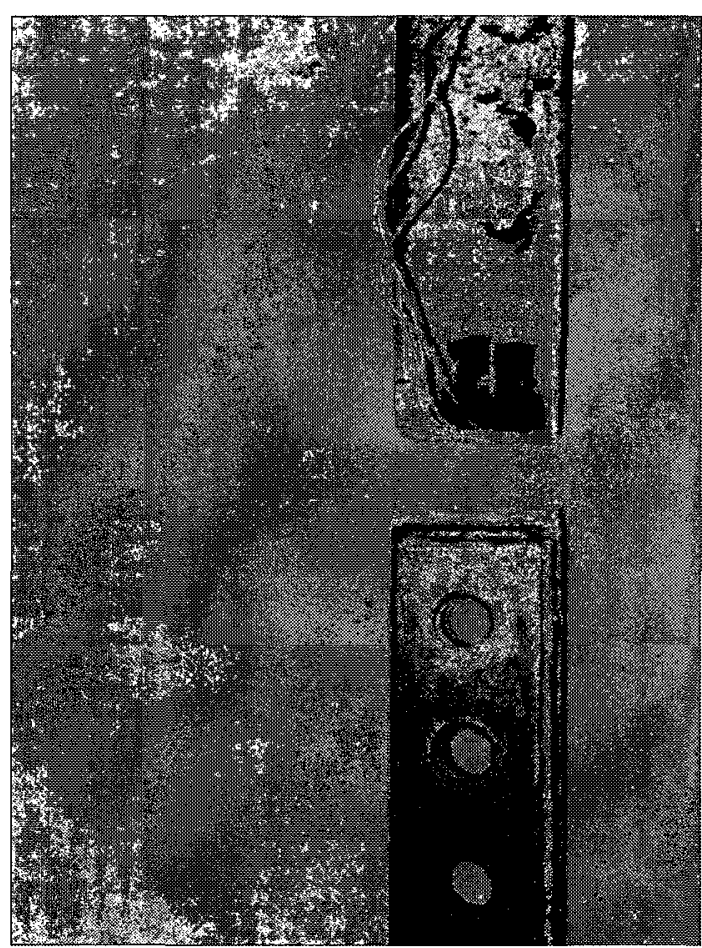

$\mathrm{C} 2078 b$

Figure C.21 Failure of C2078a and C2078b.

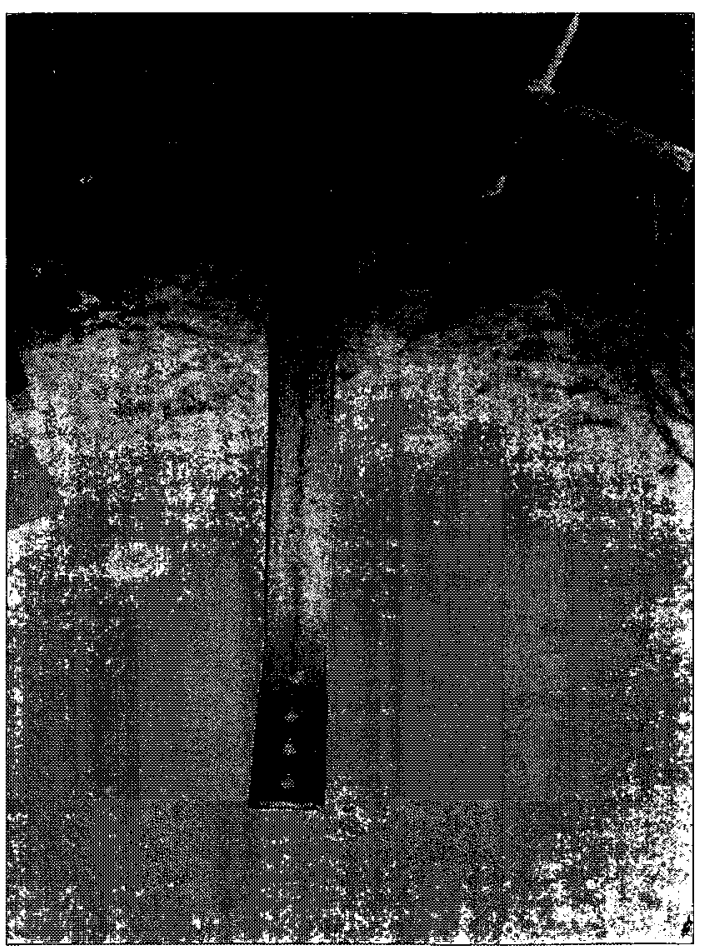
C4108a

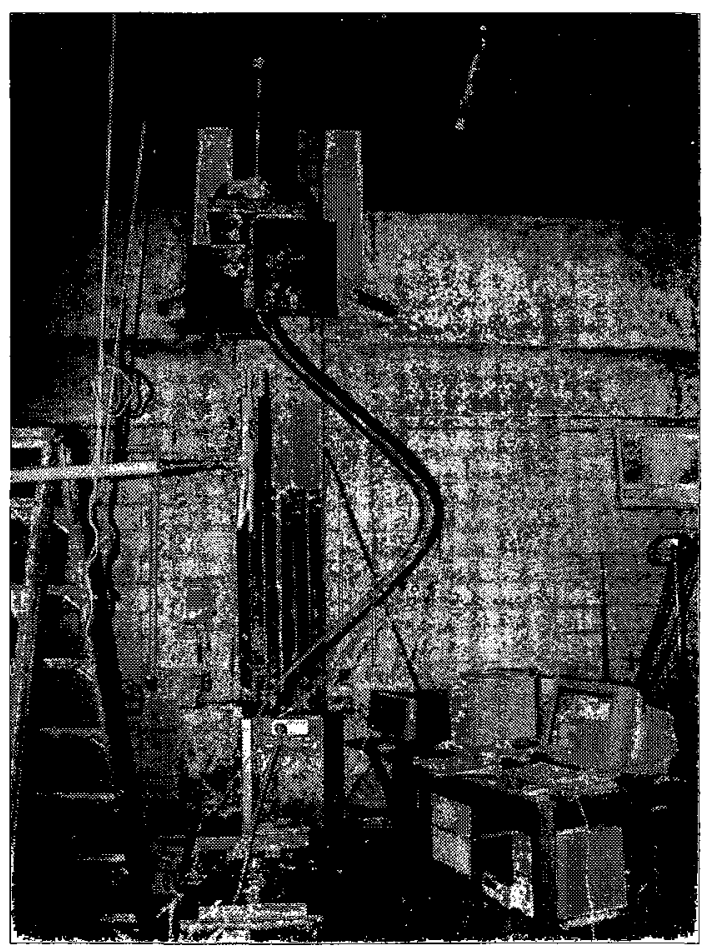

C4108b

Figure $\mathbb{C} .22$ Buckling of $\mathbb{C} 4108$ a and $\mathbb{C} 4108 B$. 


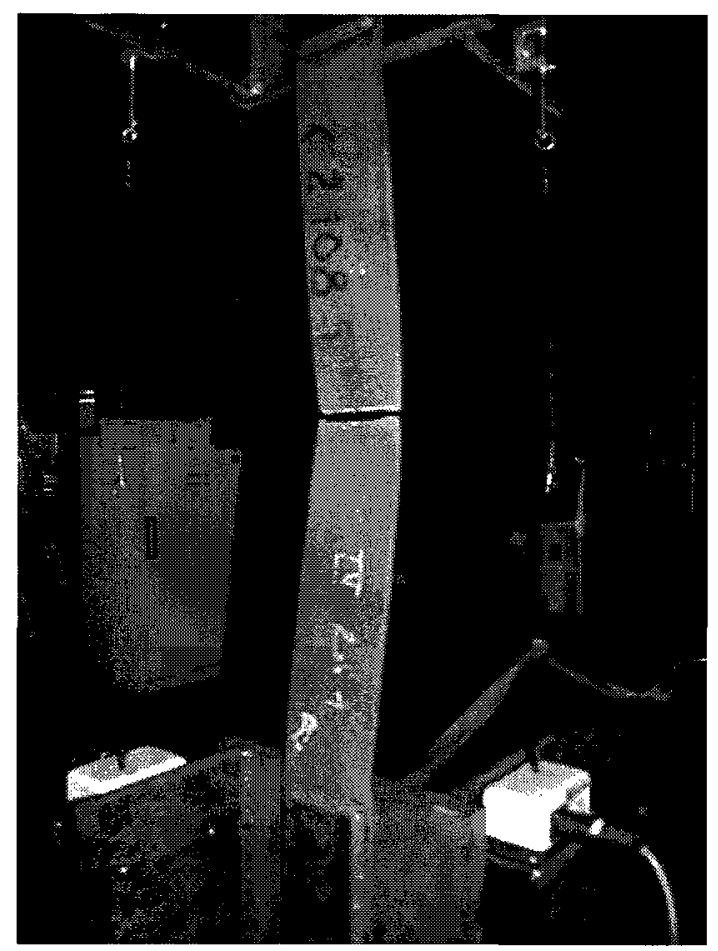

C2108a

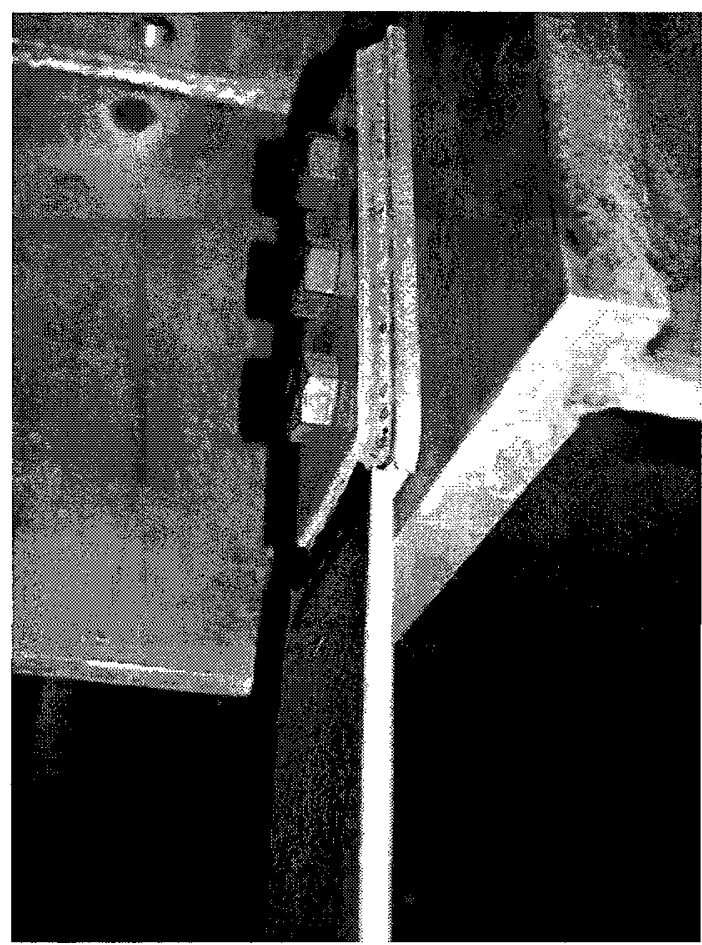

$\mathrm{C} 2108 \mathrm{~b}$

Figure C.23 Failure of C2108a and C2108b.

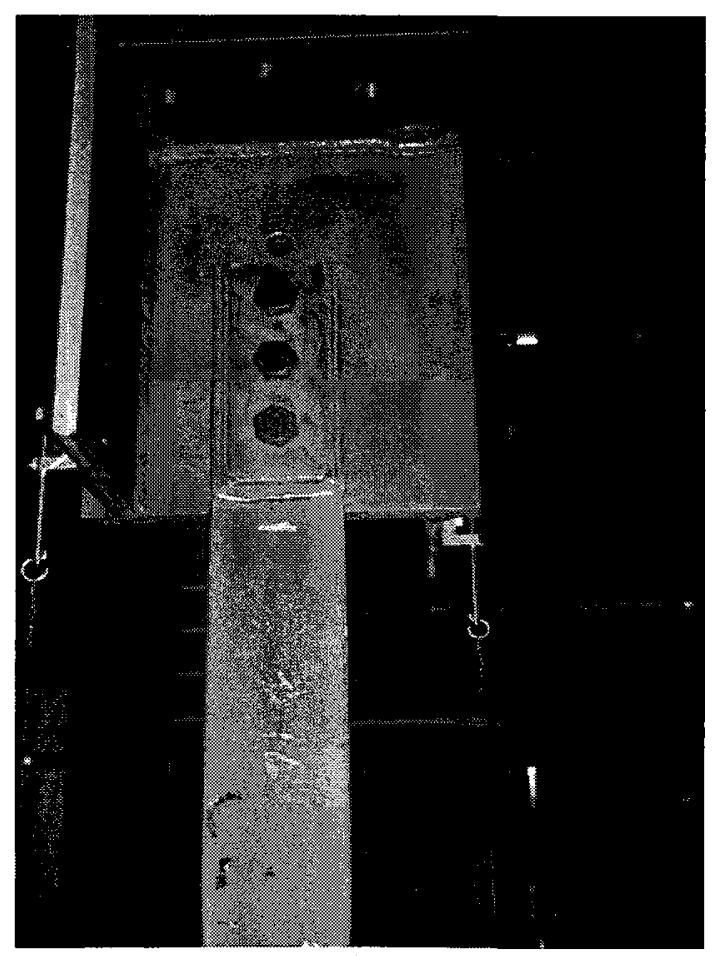

$\mathrm{C} 2108 \mathrm{c}$

Figure C.24 Failure of $\mathrm{C} 2108 \mathrm{c}$. 